Portland State University

PDXScholar

Spring 6-5-2013

\title{
Shaping School Culture: to Support Moving from a Targeted-Assistance to Schoolwide Title I Program
}

Paul Edward Coakley

Portland State University

Follow this and additional works at: https://pdxscholar.library.pdx.edu/open_access_etds

Part of the Educational Administration and Supervision Commons, and the Educational Leadership Commons

Let us know how access to this document benefits you.

\section{Recommended Citation}

Coakley, Paul Edward, "Shaping School Culture: to Support Moving from a Targeted-Assistance to Schoolwide Title I Program" (2013). Dissertations and Theses. Paper 1067.

https://doi.org/10.15760/etd.1067

This Dissertation is brought to you for free and open access. It has been accepted for inclusion in Dissertations and Theses by an authorized administrator of PDXScholar. Please contact us if we can make this document more accessible: pdxscholar@pdx.edu. 
Shaping School Culture: To Support Moving from a Targeted-Assistance to Schoolwide Title I Program

\title{
by
}

\section{Paul Edward Coakley}

A dissertation submitted in partial fulfillment of the requirements for the degree of

\section{Doctor of Education} in Educational Leadership: Administration

\author{
Dissertation Committee: \\ Tom Chenoweth, Chair \\ Samuel Henry \\ Amy Petti \\ Laurie Kash \\ Yves Labissiere
}

Portland State University 2013 
(C) 2013 Paul E. Coakley 


\begin{abstract}
As budget belts tighten in the public schools today, more and more schools are moving toward participation in federal Schoolwide Title I Programs to most effectively meet the needs of struggling students. This study seeks to inform school administrators how best to approach this yearlong change initiative by both meeting the needs of the rigorous federal standards and facilitating a positive school climate for staff, students, and community. Using a Problem-Based Learning method, the purpose of this study was to research, develop, and validate a handbook for shaping school culture during a major school change project while creating or maintaining a positive school culture. The handbook was developed as a resource for principals, and will ultimately be disseminated to Oregon school leaders with the goal of improving the transition process from a Targeted-Assistance Program (TAP) to a Schoolwide Title I Program (SWP).

Research and development (R\&D) methodology (Borg \& Gall, 1989) was used to develop and validate Moving to a Schoolwide Title I Program: The Path Principals Should Follow to Maintain a Healthy School Culture. The literature review and the researcher's experience in Title I schools provided the necessary information to build the preliminary product (prototype). Field-test reviewers used an evaluation rubric to measure efficacy, practicality, effectiveness, and impact on school climate for each section of the handbook. The handbook was reviewed by three groups: principals of Title I schools, Title I directors and coordinators, and Title I compliance officials. The handbook was then piloted by the principal of an elementary school that is currently making the transition from a TAP to a SWP.
\end{abstract}


Changes in the school's curriculum and innovations in the classroom, even if they are beneficial to student learning, can be challenging to the health of the school culture. Research suggests that school culture is defined by rituals, expectations, relationships, curricular focus, co-curricular activities, decision-making processes, school requirements, and a sense of the "way we do things here" (Bower, 1966, p. 22). School culture directly impacts a school's social, emotional, and academic end results.

Through conversations with educators across the state, it is evident that the transition is not always sustainable or fully implemented by all staff, and many times the efforts for change are overcome by resistance, and the momentum toward change is abandoned. The handbook promotes the idea that though collaboration, shared leadership, data driven instruction, and staff buy-in, the yearlong transition process is not only possible, but it can also positively impact a variety of aspects which make up the school culture in hopes of creating a sustainable change. 


\section{Dedication}

I dedicate my dissertation work to students of all backgrounds who attend Title I schools across the US, and the educators who work tirelessly each day to provide a quality education for the students that they serve. Moreover, I dedicate this work to the educators who have enriched my research by sharing their stories, strategies, expertise and experiences. Your passion, commitment, and leadership are embodied in these words from John F. Kennedy:

Let us think of education as the means of developing our greatest abilities, because in each of us there is a private hope and dream which, fulfilled, can be translated into benefit for everyone and greater strength of the nation. (Kennedy, 1961, p. 1)

This dissertation is also dedicated to my daughter Azaria and my son Paul Jr. Azaria, you can do anything that you put your mind to. I am proud of the person that you are growing to be. Keep up your work ethic, positive attitude and drive to never give up. You are a superstar! Paul, I want you to know that every time I thought about giving up on this process, I looked at you and changed my mind. You can do anything, be anything, and achieve anything that you want. Set your goals high and don't let anyone tell you that you can't! One day you will surpass all that I have ever accomplished. I love you both with all my heart. 


\section{Acknowledgments}

I am profoundly grateful to my Superintendent, R. Michael Carter. I have been very fortunate to have Dr. Carter as my mentor. I have benefited greatly from his high standards on leadership and accountability. His tireless pursuit of excellence in modeling, teaching and coaching, and every other aspect of his job are truly inspirational. He has been incredibly supportive and patient with me over the past four years and I learn and grow as a building and district level administrator.

I would like to thank my committee members, Dr. Samuel Henry, Dr. Amy Petti, Dr. Yves Labissiere and Dr. Laurie Kash for their excellent suggestions and thoughtprovoking questions. I have learned a great deal from their work and their influence on this dissertation is immense. I want to extend my deepest appreciation to my advisor Dr. Tom Chenoweth. His research on school change and educational leadership has inspired my work. Dr. Chenoweth is always full of enthusiasm and good ideas, which have greatly shaped this dissertation. I am grateful to Dr. Chenoweth for teaching me the beauty of Problem-Based Learning and the Research and Development process, as well as always being available to answer questions.

I have had the pleasure of being part of a cohort of administrators as I navigate through this doctoral program. I can't say enough about all the support and camaraderie that I have received from my cohort members: Brian Sien, Dan Huld, Peter Siamoo, Teri Tilley and Carol Campbell. It has been a pleasure working with such inspirational individuals. I could not have gone through the classes with a better group of people. Special thanks to my mother-in-law Marilyn, for the countless hours she spent editing, and advising me on my writing. It was no easy task, thanks for everything. 
Finally, and most importantly, I would like to thank my wonderful wife Shante. Her support, encouragement, patience and unwavering love were undeniably the cornerstone of my success throughout this process. Her tolerance of my occasional moods and attitudes is a testament in itself of her unyielding devotion and love. I thank my parents, Paul and Carlus, for their faith in me, and instilling in me the importance of a quality education. It was under their watchful eye that I gained the drive and determination to tackle challenges head on and overcome obstacles and barriers. I recognize that none of this would be possible without God; I have been blessed in so many ways and have so much to be thankful for. God has put me in the right place at the right time among the right people and this dissertation is the outcome. 
Table of Contents

Page

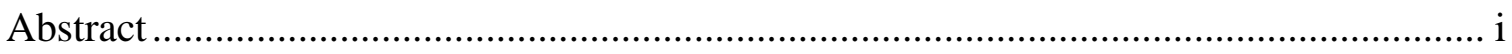

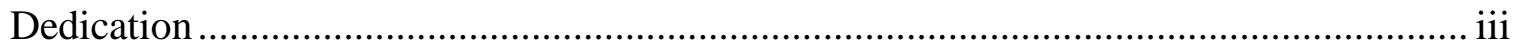

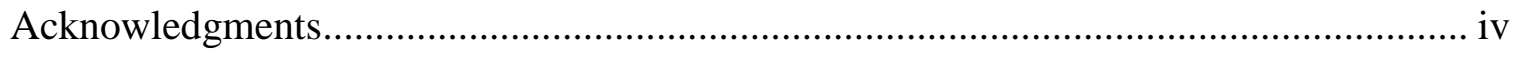

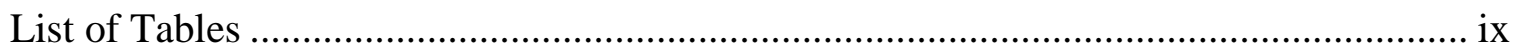

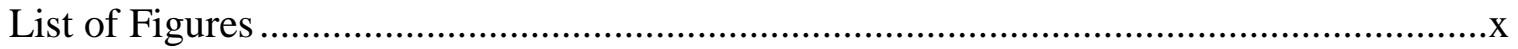

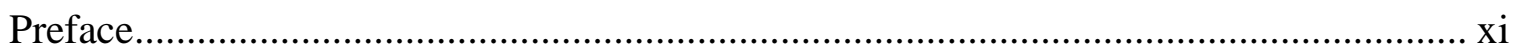

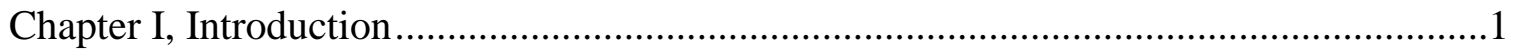

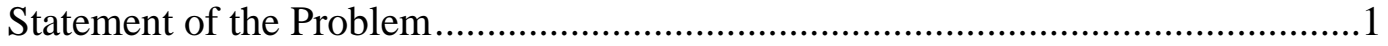

Purpose and Significance of the Study .....................................................6

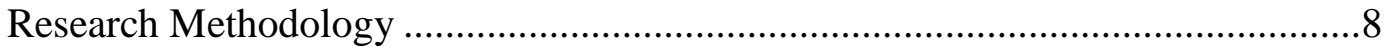

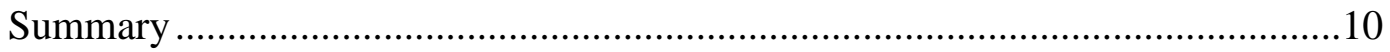

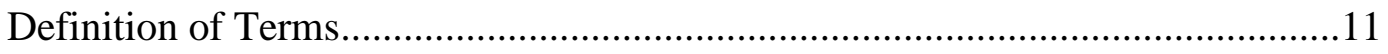

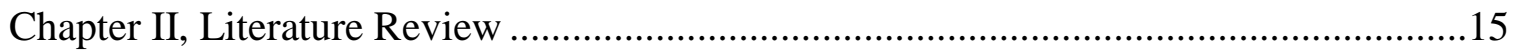

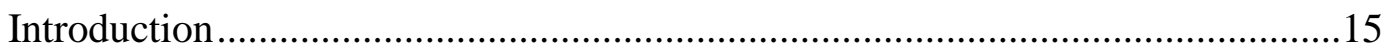

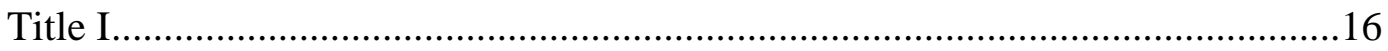

History and Purpose

Evaluative Studies

No Child Left Behind

TAPs and SWPs

Research Approaches

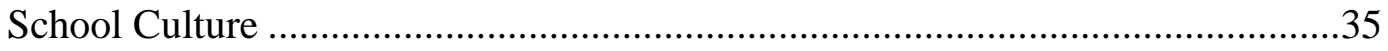

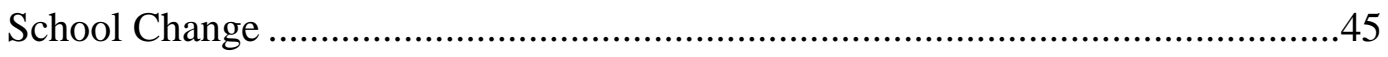

Field Visits, Interviews, Document Review

Interviews

Field Notes

Document Review 


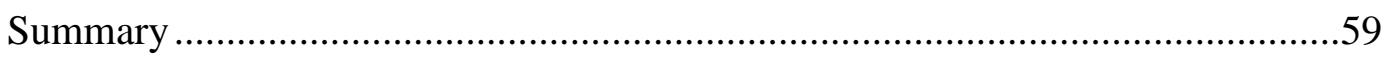

Chapter III, Methodology and Research Techniques ................................................61

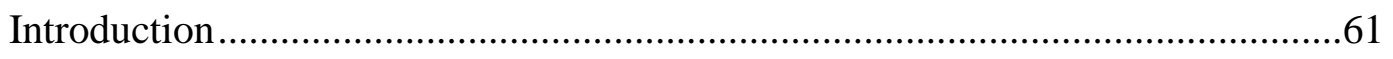

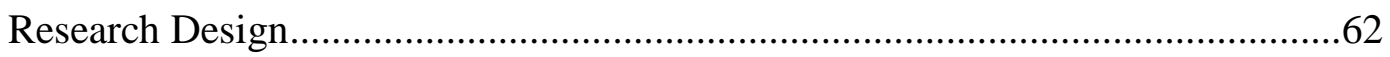

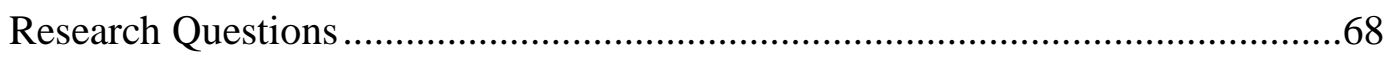

Guiding Questions

Data Collection Procedures.......................................................................... 70

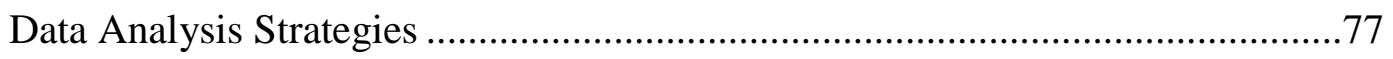

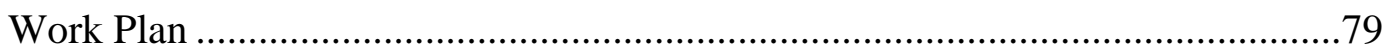

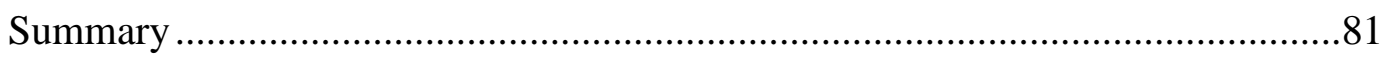

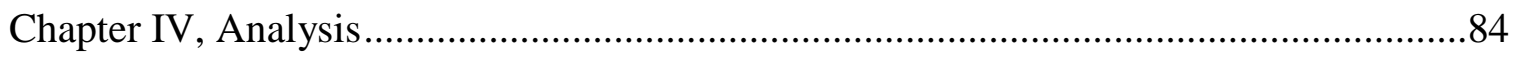

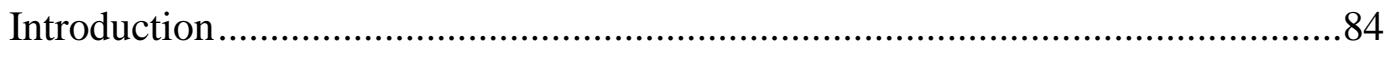

Development and Implementation of the PBL Project .......................................85 Seven steps of the Research \& Development Process GAE Acres Public Information

Research Questions, Design, and Findings ................................................114 FG1 Lessons Learned and Evaluative Breakthroughs FG2 Title I/Central Office Group Specifics FG3 ODE Review Specifics

GAE Pilot School Research Findings ....................................................131

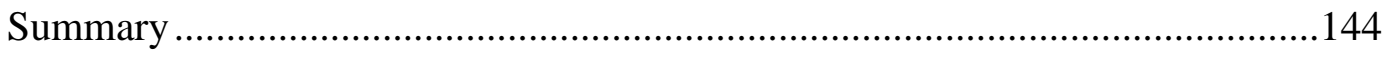

Chapter V, Conclusions, Speculations, and Recommendations for Leadership..............145

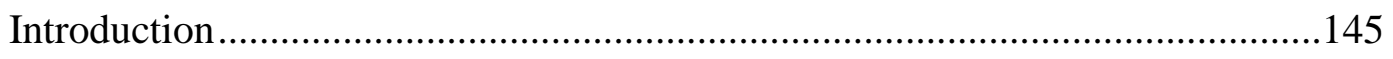

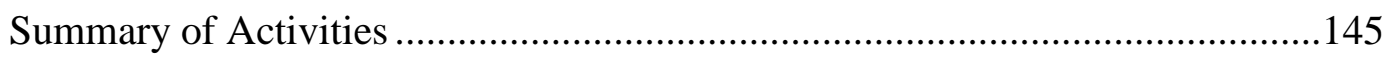

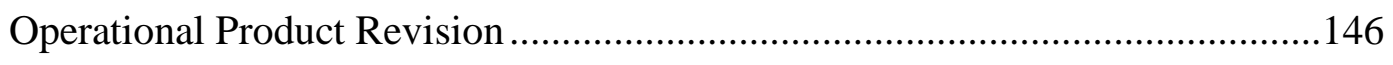


Overall Conclusion and Assessment of the Experience ...................................149

Researcher's Reflection

Speculation About Future Research

Future Research Goals

Development

Use of the Product

Principal's Role During the Transition Process

Recommendations for Leaders

Conclusions

References.

\section{Appendix}

Handbook: Moving to a Schoolwide Title I Program. 
List of Tables

Table

Page

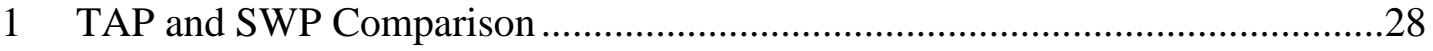

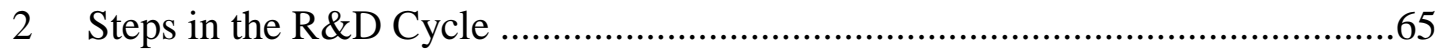

3 Evaluation Rubric I: Summary of Responses for Preliminary Field

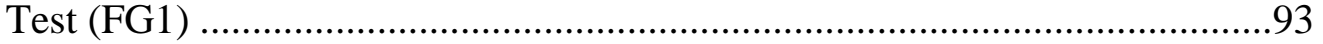

4 Evaluation Rubric II: Summary of Responses for Main Field Test (FG2)

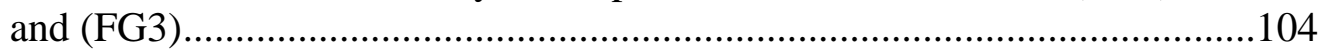

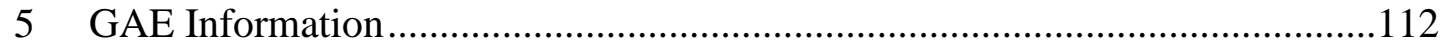

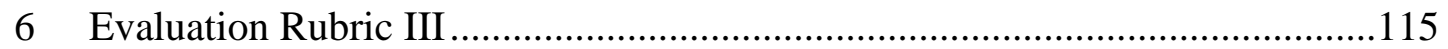

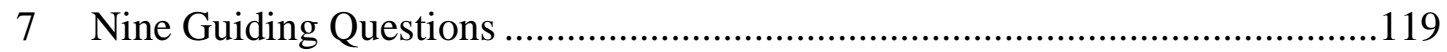


List of Figures

Figure

Page

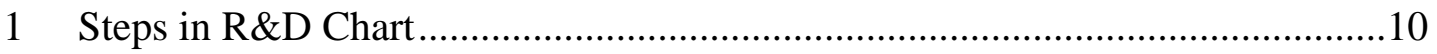

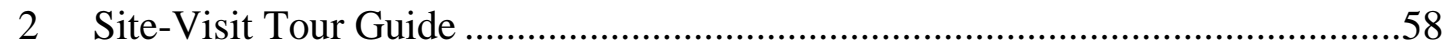

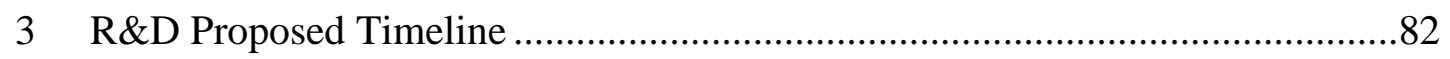


Preface

\section{A Title I Story}

Title I is the largest federal education-funding program. It provides funding for high poverty schools in the U.S. to provide support for students who are falling below grade level academically or are at risk of falling behind. Title I schools provide programs that support mathematics and literacy. The following scenario, designed to help illustrate a typical conversation about Title I services, takes place in the office of a small elementary school.

A principal of a Title I elementary School sits down with his Title I literacy and math teachers; the goal of the meeting is for the principal to gather information regarding the details of the program for the current school year. How many students are being served for math and literacy? How much seat time do the students receive per week? How is the Title I instruction supporting the work that is being done in the general classroom setting? "So you are only providing math support for nine, third-grade students for 30 minutes each day?" The principal pauses and sits, quiet and frustrated. Then he speaks, "We have over 30 students who qualify for services according to our first-round assessments. You have got to serve more students," he said intently while staring at both teachers. The teachers in turn, acknowledge that they would like to serve more students. Both teachers express that they are trying to provide quality instruction to small groups through pullout support at each grade level, but due to block scheduling and other programs that encompass the school day, it is extremely difficult to serve more students. The principal makes his declaration, "I am requiring you to serve a minimum of 20 students per grade level; this is now your first priority." Then looking at the third grade 
math assessment results, he quickly identifies 11 more students for the Title I math teacher to add to her caseload. Although the meeting continued for another 30 minutes, and the principal received the rest of the disappointing information that he set out to gain, the conversation fell flat. The teachers began reporting instead of discussing, saying just enough to not incriminate themselves. In leaving the meeting, one of the teachers said to her colleague, within earshot of the principal, "Our groups are going to be as large as some classrooms. Is that what Title I is supposed to be?"

A few months later, the school celebrates the addition of a computer lab, which was purchased with Title I funds. However, working under the Targeted-Assistance Program (TAP) model, the lab can only be used by Title I teachers and the students who are being served under the Title I program. Of course, with the lab being new, it creates a buzz among the staff and students around the building. Thirty shiny black monitors, pristine tables and bright colored chairs, plus a Smartboard are waiting for Title I use. Although there is a computer lab for all to use, with the same equipment, the contemporary "Title lab" makes the lab, which was created for all students just 2 years prior, look like old news. The principal spends an inordinate amount of time with his staff explaining that the funds used to purchase the Title lab restrict the lab use to Title I students and staff only. However, it would allow the struggling Title I students access to support programs that would tailor instruction to meet each student's needs and focus on building their skills on the standards that they were most at risk of failing. Ultimately, this would help them make gains which would also help them in the general classroom, creating a win-win for everyone. A few teachers spoke positively about the new lab, expressing excitement for the students in their rooms who were in the Title I program 
who will benefit from the new technology, using it to become more fluent in literacy and grounded in mathematics. Of course, every school has people who struggle to see what is best for all students due to the fact that they cannot see past their own classrooms or sometimes past themselves. "How does this affect me? Why purchase a lab that can't be used by everyone? This doesn't seem fair?” This school was no different. A few staff members rolled their eyes, mumbling to one another after the meeting with flabbergasted looks on their faces, as if the words coming out of the principal's mouth during the meeting were so offensive that they were literally left in dismay by his attempt to improve the school's Title I program.

In the next few days, that small group of negative grumblers began to spread their message of disapproval to any ear that would listen. In the meantime, the Title I program was off to a decent start, the teachers were serving at least 20 students per grade level in their pullout support groups working with the students in groups of ten, while the other students worked on computers, using standards-based instructional programs like Khan Academy or Study Island to develop test preparation skills that support student learning $\mathrm{K}-12$. The parents seemed excited about the lab as well; many would grab a visitor's pass and rush to take a look. Because the school is located in an area of high poverty, they were pleasantly surprised by the change, commenting to the principal about the upbeat changes in the school. Of course, the students in the Title I program were ecstatic, which showed not only in their engagement, but also in their behavior, working to please their teachers and coming to Title class prepared and ready to learn.

One parent who volunteers regularly in the library was having a conversation with the school librarian. She happened to mention how nice it was that the school now had 
two computer labs and went on to talk about the programs, sharing how much they had helped her daughter to become excited about reading. The librarian smiled, and before she could comment, a third-grade teacher who happened to be standing next to the nonfiction bookshelf during her duty-free lunch said loud and sarcastically, "Yeah, it looks great. Too bad no one gets to use it!” This comment sparked several other conversations, one of which was held at the Parent Teacher Organization (PTO) meeting. A few supportive parents sent emails to the principal asking for more information and clarification on the use of the lab, and if it could be accessed by all students. A few parents sent complaint emails that questioned his judgment in terms of fairness and equity. Although the majority of parents did not voice their opinions, everyone had feelings on the matter, and would voice it to others in what they deemed safer surroundings.

What the school community did not know was that at the end of the previous school year, the principal had met with educational advisors from the State Department of Education, who suggested that his school should think about transitioning from a TAP to a Schoolwide Title I program (SWP) due to the increasing enrollment of students in the federal free-and-reduced lunch program, as well as the decrease in achievement on statewide assessments. In discussing today's economy and its effect on the job market, they quickly came to the realization that their school would continue to increase in the number of families and students who would be moving into the low-income housing that surrounded their school community, increasing the number of students on free-andreduced lunch. The decision to move to a SWP seemed like a no-brainer to the principal, but he knew we would be met with resistance. Some staff members would have a difficult 
time accepting the change or seeing the benefit of restructuring the way they serve students. He had difficulty gaining buy-in from all staff members on decisions in the past, and knew that to win them over he needed to be more knowledgeable about the SWP model. So, he spent the summer doing his homework, talking with principals of SWPs, asking questions about the transition, attending workshops, and learning as much as he could about the differences between both programs and the benefit of one over the other. Based on his research, he was certain that a SWP would best serve his school which had reached the $40^{\text {th }}$ percentile for students receiving free-and-reduce lunch 3 years ago. He knew that it was time for a change; a large undertaking that would be met, both with opposition, questions, and excitement. When the doors opened on the first day of school, he needed a clear vision and an effective way to articulate that vision. He knew the direction he wanted his school to take in order to begin their journey. Unfortunately, his vision was not completely clear and sometimes foggy at best. How would he gain buy-in? When should he share the information with the staff? Had he waited until it was too late? School had only been in session a little over a month, yet the lack of information to staff and parents seemed to be negatively affecting the school's culture. How could he change the perception, minimize the gripes, whispers and eye rolling, and get everyone back on a positive track? What if others did not see the benefit of the change? How could he prove that it was a necessary change that would be beneficial to all students? He did not want the transition to feel top down. Yet, he did not want it to move too slowly either. What would he do with the Title I money that needed to be spent before the new school year to assist in improving the achievement of his Title I students? The new "Title I" lab, during the transition year would only be accessed by Title I students, which on many levels did 
not seem fair. The lab was purchased with the hope of successfully transitioning to a SWP, where the lab could be used by all. The principal had many ideas to improve achievement for all; instead of pulling students out of their classroom to work in small Title I groups, they could use a push in model, such as "Walk to Read" where all students receive 30 minutes of core instruction at their grade level, and then they walk to a classroom to receive 90 minutes of instruction at their ability level. Classified staff, Title I and Special Education teachers assist teachers in groups that are below benchmarks, while groups on or above grade level receive instruction that will also challenge them at their level. He also hoped to gain insight from his staff, parents, and students on their feelings about the school, and what they felt was working will and what could be improved. He did however need some guidance and support in getting the ball rolling in the right direction.

Unfortunately, this particular principal muddled through the process by selecting a SWP planning team and holding monthly meetings. They made some decisions based on surveys and school data which lead them to a few program and intervention ideas that they put in place to improve academic achievement. Ultimately, their SWP plan was approved by the state, due to the fact that they completed the necessary documents required to make the transition. However, he was met with several barriers, opposition, and roadblocks throughout the yearlong transition. For example, some of the program and intervention strategies that the planning team outlined in their SWP plan were not put to use by all staff due to the fact that they had little information about the new practice and had not bought-in to the change. The "Walk to Read" idea began with baby steps because many staff members were not on board and voiced their negative perspectives on ability 
grouping. Instead of utilizing every staff member as he had hoped, he began with a portion of teachers who were excited about the idea and hoped it would prove effective enough to spark the interest of the naysayers. Looking back on the process, he found that his key mistake was a misstep that he took with regard to the culture of the school. By waiting to openly share and discuss his vision with the staff, as well the reasons and data that guided his decision to look into a change of program in the first place, he unknowingly allowed hearsay, anxiety about job stability, and dissention to fester. Although he worked through these roadblocks and eventually gained buy-in from the staff's majority by providing more surveys, having open discussion during staff meetings, allowing the staff to assist in identifying the school's priorities and providing opportunities for members of his planning team to update the staff on the monthly meetings. Still, he was not able to get everyone on board. He realized that for a few members of his staff, that first misstep was all it took for them to take issue with the change, and he had somehow influenced their decision to keep a closed-minded view of the process. Fortunately, the change led to a stronger Title I program that currently supports and serves more students. Unfortunately, he is still working to combat the naysayers who continually argue that the transition is more work for the same pay for the teachers.

This story shows us how importance it is for school leaders to spend time gaining support from the large majority during a change process. The time that is spent building support fosters a positive school culture, which will impact the fidelity of the changes that are being made. Leaders who briefly address issues and concerns, by providing 
minimal communication, feedback and buy-in foster a negative culture. These types of change efforts are met with opposition, sabotage, and in many cases, failure.

This case is typical of the Title I transition from a TAP to a SWP: principals end up taking their bumps and bruises as they struggle through this large change initiative. In some cases, the school will opt out of the transition and continue with the status quo because they do not want to rock the boat and damage the culture. For example, some principals are met with so much opposition that they begin to blame the transition process for the negative school environment. So, they decide that the best thing for their school is "consistency." Instead of completing the transition to a SWP model, they update their Smart Goals and continue with their current TAP. Sadly, the students are the ones who suffer in those cases. Schools continue to see gaps in achievement as they receive students who need support, but are not getting that support due to the structure of their TAP.

This principal, like many others, has a heart for his students and hopes to create an environment that will meet the academic needs of all. As educational leaders, we are responsible for managing policies, regulations, and procedures to ensure that all students are provided a safe learning environment that meets state curriculum standards as well as the district's mission and the school's vision. It is their job to work collaboratively with parents, teachers, community members, administrators, and the local school board to provide a quality education for the students they serve.

Excellent leaders all have a vision. They also have the ability to motivate others to follow that vision, and ultimately transform their schools into a community where all 
students can be successful. School leaders must strive to create an environment that equips young people with the skills they will need to live and work in a democracy.

Personally, as an African-American principal, I believe in providing all students with a quality education regardless of race, gender or socioeconomic status. Many African-American principals find themselves stereotyped, pigeonholed, and only considered for leadership roles in schools that are predominately populated with minority students. When it comes to the topic of race, most of us will readily agree that minority students benefit from having school leaders in their building from diverse backgrounds whom they can look up to. Although I agree that with this point, I cannot accept the myth that minority leaders can only benefit minority students. As an African-American principal, I find myself as qualified, passionate, and knowledgeable as any other school leader, regardless of race, gender, or socioeconomic status. I have been fortunate enough to lead predominately white, black, and Hispanic schools, and I celebrate the fact that students are students. Strong leaders are based on their actions, not on their skin color. I am proud to be an educator in America. I am the voice that articulates the hopes, dreams, feelings, and values for the members of my school community that may not be able to articulate it for themselves. I believe that ALL students can learn in a school that has a culture where everyone is welcomed, valued, and respected. As school leaders if we cannot address the achievement gap with the programs that our schools are currently using, it is our responsibility to make a change that will be beneficial to all students. As the rates of poverty increase so does the number of students at risk of not meeting benchmark. With large numbers of students needing Title I services, it becomes very difficult to serve students in a TAP (pullout) model. A SWP (push-in) program will best 
meet the needs of all students. However, SWP models are only effective if they are properly implemented with fidelity, which takes strong leaders and collaboration from start to finish through the yearlong transition process for schools that are moving from a TAP to a SWP.

Principals need to possess the ability to make key decisions; they also need the courage to take risks. I view myself as an ethical educational leader. Ethical leaders are trustworthy, reliable and have the ability to empower students, staff, and the school community. Ethical leaders uphold laws and policies, and challenge policies that impede student learning. Ethical leaders hold all their students to high expectations, they have the determination and will power to never give up, and they are proactive in ensuring that their students meet or exceed benchmarks and state standards. I feel that in our society, education must help our students realize their worth as individuals and recognize their ability to achieve at their greatest capacities. The learning environment should encourage a person's drive for learning and motivate them to achieve while promoting, through teaching and example, the principles of a successful life. 


\section{CHAPTER I}

\section{INTRODUCTION}

This chapter identifies the problems and challenges school leaders face as they navigate through the yearlong transition process of moving a school from a TargetedAssistance Program (TAP) to a Schoolwide Title I program (SWP). It provides information on the history of Title I and its overall aims. It then clarifies the difference between the TAP and SWP services. This chapter offers research on the significant connection between school culture and school reform in relation to the Title I transition. I then discuss the purpose and significance of the study and describe the research methodology. This chapter concludes with a definition key of terms that are useful to those reading this dissertation.

In our society, education must help our students realize their worth as individuals and recognize their ability to achieve at their greatest capacities. The learning environment should encourage a person's drive for learning and motivate them to achieve while promoting, through teaching and example, the principles of a successful life.

\section{Statement of the Problem}

According to the Oregon Department of Education (ODE, 2009), Title I schools service their students one of two ways, either through a SWP or a TAP. A TAP uses Title I-A funds to pay for specialized staff members who meet specific criteria to serve only the students who have been identified as being the most in danger of not meeting state standards. The school uses multiple measures of student achievement to decide which 
students qualify for program participation. Title I staff may provide a "pullout" setting on a limited basis to students who are identified as being at-risk for academic failure in the areas of reading and math. The services provided must be clearly supplemental (in addition to) what general education students receive. For example, a student who is below grade level in reading, will receive instruction from his classroom teacher, and will also be provided additional reading support through the Title I program. A SWP uses Title I-A funds to meet the needs of all students in the school, based on the outcome of a comprehensive needs assessment. Individual students are not identified as eligible participants. No distinctions are made between staff paid with Title I-A funds and staff who are not. All staff members are expected to focus their efforts toward moving and improving the entire educational program for all students (ODE, 2010). Although the TAP model may work for many Title I schools with poverty rates less than $35 \%$, effective school leaders have long known that schools are more effective when all staff assume responsibility and ownership for moving all students toward benchmark (Borman \& Agostino, 1996). The latter places the responsibility on the designated few "Title I" teachers as is done in the TAP model. As the poverty rate increases across the nation, a large majority of schools are trying to make the transition from the TAP model to the SWP model to meet the needs of the increasing number of students below benchmark. However, many schools find that the transition is not sustainable. Based on this trend, this research study defines the problem as a lack of information and professional development available to school leaders to assist in guiding them through successful implementation of the transition process. The problem also encompasses that fact that 
most principals see school culture as a broad and abstract concept, so when initiating school change, they rarely consider or understand how to impact their school's culture in a positive manner, nor do they know how to reshape or address negative school culture. Many principals follow the basic requirements listed by their state to make the transition from one program to the other. They kind of muddle through the process, ending up with a new program that is not supported by the majority of their staff or the current school culture; therefore, their SWP model is not implemented with fidelity. Hinde (2004) pointed out that it is imperative to have an understanding and consideration for the school culture when implementing a school reform initiative. School reform encompasses all facets of school culture. A point that needs emphasizing is that there is very little information and a lack of research concerning the transition process from TAP to SWP. This leaves very minimal guidelines and resources for leaders to use in enhancing or sustaining a positive school culture during the process. Thus, we find schools making unsuccessful changes that are not effective or sustainable.

According to Chenoweth and Everhart (1994), a large majority of school reform efforts have been unsuccessful because leaders tend to focus on the new program or initiative and ignore the school culture. In doing so, they fail to realize that the new initiative or program may not fit and/or work within the existing school culture. Research clearly proves that shaping school culture is critical in raising student achievement in terms of productivity and success (D. H. Hargreaves, 1995; Muhammad, 2009; Renchler, 1992; Stolp \& Smith, 1994). Research has also identified school culture as a building block in implementing successful school reform (Chenoweth \& Everhart, 2002; Deal \& 
Peterson, 1999; DeHart, 2003; Friedman, 1991; Muhammad, 2009). Muhammad (2009) stated that cultivating school culture during reform allows for change that is supported and sustainable. If this group of researchers is correct that school culture is a key component of successful school reform, then school culture is an area that must become a focal point of research in this study.

Thinking along the lines of school culture, evidence shows us that school culture can be a very positive factor in the achievement and climate of a school (DeHart, 2003; Friedman, 1991; Lieberman, 1988; Muhammad, 2009). However, some school cultures are not conducive to the achievement and success of all students (Friedman, 1991). Many people have difficulty staying positive when they are faced with significant changes from the norm to which they are accustomed. Think back to the small group of negative grumblers in the preceding story who had difficulty looking past how the change would personally affect them. Many of them were not willing to step outside of their comfort zone or to let go of old routines, despite what might be best practice for the students they serve. These small groups of naysayers have the ability to stifle or sabotage the positive change or reform effort no matter how needed or beneficial to students it may be. School leaders are challenged with shaping and fostering a school culture that can address problems and attitudes, encourage and support teachers of quality, and provide for the academic needs of each and every student. The attributes and beliefs that make up school culture can be changed or altered for the positive through the guidance of strong leadership. The core beliefs of the people in the school are the source for altering or adjusting the school's atmosphere (Sargent, 2001). As a building administrator and 
educational researcher, my research was conducted on the reshaping of school cultures while going through a large, school-change initiative, specifically, by examining the movement of schools from a TAP to a SWP. In addition, I examined the actual Title I transition process in order to create a tool for leaders that was beneficial in navigating the Title I program transition while sustaining or reshaping their school culture. Steps taken by teachers, community members, students, and administrators were analyzed. By expanding our understanding of this transition, principals, central office administrators, and school leaders were better equipped to guide their schools through this change process so could serve a larger population of students in jeopardy of failing to meet benchmarks and state standards.

There is a wealth of information on school-culture research. The majority of school culture research is centered in one of four areas: the relationship to change or reform, connections to student achievement, parallels between positive and negative cultures, and leaders rebuilding negative school cultures (DeHart, 2003; K. D. Peterson, 2002; Spindler \& Spindler, 1994). Whereas the research on school culture provides ample information in the following areas, there is little specific information to be found on shaping school culture pertaining to Title I programs. Think of all the money the government invests in Title I and the lack of guidance provided to those responsible for making change happen. Many principals find themselves muddling through the Title I transition process and creating a plan that does not address or fit within the existing culture of their school. However, instead of taking the time to change the existing culture, to support the new change, the leaders focused on changing programs and structures and 
ignored the existing problem with the school culture. Changes such as these are short lived because they are not supported by all staff and school constituents. Many schools have gone through the yearlong planning process and are now listed as a SWP on paper, however, they still sometimes function as a TAP school, serving only the students that they identify as below benchmark. Unfortunately, these schools have reverted back to doing what is easiest, not what is best or most equitable. The yearlong transition process they endured was not a sustainable change; the roadblocks that needed to be overcome regarding the school culture were not met, which led to the downfall of another change initiative. These failed initiatives leave students with little support in schools that are over the $35 \%$ mark for free-and-reduced lunch.

\section{Purpose and Significance of the Study}

In our current economy, each year our schools are experiencing higher numbers

of families falling into the low-income category, and numbers for students qualifying for free-and-reduced lunch are rapidly increasing. The ODE (2009) strongly recommended that schools that have reached $35 \%$ free and reduced lunch serve their students through the SWP model. However, as noted in the problem statement, there is a lack of information, resources and research to support principals in creating a successful transition as they move toward a SWP model. The primary purpose of this study was to examine the challenges of the school transition process from TAP to a SWP and then to create a handbook that helps principals successfully move their building from TAP to a SWP. The research acquired on School Culture and School Change assists principals in 
providing prospective and approaches that are beneficial in building sustainable change and full implementation of the SWP initiative by all staff.

I am currently the principal of a K-6 Title I school; Stratton Elementary (pseudonym) located in a small, rural school district in Oregon currently serving $52 \%$ of its students through the free-and-reduced lunch program. Stratton has always been a TAP school. Considering the growing number of students who qualify for the free-and-reduced lunch program, Stratton planned to enter into the planning and transition stage during the 2011-2012 school year, as we worked toward moving our school from a TAP to a SWP. Superintendent Carter stated, "when making a schoolwide change, leaders can assume that they will encounter their share of obstacles, roadblocks, and pitfalls as well as rewards, triumphs, and successes” (R. Carter, personal communication, July 2011).

Due to the large body of research on school culture, the literature in this study is rooted in what schools leaders can do to reshape and positively impact school culture. The review also takes a specific look at research focusing on the differences between TAPs and SWPs and the transition from one to the other. The ever-changing field of school culture research primarily focuses on student achievement, staff motivation, and schoolwide accountability (Chenoweth \& Everhart, 2002; Muhammad, 2009). Although SWP and TAP schools provide similar educational and support services, they vary in service delivery methods (U.S. General Accounting Office, 2000). Many educators prefer the SWP approach because they believe it provides a greater opportunity for disadvantaged students to be successful academically, particularly in schools of high poverty (Wong \& Meyer, 1998). For example, although individual student eligibility for 
Title I services is not tied to poverty, if a school has more than $50 \%$ of students who qualify for free-and-reduced lunch programs, a majority of students are less likely to have access to literacy opportunities and may begin school behind middle-class peers $(\mathrm{H}$. Pope, personal communication, September 2011). Therefore, schools with a majority of students in poverty may be denying students important literacy interventions if they stay in TAPs. The ODE (2009) found that principals and teachers in schools of high poverty most commonly support the SWP model, based on the belief that it allows them to serve a larger number of students. On the other hand, some educators express concern that a SWP model takes away from low-performing students who need additional assistance provided by specifically credentialed staff and instead provides instruction to all, not giving the low achievers a meaningful opportunity to catch up (ODE, 2010).

\section{Research Methodology}

Because minimal research regarding school culture in association with Title I programs change initiatives was available, I found myself working to clarify the following research question: What can school leaders gather from the existing literature to positively shape their school's culture as they move their school from a TAP to a SWP? Each section of my literature review provides research, examples, and connections that provide a well-rounded perspective of the body of literature surrounding school culture. Yearlong planning occurs at Stratton Elementary and two other Title I schools: Kenwood Elementary (pseudonym) and Carrie Busey Elementary (pseudonym). This research study tracked the forward course of the reform from a baseline starting point and monitored the progressive implementation of the process. While going through this 
process at Stratton, I developed and piloted a draft handbook that assisted school leaders in making a successful transition from a TAP to a SWP while taking into account factors that positively impact and shape school culture through the yearlong planning process. For the purpose of this study, Stratton is referred to as the research and development site for creating the handbook. The handbook was then piloted at the other two schools, Kenwood and Carrie Busey, for further review, refinement and research. Lastly, the handbook was peer reviewed by a group of principals and central office administrators and revised according to the information and data that were collected based on their review of the product. Through this research cycle of piloting and testing, I created a product that is ready for use in schools to positively impact the Title I transition process. The handbook provides leaders with guidance and tools that help them factor school culture into each step of the transition process. It also provides them with a framework for creating buy-in and support from staff and school constituents. I used a ProblemBased Learning (PBL) approach which utilizes Research and Development (R\&D) as the design structure for collecting data (E. M. Bridges \& Hallinger, 1995). Figure 1 shows the 10 steps in the R\&D process identified by Borg and Gall (1989). The practitioner's handbook that I am piloting was tested through the first eight steps of this process.

Data sources included informed consent documents, field notes, surveys, interviews, and debriefing notes. This research project also investigated the kinds of policies and procedures set forth by the state to foster the compliant implementation of a SWP. The goal of this study is to help leaders better understand how to transition from a TAP school to a SWP school successfully while fostering a positive school culture 
through the grueling, yet rewarding, year of planning and transition. Chapter 3 discusses in detail the research design, research questions, data collection procedures and data analysis strategies used in this study.

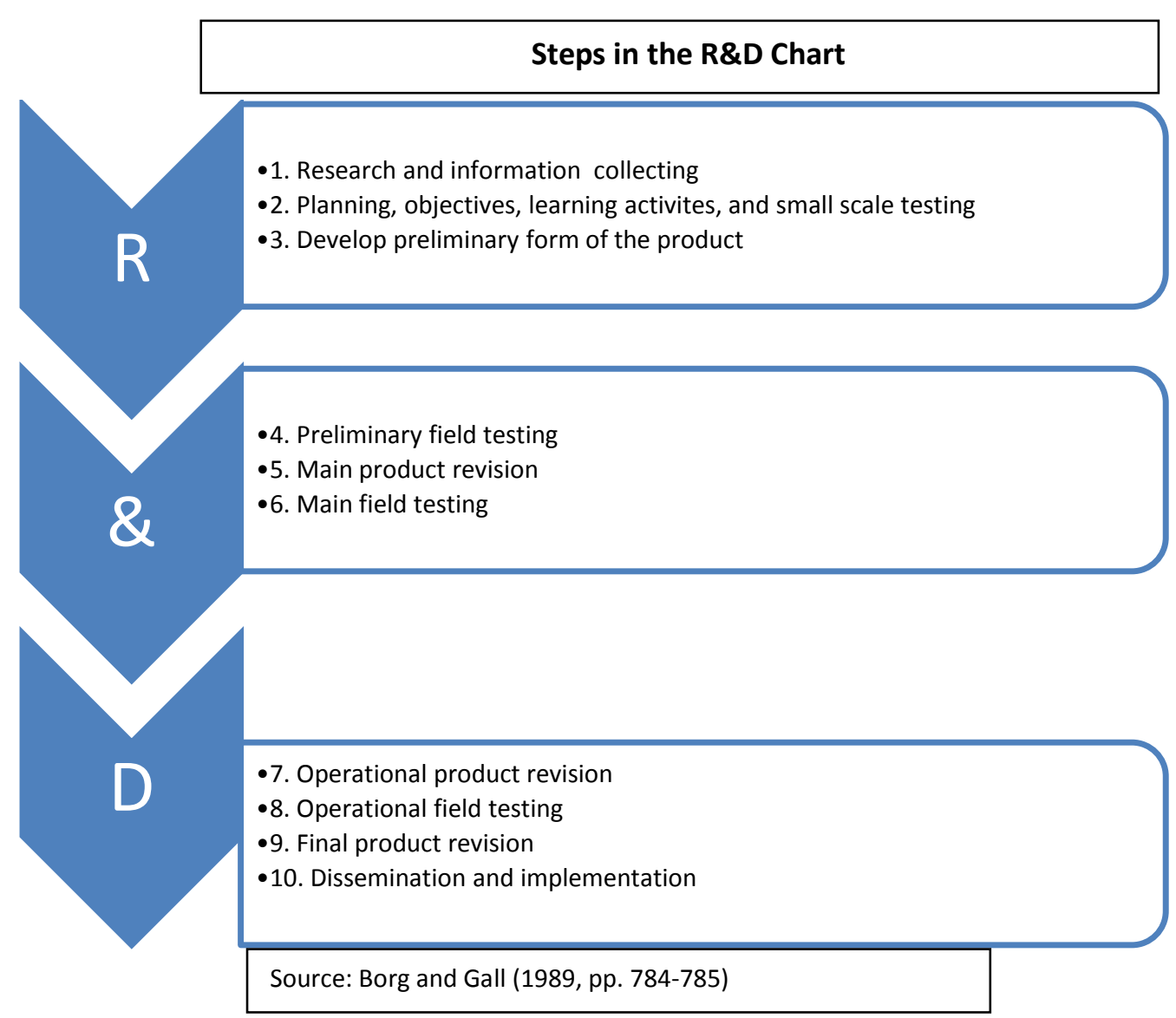

Figure 1. Steps in the R\&D chart.

\section{Summary}

The demand for schools to provide Title I services to more students each year is highlighted in this study. During these rough economic times, the number of families who qualify for free-and-reduced lunch increases, and so does the number of students who need academic support. Although the economy is improving, schools are not seeing 
the money at the same rate as other services are seeing. Superintendent Carter pointed out that funds are being distributed to health and human services at a higher rate than they are to education (R. Carter, personal communication, July 2011). Here in the United States, the Elementary and Secondary Education Act of 1965 (ESEA) holds school districts accountable and the responsibility of schools meeting state standards seems to fall squarely on the shoulders of building principals (Bailey \& Mosher, 1968). Although there is a current trend of transitioning schools from a TAP to a SWP model to provide services for all students in need of assistance, many of these program reform efforts have been unsuccessful because the current school culture is not addressed and reshaped to support the change. Many principals find themselves unaware of ways to positively impact their school culture during the yearlong transition process and create a sustainable change that is beneficial for all students.

Following is a section that defines terms, which may assist readers in understanding educational terms and jargon with which they may be unfamiliar. This next chapter reviews the literature on Title I, school culture, and school change, putting them in a context that helps provide insight to school leaders and assist them with the Title I change process. The next chapter also includes a review of pertinent information used throughout the study. The information includes findings from field visits, responses to key interview questions, and a review of essential school, state, and federal documents.

\section{Definition of Terms}

For the purpose of this study, the following terms are defined. 
Adequate Yearly Progress (AYP): AYP is an individual state's measure of progress toward the goal of students achieving to state academic standards in at least reading/language arts and math.

Culture: For the purpose of this applied dissertation, the word culture is used to address "school culture." In the context of this paper, school culture is defined as the underlying norms, beliefs, values, and customs that make up the way the staff members, parents, community members, and students feel, act, and behave within an institution.

School Reform/Change: School reform can be defined as the use of a comprehensive, unified school design to transform all aspects of a school in an effort to improve the performance of each of its students. The act, process, or result of altering or modifying programs, structures and norms in the context of a school setting.

Schoolwide Program (SWP): is a comprehensive reform model used to upgrade the entire educational program in a Title I school, and it has the primary goal of ensuring that all students, particularly those who are low-achieving, demonstrate at least proficient levels of achievement of the Oregon State Standards.

Targeted-Assistance Program (TAP) School: is a school that receives Title I, Part A funds, yet is ineligible or has chosen not to operate a SWP, and provides supplemental educational services to eligible children identified as having the greatest need for special assistance.

Pullout support: A pullout program is one in which students are taken out of their regular classroom and provided instruction in a smaller group setting. 
Push-in support: A push-in program is one in which educational support staff go into the regular classroom setting to provide small group intervention support the complements what is being learned in the classroom.

Implementation process: refers to the stage in the research process during which recommendations are put into practice. Implementation is the use of strategies to adopt interventions and change practice patterns within specific settings.

Problem-Based Learning (PBL): environments, students act as professionals and confront problems as they occur-with fuzzy edges, insufficient information, and a need to determine the best solution possible by a given date. This is the manner in which engineers, doctors, and, yes, even teachers, approach problem solving, unlike many classrooms where teachers are the "sage on the stage" and guide students to interesting solutions to contrived problems.

Research and Development (R\&D): Discovering new knowledge about products, processes, and services, and then applying that knowledge to create new and improved products, processes, and services that fill market needs.

School constituents: This term refers to all residents of the school community or district as well as all school affiliates including, parents, students and staff members. Free-and-Reduced: This term reflects the percentage of K-12 public school children enrolled in the Free or Reduced Price Meal Program at school. A child's family income must fall below $185 \%$ of the Federal Poverty Level (or $\$ 37,000$ for a family of four in 2006) to qualify for reduced-cost meals, or below $130 \%$ of the Federal Poverty Level (\$26,000 for a family of four in 2006) to qualify for free meals. Not all eligible 
children are enrolled in the program, so these numbers do not reflect all low-income school-age children. 


\section{CHAPTER II}

\section{LITERATURE REVIEW}

\section{Introduction}

Chapter 2 explores the relevant literature related to Title I, taking into account the TAP and SWP models and research approaches. This chapter also examines school culture with regard to school leaders and student achievement, and then it takes a look at school change and sustainability. This review keeps in mind the fact that due to our economy, schools are continually experiencing an increase in the number of families with students who qualify for free-and-reduced lunch. This trend is the driving force behind many Oregon schools transitioning to a SWP model as they reach the state-recommended $35 \%$ guideline. However, this transition has not been clarified, and leaders are experiencing a number of obstacles, pitfalls and very little guidance to ensure a successful transition.

The reviewed literature in this section works to clarify the question: What can be gathered from the existing literature to assist school leaders in positively impacting their school's culture as they move from a TAP to a SWP? In order to present a clear picture of the literature that I used to answer this research question, I organized the literature into three categories: Title I, School Culture, and School Change. The Title I section begins by explaining the history of Title I, then it investigates the effectiveness of the impact of Title I programs, takes a look at the No Child Left Behind Act (Orange County Department of Education, 2002) and lastly, points out similarities and differences 
between TAPs and SWPs and examines what is considered to be best practices in implementing title research approaches.

\section{Title I}

In thinking back to the discussion between the principal and Title I teachers in the preface, there was clearly a difference in opinion about the overall goal of the school's Title I program. The principal focused on the need to serve all students who were falling behind or at risk of falling behind, while the teachers' focus seemed to be on serving the students in the lowest academic percentile through small-group instruction. This discussion leads us to take a look at the history of Title I and its overall purpose or goal.

\section{History and Purposes}

Title I was created in 1965 when the ESEA was passed to provide PK-12 students living in poverty an equal opportunity to receive the highest level of education possible despite their socioeconomic status. However, under the original TAP model, the funds are distributed to support Title I students only, so instead of leveling the playing field for all students, it often caused additional inequities resulting in a deeper problem of discrimination against non-Title I students, especially as the percentage of needy students continues to increase (Wong \& Meyer, 1998). Under a SWP model however, the Title funds are equally accessible to all. For example, consider the new computer lab references in the story in the preface. Many needy students could not access it under the TAP model. The way the TAP was designed contradicts the core aims of Title I's purpose and vision. 
Title I fell under the umbrella of the Great Society, a set of domestic programs endorsed by Lyndon B. Johnson and fellow Democrats throughout the 1960s. The two main objectives of the Great Society social reforms were to eradicate racial injustice and poverty (Kezeske, 2010); Title I was a component created to achieve these goals in education. ESEA required that schools receiving Title I funds become parallel in academic achievement to schools that do not receive funds (Bailey \& Mosher, 1968). The public policy purpose: To ensure federal financial aid is spent on top of state and local funds to which all public school children are entitled (McClure, Wiener, Roza, \& Hill, 2008). ESEA was established to make up for cultural depravation and inequities that are common in schools of poverty. The Civil Rights Act of 1964, known as Title VI, prohibits recipients of federal financial assistance from discriminating on the basis of race, color, or national origin. The Powell Amendment of 1956 prohibited the use of federal money to build racially segregated schools (Gilmour, 2001). Under Title VI, school systems that operated racially segregated schools pursuant to state law were required to have acceptable desegregation plans in order to be eligible for federal funds. The passing of the Civil Rights Act opened the door for ESEA allowing the law to move forward in 1965. Title I has become a key contributor in education funding ever since. The U.S. Department of Education's most recent data on Title I participation is based on the 2009-2010 school year (ODE, 2010). During the 2009-2010 school year more than 56,000 public schools across the country received Title I funds to support approximately 21 million low-achieving students in working toward meeting state standards and academic requirements in core curriculum subject areas (ODE, 2010). Of these students 
approximately $59 \%$ were in grades $\mathrm{K}-5,21 \%$ were in grades $6-8$, and $17 \%$ in grades $9-12$, $3 \%$ from preschool and less than $1 \%$ were ungraded (U.S. Department of Education [USDE], 2004).

Schools are granted Title I funds based on the percentage of students that qualify as being low income. By government definition, low-income students are defined as the students who qualify for the federal free-and-reduced lunch program (FRLP). To qualify, families must meet income requirements in comparison to the number of family members. Schools that have at least $35 \%$ of their students in the low-income category can qualify as a Title I School. A school may apply to become a SWP when at least $40 \%$ of their students qualify for the free-and-reduced lunch program. A school is required to be a Title I school if the school has $75 \%$ or more low-income students (USDE, 2004). Title I funds are distributed to school districts according to a set of four separate formulas: Basic Grant, Concentration Grant, Targeted-Assistance Grant, and Financial Incentive Grant funding formulas.

- The Basic Grant formula allocates funding to school districts based on the number of poor children they serve. Any school district with at least 10 poor children and $2 \%$ of its students in poverty receives funding through the Basic Grant formula.

- The Concentration Grant formula also provides funding to schools based on the number of poor children they serve. To receive money though the Concentration formula, school districts must have at least $15 \%$ of children in poverty or 6,500 poor children, whichever is less.

- The Targeted-Assistance Grant formula is different: Rather than providing the same amount of Title I funding per poor child, it provides more money per child as a district's poverty rate increases, so that higher-poverty school districts get more money per poor child than lower ones do. 
- The Education Finance Incentive Grant Formula is designed to: (1) reward "good school finance states" that spend more state resources on public education and distribute that funding equitably, and (2) doubly target funds on high poverty school districts in "bad school finance states" that inequitably distribute state and local education funding.

Depending on the type of funding a district receives, there is some discretion in how they can distribute the funds among the schools within the district; however, districts are required to prioritize them from the highest poverty level to the lowest. The ODE's role is to hold schools accountable in upholding state and federal guidelines, with regard to how schools are using their Title I dollars to support student achievement. They monitor the way which schools are serving students under TAP and SWP restrictions. ODE also uses achievement data to monitor schools that have fallen into the School Improvement phase, meaning that the school has failed to meet AYP two consecutive years in a row.

The history of Title I is of crucial importance in terms of my research study. It is vital for principals and district administrators to have a clear understanding of the purpose and aims of Title I as they take on changes in their buildings to serve students in Title I schools. As principals navigate through the transition of moving from a TAP to a SWP, they must work to level the playing field for all students, as well as properly use the funds they receive to make Title I schools as equitable as any school located in affluent areas.

\section{Evaluative Studies}

There is an array of research-based studies on the operation and assessment portion of the program, which is closely monitored by the state; districts are held 
accountable through reports and audits (Nitko, 2001; Popham, 1999; Wiggins, 1998). There is also a wide variety of research on the history of Title I (Borman \& Agostino, 1996; McNeil, 2011; USDE, 2004; Wargo, 1972; Wong, 2003). Title I, also known as the No Child Left Behind Act of 2001 (formerly: ECIA, ESEA, or chapter 1) is the largest federally-funded education program in the United States (Carroll, 2009; McKeown, 1996; ODE, 2010). There is also research from state to state that focuses on schools and district accountability for the outcomes of disadvantaged students with regard to Title I (Abedi, 2004; Erpenbach, Forte-Fast, \& Potts, 2003; Kim \& Sunderman, 2005).

Over the past 30 years, research regarding Title I has primarily been concentrated around student achievement for economically disadvantaged students (Howse, Lange, Farran, \& Boyles, 2003; Wargo, 1972). However, the research efforts to verify the effect of Title I programs on student achievement provide only limited information. Very little information is obtainable on the effects of a SWP in general (Wong \& Meyer, 1998). Recent evaluations suggest that Title I may have a small overall effect on the achievement of high-poverty schools (Sunderman \& Mickelsen, 2000). Gill, Zimmer, Christman, and Blanc (2007) conducted studies to test the effect size of Title I supplemental educational services and found positive effects averaging 0.08 of a standard deviation unit in both reading and math for students receiving Title I services over the course of one school year. Zimmer et al. compared the positive gain as being equivalent to 1.7 to 2.4 months of additional classroom instruction for an elementary student, with a one tenth to one seventh decrease in the gap for minority students and white students. Educational researcher Benton (1997) conducted a comparison investigating the TAP 
model and the SWP model to determine which program was more effective using the California Achievement Test to measure reading comprehension growth over a 3-year period. Benton found that over three grade levels (third, fourth, and fifth) the findings indicated there were no significant differences between the two programs. However, findings indicated a significant difference in favor of SWPs over TAPs only in the first year of the study at the third grade level. The results also suggested that although the programs had close to the same effect on the total student population, that the TAP was limited in the number of students who were served, and favored the SWP that has the ability to serve a large population of students (Benton, 1997).

Borman and Agostino (1996) conducted 17 large scale federal studies, ranging from 1966 to 1993 . They focused their efforts on students who participated in Title I programs. Eleven of their 17 studies were of schools (or districts) that provided Title I support for students in both reading and math, and six of the studies only examined Title I student support in reading only. All of the student participants received Title I services for at least one year. These researchers found that students who participated in math programs tended to have larger gains than students in reading. They also found that summer vacation had a larger negative impact on math than in reading. Lastly, they also found that students that participated in Title I in early elementary school tended to outperform their peers in middle and high school. Borman and Agostino suggested that schools use part of their Title I funds to provide summer math programs for students so they do not lose the gains they make during the school year. However, Borman and 
Agostino did not specify where the students were participating in SWPs or TAPs; therefore, no research was gathered in that regard.

The reviewed studies above are critical to my research question; why would the principal be investing so much time transitioning to a program that may not be much more effective than what they are already doing in their schools? Is moving to a SWP just a "fad" that will be found ineffective down the road? How do leaders justify this change to their staff when there is minimal research on the benefit of a SWP over a TAP? Thinking along these lines, Benton (1997) pointed out a slight advantage of SWP or TAP, in that more students are served. Personally, that is justification enough for me to move forward in the process. Title I schools are responsible for meeting the needs of all students to the best of their ability with the funds they are provided. Since the existing research proves that TAPs are limited in the number of students that can be served, it seems only logical for schools of $35 \%$ free-and-reduced lunch to move toward a SWP model simply for the benefit of serving more students.

It has been difficult for researchers to clearly link Title I services to student achievement for a variety of reasons. One reason is due to the lack of data that could eliminate the many other variables and isolate the many factors that can affect the data. For example, the USDE analyzes Common Core Data which does not provide information on whether a school receives Title I funds or has a SWP; the Common Core Data only provides limited information on the school's poverty rates.

The small body of research suggests that with the current trend of schools transitioning from a TAP to a SWP, it would be beneficial to expand the field of research 
regarding program effectiveness with regard to SWPs (USDE, 1996). This data could be combined with school culture data to provide a comprehensive guide for school leaders who are facilitating the transition from the TAP model to a SWP model with their staff. However, additional work would be needed to improve the reliability of the study, by taking into account key variables, such as schools' poverty rates, demographic compositions, and funding variances.

\section{No Child Left Behind}

Within the literature that I reviewed are the writings of McNeil (2011), Klein (2011), and Mathis (2003), all researchers who have contributed work in the area of the history of Title I as well as its purpose and accomplishments. The No Child Left Behind Act (NCLB) was reviewed and signed January 8, 2002, as the reauthorization of the ESEA (Bailey \& Mosher, 1968). As stated in the introduction, the ESEA was born in the context of the Great Society legislation of the 1960s with the intent to address the plight of disadvantaged students in the nation. ESEA encompasses the federal government's flagship program to aid disadvantaged students, Title I. The reauthorization came during a time of wide public concern for the state of education in America (Klein, 2011).

In making this comment, Klein (2011) pointed out that NCLB set forth requirements that reach into practically every public school across America. Reauthorization expanded the federal government's role in education: Title I not only takes a look at improving the educational platform for disadvantaged students, it also holds districts and school leaders accountable for these improvements. According to a Mathis (2003) study of 10 states that had conducted a cost analysis on students meeting 
state standards, he concluded that it cost states $24-46 \%$ more to meet the state

requirement. The essence of Mathis's argument is that although the promise of providing

all students with education is a noble one, he fears that the government is asking too

much and providing too little based on the cost projections for the 10 states on which he

conducted his research. Mathis's research lead to prove that limited resources and raised

expectations played a key role in these states not making the academic progress expected

by the government. McNeil (2011) insisted that at the crux of NCLB are a number of

measures intended to drive gains and achievement in student achievement and hold states

and schools accountable for student progress. McNeil suggested the landscapes of these

changes include the following:

- Academic progress: States are required to bring all students to proficiency level on state tests by 2013-2014 school year. Schools must meet individual AYP (Average Yearly Progress) targets toward this goal for the student population as well as demographic subgroups. Title I schools failing to meet this requirement 2 years in a row will receive technical assistance, and students have the choice of attending another school.

- Annual Testing: During the 2005-2006 school year states were required to test students in grades 3-8 annually in reading and math. By 2007-2008 states were required to test students in science at least once in elementary, middle and high school levels. Annual testing provides a point of comparison for state test results. Possibly by 2014 the comparison will be even more accurate as America moves toward the implementation of the Common Core State Standards (CCSS).

- Report Cards: Beginning with the 2002-2003 school year, states were required to provide annual report cards which give information on the performance of individual schools and districts, as well as student achievement data by population and subgroups.

- Teacher Qualifications: By completion of the 2005-2006 school year, all teachers in core content areas working in a public school were required to be "highly qualified" in each subject area for which they were teaching. Under the law, highly qualified generally means that a teacher has earned an 
endorsement or certification by demonstrating proficiency in the subject matter in a specific area. In 2002-2003 school year, all new teachers hired with federal Title I money must be highly qualified. In the 2005-2006 school year it became a requirement that all school paraprofessionals hired with Title I money must have completed at least two years of college, obtained an associate's degree or higher, or passed an evaluation to demonstrate knowledge and teaching ability.

- Reading First: The act created a new competitive-grant program called Reading First, funded at \$1.02 billion in 2004, to help states and districts set up "scientific, research-based" reading programs for children in grades K-3 (with priority given to high-poverty areas). A smaller early-reading program sought to help states better prepare 3- to 5-year-olds in disadvantaged areas to read. The program's funding was later cut drastically by Congress amid budget talks.

- Funding Changes: Through a modification in the Title I funding formula, the No Child Left Behind Act was expected to specifically aim resources to school districts with high concentrations of poor children. NCLB also included provisions intended to give states and districts greater flexibility in how they spent a portion of their federal allotments.

The NCLB Act required educational programs and practices to use scientifically based research, and indeed, the research studies with regard to Title I are also scientifically based studies (Orange County Department of Education, 2002). Educators can use scientifically based research to inform teaching practice, curriculum decisions, and SWPs (Margolin \& Buchler, 2003).

NCLB monitors student achievement through school ratings; these ratings reveal how well schools teach reading and math to all their students, including minorities, English language learners and special education students. These school ratings can either boost a school's public image or tarnish a school's reputation (Ellis \& Magee, 2007; Kim \& Sunderman, 2005). In Oregon 55\% of schools do not receive federal Title I funds, but of the 500 Oregon schools that do receive funds, two thirds of those schools are 
elementary schools. The ratings carry a lot of weight for these Oregon schools; if a school does not meet the federal achievement targets 2 years in a row the school is required to notify parents, offer transfers to higher performing schools, and report to the state (ODE) an improvement plan that meets federal requirements. These schools also receive approximately $\$ 100,000$ or more a year to assist with improvement.

Every state has developed measurements for determining whether schools are making adequate yearly progress (AYP) citation. In 2011 the mandated performance standards for Oregon schools rose to a higher requirement, resulting in a huge jump in the number of schools rated as inadequate. More than 80 schools in Oregon that serve a concentration of low-income students must provide transfers to other schools or afterschool tutoring because of repeatedly missing the academic targets (ODE, 2010). Other states such as Arizona and New Mexico are seeing similar failure rates as target expectations are raised.

In regard to this study, these AYP statistics hit home, as much of my research was conducted at several of the sites that were affected by these mandates. I have been a part of the ongoing conversations with principals, district office administrators and state officials regarding AYP and how to improve failing Oregon schools. I feel that due to the fact that the target expectations have been raised, many school leaders use that as an excuse to fail. Personally, I feel that if the bar has been raised, it is our job to change what is not working in our schools to meet the new requirements. A successful SWP will serve more students needs than a TAP. However, the program needs to have strong 
interventions, best practices and full implementation by all, where every staff member is serving students to the best of their ability. I insist that it is imperative for principals to have support to successfully maintain a positive transition to a SWP model to avoid roadblocks and negativity, and begin serving students right away.

\section{TAPs and SWPs}

My whole life I have heard it said that history repeats itself, and we are doomed to relive our past if we fail to learn from it. The past is not a map to where you are going; it's a record of where you have been. Its purpose is not to drag you back through the muck, but to benefit you by reminding you of lessons learned so you can safely navigate through issues in the future. Along these lines, I feel that it is relevant to my research question to include information on the similarities and differences between TAPs and SWPs. Schools in the transition process are moving from their current TAPs by changing them into SWPs. Therefore, they not only need to have a roadmap for where they are going, but they should also reflect on where they have been.

The research implies that although TAPs and SWPs have many similarities, there are also noteworthy differences, and that school leaders will want to review these issues (Colorado Staff Development Council, 2011; McNeil, 2011; Wong, 2003). As schools transition from TAP to SWP, it is important that they are aware of these differences and take them into consideration as they develop their school's Title I plans. Table 1 gives us a clear example of similarity and differences and allows us to compare and contrast TAP and SWP. 
Table 1

TAP and SWP Comparison

\begin{tabular}{|c|c|c|}
\hline TAP & Both & SWP \\
\hline \multirow[t]{3}{*}{$\begin{array}{l}\text { Students are identified and made } \\
\text { eligible for services. The students } \\
\text { recognized as being most at risk } \\
\text { of not meeting state standards are } \\
\text { served. }\end{array}$} & & $\begin{array}{l}\text { All students can receive } \\
\text { additional services. No } \\
\text { identification is made to provide } \\
\text { services. Students deemed at } \\
\text { risk are provided additional } \\
\text { assistance. }\end{array}$ \\
\hline & & $\begin{array}{l}\text { Plan must be based on a } \\
\text { comprehensive needs } \\
\text { assessment. }\end{array}$ \\
\hline & $\begin{array}{l}\text { Plans and programs must } \\
\text { be scientifically research } \\
\text { based and strengthen the } \\
\text { core academic program } \\
\text { of the school }\end{array}$ & \\
\hline $\begin{array}{l}\text { Program gears instruction only to } \\
\text { students who are most at-risk } \\
\text { academically in reading and/or } \\
\text { math. }\end{array}$ & & $\begin{array}{l}\text { Program constitutes } \\
\text { comprehensive school reform } \\
\text { and promotes improved } \\
\text { instruction for all students. }\end{array}$ \\
\hline $\begin{array}{l}\text { Title I professional development } \\
\text { funds are used on staff that } \\
\text { provides direct support to Title I } \\
\text { students to address their needs. }\end{array}$ & $\begin{array}{l}\text { Professional } \\
\text { development must align } \\
\text { with the Title I program } \\
\text { goals. }\end{array}$ & $\begin{array}{l}\text { Title I funds are used to provide } \\
\text { professional development for all } \\
\text { staff to support all students. }\end{array}$ \\
\hline $\begin{array}{l}\text { The program is not based on the } \\
\text { school's poverty rate. }\end{array}$ & & $\begin{array}{l}\text { Unless a waiver is granted, only } \\
\text { schools with a poverty rate of } \\
35 \% \text { or more may operate a } \\
\text { SWP. }\end{array}$ \\
\hline $\begin{array}{l}\text { Title I funds are used to support } \\
\text { additional instruction }\end{array}$ & $\begin{array}{l}\text { Additional learning time } \\
\text { must be provided to } \\
\text { students who are } \\
\text { identified as most at risk } \\
\text { of meeting standards. }\end{array}$ & $\begin{array}{l}\text { Title I funds may be merged with } \\
\text { Federal, State, and local funds to } \\
\text { support additional instruction. }\end{array}$ \\
\hline $\begin{array}{l}\text { Careful accounting must show } \\
\text { that funds otherwise received } \\
\text { from non-Title I sources are } \\
\text { replaced with Title I funds. }\end{array}$ & & $\begin{array}{l}\text { Districts must show that overall } \\
\text { the level of educational services } \\
\text { is higher in schools with Title I } \\
\text { funds than they are without } \\
\text { federal dollars. SWP plan must } \\
\text { align with budget expenditures. }\end{array}$ \\
\hline
\end{tabular}


Table 1 (continued)

\begin{tabular}{|c|c|c|}
\hline TAP & Both & SWP \\
\hline $\begin{array}{l}\text { Students are pulled from the } \\
\text { regular education setting as } \\
\text { little as possible. After-school } \\
\text { and summer classes should be } \\
\text { considered for students who } \\
\text { are Title I eligible. }\end{array}$ & & $\begin{array}{l}\text { Since the program serves all } \\
\text { students, there may be a need } \\
\text { to pull students from the } \\
\text { regular educational setting to } \\
\text { receive the benefits of federal } \\
\text { money, but pullout should be } \\
\text { as minimal as possible. Push-in } \\
\text { services are permitted. }\end{array}$ \\
\hline $\begin{array}{l}\text { Ongoing progress monitoring } \\
\text { is in place to identify students } \\
\text { at risk for service eligibility. }\end{array}$ & $\begin{array}{l}\text { Ongoing monitoring and } \\
\text { assessment of student progress } \\
\text { determine intervention } \\
\text { program modifications. }\end{array}$ & $\begin{array}{l}\text { Delivery of services is based on } \\
\text { a comprehensive needs } \\
\text { assessment. Teachers are } \\
\text { involved in analysis of } \\
\text { academic assessment. }\end{array}$ \\
\hline \multirow[t]{2}{*}{$\begin{array}{l}\text { Title I services are a part of the } \\
\text { overall school planning } \\
\text { process and are considered } \\
\text { whenever new school plans } \\
\text { are developed. }\end{array}$} & & $\begin{array}{l}\text { A formal and comprehensive } \\
\text { plan must be developed for } \\
\text { each school on a SWP plan, } \\
\text { explaining how both school } \\
\text { and Title I resources will be } \\
\text { used to meet students' needs. }\end{array}$ \\
\hline & $\begin{array}{l}\text { Plans must coordinate and } \\
\text { integrate Federal, State, and } \\
\text { local services and programs }\end{array}$ & \\
\hline $\begin{array}{l}\text { Parents must be notified of } \\
\text { students eligible for Title I } \\
\text { services. }\end{array}$ & & $\begin{array}{l}\text { No parent notification of } \\
\text { services is necessary. }\end{array}$ \\
\hline \multirow{3}{*}{$\begin{array}{l}\text { Title I teachers and } \\
\text { paraprofessionals must be } \\
\text { highly qualified. }\end{array}$} & & $\begin{array}{l}\text { All staff must be highly } \\
\text { qualified. }\end{array}$ \\
\hline & $\begin{array}{l}\text { Emphasis is placed on parental } \\
\text { involvement and family } \\
\text { literacy. Parent-School Policy/ } \\
\text { compact must be developed. }\end{array}$ & $\begin{array}{l}\text { Parents are involved in plan } \\
\text { development, revision, and } \\
\text { review. }\end{array}$ \\
\hline & $\begin{array}{l}\text { Program must facilitate } \\
\text { transition from early- } \\
\text { childhood programs to school. }\end{array}$ & \\
\hline
\end{tabular}

Source: Colorado Staff Development Council (2011).

Table 1 proves that many similarities exist between TAPs and SWPs; it also shows us significant differences. For example SWPs conduct a comprehensive needs 
assessment and create the schools' plan of action based on the data collected; they also must have $100 \%$ highly qualified staff. On the other hand TAPs must notify parents if their child is eligible for services and only Title I teachers and paraprofessionals must be highly qualified. It is important for schools that have moved or are in the process of moving from TAP to SWP be aware of these differences and address them as they develop their Title I plans.

Researchers cannot use the national database to identify SWP and TAP schools with similar poverty rates to compare student achievement, growth, and effectiveness (U.S. General Accounting Office, 2000). Student achievement data are not comparable with examining school factors such as cultural norms, motivation, and behavior of staff and school leadership. As Stratton, Kenwood, and Carrie Busey reported elementary schools enter into the transition stage; it would be beneficial to look back at the schools' growth over time, comparing growth through the TAP and SWP models in hopes to gain more insight on program effectiveness.

There is no national measure used to evaluate the effectiveness of educational services in both SWPs and TAPs, so the measures of student achievement are not comparable across states. Also, with regard to achievement, there is still no clear consensus on what criteria should be used to determine the effectiveness of Title I. A Prospects Study conducted in 1999 indicated that Title I students learn at the same pace as their more advantaged peers, but the initial achievement gaps tend to remain (Baker, O’Neil, \& Linn, 1993). Some researchers interpreted these results as proving that Title I programs may not be effective (Sunderman \& Mickelsen, 2000). Others oppose this idea, 
pointing out research that tells us without interventions, gaps in achievement between students of poverty and others becomes greater over time (U.S. General Accounting Office, 2000). Growth models, relatively new statistical techniques, may provide promise in this area and help to measure what a student gains in a particular program rather than reporting the simple outcome of the state benchmark testing. For the past 2 years, Stratton Elementary has used Title I funding to build interventions that provide support for Title I students in the areas of literacy and math. Student progress and program effectiveness is measured through common formative assessments and the Standardized Test for Assessment of Reading; summative assessments, as well as statewide achievement tests. Our hope is to have the ability to offer these interventions to all students who need support through the SWP models.

Title I has a positive impact on student achievement in high-poverty schools as measured by the USDE's (2004) assessment measuring the nation's reading and math scores. The results showed that both math and reading had improved over the last 9 years in schools of poverty_primarily in schools that received Title I funds (USDE, 2004). However, the report revealed a gap in achievement between the highest and lowest poverty schools. The USDE concluded that although Title I schools helped students of poverty; they do not ensure that the students are being brought up to the level of their affluent peers. As school leaders we know that this problem cannot be solved by money alone. As a nation we have seen little progress in closing the achievement gap. In order for us to make significant growth, it means looking at the whole educational system and making some changes. 
My own view is that it is important for SWP Planning Team to reflect on what is working well and what is not working in their buildings as they restructure their programs and reshape their school cultures. I insist that school leaders who are entering the process of transitioning their school from a TAP to a SWP need to understand the similarities and differences between each model, as well as how they can benefit or derail achievement in their respective buildings. Leaders often have a clear picture or a roadmap of where they want go in terms of change. The challenge leaders face in implementing change is communication: clearly and effectively being able to communicate their vision to others and gain their buy-in and support. Although there are steps and an outline process for the paperwork needed to move to a SWP, there is not a tool specific to principals for successful ways to implement the yearlong process.

\section{Research Approaches}

Various research approaches and methodologies are commonly used in current Title I research. While each study is different in its own way, it benefits me to gather information on the approaches, findings and methodologies of a variety of researchers to keep me informed in my decision to select an approach for my study. In this section I highlight research approaches and methodologies of Title I researchers that helped me gain information that helped guide my dissertation.

Much of the research connected with Title I is conducted through evidence-based practices. The USDE sponsors the What Works Clearinghouse. The What Works Clearinghouse, established in 2002 by the Department's Institute of Educational Sciences, was created to provide educators, policymakers, and the public with valuable 
information and scientific evidence on what is working in education. Each year they conduct research studies on a broad array of educational topics including Title I. For each topic an evidence report is produced to help inform the public and anyone in the educational field.

Many researchers tend to focus on studies that are program based. These approaches range from cases studies by class, ethnicity, and cohorts over time that focus on program effectiveness with Title I students (Borman \& Hewes, 2003; Dynarski, Agodini, Heaviside, Novak, \& Carey, 2007; Slavin, 2009). Others focus on instructional strategies and professional development, for example, providing educators with professional development to prevent reading difficulties at an early age (Snow, Burns, \& Griffin, 1998) or effective strategies to teaching reading and writing for students who are struggling (Chall, 1983; Juel, 1988). A considerable body of literature has been developed about how evaluation results can and should be used for improvement (Hopkins, 1989; Miles, 1990; Spillane \& Louis, 2002; Wong \& Meyer, 1998). Much of this literature has taken a systems approach, in which the authors have examined decision-making in school systems, and have recommended approaches for generating school improvement.

The Sitkin-Lind model uses an integrative approach based on scientific research to address professional development for leaders (Sitkin Lind, \& Siang, 2006). These researchers claim that their skill-based approach to leadership training has the ability to enhance each leader's personal strength, rather instead of having a leader conform to a specific leadership style (Sitkin et al., 2006). 
Researchers Wargo (1972) and Wong (2003) focused their Title I efforts toward correlational research approach. Meaning the researcher collects data on at least two variables for the same group of subjects and then calculates a correlation coefficient between the variables, for example, the correlation between race and achievement of students in Title I schools.

In my examination of Title I research studies, one controversial issue has been the ability to maintain confidentiality, so researchers (Chapman, 2008; Evers, 2010) argue that casual-comparative research is effective for educational studies such as Title I. For example, suppose you wanted to test the hypothesis that students from lowersocioeconomic groups benefit more from direct instruction compared to those in highersocioeconomic groups; because you cannot assign students to an actual socioeconomic group without a significant breach of confidentiality, you would use causal-comparative research methods.

Descriptive research tells "what is." No manipulations of variables are attempted, only descriptions of variables and their relationships as they naturally occur. Descriptive research answers questions like, "what behaviors and interactions can we contribute to the role of the principalship?" Wolcott (1973) did just this in his book The Man in the Principal's Office, providing an ethnographic account of descriptive study of an elementary school principal. I feel that Wolcott's research proved to be beneficial in providing detailed information based on his area of focus. Qualitative research is sometimes called ethnographic research (Shank, 2002). It involves collection of narrative data in a natural setting in order to gain insights into phenomena of interest. Wolcott 
studied many variables over an extensive period of time in order to find out the way things worked, the history behind why they came to be that way, and what the deeper meaning was. Qualitative researchers do not want to intervene or control anything. The most common method of data collection involves participant observation (Shank, 2002).

This section highlighted the history and purpose of Title I, then explored evaluative Title I studies to measure the effectiveness of the program. It also highlighted NCLB and compared similarities and differences of a TAP and SWP. Lastly, it investigates research approached for Title I studies. In the upcoming section of this paper, I discuss the research available on school culture exploring the correlation in the literature with regard to student achievement and school leaders. The next section poses the question: What can leaders do to positively impact their school's culture and to improve the educational outcome for all students?

\section{School Culture}

Culture is a word with a variety of interrelated meanings. The standard way of thinking about culture most typically refers to those behaviors and practices that are rooted in ethnicity; group systems of meaning and communication that have been in existence for generations and, while dynamic, are conforming to belief systems that come from biologically related social groups need citation. Along these lines, this study uses the word culture to address school culture. Research suggests that school culture is defined by rituals, expectations, relationships, curricular focus, co-curricular activities, decision-making processes, school requirements, and a sense of the "way we do things here" (Bower, 1966, p. 22). Cultures are built through the everyday business of school 
life (Sargent, 2001). School culture directly impacts a school's social, emotional and academic end results. In the context of this paper, I define school culture as the underlying norms, beliefs, values, and customs that make up the way staff members, parents, community members, and students feel, act, and behave within the school. Culture affects all aspects of a school experience. It influences, for instance, casual conversations in the staff lounge, the importance of professional development, the value of differentiated instruction, and the promise of assuring that all students learn (Deal \& Peterson, 1999). School leaders who are aware of the dynamics of school culture and work with culture building in mind have the ability to affect the school culture spontaneously through daily interactions and regular practices. Chenoweth and Everhart (2002) suggested that schools serious about creating significant changes in teaching and learning that will positively impact student achievement must go through the difficult process of "reculturing." Reculturing is defined as challenging current practices, patterns, and norms by examining them and implementing change when it is appropriate for the success of all students. Hinde (2004) pointed out that school culture is a key component of any reform initiative. She stated that any type of school change is often met with resistance and is doomed to fail once it is countered by the nebulous, yet all encompassing, facet of school culture.

My own view is that school culture is an abstract concept that school leaders can analyze and explain, but have difficulty changing and positive influencing. I concur with Chenoweth and Everhart (2002); changing the culture means challenging the everyday routines, practices and, many times, the very values of the school. 
Expanding awareness of school culture among educators can help promote student growth, achievement, self-confidence, and respect for all. Wheatley and KellnerRogers (1996) referred to schools as organizations that are comprised of educators. In their research on the "humanness" of an organization, they found that organizations seek meaning, and do so by becoming a purposeful collective unit. The authors discuss selforganizing systems as organizations that "create their own structures through patterns of behavior and processes for accomplishing them" (Wheatley \& Kellner-Rogers, 1996, p. 38). Wheatley and Kellner-Rogers claimed that organizations such as schools are selforganizing. On the one hand, I agree that there are schools that are self-organizing organizations. However, in many instances this self-organization can negatively affect the culture of the school. On the other hand, I wholeheartedly endorse the idea that effective school leaders have the ability, and sometimes the responsibility, to shape, rebuild, and "reculture" a school's culture.

Think of a school as possessing its own unique culture; no two schools are exactly alike. Thinking back to the principal's school in chapter 1, you may find similarities between his building and your school; however, each school has its own combination of characteristics that influence a school's culture ranging from the principal's leadership style to the personalities of the staff. Experts in the fields of anthropology, sociology, psychology, and organizational development have studied culture for years. Common themes that have come out of these studies include values, beliefs, and rituals. This section delves into school culture research and looks at common themes and trends 
within the research while taking into account Title I programs and the transition of moving from TAP to SWP.

Studying school culture can give leaders insight, new levels of awareness and purpose that can serve as a catalyst for change and innovation. As I delve into the research, I hope to find key ideas that can be applied to a handbook for leaders to assist them in positively impacting their school culture through the transition from a TAP to a SWP.

The body of literature I collected on school culture portrays an overall image of what we as leaders hope (and expect) to see, feel, and hear when we walk into the doors of a school. When entering into a school, based on what we see and feel, we all are affected by different norms depending on our race, gender, ethnicity, and environment. However, we as school leaders have high expectations and a clear picture in our minds of what we want schools to aspire to with regard to school culture. My point here- $-\mathrm{I}$ am primarily researching school culture for those ethnically and socioeconomically minded school leaders who are interested in improving the culture of their schools for their community. Beyond this limited audience, however, my research should speak to anyone who cares about the larger issue of improving Title I schools. Accordingly, the literature reviewed is primarily about the following factors:

- The decision-making process (reflecting the belief that schools with collaborative culture and leadership tend to be higher-achievement environments)

- Values and beliefs (reflecting that shared values and beliefs of an organization can effect achievement and productivity in a negative or positive way) 
- Professional development (reflecting the way in which school leaders and staff view, approach, implement, and reflect of professional growth, teaching, and learning). (Deal \& Peterson, 1999)

Preliminary research conducted through the Portland State University library, online databases, and personal communications with colleagues throughout the field of education demonstrated that there is a wide array of academic material on the subject of school culture. Searches of academic search engines, Google Scholar and research databases yielded many articles on school culture (most from the 1990s) about building a professional school culture (Deal \& Peterson, 1999; Stolp \& Smith, 1994), while a few focused around leadership and school culture (Deal \& Peterson, 1999; Friedman, 1991; Lieberman, 1988; K. D. Peterson \& Chenoweth, 1992), and the influence and effectiveness of school culture (Friedman, 1991; D. H. Hargreaves, 1995). Ebscohost yielded a few articles on school culture as it relates to student achievement in the school organization (Marshall \& Gerstl-Pepin, 2005; Mok \& Flynn, 1996, 1998; Nieto, 2004). Regardless of various attempts, this research found minimal information on school leaders shaping and changing school culture to meet the needs of all students in spite of racial, socioeconomic, and/or ethnic background. There is a wide variety of information on the subject of organizational climate; however, the existing research tends to center on large organizational issues based around change. For example, Fullan and Ballew (2001) explored cultural change from a large-scale perspective. Muhammad (2009), on the other hand, discussed making changes in school culture as it pertains to difficult staff. My assumption is that effectively changing a school culture in a positive manner will improve student achievement. This assumption is deeply rooted in the works of Renchler 
(1992), as well as Deal and Peterson (1999), whose research findings include school culture and the positive relation to academically effective schools. But who really cares or takes notice of these studies? Besides a handful of educational researchers and me, who has a stake in this claim? At the very least, principals, superintendents, and districtlevel administrators who are held accountable for improving student achievement in their buildings and districts should care. Yet they are often too busy to extract and use key ideas from the literature on school change. For purposes of this study I turn my focus toward school leaders rebuilding cultures in low-achieving school environments to produce school cultures capable of supporting improved student achievement, specifically through Title I Services. There are a number of schools still struggling to bring students to higher levels of success, and yet the lack of current published research on the subject regarding Title I schools implies that additional investigation could be valuable to the field of educational leadership on the benefit of TAPs and SWPs.

According to Renchler (1992), we live in an "accountability era" where highstakes state and federal assessments make achievement a top priority. It is important to consider school culture when looking at achievement (Fullan \& Ballew, 2001). Renchler, referencing Wagener and Hall-O'Phelan (1998), stated that many researchers and educators alike are realizing a "missing piece" in the school improvement puzzle. This missing piece has more to do with school culture than it does aligning curriculum, analyzing assessments, or being in tune with the latest educational buzzwords. Maryland State Department of Education (2003) held a series of principals' workshops focused on building positive school culture to increase students' achievement. These workshops are 
based on aligning all aspects of school culture to student and adult learning to enhance the needs of the individual learner; they challenged administrators to build a collaborative culture, create a shared vision, as well as ways to monitor accountability. The research suggests that creating an effective school culture directly impacts the environment of learning for adults and students. In a culture where staff members feel respected, collaboration and discussion is encouraged, and everyone is working toward a common vision, the teacher will also carry that culture into the classroom, thereby positively impacting their students. It is possible for school leaders to foster sustained improvement in student learning and achievement by cultivating a healthy school culture (DeHart, 2003).

An atmosphere that fosters the inspiration to learn can be developed in the home, in the classroom or, on a larger scale, throughout an entire school (Renchler, 1992). The majority of academic learning takes place in the classroom, and much research on educational motivation has been centered on the classroom environment. However, making an individual classroom a place that promotes student learning is much simpler if students and teachers operate in a school culture where academic excellence and the ability to learn is expected, cultivated, and celebrated (Renchler, 1992). The connection I found between school culture and student achievement relates to the influence it has on attitudes, motivation, and the spirit for learning. Leaders can positively impact the culture of their buildings by the way they lead throughout their day-to-day interactions. For example, pointing out positives and public recognition during building walkthroughs and staff meetings can serve as a motivator for staff. Chenoweth and Everhart (2002) pointed 
out that leaders know they are building commitment to school change, when they "celebrate quick-wins and accomplishments related to student learning with their staff" (p. 85). At Stratton, our administrative team recognizes our teachers' academic successes through positive conversation, all-staff emails, newsletters and public meetings. Purkey and Smith's (1983) findings indicate that a student's chances for success in developing cognitive skills are heavily influenced by the climate of the school. "A school-level culture presses in the direction of academic achievement and helps shape the environment (and climate) in which the student learns" (p. 440).

As a school leader, I believe that we cannot leave the culture of our buildings up to chance. We must ensure a positive learning environment for all students if we plan on closing the achievement gap. This study not only compares and contrasts the differences between TAPs and SWPs, but it also assists in guiding school leaders as they work to create a culture that improves the educational outcome for all students throughout any process of change. In the next section of this study, I discuss the research available on Title I programs, the yearlong planning and transitioning process, and what researchers choose to address in terms of Title I. We also look at a chart developed to point out the similarities and differences of a TAP and a SWP.

The relationship linking school culture and student achievement has been analyzed in numerous ways in the literature. Research that I reviewed connected many parallels between a positive school culture and its positive results on the achievement of students, as well as some of the writings on corporate culture and its effect on an organization (Borman \& Agostino, 1996; Gill et al., 2007; Mok \& Flynn, 1998). There 
seems to be an indirect connection between schools and business or organizations in regards to the way they function, as well as how they can implement change (Fullan \& Ballew, 2001). Literature can be used in the public or private sector; however, not all of this work applies to schools; some of the work is focused on business organizations. Most of the studies I reviewed address aspects such as relationships, collaboration, core values, beliefs, and motivation as a foundation for an effective school culture (Bolman \& Deal, 2003; Deal \& Peterson, 1999; K. D. Peterson, 2002; Raywid, 2001; Stolp \& Smith, 1994). My personal view is that these topics shed light on the issues that school leaders will face in terms of culture when they enter into the yearlong Title I transition process. Some case-study researchers concentrated on toxic school culture, where achievement is damaged by a negative approach to teaching, learning, leadership and community (Friedman, 1991; Reeves, 2004; Spindler \& Spindler, 1994; Varenne \& Mcdermott, 1999). There are a few studies that compare and contrast toxic and healthy school culture (Muhammad, 2009; K. D. Peterson \& Deal, 2009). Yet I found that the body of research is not as large as many may think in terms of comparing and contrasting effective school culture to negative or toxic school culture (i.e., the correlation between negative school culture and negative achievement as well as positive culture as it relates to positive achievement). In my estimation, school culture is not as cut and dry as measuring student achievement and success on a standardized test. Opinions may overlap regarding the measurement of school culture Experts may not exactly be of the same mind as to what constitutes a positive or negative school culture (e.g., what elements are most important in building a foundation for an effective school culture, or what role school leaders can 
play in transforming a toxic school culture and/or enhancing a positive school culture). Some experts appear to measure school culture by the feeling they get when entering the school environment (DeHart, 2003; Hoy, 1990, while others base measurement on collaboration and decision which promote achievement (M.W. Peterson \& Dill, 1999). Some tend to measure success on whether or not the school culture recognizes, celebrates, and embraces the differences of all students (Ogbu, 1982; Pankratz \& Petrosko, 2000; Stefkovich \& O’Brien, 2004). Much research still remains to be done in the field of school culture during a large change initiative, more specifically, the transitioning from a TAP to a SWP. I hope to address the gaps in the research that help school leaders maintain, sustain or reshape a school culture as they navigate through the yearlong planning process.

In what ways can school leaders improve school culture, and how does this impact student achievement? Researchers have gathered a wealth of observations, key elements, ideas, and interviews to narrow down the answer to this question. As noted by Raywid (2001), school improvement emerges from the confluence of four elements: the strengthening of teachers' skills, the systematic renovation of curriculum, the improvement of the organization, and the involvement of parents and citizens in responsible school-community partnerships. Underlying all four strands, however, is a school culture that either energizes or undermines them. Essentially, the culture of the school is the foundation for school improvement, a view summarized by Purkey and Smith (1983). The next section is a review of the literature on school change, with regard to the reform efforts and Title I. This section school change was written with 
consideration to school culture. It also takes into account school leaders and what they can do to make change that is sustainable and implemented by all.

\section{School Change}

In this section we review the body of school-change literature to gain a deeper understanding of what school leaders can do to make positive sustainable change. This section poses the questions: why change schools? What is change? It also discusses roadblocks and barriers that impede the success of school change.

Fullan (1997b) said most educators' general assumptions about change are that change can be challenging and invigorating, but if it is valued by all it is more likely to be implemented and sustained. I feel that in terms of school change, schools must be "recultured" and not simply restructured or reformed. Why change schools? Schools are continually responding to policies and federal mandates that require them to change. Schools must also work for continual progress that is measured by state standards driven by adequate yearly progress (AYP) test results. Title I is one of the largest federal programs designed to help schools meet these requirements. However, there are other noble reasons to consider school change. Across the nation administrators, teachers, parents, and policymakers continue to voice two common concerns about schools:

1. The large number of students failing in school, dropping out, or being bored and disengaged. These collective groups want schools to do more to provide a quality education for all students.

2. The changes that have been made over the past decade in education are still inadequate in preparing students for the $21^{\text {st }}$ century after graduation. 
Lieberman (1988) stated that different reasons for change leads to different processes. She went on to explain that it is important to connect the reason for change with the strategies used to reach a solution. In chapter 1, the principal noticed that his Title I teachers did not have the ability to serve the large number of students that qualified for services under the structure of the school's TAP. He then identified the transition to a SWP as the change or solution needed to serve all students. Although I agree with Lieberman up to a point, I would go further, insisting that the school leader must not only consider the reason for change, correlating it to the strategies, but also must take the existing culture into account when building a strategy to implement the change.

Schweiker-Marra (1995) conducted a study probing the relationship between school culture and teacher change. This study identified six norms that guide a change in school culture: (a) collegiality, (b) experimentation, (c) high expectations, (d) trust, (e) support, and (f) knowledge base. Schweiker-Marra stated "not only does the presence of these norms promote change, but the norms increase as change progresses" (p. 9).

Before elaborating on the principal's role in promoting school change, it is important to consider what we mean by school change. Many researchers have examined school change in two aspects (a) change as both a process and a product, and (b) as transformative or incremental.

Thinking along the lines of change as a process and product, Fullan (1982) insisted that change is not an event that occurred in such context as a "before" and "after" that could be recognized and measured, rather he defined change as a process. However, more recent change studies suggest that there are key places in the school where this 
process can occur more or less effectively, and some key issues on which change should focus; these include:

1. "Moral purpose" taken to be a particularly meaningful form of vision which requires commitment;

2. "School structure and culture," the materials and resources available to the school and the way in which the school community conducts its everyday business.

3. "Capacity" taken to mean both the knowledge and skills of the school staff. (Caldwell \& Spinks, 1988, 1992, 1998; Fullan, 1993, 1999, 2005; Fullan \& Ballew, 2001; A. Hargreaves, 1994; A. Hargreaves \& Goodson, 1996; Louis \& Miles, 1990).

I feel that it is helpful to go deeper than this when thinking about the process of school change. Fullan (1993) pointed out the theory of "ends and means." Put simply, where you end up and what you end up with (outcome) is inextricably connected with what you are trying to achieve (purpose), and the avenues you use to get there is the process.

I am in agreement with Fullan (2004) with regard to the Title I transition. For example it would be clearly problematic for a principal to lead the SWP transition process through top-down leadership. If the leader was successful in making the transition, the likelihood of the school functioning as a SWP school would be very low due to the fact the staff had no ownership in the process.

A vital aspect of promoting school change is the role that the principal and school leaders take on in facilitating or initiating the change. The role of the school leader 
defines the assumptions of the school culture to others. The principal is a key contributor in enacting change or frustrating it (K.D. Peterson \& Deal, 1998). Fullan and Ballew (2001) identified principals with the skills and ability to bring about school change as “initiators." This type of principal has a clear vision, works collaboratively with all school community, elicits other change agents for support, and continues this process throughout the school year (Fullan \& Ballew, 1991). I feel that effective school leaders spend the time it takes to develop support from their staff, communicate openly about the change, understand how to monitor the change, and develop a roadmap for guiding others through the process.

Thinking along the lines of change as improvement or transformation, change can be something small and unchallenging, or something gradual and incremental, or it can be something quite radical and transformational. Sarason (1990) argued that in order for schools to meet the needs of all students they need to be radically overhauled because it is the school system that is flawed. On the other hand, Lara and Whittier (2003) felt that to meet the need of students today the school needs to be equipped with the most up-to-date technology to enhance the curriculum and pedagogy. Personally, I feel that the way in which the change is viewed by the school community determines whether the change is deemed as improvement or transformative. Based on the magnitude of the change and the ways in which the stakeholders have been involved in the change process, the leader may be met with acceptance or resistance from others.

With changes come many barriers that can slow down or impede the process. There are always people who get on board with change right away, while others need 
time to embrace the change before implementing it with fidelity, and other still may not make the change for a long time (Hall \& Hord, 2006). Even mandated changes take time for certain people to implement. Fullan (1997a) pointed out that mandated changes are the generally least effective. Fullan stated, "Mandates alter some things, but they don't affect what matters. When complex change is involved, people do not and cannot change by being told to do so" (p. 38). I concur with Fullan; his statement illustrates the importance of educational leaders having the skills to create buy-in and gain support from those who do not believe in the change. If a staff is going to successfully implement the change, it is important for them to believe in the reason for the change, and how it will benefit the students as a result of implementation. "Change happens best when a problem is well defined, owned, and personalized by those who will carry out the change" (Chenoweth \& Everhart, 2002, p. 10). Chenoweth and Everhart (2002) referenced E. M. Bridges and Hallinger's "transition" phase, a process that one must go through in order for a cultural or external change to occur. The transition phase is an internal process for coping with the change, whereas the school's change is more of an external event (E. M. Bridges \& Hallinger, 1995).

In my experience, many times educators look at large school-change initiatives and school reform efforts such as moving from a TAP to a SWP as a negative, and if we let people's attitudes take root in others, it can be detrimental to the school culture. The transition can be viewed as a negative when you are looking at it through a personal lens. Some view it as requiring additional effort and time staff will need to spend looking at data or analyzing an issue. Others look at the unknown, worried about how the change 
will affect their teaching style or personnel. However, as a school's principal, I believe it is my job to get them to view the change through an educational lens. Personally, I challenge school leaders to guide themselves with beneficial questions: Will this change benefit students? What are the educational reasons behind this change? Will this change assist us in closing the gaps that we see in our achievement data? If the change is needed to positively impact students, principals must have the ability to implement it with fidelity. I value W. Bridges' (2009) point about the transition phase, and feel that school leaders need to not only be aware of this process, but assist the staff, as individuals, that may be struggling with this phase.

Levin and Riffel (1997) suggested that redesigning schools and systems requires careful research, discussion, and planning. It is not reasonable to assume that everyone will agree on the rationale for school change. These researchers conclude that school constituents need to debate the proposed outcome and purpose of change. There are many literature resources to assist school leaders in how to think about school change; this research is in agreement that school change is not quick nor is it easy. Although researchers agree on this, there is little agreement on a timeline for large school change efforts. In my experience it is up to the school leader to be knowledgeable of their staff and find the right pace if they want to have any type of positive impact.

The corpus of school change literature (Fullan \& Ballew, 2001; A. Hargreaves \& Goodson, 1996; Levin, 2001; Louis \& Miles, 1990) lets us know that school change encompasses a large spectrum of components from staff buy-in to philosophies and ongoing discussion and debates. Schools with the ability to change usually have a stable 
staff, established venues and protocols for communication, a clear vision, and justifiable reason for the change. I argue that sustainable change happens in schools where the culture supports innovation, discussion, and open communication. I insist that school culture and school change go hand-in-hand, and feel that school leaders cannot create strong sustainable change without considering and addressing the school culture.

Following this line of thinking, I believe that taking both of these factors into consideration can be beneficial to school leaders engaging in the yearlong move from TA to $\mathrm{SW}$.

In thinking along the lines of improving school culture in terms of achievement, I feel led to broach the subject of reform or school change. "Good intentions married to good ideas are necessary but not sufficient for action consistent with them. In accordance with Murphy's Law, if anything can go wrong it will”' (Sarason, 1990, p. 99). Sarason's statement relates to the wide range of failed school reform efforts. Sarason pointed out that proper implementation of a reform effort requires deeper understanding of all aspects of the school setting in order to overcome obstacles and roadblocks. I agree with Sarason, because based on my own personal experience working in the educational system, I have seen reform efforts that have fallen flat when the school leader does not possess enough knowledge surrounding the school culture and environment. These failed reform efforts Sarason discussed seem trivial to our nation's school system; they are in fact crucial to today's concerns for the success of Title I schools.

Title I SWPs have been directly correlated to the nation's school reform movement to impact student achievement in a positive manner. Researchers look at the 
complex process of school reform analyzing its successes and failures. There is a vast amount of research explaining why reform efforts are so difficult to implement, and why it is important for the reform process to align with the school's culture (Sunderman \& Mickelsen, 2000; Wong \& Meyer, 1998). Although researchers agree that it is incumbent to understand the correlation between school culture and school reform (specifically in Title I schools), there is little research available to help guide leaders in the process of school reform while cultivating and sustaining a healthy culture. Cromwell (2002) defined healthy school cultures in this manner: "Healthy school cultures have an unwavering belief in the ability of each student to achieve success and they pass that belief on to others in overt and covert ways" (p. 1). Case studies conducted by schools that have transitioned from TAPs to SWPs find that it is important to focus on school culture by including all school constituents in the planning and transitioning process (Wong, 2003; Wong \& Meyer, 1998). These case studies recommend teacher input and shared decision making from the initial step of planning a SWP. Schools generally conduct their information through a comprehensive needs assessment based on careful review of student performance data, school data, stakeholders survey and group discussions to pinpoint school improvement initiatives. I concur with Wong's research; if the first step begins with creating a survey to find out what the school's needs consist of, it is important for leaders to gather information from multiple perspectives. As we west through this process at Stratton Elementary, our SWP Planning Team was in alignment with Wong's recommended steps. 


\section{Field Visits, Interviews, Document Review}

E. M. Bridges and Hallinger (1995) suggested that researchers conducting PBL for the purpose of an Ed.D dissertation should conduct preliminary research by seeking to generate all the information that is available about the problem. E. M. Bridges and Hallinger implored the researcher to conduct "small-scale research," such as "observations in schools and interviews with practitioners and researchers who are knowledgeable about the problem" (p. 120). The goal of this small-scale research is to give the researcher a deeper understanding of the problem and ideas about how the product they are creating will address the problem. Research that addresses a particular problem must consider the target audience as well as the venue for testing. In the initial stages, the researcher must take into account the body of literature on the problem as well as conversations with knowledgeable practitioners. Thus, this section includes key components of principal interviews, descriptions of field notes from school site visits, and artifacts and documents.

\section{Interviews}

Through the use of interviews, I learned about the culture, challenges, and successes of four schools that are functioning under Title I SWPs. All of these schools were TAPs that made the transition to SWPs. I was able to hear the perceptions of each school's principal, as well as those of teachers and members of the school community. I conducted these interviews through a series of school site visits to find out what other SWP elementary schools are doing to serve students, and if what they are doing has proven beneficial. The accounts of their experiences provided important stories that have 
added to the literature on change, culture, and Title I program models. In speaking with a Title I teacher at an elementary school, she stressed the importance of collaboration and communication. Her program structure has support from an educational assistant. She explained that in order for the program to run effectively, they need to be in constant communication with each other, as well as have an open line of communication with their principal.

Principal Tina Griffith of National Elementary (pseudonyms), talked about changing the expectations and culture by having a clear vision and goal. She discussed the important of creating a master schedule that drives the school's goals and vision. She used the method of raising the expectations of her staff by requiring them to assess their students once a month and report back to her with the results. She gained a large majority of staff buy-in through monthly collaboration meeting with her SWP Planning Team during their transition year. She constantly monitored and held all staff accountable for implementation of their programs. If someone was not following the school's vision, she addressed it head on. Tina said, "We are a work in progress; each year we work to become better than we were the year before." In visiting Principal Griffith's school, the culture of academic excellence is evident in the rich displays of student writing and math projects that cover the walls.

Principal Gina Roland of Earlybird Elementary (pseudonyms) told the staff, "You all are living in a dreamland" regarding the solutions that they came up with during their transition year, which included adding positions and purchasing new programs. Principal Roland said, "Unless you know of some hidden money that I don't know about, we need 
to find out what we can do with the resources we have right here." Her school ended up putting into practice two program models "Walk to Read" and "Walk to Math." This model utilizes all staff members by grouping two grades together during a reading and math block to provide ability groups and push-in services from Title I and Special Education staff. Gina said, "Beware of the person who interrupts my blocks. Every staff member is working with a group during those designated times." In my opinion, Principal Roland's school is truly working under the SWP model. Their "Walk To" programs service and support every student in the school by meeting them at their ability level. They assess, evaluate, and continue to move students to the next level. After talking with several teachers about their SWPs, I got overwhelmingly positive responses. Many talked about the effectiveness of interventions; many interventions were technology based and others were based on small group instruction through a push-in model. One teacher in particular explained that the homogeneous grouping created though models such as Walk To programs make differentiation easy for students, and also make learning fun and interesting for students above grade level, while providing support to students below grade level as well.

Through attending ODE's statewide training for Title I Coordinators, I found that ODE is in support of SWPs over TAPs. Janet Bubl stated that basing a plan on a comprehensive needs assessment has proven to be more effective that just creating a plan based on statewide assessments. She also pointed out that schools should be meeting the needs of all students, not just the lowest percentage of academic achievers.

National experts such as Cheryl Henjum and Marjorie Grigsby, both of whom presented at the National Association of Elementary Principals conference (NAPSE) both 
discussed the success and growth that they have witnessed in their districts using SWP models. Henjum highlighted Walk To Read and Walk To Math support models, utilizing classified staff for push-in support. Grigsby pointed out that affective SWPs assess their students at least three times a year and create interventions based around the assessments. She also discussed using Title I funds to support afterschool programs and summer school, which is a trend for many SWPs.

\section{Field Notes}

Field notes are a primary source of my data in this study. The field notes I collected were based on a number of school site visits. The schools visited were all Oregon elementary schools that had made the transition from TAP to SWP. The preliminary field notes that I collected are based on recording what was said, the context of what was happening at the time and my thoughts about it during specific time periods or at specific locations or events. Approximately halfway through the school year, the field notes appear to have gotten a bit repetitive, which others have assured me it is a good sign that themes are emerging. My field notes reflect classroom actions, meetings, and observations that were conducted at Stratton, Carey Busey, Kenwood and four other anonymous Oregon elementary schools. During these site visits I was accompanied by members of Stratton's SWP Planning team, each team member took notes, and we met after each site visit to debrief. Observations specific to the school culture, Title I program and interventions used were recorded on an iPad. These observations help to provide me with an understanding of the values, beliefs, educational philosophies, and rituals of the school, giving me insight on the school's culture. 
In order to keep accurate notes, I also observed while recording my notes with an iPad. In taking my notes I took into account two observation techniques. First, I tried to stay "detached" from the situation and observe as much of the school environment as possible by using a guide, Tool \#4 in my draft handbook, listed below as Figure 2. Secondly, I looked to seek information from our number one commodity as educators (i.e., the students). I solicited pupil impressions from elementary students sparked by a series of open-ended questions about how they felt about their school, their principal, and their teachers.

Figure 2 was used by me and the other SWP planning team observers to guide our thinking and note-taking as we sought to gain insight to three categories: meaningful change, organizational/structural change and the climate of change.

\section{Document Review}

Throughout the yearlong planning and transition year schools are required to complete documents and evidence. ODE requires each school to submit this collection of items at the end of the school year. For the compliance with the Title I transition process and the validity of this study, I collected artifact and samples from each site visit that will inform and support the research that I plan to conduct regarding Title I (i.e., school culture and school change as it relates to this study). Artifacts that I collected include meeting agendas, staff memos, and announcements, mission and vision statements, and school newsletters, school master schedules, meeting schedules, intervention plans and survey results. Other artifacts would include state report cards and adequate yearly progress (AYP) results. 


\section{Site-Visit Tour Guide}

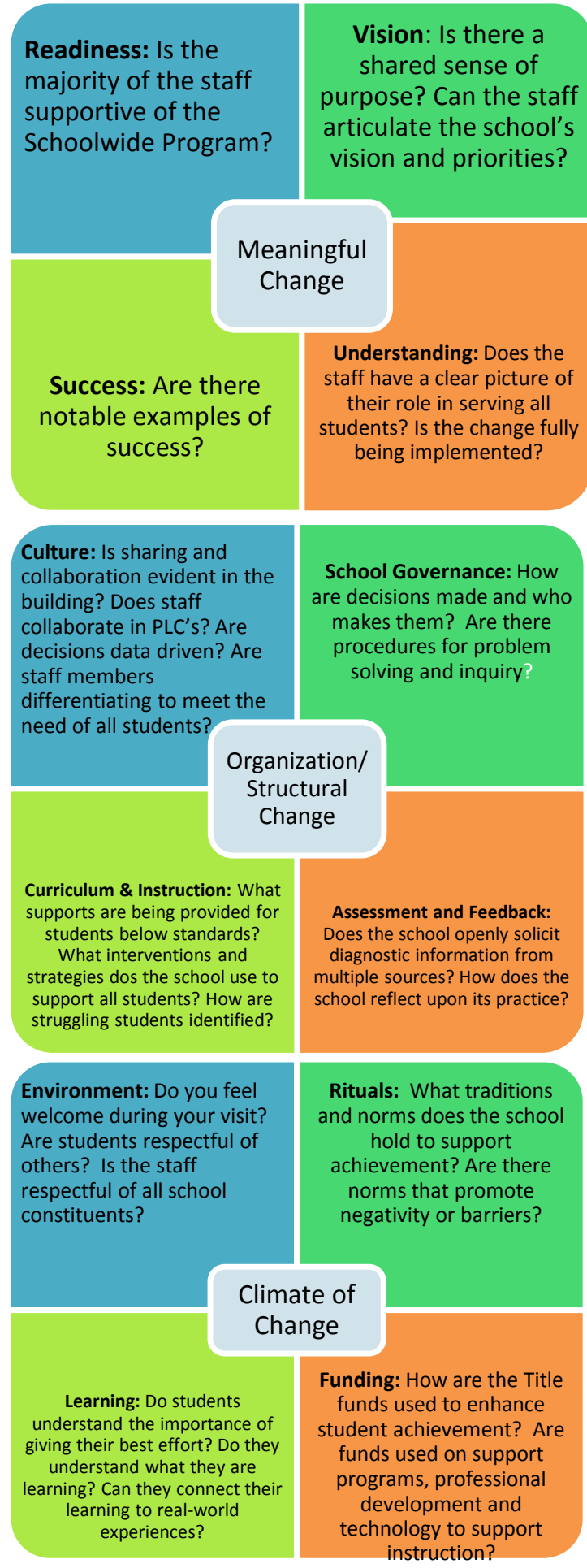

This tool has been adapted and updated by Chenoweth and Everhart (2002).

Figure 2. Site-visit tour guide. 
Many of documents I used are in the Appendix. The document's format and presentation remain the same; however, I recreated the document from the original due to the lengthy text.

\section{Summary}

This chapter highlighted the literature on school change along with the importance of leaders expanding their awareness of using school culture as a catalyst for change. This chapter also explores the research on school reform efforts, and connects them to the SWP transition. Lastly, this chapter explains the process that was used up to this point to collect field notes, interviews and document review.

This next chapter explains the research design and lists several questions that guided the study. It also explains the data collection process and the strategy I used to ensure the validity of the study. I describe in detail the methods of collecting data from school- and district-level administrators and members of SWP Planning Teams. I inquired about their ideas and recommendations for improving tools and information presented in the practitioner's handbook intended to address the needs of school leaders transitioning from a TAP to a SWP. The handbook is based on the research question: What tools and information do school leaders need to assist them to positively shape their school's culture as they move their schools from a TAP to a SWP? Since the Title I transition process is a new and growing trend based on today's economy and the growing number of students qualifying for free-and-reduced lunch; it is well to note this research question has not been adequately addressed in the research literature. It is hoped that this research study will provide school leaders with insight and guidance to effectively 
navigate through the Title I transition processes. The intent is to assist school leaders in shaping school culture, to better support student learning in Title I schools. 


\section{CHAPTER III \\ METHODOLOGY AND RESEARCH TECHNIQUES \\ Introduction}

This process began with developing the research question: What can school leaders do to positively shape their school's culture as they move their schools from a TAP to a SWP? This section discusses the research design and research questions that were used to evaluate the impact of the product in a school setting. It then describes the data collection procedures that I used to justify my data. The data analysis section clarifies how I safeguarded the study against bias and defended the validity of the study. Lastly, this chapter explains the action plan used to manage the development of fieldtesting of the product.

As pointed out in chapter 1 , as poverty increases across the nation, we will see more families whose children qualify for free-and-reduced lunch. This epidemic makes it more likely that schools will be making the transition from TAPs to SWPs to serve the increasing number of students below benchmark. However, in many cases schools have been unsuccessful in sustaining their SWPs after making the shift from TAP. Based on this tendency, I have identified the research problem as a lack of information and professional development available to school leaders to assist them in successful implementation of the transition process. Furthermore, the very topic of school culture is an abstract concept, which only exacerbates the problem, as many principals do not understand how to make a positive impact when initiating school change. This chapter 
focuses on the product that was created, tested and refined to assist school leaders in addressing this problem.

In my opinion, the lack of research on the transition to a SWP led me to believe that there is a need for a tool or guidebook that can assist administrators in reshaping or maintaining a positive culture as they lead their schools through this yearlong transition. I feel that this handbook is a powerful tool in the hands of principals and school administrators. They gain perspectives from others that have gone through the process or are knowledgeable about school culture and change. The handbook is intended to help principals avoid the pitfalls and roadblocks that many schools have experienced throughout their transition year. The handbook also focuses on ways to keep staff members and school constituents positively engaged during the process.

\section{Research Design}

After looking at several research designs, I have identified the PBL approach that employs R\&D as the method and design structure most beneficial for collecting the qualitative data for this study (Borg \& Gall, 1989; E. M. Bridges \& Hallinger, 1995). PBL is a research approach that consists of carefully addressing a problem that demands acquisition of critical knowledge from the learner, problem-solving proficiency, selfdirected learning strategies, and team participation skills. The model uses systematic approaches to resolving problems and meeting challenges that are encountered in life and career (E. M. Bridges \& Hallinger, 1995).

E. M. Bridges and Hallinger (1995) have identified PBL as a strong vehicle for assisting professional doctoral students, who are in educational administration, 
accomplish successful Doctorate of Education dissertations. Many of these doctoral students, who are educational administrators in a variety of respected positions, are looking to participate in an experience that will have instrumental value in their future work.

For the benefit of this study, I incorporated E. M. Bridges and Hallinger's (1995) work by using PBL as my research method. PBL provides a R\&D model that complements my overall research goal. Borg and Gall (1989) depicted educational R\&D as "a process used to develop and validate educational products" (p. 782). Researchers engaged in the $R \& D$ practice use their findings to create tested products that are ready to be implemented in school settings. Borg and Gall's research has proven that the R\&D cycle is an effective way to develop, field test and refine products, ensuring that the product is ready to assist practitioners. This cycle assisted me in developing and fieldtesting a handbook for school leaders, which was used to shape culture and navigate successfully through the process of transitioning buildings from a TAP to a SWP. This study provides school leaders with a tested product that is ready for operational use in schools. In creating this handbook, I am guided by the question: What is essential for leaders to know and do as they work to create a positive culture during the transition from a TAP to a SWP? The potential benefit to school leaders is to provide a tool that can help schools sustain a positive school culture while tailoring their Title I program to serve the needs of their schools. The study could provide significant practical and conceptual value to school leaders who plan to engage in the transition process. 
According to the ODE, schools transitioning to a SWP must conduct a comprehensive needs assessment to find out what areas of weakness can be improved and how this can be addressed through a SWP model. I conducted preliminary testing of the product at three schools that were going through the Title I process. Several of these tools were used to assist teams in addressing their areas of weakness. As these schools navigated through the 2011-2012 Title I planning year, in which they were moving from a TAP model to a SWP model, I refined the tools in my handbook based on their feedback and data. Then, from May 2012 through August 2012 the handbook was tested at each of the first seven steps in the R\&D cycle by school principals and district office administrators, as well as Title I Directors and Coordinators throughout the state of Oregon who were in attendance at the annual COSA (Confederation of Oregon School Administrators) convention in June. I carried out a mixed method study analyzing survey data provided by each participant testing the handbook. From August 2012 until December 2012, the handbook was piloted at an elementary school that was entering the Title I transition process, during this piloting period the data that I collected was through the research/instructional coach lens. Specific to this study, I conducted small-scale research for example: school observations, as well as interviews with principals and Title I administrators and researchers who are knowledgeable about school culture or transitioning to a Title I SWP. Through this study, my intent was to develop a deeper understanding of how the handbook would address the problems school leaders and principals face in reshaping or sustaining a positive school culture as they go through the state's recommendation of moving a school from a TAP to a SWP. The goal of the 
handbook is to provide assistance to practitioners as they go through the yearlong implementation phase. I followed Borg and Gall's (1989) suggested steps in the R\&D cycle listed in Table 2.

Table 2

Steps in the $R \& D$ Cycle

1. Research and information collecting

2. Planning, objectives, learning activities, and small scale testing

3. Develop preliminary form of the product

4. Preliminary field testing

5. Main product revision

6. Main Field testing

7. Operational product revision

8. Operational field testing

9. Final product revision

10. Dissemination and implementation

Source: Borg and Gall (1989, pp. 784-785)

Step 1, Research and information collecting, was accomplished through the research and information that I collected, referenced in my Literature Review on Title I, School Culture and School Change. This step also includes information collected while attending state and national conferences on Title I. During this research period I had the opportunity to interview superintendents, principals, and Title I coordinators. Most importantly I had the honor of speaking with ODE's Title I staff: Tryna Lutton, Director of Reading First; Russ Sweet, Educational Specialist; and Janet Bubl, School Improvement \& Accountability Specialist Title I-A. Research and information was a continual step for me as I went through the R\&D cycle. 
Step 2, Planning, objectives, learning activities, and small scale testing, began through conversations with my advisor, superintendents, and principals of Title I schools, and SWP Planning Team members. Site Visits were conducted to talk with staff and administrators who were going through, or had gone through the Title I transition. One goal was to learn what obstacles and roadblocks they faced, as well as what would have been beneficial in assisting them in the process. This information collected was used to begin developing the handbook.

Step 3, Develop preliminary form of the product, was an ongoing process that is cyclical. I began creating the handbook based on information and insight that I received in Steps 1 and 2 of the R\&D cycle. ODE's recommendation of the Title I transition process was used to guide my logic in creating the handbook. However, the handbook became more developed as Stratton, Carrie Busey and Kenwood Elementary schools navigated through the Schoolwide process. Through experiences, conversations, observations and feedback, participants made suggestions and recommendations that helped guide me in creating a preliminary form of the handbook.

During Step 4, Preliminary field testing, I conducted focus groups where principals, district office administrators, SWP Planning Team members and Title I personnel discussed, evaluated and tested tools provided in the handbook. In May, I identified the participants of the focus groups as well as distributed and collected consent forms. Then during COSA in June the Principal's focus group (FG1) participated in an overview of the handbook and the use of tools provided. They began preliminary field 
testing of the handbook after hearing a presentation, by using in-basket scenarios, group discussions and feedback to test the tools and evaluate the effectiveness of the handbook.

Based on the data and information collected in Step 4 then Step 5, Main Product Revision, began. The handbook was revised and refined according to the surveys, focus groups, interviews, suggestions, and information gathered. Step 6, Main Field Testing, was conducted by Title I Coordinators and Central Office Administrators' group (FG2) who went through the transition successfully as well as unsuccessfully. They evaluated the effectiveness of the handbook's tools in assisting principals as a guide. This step also included a training that I led on how to use the handbook to ensure a successful transition. Continued refinement included the ODE group (FG3), where the handbook was reviewed by Title I experts from the ODE. In turn, these educators were able to provide beneficial feedback on both the presentation, as well as feedback on the handbook itself.

Step 7, the handbook was professionally edited, refined and made user-friendly in order to be made operational for school leaders who intend to make the transition from TAP to SWP. I am confident that the R\&D process provided me with the information needed to create a product worthy of use and be beneficial to school leaders.

Step 8, Operational field testing, took place from August 2012 until December 2012 when the handbook was piloted at an elementary school site that was entering the Title I Transition process. The principal who use that handbook as a guide provided feedback on the experience. Piloting the handbook ensured validity of the handbook's effectiveness as a guide. 
Steps 9-10 were not pursued at this time, as they are more specifically geared toward professional publication and dissemination.

\section{Research Questions}

As I have stated before, this journey began by setting forth research questions that will guide this study; my overarching question: What can school leaders gather from the existing literature to positively shape their school's culture as they move their school from a TAP to a SWP? The following questions helped guide me in evaluating the handbook. The handbook is intended to provide leaders with tips, tools and resources to help them successfully navigate the Title I transition process.

\section{Guiding Questions}

1. What have been the experiences of principals who have gone through this process? What barriers, roadblocks and success stories can they share to help others in the future? How well does the handbook present ways to work through and address barriers and roadblocks?

2. What strategies have been successful in building and sustaining a positive school culture during a large change initiative, and are those strategies represented in the handbook?

3. What significant impact, if any, can this product have on student achievement, school leadership and school culture?

4. What effect did the cohesion of the planning team have on the implementation process? How does the handbook emphasize the importance of selecting a 
strong team? How effective are the tools in the handbook at assisting principals in selecting a team?

5. How effective are the tools in the handbook in assisting school leaders to create buy-in from their staff for the transition?

6. Does the handbook provide a cultural lens for leaders when making the program transition?

7. How beneficial is the handbook at addressing school culture during the Title I transition?

8. What suggestions do these school leaders have for improving the handbook?

My own view is that these open-ended questions helped me evaluate the effectiveness of the handbook. Taking into account the research questions above, I created a draft product (handbook) for administrators that was piloted, tested, and further refined based on the practitioner's feedback. The questions above can be viewed as a guide for self-reflection, before being evaluated by other participants in the study. As I dug further into refining the handbook, I anticipated that more questions would arise, leading me to adjust, recreate and shape the handbook. My hope was that with more questions I would deepen my knowledge of what will be most helpful in assisting school leaders through the transition. I hope to utilize and display this expertise in the handbook toward the enhancement and benefit of implementing a more efficient Title I transition process. 


\section{Data Collection Procedures}

Superintendents and principals are becoming increasingly aware of the importance of school culture and its ability to help promote or impede the progress of a school or district. There are handbooks that help administrators understand how culture is formed as well as how it influences behavior and motivation. However, throughout my research, I have not found a handbook or tool that gives school leaders concrete steps that they can follow to reculture a school's environment during this SWP transition process. In developing and field testing the handbook's tools at three elementary schools going through the Title I transition, I have been able to create a preliminary product to assist in building or maintaining a positive culture as schools move through the transition process.

Before a researcher begins to gather information, it is important to think about what type of data will be relevant and useful to his or her problem statement and research question (Hubbard \& Power, 1993). Hubbard and Power (1993) used information from focus groups, observations and interviews as they studied the keys to creating a classroom environment driven by inquiry. Many researchers use multiple methods of data collection, and because every method has its limitations, the triangulation of data (multiple methods) helps the researcher get more than one perspective, making the data more valid (M. Caskey, personal communication, October 2010). Multiple methods of data collection can also have the tendency to make data analysis more complicated, so many researchers settle on using one standpoint when exploring cultural issues. Since the handbook for the Title I transition was intended as a resource for leaders; it was tested, 
evaluated and refined based on data, feedback and interviews of school leaders, administrators and ODE employees.

Wolcott (1973) pointed out that quantitative researchers use data that can be described as the "hard numbers." A few examples of quantitative data with regard to education would be standardized testing and hypothesis testing (Wolcott, 1973). This type of research can be loosely related to school culture; a researcher could make some standard generalizations about a school's culture by analyzing data and its outcomes. Quantitative researchers use formal methods to collect data to assist them in analyzing an experimental group, or control group to measure specific growth and significant variables. In several of these cases, researcher look at pre-existing data such as, statewide standardized test scores, and disaggregated data on levels that can be national, by state, district or even building level (Reeves, 2004; Wong, 2003). Quantitative researchers would take into account data about academics, behavior, student/staff retention, as well as attendance and other measures (Johnson \& Christensen, 2007). For the purpose of this study, I took into account preexisting data such as standardized test scores and disaggregated achievement data for Stratton Elementary School (pseudonym). However, quantitative analysis was only a small portion of the research methodology. I felt that it was logical to exclude the collection of new quantitative data when analyzing the transition process and creating a handbook for practitioners. I felt that I gained the necessary information to conduct my study by working in the field with principals, and gathering insight and information from actual educators who had been through or were experiencing the process. 
Qualitative researchers explore educational issues and gather data through a more open-ended process. Examples of this type of data collection would be group survey, case studies, and interviews that provide information from the participants' points of view. Many of these interviews are recorded with the interviewer's actual words (Johnson \& Christensen, 2007). This process is very beneficial when collecting data on school culture. A scientific research-based strategy that is used in researching culture is ethnography. Ethnography is a method of studying people in the fullest possible context (Abate, 2009). Cultural anthropologists examine culture and its relationship to humanity. With regard to school culture, the researcher would study the staff, students, and families at a particular school to get a deeper understanding of that school's culture. Interview questions about the feelings of the school, attitudes, values, and beliefs, both educational and personal, can give us the pertinent information that one needs to guide their study (Byrne, 2001). Collection of survey data that explores one's logic, feelings, or justifications is also a method that has proven beneficial in gathering educational research. Anthropologists not only use participant observation, interviews, and surveys as a way to gather information; they also spend time completing fieldwork. Fieldwork occurs when the researcher spends a significant period of time at their research location gathering observations and other data (M. Caskey, personal communication, October 2010). In conducting the research, I will take on the role of researcher-facilitator in the focus groups allowing me to gather data from multiple sources. I also have the benefit of being a practitioner myself, putting me in a quasi participant-observer role. This allows me access to the necessary resources and fieldwork required to gather a sufficient amount 
of information about the effectiveness of the handbook from reputable sources. The outcome desired is the creation of a valuable resource for practitioners who are looking to undergo the Title I transition process in the future.

Standard methods for gathering information about a school's culture can be done through interviews and observations. An informal interview or open-ended interview is conversation that could be spontaneous, such as a daily interaction, with a participant of a study, and conversations with principals experiencing the process. The key to keeping track of these conversations in by taking field notes as soon as possible, then expanding these notes into a more formal summary of the informal interview (Anderson, Herr, \& Nihlen, 2007). Another approach to these open-ended interviews involves collecting firstperson narratives from students, staff, parents, and community members. Researchers who use this method collect and analyze narratives about the culture of the school from students, families, and school constituents of different backgrounds, cultures, and socioeconomic status to gain the perspective of the school culture through multiple lenses (Morris, 1997).

Participant observation is also a method that has been used by researchers and administrators when assessing school culture (Mills, 2000; Stringer, 2004). These observations can be conducted in the classroom, staff room, and staff meetings. The researcher poses questions: How does the staff interact with each other? How do students respond to the staff? How does the staff respond to students? How do parents react to teachers and administrators? These questions provide insight to the culture of the school. It is crucial that these questions, observations, and information be reflected in the 
handbook and examined by school leaders and educators who are knowledgeable about the process. Self-evaluation of the handbook does not provide me with the outside perspective needed to ensure a quality product. The administrators evaluating the tools were from a variety of different districts, providing me with the neutrality by which to avoid issues that could easily influence the study. If a researcher is personally involved in their site and has power and influence over the participants, it can bias the study (Wollcott, 1973). I created an unbiased atmosphere by providing the focus group participants with a copy of the handbook to review beforehand. The first group met in a conference room at a hotel in Seaside, Oregon at the June COSA conference. This group, FG1, debriefed about the product, tested the tools through simulations, and discussed the effectiveness of each tool. They also took a survey and completed a rubric regarding the product. I only facilitated this process; I did not take on the participant role during this stage. The product was revised and refined based on the data collected on the handbook's effectiveness. Next, I provided professional development and training for school leaders on how successfully navigate through the SWP transition process while using the handbook. During this July training, to be held at a regional Education Service District (ESD) site, principals, Title I Coordinators and Central Office administration discussed, collaborated, debriefed and provided insight on issues regarding Title I, School Culture and School Change, as they relate to the handbook. They evaluated the training process through survey and rubric. The handbook became more polished after revising it according to the data received in the training. Lastly, the handbook wsd assessed by Title I experts for proper alignment with the state requirements. It was my hope to have the 
handbook reviewed by ODE staff, to have it rated as a support tool for the Oregon Title I transition process via email and telephone conference in August.

The following data sources were used in this study:

- Semi-structured interviews with the following key subjects: Three teams of teachers (approximately) 30 people from three schools that are serving on the SWP planning teams; two groups of principal and central office administrators; six parents serving on the SWP Planning Teams; two ODE staff, and seven Title I staff members/administrators who work in SWP schools currently (may not be currently going through the transition process)

- Survey, rubric and debrief data on the effectiveness of the handbook.

- Meeting notes from monthly SWP planning meetings, staff meetings and administrative meetings, focus groups and training for principals

- My own notes and observations as I work with principals, parents, students, leadership teams, SWP Planning Teams and schools with regard to the Title I process

- Numerous visits to the three schools, which provide opportunities to conduct unstructured observations of classroom life and school culture

- Achievement, demographic and background data on the schools and school community.

This research study falls under the "Waived Review" in the Exempt category; this is research involving the use of educational tests (achievement), survey procedures, interview procedures and observational procedures. Waived review was used since the transition process is one that the district would have conducted regardless of the presence of this research study. Stated in Portland State University’s (2012) IRB Contents list, exempt categories that apply to this study are listed below:

1. Research involving the use of educational tests, survey procedures, interview procedures and observations of public behavior.

2. Research involving the collection or study of existing data, documents, records; if these sources are publicly available or if the information is 
recorded by the investigator in such a manner that subjects cannot be identified, directly or through identifiers linked to the subject.

3. Research projects which are conducted by or subject to the approval of department or agency heads, and which are designed to study, evaluate, or otherwise examine: possible changes in, or alternatives to, those programs or procedures. (Section 4.1)

Principals and Central office administrators were recruited from a variety of districts in Oregon, as well as principals and school leaders who had gone through the process and been recommended to me by ODE. There were 10 principals and 13 central office administrators who were invited to participate in the study; they were assured that their participation in the focus groups or trainings was completely voluntary. In addition, their decision to participate would not have any effect on their relationship with their school or district or the researcher. The participants would not be offered, nor would nonparticipants be denied, any financial compensation. The participants were advised that they could withdraw from the study at any time without any negative effect on their relationship with their school, district, or the researcher. The participants were assured that their responses and the information gathered would be kept confidential.

The data collection process $(R \& D)$ methods that have been covered in this section are all methods that contribute to creating a quality handbook for the users of the product. One key factor to take into account pertinent to this study is that research findings and handbook revisions were presented and discussed with each school principal in order to identify any inaccuracies or oversights. Primarily, the principals validated the strength and effectiveness of the handbook, providing their insight and interpretations, which are included in the study. 


\section{Data Analysis Strategies}

Using valid research methods is the key to collecting the information needed to conduct a reliable study. When conducting school culture research, there are a multitude of avenues from which to choose when selecting a method of research; factors to keep in mind are: does the researcher's method answer the original research question; are the questions broad enough to get a true perspective; does the researcher know when to stop collecting data, as collecting an overwhelming amount of data can sometimes compromise its meaning; and, is the research focused around a central research question (T. Chenoweth, personal communication, October 2009). Even with something as seemingly subjective and ephemeral as school culture, analyzing a school culture cannot be done without a carefully designed research framework and well-defined research methods.

The surveys conducted in this study were given through Survey Monkey. In analyzing the data, Survey Monkey provided a summary of the survey results and provides information such as the number of respondents that answered each question and the percentage each answer received; the data can also be viewed in graph format. The researcher also has the ability to chart individual questions, crosstab questions, and view them side by side. The trends and results of the surveys helped guide the revision of the handbook. The rubric that was used to evaluate the handbook measured the tools and overall effectiveness of the handbook in several categories. Participants ranked the tools as: exemplary, adequate, minimal, and attempted. The handbook was changed and improved in each category based on the groups rubric rating. Refining continued until the 
handbook received an exemplary rating overall by the majority of reviewers. Interviews, observations and debriefs were analyzed through reoccurring trends, identified areas of strength and weakness in the handbook.

To help minimize any personal bias of the research, I tape recorded all interviews and then transcribed and coded them before analyzing the field notes. When facilitating focus groups, I was viewed as a peer by other administrators, which took bias and power out of the equation. I informed the evaluators that I needed genuine feedback to guide me in improving the product. When visiting at Kenwood and Carey Busie, I was an outside observer, with no connection, power or significance to the success of either school's transition or proposal. At my own school building, as I have stated previously, the team was led, and the tools piloted by, a neutral outside party. I only collected data as an outside observer or facilitator in the field. It was crucial to gain insight from a variety of people who had been exposed to the process; such as principals, teachers, parents, students, and central office administrators, in order to ensure that the handbook addresses the proper concerns and victories that will assist practitioners throughout the transition.

I assumed the role of SWP team member, and my vote in decisions was equivalent to any members of the team. I assumed the role of note taker and talked as little as possible, not weighing in on the discussions, to allow the members to guide the process through their discussions. I imagined that my presence in the role of team member/principal might produce some change in other members' behavior; however, I was unable to provide much evidence ???at this time to such a change. At the end of the process, the three schools presented their SWP proposals to their staff. They must have at 
least $70 \%$ buy-in for the proposal to be adopted. At my school site, the proposal was presented by teachers and parents serving on the team and the vote was taken anonymously via Survey Monkey.

\section{Work Plan}

This research protocol was submitted to Portland State University's Human Subjects Department along with the informed consent document, the survey questions with the link to the online survey, and the individual interview questions. To provide more information on the validity of this study, in this section you will find detailed information on the work plan and timeline that I followed as I conducted this research study.

Preliminary research began in September 2011 to gather insight in creating a starting point for the handbook. Preliminary research and data collection trials which consisted of duties required of me in my everyday work environment, such as: informal observations of teachers on a SWP Planning Team, administrator surveys, field notes, and student achievement data were collected throughout the 2011-2012 school year. This information was primarily collected at Stratton; however, required site visits were conducted at Kenwood Elementary, Carrie Busey Elementary (all pseudonyms) to gather similar information. The data used from the site visit research includes anonymous staff, parent, and student surveys, anonymous feedback regarding school culture, and student achievement data. The preliminary information combined with my review of the existing literature provided me with enough information to create a draft handbook. In May 2012, I began conducting the field testing for this research study to provide information on the 
handbooks effectiveness in assisting school leaders (primarily principals) in successfully navigating the transition between a Target-Assistance Title I program and a SWP while building and sustaining a positive school culture. The handbook underwent revisions after each step in the R\&D Cycle: Preliminary field testing, main field testing and operational field-testing.

In May of 2012, principals and central office administrators were invited to participate in the study. The study was discussed during an initial focus group meeting and consent forms were distributed. Those not wishing to participate could turn in a blank form. Upon review of the consent forms, the researcher knew who had agreed to participate and who did not want to be included in the study. Participants were briefed about the nature of the study, and received written information that included an outline of the information to be collected and a description of the data collection activities. The researcher explained that participation is completely voluntary. In signing the consent form, participants indicated that they were giving the researcher permission to gather data from surveys, observations, reflections as well as the copies of the tested tool(s) that were piloted (in the handbook). The signed form assured the participants that they had the option not to participate in the study and/or could withdraw from the study at any time without any negative consequences. The participants were left with forms that included the contact information of the researcher and the major professor in the event they would like to revoke consent. All information was coded to protect the identities of study participants. The coding ensured that any data collected would have no impact on participant's relationship with colleagues or supervisors. The coding system protects the 
identities of the participants by listing each individual as a number, and each school as a symbol. The researcher will not reveal the symbol for the school, nor the number of each participant. All surveys, observation notes, reflections, and product notes, coding lists and field notes were secured in the home office of the researcher. The coding list is kept separate from the data so as not to inadvertently reveal the identity of any participant. Three years after dissertation defense, the coding list will be destroyed. FG1 was reconvened at COSA summer conference in Seaside, Oregon in June 2012. FG2 met in July and FG3 participated in August. After the handbook had gone through this refinement process, it was piloted at an elementary school from August until December 2012.

Figure 3 is a timeline for conducting the research, the arrows represent that it is an ongoing process dedicated to evaluating a refining the handbook. The process is based on the first seven steps of the R\&D model (Borg \& Gall, 1998). Figure 3 covers three sections: month, activity and action.

\section{Summary}

This chapter highlights the Research Methodology by providing an overview of the chapter, then it links the methodology back to the problem identified in the study, pointing out the lack of information and resources available to support school leaders in making a successful transition to a SWP. Next, it explains the Research Design of the study, identifying the PLB approach in collaboration with the R\&D process as the most fitting way to collect data for this study. Then the research questions are provided that assisted in evaluating the effectiveness of the handbook. Afterwards, it clarifies how the 


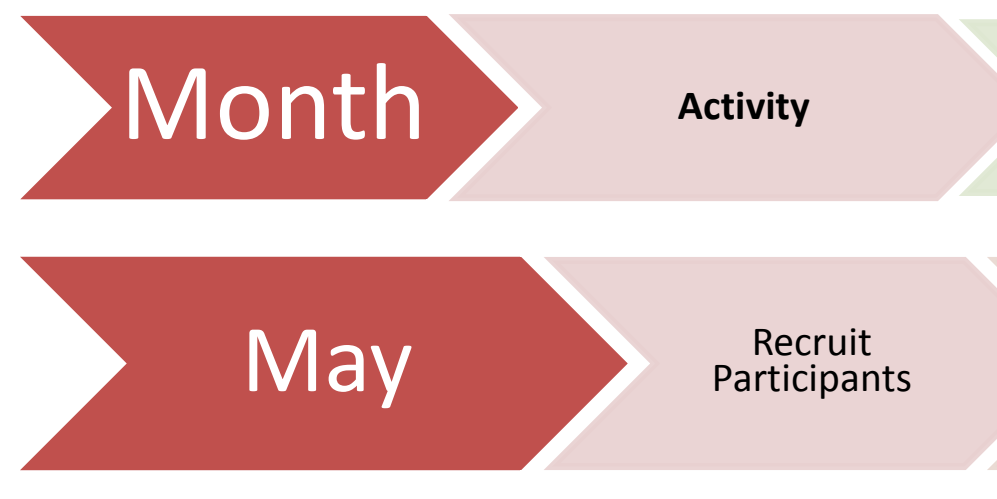

\section{Stage of Product \\ Development}

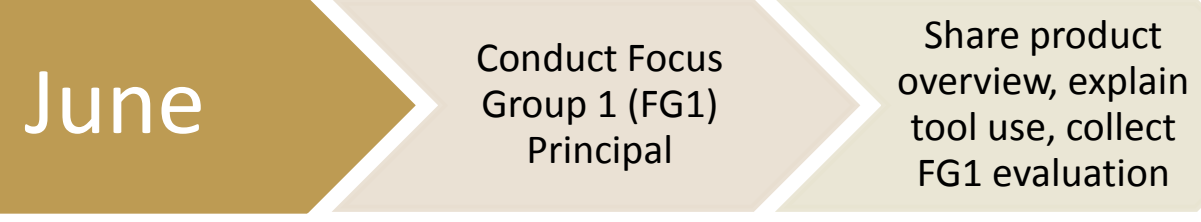

Identify focus

groups; distribute and collect consent forms

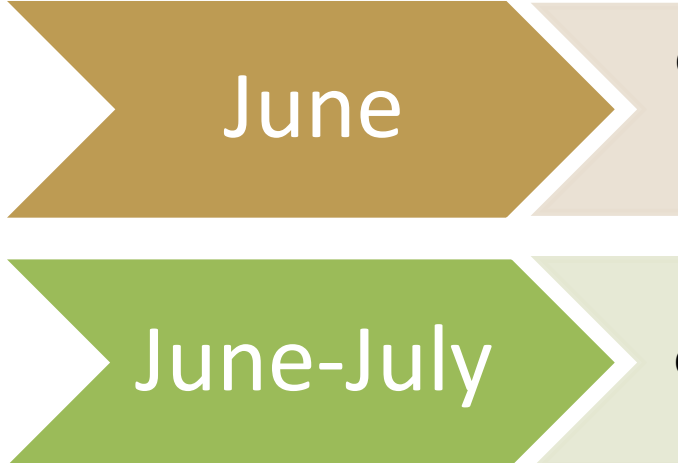

Analyze Data Collected from FG1

Product revision 1 based on feedback from FG1

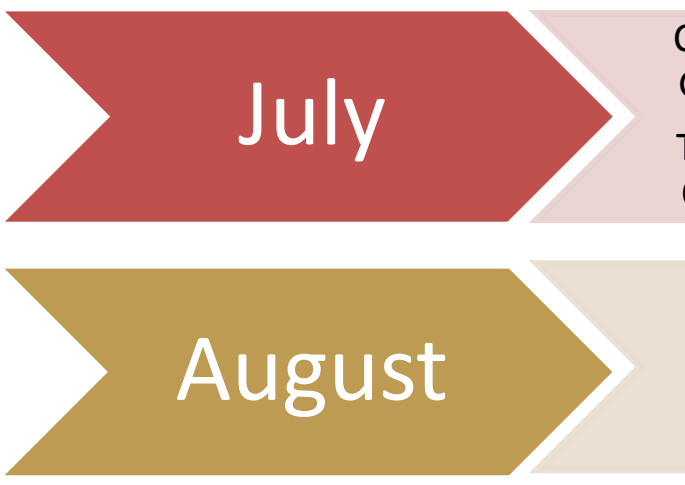

Conduct Focus Group 2 (FG2)

Title I/ Central Office Admin.

\section{Aug.-Sept}

Analyze Data Collected from FG2 and FG3
Conduct ODE Review (FG3)
Share product overview, explain tool use, collect ODE evaluation

Product revision 2 based on feedback from

FG2 \& FG3

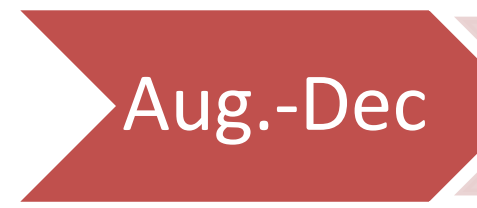

Figure 3. R\&D proposed timeline. 
data were collected and analyzed, justifying the way in which the data were safeguarded against bias and influence. Lastly, it illustrates the Work Plan for the study by furnishing a timeline specific to the research, and expounds on the development and field-testing of the handbook.

Principal Garcia (pseudonym) (personal communication, March 5, 2011), said, "I am interested in seeing the handbook that you create; it is going to be a successful resource. Looking back, I wish I had something to reference for suggestions. We made it through the transition with a hit or miss approach." Deepening the understanding of the yearlong Title I planning and transition process will assist school leaders, principals, and administrators in successfully achieving this goal while sustaining a positive school culture. Becoming more in-depth with multifaceted, rigorous, long-term research in this field is important to me due to the impact that it has on student achievement. My dedication to student achievement and the belief that all students have the right to a quality education motivates me to spend time researching and addressing these educational issues. As an educator, I am interested in sharing my experiences in reference to changing the school culture in Title I schools, by assisting principals in the Title I transition process in a positive manner that enhances collaboration, builds trust, and promotes a shared vision. I hope that it will help present and future administrators improve their school's overall Title I program, as they build and reshape their school culture. 


\section{CHAPTER IV}

\section{ANALYSIS}

\section{Introduction}

The purpose of this study is to explore what school leaders can do to positively shape their school's culture as they transition their schools from a TAP to a SWP. The handbook, Moving to a Schoolwide Title I Program: The Path Principals Should Follow to Maintain a Healthy School Culture, was created following Borg and Gall's (1989) R\&D process. It was then evaluated by a group of 22 school leaders, and piloted at a Title I elementary school that is transitioning to a SWP model.

The participants in this study come from a wide range of educational experiences and represent a variety of diverse backgrounds. Each individual participant reacted differently to the handbook and shared openly with the researcher in varying degrees. Great care was taken by the researcher to gain understanding as it surfaced throughout the field research as to the effectiveness of the handbook in order to improve the overall usefulness of this product. The researcher utilized common trends and themes in the data collection and analysis process to achieve this goal. Literature that was used as a framework to develop the Moving to a Schoolwide Title I Program handbook focused on three key areas: Title I, Culture, and Change.

This chapter explains steps 1-7 of the R\&D process, describing what happened at each step as well the outcome. Then it provides a description for three focus groups explaining the process, lesson learned and evaluative breakthroughs. The nine research 
questions that guided this study are reviewed. This chapter also explains the research design used in this study. It then describes the development and field testing of the SWP handbook (product), as well as the researcher's experience progressing through the first seven steps of the R\&D process. Lastly, it explains the results and findings of the study.

This process began with developing a primary research question: What can school leaders do to positively shape their school's culture as they move their schools from a TAP to a SWP? This next section outlines the study's research design, which led to the development of the handbook Moving to a Schoolwide Title I Program: The Path Principals Should Follow to Maintain a Healthy School Culture.

\section{Development and Implementation of the PBL Project}

\section{Seven Steps of the R\&D Process}

The PBL approach that employs R\&D was used as the design structure for this study. Borg and Gall (1989) depict educational R\&D as "a process used to develop and validate educational products" (p. 782). Researchers engage in the R\&D practice and use their findings to create tested products that are ready to be implemented in school settings. This research study follows the first seven steps in the R\&D cycle to develop, field test and refine the handbook Moving to a Schoolwide Title I Program: The Path Principals Should Follow to Maintain a Healthy School Culture. The seven steps in the $\mathrm{R} \& \mathrm{D}$ process were implemented to ensure that the product is ready to assist practitioners in the field. This section provides information on the researchers experience in the development, field testing, and refinement of the handbook at each of the seven steps in the process. Steps in the R\&D process are listed below. 
1. Research and information collecting

2. Planning, objectives, learning activities, and small scale testing

3. Develop preliminary form of the product

4. Preliminary field testing

5. Main product revision

6. Main Field testing

7. Operational product revision

Step 1: Research and information collecting. A need for this principal's handbook was identified as a result of the literature review and the lack of information available regarding the yearlong transition from a TAP to a SWP. The literature review exposed the need for building administrators to have a guide to assist them with the transition while positively influencing the culture of their buildings during this change. The literature review served to demonstrate not only the lack of information on the Title I transition process, it also highlighted that principals view school culture as an abstract concept that is difficult to impact in a positive manner while making changes that are sustainable and implemented with fidelity.

Additionally, the literature review served to demonstrate that the need for developing a positive school culture is becoming increasingly more crucial as schools work to increase growth for all students across the board. The speed and scope of changes occurring in schools further exacerbates the need for principals to have the skills to properly make changes that are beneficial to all students and implemented by all staff. Year after year schools are challenged to make it work with scarce finances, less staff, 
and limited resources. There is a need for the handbook to provide guidance for school leaders, enabling them to use the readily available resources and to make expertise available to them and their staff to create a success program transition.

The only information available to principals making the transition is a guideline or framework provided by the ODE. However, many program transitions were found to be unsuccessful or not implemented by all staff. The lack of information on this process made it evident that there is a fundamental need for principals to have access to a handbook to guide them in transitioning to a SWP. Maintaining a healthy culture also became an apparent need through discussion with principals, Title I coordinators, and central office administrators, who have gone through the process.

The literature review further revealed that there is no existing guide of this sort. The majority of information available to educators was about how Target-Assistance and SWPs function and the differences between each program. ODE has created guidelines for school leaders to follow, listing 9 steps for the transition from TAP to SWP. However, the guidelines do not address the real world situations that principals face while implementing the change, such as staff resistance, sharing the information with staff, gaining buy-in, and addressing school culture. As a principal and Title I Coordinator in Oregon, the successes and failures of transitioning for TAP to SWP are hit or miss, and the general theme I hear from school leaders is that they wish they had more information and guidance as they embarked on their program transition.

Step 2: Planning, objectives, learning activities, and small scale testing. With the obvious void of resources available concerning the transition to a SWP exposed by 
the literature review and feedback from principals and Title I practitioners, a plan for developing a practitioner's handbook originated. The ODE's Schoolwide grant proposal (state guidelines) was used as reference for compliance with the law to ensure the validity of the creation of the handbook. As a principal of a Title I school that was currently beginning the process of transitioning to a SWP model (August 2011) the Stratton Elementary (pseudonym) SWP Planning Team was able to tryout tools and activities that were eventually used in the handbook after trying them out, gathering feedback and refining them through trial and error. The Stratton Elementary SWP Planning Team ranged from teachers, Title I coordinators, administrators and parents. Four site visits were conducted by the researcher and the SWP Planning Team to Title I schools that were serving as SWPs, which had undergone the transition process in the past 3 years. Discussions were held with the staff, principals, and Title Coordinators regarding both the celebrations and the roadblocks they faced during the yearlong transition. Field notes on the tools that were tested and the information gathered during these site visits was instrumental in planning the sequence, outlining of activities, and creating tools to guide principals through the transition process.

Small scale testing continued from August 2011 through June 2012, as Stratton Elementary SWP Planning Team continued through the yearlong transition process. During this time period the components in the practitioner's handbook went through numerous revisions and refinements as the researcher gathered more insight into how the Stratton school community reacted to the transition process each step of the way throughout the school year. With the information supplied by the literature review and the 
small scale field testing of the tool at the researcher's own school site, product development began.

Step 3: Develop a preliminary form of the product. Product planning and design took place based on the analysis of the literature review, collected information from site visits that were conducted, along with field notes and small scale testing of tools throughout the 2011-2012 school year at the Stratton site. Development of the product, Moving to a Schoolwide Title I Program: The Path Principals Should Follow to Maintain a Healthy School Culture began in the March of 2012. The objectives of the project were as follows:

1. The product was to be an educational leader's guide that could be used to take a school month by month through the transition from a TAP to a SWP.

2. The product was designed to assist educational leaders, and though intended mostly for principals and Title I Coordinators, educational leaders may also include assistant principals, vice-principals, central office administration, and any other person serving in the capacity of the facilitator of the Title I program change.

3. The product was designed specifically for Title I schools in Oregon. Although the handbook may be a successful guide for Title I schools in other states, the handbook was specifically aligned to ODE’s Schoolwide Grant Proposal document (as reflected in the Crosswalk listed on pages: 9-13, of the handbook: Moving To A Schoolwide Title I Program: The Path Principals Should Follow to Maintain a Healthy School Culture). 
4. The product was created to assist in creating a sustainable program change, through a collaborative approach that enhances school culture. Research shows that changes are sustained when they have been created and accepted by all (Fullan \& Ballew, 2001; Deal \& Peterson, 1999). Each section of the handbook provides activities that incorporate staff, parents, and community members into the decision making process, giving them information into the needs of the program, as well as a voice in how the school will address each of the needs, and ultimately what the program will look like.

5. The product was designed from the onset to be divided into sections that follow ODE's grant process over a yearlong timeline. The sections follow these steps as identified by ODE: Planning, Comprehensive needs Assessment, Inquiry Process, Instructional Program/School Reform, Professional Development, Highly Qualified Staff, Transitioning Strategies for Students, Coordination \& Integration of Services \& Programs, Ongoing Plan/Monitoring the Effectiveness of the Schoolwide Plan.

6. The product's sections were designed to provide a framework for each one of the nine steps as well as practical tools and activities for developing a collaborative process and a cultural lens throughout the school year. Each section focuses on creating buy-in amongst all school constituencies to cultivate a sustainable program change that will benefit all students and be fully implemented by all staff. 
The principal's handbook begins with a Handbook Crosswalk which crossreferences the product with ODE's Title I-A SWP Planning Grant. The Crosswalk was added after the initial draft of the handbook was created. The Crosswalk was suggested by the dissertation committee members, as they discussed the importance of visually sharing the direct correlation between the product and Oregon's grant process. Themes that are addressed within the handbook include: assessing your school culture, the pros and cons of an outside consultant, selecting your SWP Planning Team, tracking your communication, having a clear mission and vision, communicating the process to all, conducting a thorough inquiry process, dealing with fear of change, reculturing your building, and things the principal needs to complete the transition process. Lastly, the appendix provides a copy of the handbook, Moving to a Schoolwide Title I Program: The Path Principals Should Follow to Maintain a Healthy School Culture as well as samples of forms and documents that are required by ODE for successful grant completion.

PDF versions of the product were produced throughout the preliminary and main field testing cycles of the participants who wished to review an electronic version of the handbook. Six prototypes were bound and printed in full-color by the Clackamas ESD print shop for review and evaluation prior to the focus group research.

Step 4: Preliminary field testing. The purpose of the preliminary field test was to obtain an evaluation of the effectiveness of the initial product (Dick \& Carey, 1985; Gall, Borg, \& Gall, 1996). The Title Transition handbook (prototype) was evaluated through a critique of the product's development (FG1). Nine building administrators were asked to complete a Focus Group Data Collection Form (see Appendix C), as well as a 
Focus Group Topic Guide (see Appendix D) while collaboratively discussing the prototype. Lastly, the principals were asked to evaluate the handbook through an Evaluation Rubric (see Appendix E) with a response rate of four. The participants were solicited based on the following criteria:

1. Must be a building administrator of a Title I school in Oregon.

2. Must have gone through the Title I transition recently, or are planning to go through the process in the near future

3. Must have knowledge in working in collaborative teams.

This evaluation tool was given to provide the researcher with insight on what principals felt was most helpful, what would they add or remove from each section, and whether or not each section was easy to follow and relevant in their school settings.

The Evaluation rubric, Table 3, evaluates each of the seven sections of the handbook: (a) Determine Your Readiness, (b) Conduct a Needs Assessment, (c) Conduct Your Inquiry Process, (d) Design Your Program, (e) Getting Down To Writing, (f) Plan Your Action, and (g) Monitor Your Progress. The evaluators scored the section based on four categories: Beginning, Developing, Accomplished and Exemplary. They also had the options of leaving comments about each section. The comments are intended to provide the researcher with further insight on the effectiveness of the handbook in guiding principals through the yearlong transition process while creating or maintaining a positive school culture. The comments are specific to each section of the handbook; the findings are based on the data collected from all the evaluation tools, evaluator's 
comments and notes taken during the Preliminary Field Testing phase conducted with the (FG1) principal's group.

Table 3

Evaluation Rubric I: Summary of Responses for Preliminary Field Test (FG1)

\begin{tabular}{|c|c|c|c|c|c|c|}
\hline \multicolumn{7}{|c|}{$\begin{array}{l}\text { In order to protect the rights of the human subjects who participated in the preliminary field testing of } \\
\text { the handbook, individual participants and their ratings and comments are not identifiable as recorded in } \\
\text { the study }\end{array}$} \\
\hline & Beginning & Developing & Accomplished & Exemplary & Scor & \\
\hline $\begin{array}{l}\text { Determine Your } \\
\text { Readiness }\end{array}$ & & & IIII & IIIII & $\begin{array}{l}B=0 \\
A=4\end{array}$ & $\begin{array}{l}\mathrm{D}=0 \\
\mathrm{E}=6\end{array}$ \\
\hline $\begin{array}{l}\text { Conduct Needs } \\
\text { Assessment }\end{array}$ & & & IIII & IIIII & $\begin{array}{l}B=0 \\
A=4\end{array}$ & $\begin{array}{l}\mathrm{D}=0 \\
\mathrm{E}=6\end{array}$ \\
\hline $\begin{array}{l}\text { Conduct Your } \\
\text { Inquiry Process }\end{array}$ & & & II & IIIIIII & $\begin{array}{l}B=0 \\
A=2\end{array}$ & $\begin{array}{l}\mathrm{D}=0 \\
\mathrm{E}=7\end{array}$ \\
\hline $\begin{array}{l}\text { Design Your } \\
\text { Program }\end{array}$ & & & IIII & IIIII & $\begin{array}{l}B=0 \\
A=4\end{array}$ & $\begin{array}{l}\mathrm{D}=0 \\
\mathrm{E}=6\end{array}$ \\
\hline $\begin{array}{l}\text { Getting Down to } \\
\text { Writing }\end{array}$ & & & IIIIII & III & $\begin{array}{l}B=0 \\
A=6\end{array}$ & $\begin{array}{l}D=0 \\
E=3\end{array}$ \\
\hline Plan Your Action & & & II & IIIIIII & $\begin{array}{l}B=0 \\
A=2\end{array}$ & $\begin{array}{l}D=0 \\
E=7\end{array}$ \\
\hline $\begin{array}{l}\text { Monitor Your } \\
\text { Progress }\end{array}$ & & & I & IIIIIII & $\begin{array}{l}B=0 \\
A=1\end{array}$ & $\begin{array}{l}D=0 \\
E=8\end{array}$ \\
\hline
\end{tabular}

This section takes a look at the findings of the handbooks effectiveness based on information provided by FG1. Each of the seven sections of the handbook is analyzed, exposing themes that arose amongst the FG1 group, as well as suggestions for improvement. The researcher discusses what they learned after analyzing the FG1 data, and then outlines the next steps that were taken before conducting FG2. The researcher 
was pleased to find that the evaluators' comments seemed to be positive overall. No section in the handbook received a beginning or developing score from an evaluator.

Determine your readiness. The first section of the handbook, Determine Your Readiness, received four "accomplished" scores and six "exemplary" scores from the group on the Evaluation Rubric. The group indicated that section 1 does an excellent job of setting the stage for change. The group identified this section as having helpful tools and adequate information. Tools in this section that received consistently positive feedback and were listed as highlights from evaluators were: Tool 1.0 Assessing Your School Culture, Tool 2.0 Team Construction, and Activity 1 entitled "What does the data tell us?" One evaluating principal shared these thoughts:

Section one is very detailed and helpful; I appreciate beginning with assessing the culture of your school. That provides the insight you need to begin the process and anticipate some of the barriers you might face during the transition.

In discussions held by the group, they were in agreement that a cultural assessment was a good starting point for the process, and that it is crucial information needed by the principal prior to implementation. Having the assessment as the first tool in the handbook proved to be a strength amongst the group.

A theme for improving Section 1 was based on providing more information on how a principal can prepare for the transition during the summer months. A reviewing evaluator shared this comment with regard to Section 1: "I would like more detail on the how you prepared for the transition. It could be a personal story...your own experience." In addressing this issue, the researcher made an addition to the "entering the process" section on page 22 of the handbook. The addition is called Preparing the Ground 
Work, which provides information for principals on how to best prepare for the yearlong transition; this addition highlights tips that worked for principals in the field as they prepared for their transition to SWP.

Conduct your needs assessment. In section two, Conduct Your Needs Assessment, there were no areas of improvement that were pointed out by the group. Section 2 also received four accomplished scores and six exemplary scores from the group on the Evaluation Rubric. All comments received from evaluators pointed out the positive points of the section. An evaluator shared these comments regarding Section 2: "There are lots of helpful tools and activities to use with the school committee when conducting the needs assessment."

Themed highlights of Section 2 pointed out by evaluators in group discussion were: Community School Partnership Assessment, Activity 2 entitled Prioritize Your Needs and the School Compact Builder and samples. A few evaluators also mentioned the helpfulness of the Mission and Vision section and the examples provided in the handbook.

No additions were made to this section after the analysis of FG1.

Conduct your inquiry process. Section 3's Evaluation Rubric results were three accomplished scores and seven exemplary scores from evaluators. All comments received by evaluators were overwhelmingly positive and this section had no issues that were raised by FG1. One evaluator shared this information: "Overall excellent job, the details in the 'Conduct Your Inquiry Process' I found to be the strongest, most helpful section." 
During FG1 discussion the participating evaluators seemed to point out different areas of the section they found most effective. Areas mentioned as strengths in this section were: Tool 5.0 Survey Alignment, Tool 5.5 Site Visit Tour Guide and Tool 6.5 Impact Inventory. Evaluator's comments are listed below.

It can be difficult to analyze multiple survey data for trends and themes when you can't give the same exact survey to each group. I love the survey alignment tool, what a great concept!

The impact inventory tool paints a realistic picture for the staff on what possibilities are actually doable, and sustainable. There is no need of spending time coming up with unrealistic solutions. I wish I had this resource for my staff when we created our Schoolwide plans.

As we made our transition we found the site visit to be the most engaging part of the planning teams' process. The site visit tool provided in the handbook gives the team members guidance in what to look for during the visit. This is excellent for planning teams; it keeps them on the same page and focused on the right things.

No additions were made to this section after the analysis of FG1.

Design your program. Section 4, Design Program received four accomplished scores and six exemplary scores from the group on the Evaluation Rubric. The discussion from the group pointed out that much of this section is to be open-ended. The general consensus from that group was that the researcher did a nice job of finding a balance between providing information and keeping the inquiry process open enough for school to draw their own conclusions. One evaluator shared this point: "A lot of the items in the 'Design Your Inquiry Process' section end up being school-specific."

Additions made to this section include more details on the data teams and personal learning community's (PLC) process. In the section of the handbook entitled Reculturing is the Name of the Game, a tool was added outlining the steps required in the 
data team's process, as well as a data team's evaluation tool adapted by the Oregon Data Project (2013). These additions were made based on the notes taken during the FG1 discussion. Three members of the evaluating group felt that principals could benefit from having clarification on how effective their current data teams and PLC's are, or how to put them in place if they are not currently in place.

Additional revisions were made by expanding the Dealing with Change area in this section of the handbook as this was an area that was deemed as insufficient by the evaluating participant in FG1, they felt that more information would be helpful. Several comments collected through the Data Collection Form, and Focus Group guide specified more information on ways to deal with negative people and fear of change.

Getting down to writing. The rubric result's for Section 5's Getting Down to Writing resulted in six accomplished scores and four exemplary scores. Although these marks seem to quite positive, this section received the lowest number of exemplary scores in the handbook. Below is the information shared by evaluators: "I would like more details and a sample of what the grant looks like in the 'Getting Down To Writing' section" and "It is tough to satisfy requirements for compliance, while also being openended. Finding the balance between guiding or coaching and providing examples is the key."

Based on FG1 discussion and the lukewarm results, the researcher identified this section is an area that is in need of improvement. However, the feedback was not specific enough to pinpoint a specific area in the section that needed to be revised. The lack of information prompted the researcher to compare the Getting Down To Writing section to 
all other sections. The researcher noted that this section provided much less insight and information than the other sections in the handbook.

Additions made to improve this section include a list of all the required grant questions for SWP Planning Team reflection. More detailed descriptions were added about how tools 8.5 and 9.0 should be used to effectively assist the grant writing. Lastly, an additional tool called the Daily Time Sheet to monitor and motivate the team to work on some portion of the grant writing on a daily basis. The new tool Daily Time Sheet became tool 10.5 changing the number of each tool after p.108 in the handbook.

Plan your action. In Section 6 of the handbook entitled Plan Your Action had no areas of improvement that were identified by FG1. Section 6 also received two accomplished scores and eight exemplary scores from the group on the Evaluation Rubric, receiving the highest scores in the handbook overall. All comments received from evaluators were pointing out the strengths of the section. An evaluator shared these comments regarding Section 6: "The instruments in the handbook for action planning are excellent!" and "The smart goal examples in this section are right on target, and the template provided guide teams in creating measurable goals and specific, nice job!”

Themed highlights of Section 6 that were pointed out by evaluators in group discussion were: Activity 5, and the sample Action Planning Template.

No additions were made to this section after the analysis of FG1.

Monitor your progress. In the final section, Monitor Your Progress, the rubric results indicated two accomplished scores and eight exemplary scores from the group of participant evaluators. The comments received from evaluators were supportive of the 
section's effectiveness. Evaluators shared these comments regarding Section 7:

"Monitoring progress is perhaps the most important part of this whole process. This section is well written." "The Accountability Matrix is a great tool for SPT; it will be helpful in delegating responsibilities and ensuring that every team member has a role."

Through group discussion, the principals seemed to want more added to this section about how to monitor progress over the coming year. Questions that arose were: What does good monitoring and accountability look like? What does it look like in your school? Through the researcher's experience in the field, as well as observations and principal feedback, an addition was made to this section; the addition is called Progress Monitoring through a Leadership Teams Model. The addition provides information on how principals can implement a leadership team, to monitor fidelity to the SWP transition process. The leadership team provides guidance and information to the staff to improve the SWPs effectiveness. It also provides a two page template of an agenda that can be used for leadership teams. Other general feedback shared by FG1evaluators is listed below.

The handbook provides a lot of things to think about regarding school culture and collaboration as you navigate through the process. You have accomplished your goals with this handbook! This is a nice guide for schools engaging in the process.

The appendix was extremely helpful; the more resources the better. I appreciate your attention to detail; I feel that I could guide my staff through the process using this handbook.

Every area is accomplished-nothing falls into the beginning/developing stages. 
These comments all served as affirmation that information provided in the handbook is on target with the goal of becoming a tool that will assist principals though the transition process in the future.

Step 5: Main product revision. Revision of the handbook in June and July of 2012 was based on the data collected by the evaluator participants in the FG1 group. The appropriateness of the evaluators' recommendations was established through research and formative evaluation of the handbook. According to Dick and Carey (1985) the concept of formative evaluation is one of collecting data for identifying problems and revising products. The data collected was analyzed and interpreted "in the most reasonable way possible" (Dick \& Carey, 1985, p. 223) to make changes that "seem" to be implied within the data.

There were two key types of revisions to consider at this stage of the process. First, deliberation was given to making changes or additions in the content that would improve its effectiveness in guiding the yearlong Title I transition. Secondly, changes related to the key themes were made, with regard to the overall concepts (Title I, School Culture, Change) of the handbook and how the procedures and tools should be used to most effectively navigate the transition process (W. Bridges, 2003). Based on the rubric and comments collected from the three tools used during FG1, several revisions were made to the handbook, Moving to a Schoolwide Title I Program: The Path Principals Should Follow to Maintain a Healthy School Culture.

Key revisions made to the Title I handbook are as follows: 
1. In response to providing more support in the grant writing area, each of ODE's grant questions were added to the handbook, along with essential questions to address and suggest writing points for the SWP Planning Team to consider when writing the grant. Several evaluating participants indicated that they would like to see more guidance in this area. A SWP Planning Summary Table was added to this section of the handbook to provide a continuum of the meetings that have happened throughout the year; what was accomplished or discussed during each meeting; and which school constituency was involved. This addition provided a framework for principals to write from. A tool called “5 Dimensions Plus/Delta” was added to highlight the schools' identified strengths and weaknesses, which provided SWP Planning Team with details that address the specific dimensions written within the grant. From the perspective of a building principal, the researcher felt that these two additions uphold the inquiry process for teams, and are open-ended enough to maintain the integrity of the grant writing process.

2. In response to addressing how to deal with fear of change and negative people, additional tools and narrative were added to the Explaining the Process and Dealing with Change sections of the handbook. In the Explaining the Process section, more narrative was added to Figure 1.0 to provide SWP Planning Team with guidance on the importance of keeping all school constituency involved in the process throughout the year. A tool was also added as a follow up of Figure 1.0, called Involve All which helps schools 
assess how they are doing concerning sharing the decision making process with parents and community members. Based on these additions, the decision was made to provide three sample(s) of the schools' Family Involvement Plans.

3. In response to ensuring the theme of building a healthy school culture is maintained throughout the handbook, a "Principal's School Culture Atlas" has been added for easier transition of school culture reshaping. The Principal's School Culture Atlas provides a school culture analysis ongoing throughout the process, which keeps school culture as a key focus through the yearlong transition, allowing school leaders and teams to continually assess their progress along the way and make adjustments.

4. In response to the problem associated with jargon, a Definition of Terms was added to the beginning of the handbook. The logic behind the definition of terms is clarified to the reader of the handbook (i.e., educational terms that were identified by evaluations editors and educational professionals as "jargon"). The definition of terms clarifies the meaning of the word, and the context in which the word is being used in the handbook.

Additional evaluation and revisions took place in July and August of 2012 using representatives from the product's targeted group. Thirteen educational leaders were asked to evaluate the effectiveness of the handbook through an evaluation rubric (Appendix A). The thirteen educational leaders were selected based on the following criteria: 
1. Must be employed professionally as a district office administrator or Title I Coordinator or Director in Oregon.

2. Must be knowledgeable of, or have gone through, the Title I transition, or plan to assist a school through the process in the future.

3. Must have knowledge in working in collaborative teams.

The 13 evaluators of the handbook identified by the above criteria were selected to participate in FG2 or FG3. All participants in the additional evaluation were provided with a revised copy of Moving to a Schoolwide Title I Program: The Path Principals Should Follow to Maintain a Healthy School Culture. The FG2 participants received all three evaluation tools (Appendices C, D, and E). Participants in FG3 received a revised copy of the handbook and the evaluation rubric only (Appendix E).

Both groups evaluated the handbook based on the measures listed in Step 4 (preliminary field test) with one addition: a section rating whether or not the "Principal's School Culture Atlas" additions seemed appropriate. The same rubric used in the preliminary test was used in the additional review for evaluating and collecting data. These summative evaluations include interpretation of the data and information collected about the effectiveness of the handbook. The key difference between the additional evaluations and the preliminary field test (formative evaluation), Step 4, is that the formative field test is to provide data for further revision of the handbook, while the summative evaluation's goal is to determine the quality of the product for the targeted group or targeted setting, in addition to providing data for additional revision for the use of the handbook in an educational setting. A summary of the data is shown in the Table 4. 
The additional field test provided an opportunity to evaluate the changes that were made after revisions and additions were made to the handbook.

Table 4

Evaluation Rubric II: Summary of Responses for Main Field Test (FG2) and (FG3)

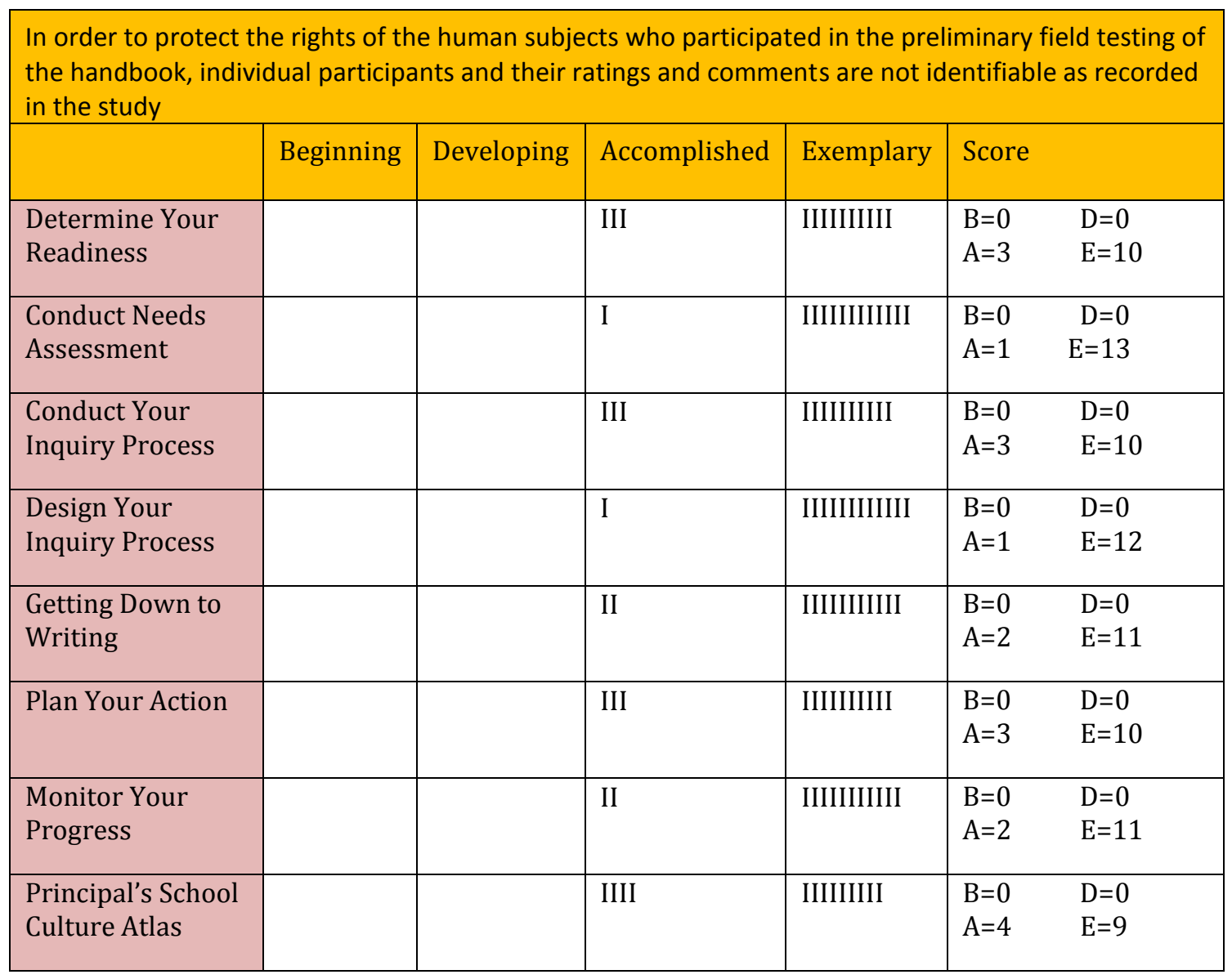

This section takes a look at the findings of the handbooks effectiveness based on information provided by FG2 and FG3. Similar to the preliminary test, the general results of the additional field test were very affirming of the handbook's effectiveness. This section highlights the results of the additional field test through evaluation comments and researcher narrative. 
Listed below are comments from evaluators that affirmation of the effectiveness of the handbook.

Love the beginning quotes! The crosswalk makes it easy to see the correlation between the handbook and state requirements.

Well done!!! You have created very comprehensive support through the yearlong process.

The author has correctly interpreted the need for distinctly different tools for principals to guide culture and change effectively.

The author has used the latest research to develop a practical guide for Title I school leaders.

An excellent creative planning tool. The colors, charts and graphics make it very attractive.

You put an importance on shared development of the program as well as gaining buy-in from all people; I feel that this it will be a helpful guide in assisting leaders to implement this challenging yet rewarding change.

Very easy to follow. I especially liked the "activity sheets."

Each section provides ample support for the process. All section(s) dealt very effectively with helping any school administrator or Title I leader in understanding the process for transitioning to a sustainable SWP.

The handbook provides a lot of things to think about regarding school culture and collaboration as you navigate through the process.

Very thorough. I like the way that you have avoided the ubiquitous "review of research" and instead provide practical support for principals throughout the guide book.

Based on these comments, plus the discussions and field notes that arose from FG1 and FG2, the general consensus was that the handbook is an effective representation of a tool that would be helpful in guiding a principal and SWP Planning Team through the transition from a TAP to a SWP model. The educational crosswalk continued to be a 
strength as the majority of the evaluations consistently pointed out the importance of being able to link the handbook Moving to a Schoolwide Title I Program: the Path Principals Should Follow to Maintain a Healthy School Culture to Oregon SWP planning grant. The rubric results received higher scores in each of the seven sections of the handbook in the additional field test in comparison to the preliminary field test (results can be referenced in Table 4)

Minimal suggestions for improvement were given by FG2 and FG3 evaluators. The only new addition to the handbook that received a suggestion came from one evaluator, and was not an issue or reoccurring theme held by the group. The evaluator's comment is followed by a response from the author/researcher: "I did like the Principal's School Culture Atlas; however, it did seem a bit repetitious."

In thinking about the repetition of the Principal's School Culture Atlas, the idea behind this tool is to provide reflection and assessment on the school culture throughout the yearlong process to provide teams with a clear picture of where they are and where they need to go. Based on the logic behind the use of the tool, no further revisions were made to this tool.

A few discussions led the author to revisit the overall format of the handbook for readability and the ease of its use.

If it were in a notebook instead of a book format, it could have tabs to indicate sections, perhaps different colors to indicate tools or activities.

I like the general layout, but sometimes it gets wrapped up in language that make it hard to understand (e.g., peripheral issue, etc.) 
The author was in agreement-that a notebook could be deemed as an acceptable format for presenting the handbook. This suggestion basically comes down to personal preference. The majority of all evaluators seemed fond of the handbook format; it was never brought to the attention of the group that a notebook might be more effective. For the purposes of this dissertation, tabs and color coding are not suitable, therefore, the researcher opted to keep the handbook format as a personal preference.

One comment in the field notes that did warrant some discussion, and which resulted in an addition to the handbook, was based around providing more information in the dissemination and collection of survey data. A few evaluators indicated that they would like more information in this section. One evaluator's comment: "Maybe a bit more information on how to disseminate and collect the results of the school surveys."

A Survey Dissemination and Collection Strategy was added on pages 53-54 of the handbook. This is a two page addition that gives examples of ways in which other schools disseminated their surveys and collected data. The samples ensured the confidentiality of the individual taking the survey, the integrity of the survey, and the ethnic and cultural backgrounds of the survey participants.

Revisions to the Moving to a Schoolwide Title I Program handbook were completed in early September 2012. The handbook was then submitted for Step 6, Main Field Testing (piloting), at a Title I school entering the transition process. Lastly, Step 7, the Operational Product Revision was completed in January 2013, based on the results of the main field testing. Steps 8 (Operation Field Testing), 9 (Final Product Revision), and 
10 (Dissemination \& Implementation) are not expectations for completion of a dissertation. However, they are the steps that the author/researcher may follow by publishing and then disseminating the handbook to a wider audience. Consideration and revision of this handbook is a result of data compiled from FG1, FG2, \& FG3. Revisions are listed as follows:

1. In response to the request of addressing the repetitiveness of the Principal's School Culture Atlas consideration was taken, and additional revisions were made to the narrative. However, the author believes that the foundation provided in the text is necessary in effectively assessing school culture.

2. In response to the language and definition in the handbook, the Definition of Terms section was expanded and revised to provide a clearer picture for the reader.

With regard to the requirements of this dissertation, the researcher has recorded the results of the R\&D process through Step 7.

Step 6: Main field testing. In the summer of 2012, the researcher began gathering the names of schools that were planning to go through the Title I transition process during the 2012-2013 school year. The researcher quickly realized that although this transition had been a trend that several districts were undertaking over the past 3 years based on ODE's recommendation, this year there were very few schools that were choosing to make this transition. The low number of schools making the move from TAP to SWP during the 2012-2013 school year directly correlated with the fact that the state 
of Oregon adopted a new growth model evaluation system to measure student achievement. This new statewide Growth Model in Oregon ensued following the hiring of a new State Superintendent of Education. The newly adopted system identified over 90 schools in the state as schools that are in Need of Improvement. Many schools that planned to make the Title I transition were given clear directives not to make any changes this year by their superintendent or central office administration, so a large number of schools decided to postpone the transition. In the researcher's effort to accomplish Step 6, it became increasingly difficult to find schools that were planning to take on the transition process in September 2012, let alone pilot the handbook. It was through conversations with administrators during ODE's Title I Coordinator's August meeting that a connection was made with a principal entering the transition process, whose school was not in a "needs improvement" status. The principal agreed to participate in the study by piloting the handbook, Moving to a Schoolwide Title I Program: The Path Principals Should Take to Maintain a Healthy School Culture. This agreement was made after a face-to-face meeting was held between the principal and the researcher. During the meeting all documents approved by the Human Subject Board were reviewed, as the piloting principal did not participate in any of the evaluation Focus groups. The principal seemed very concerned with keeping all records, documents, and names anonymous. The researcher assured the principal that the school's identity and all participants involved in the piloting would be kept anonymous. For the purpose of this dissertation, the piloting school is referred to as Garden Acres (pseudonym) Elementary (GAE). 
Mr. Johnson (pseudonym) the building principal agreed to pilot the handbook by using it as a guide to assist GAE in making a successful transition from TAP to SWP. Data were collected through field notes, principal/researcher discussions, reflections and debriefs held after the use of tools, activities and figures within the handbook, as well as notes, comments, and suggestions made by the school. The researcher also made himself available to Mr. Johnson by phone and in person to answer questions and provide the principal with additional guidance.

The main field testing pilot was conducted over a 6-month period. The overall results clearly indicated that the handbook was a valuable tool that Mr. Johnson referred to on a regular basis for support and guidance throughout the yearlong process. Through the principal's experience testing the handbook (product) and the communication of the SWP Planning Team at GAE, the handbook was determined to be a product that is ready for use in schools after making some minor adjustments. Mr. Johnson stated,

The principal's handbook gave me everything I needed to know to lead my meetings and be in compliance with the state's expectations. I utilized the activities and school culture components with my staff and they were well received. The handbook provided excellent ways to keep parents, students, staff and community members involved in the process. Through this transition people feel they have a voice, they appreciate that we value their opinion, and in turn they are supportive of the changes that we are making to meet the needs of all students. As an administrator I would recommend the handbook to any principal going through the process. It is easy to use and was right on target!

Detailed results of the main field test and the researcher's findings are located later in the Findings section of this chapter. 


\section{GAE Public Information}

Garden Acres is an elementary school located in a rural Oregon school district with a population of approximately 300 students. They are currently $69.7 \%$ free and reduced lunch; however, even with the large percentage of students in the free and reduced category the school has always functioned under a TAP. The staff and administration at GAE made the decision to transition to a SWP model after discussion arose with staff during the 2011-2012 school year, Mr. Johnson (pseudonym) the building principal states that the discussions were focused around struggling students not receiving the support they need to make adequate yearly progress.

Table 5 provides public information on GAE: Grades: PK, K. 1, 2, 3. Total enrollment 290 as of September 11, 2012.

As Table 5 demonstrates, GAE is a small primary school with only one grade level participating in statewide OAKS assessments. Their class sizes are low and the student-to-teacher ratio is low. GAE did not make AYP, which could be a reason they made the transition to a SWP. We can infer that the principal of GAE, a school where only one grade takes the OAKS assessments, may face less resistance than at a traditional K-5 elementary school where half of the students are participating in OAKS testing, including the difficult writing test. GAE would be served to examine formative Reading and Math assessments throughout the year to guide their instruction and interventions.

The following section addresses the findings of the operational field testing conducted at GAE. 
Table 5

\section{GAE Information}

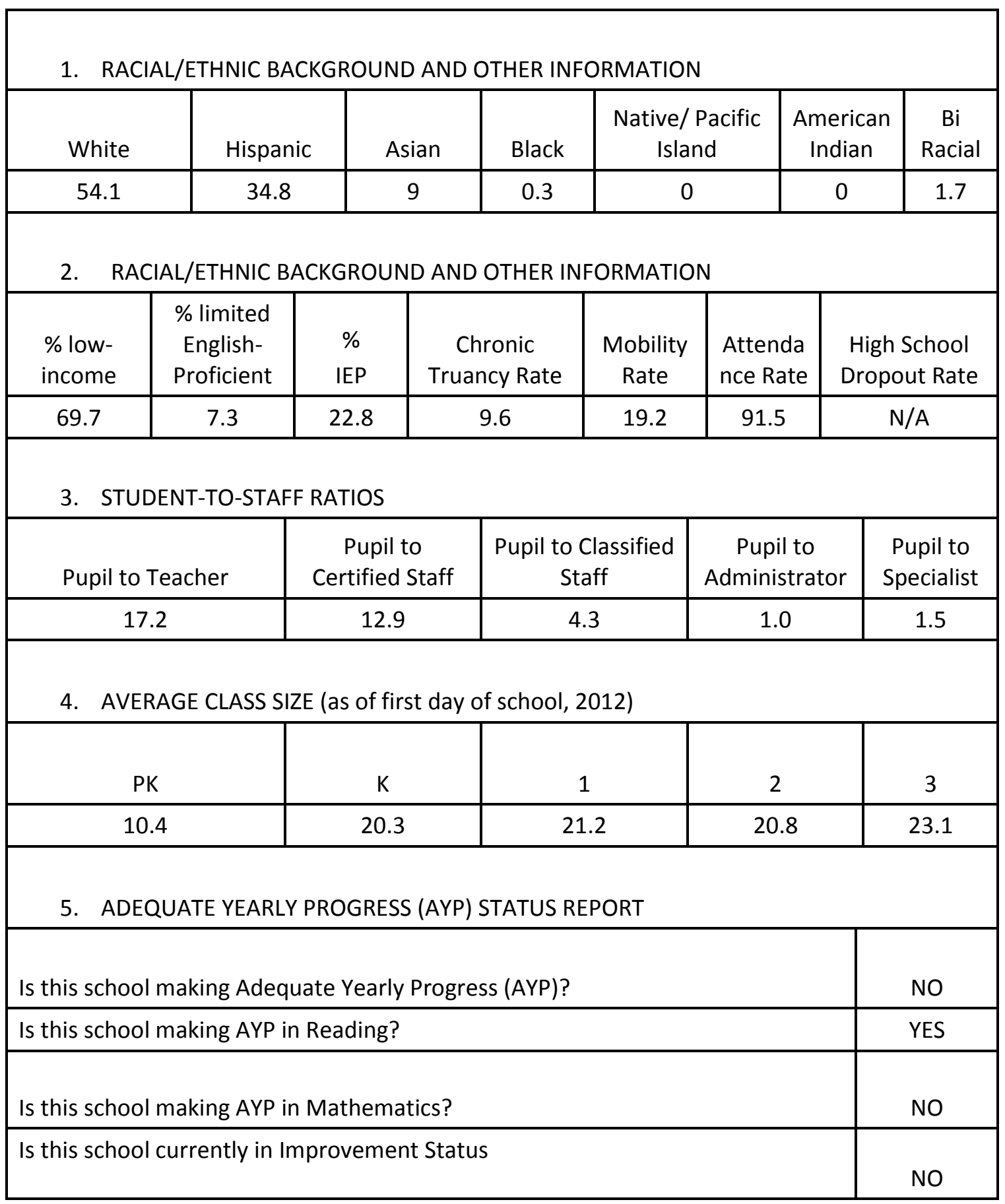

IEP = Individualized Education Program 
Step 7: Operational product revision. Operational revisions of Moving to a Schoolwide Title I Program: The Path Principals Should Follow to Maintain a Healthy School Culture were made based on the results of the main field test pilot, which took place over a 6-month period at GAE. Recommendations of the handbook's effectiveness and usability were analyzed by Principal Johnson, based on his experience using the handbook as a guide at his school during the 2012-2013 school year. Data taken into consideration for the operational revisions included: feedback from GAE SWP planning team, staff, and school constituency; relevant information gathered by experts in the field (principals, central office staff, and published researchers); Title I professional development opportunities; and Title I compliance workshops. Revisions were made based on the principal's field testing notes, the researcher's field notes, discussions with the principal, and suggestions for improvement that were documented in debriefing discussions between the principal and the GAE SWP team after reflecting on the process. The data collected were summarized to provide information about the potential effectiveness of the handbook to determine whether or not it would be a useful tool for principals entering the Title I transition process to use as a guide. Adjustments were made to the handbook based on Principal Johnson's experience to improve areas that were identified in the handbook to be problematic during the pilot. Based on discussion between the GAE SWP team and the researcher, it was difficult to determine if participation in the activities from the handbook incited some of the teacher resistance experienced by the GAE SWP team; the researcher was left with the ultimate decision of determining whether or not the resistance was generated by an issue in the handbook, or 
was it a school- (building-) specific issue only. The researcher concluded that the process of developing collaboration can be a difficult one, and the pre-existing resistance may have surfaced as a result of participation in the activity, but that perhaps this resistance would have emerged regardless at another time even if the activity had not occurred. The revisions, changes and recommendations that result from the Main Field Test are shared by the researcher in Chapter 5 of this dissertation.

\section{Research Questions, Design, and Findings}

\section{FG1 Lesson's Learned and Evaluative Breakthroughs}

The product was reviewed by 22 "experts" in the field who provided formative evaluation of the handbook's content, format, and practicality. This section highlighted the lessons learned through the R\&D process while developing the handbook. The section details the process that the researcher used to solicit information to gain participants, as well as the protocols used to facilitate the three evaluating groups FG1, FG2, and FG3. Then it takes a look at the questions that were used to guide the discussion of FG1 and FG2. The researcher then analyzed and discussed the themes that stemmed from the discussion questions. Table 6 provides background information on the Evaluation Rubric that was used by all three groups to evaluate the effectiveness of each section of the handbook.

The Evaluation Rubric is a scoring tool that the evaluators used to assess the effectiveness of each section of the handbook. Using a set of criteria that ranges from Beginning to Exemplary the evaluators can rate each section and also provide written feedback in the comments section. The sections of the handbook were discussed in each 
focus group prior to scoring the rubric. Research proves that it is often helpful to have multiple evaluators to scoring the work when using a rubric (Jonsson \& Svingby, 2007).

\section{Table 6}

Evaluation Rubric III

\begin{tabular}{|c|c|c|c|c|c|}
\hline & Beginning & Developing & Accomplished & Exemplary & Score \\
\hline $\begin{array}{l}\text { Determine } \\
\text { Your } \\
\text { Readiness }\end{array}$ & & & & & \\
\hline $\begin{array}{l}\text { Conduct Needs } \\
\text { Assessment }\end{array}$ & & & & & \\
\hline $\begin{array}{l}\text { Conduct Your } \\
\text { Inquiry } \\
\text { Process }\end{array}$ & & & & & \\
\hline $\begin{array}{l}\text { Design Your } \\
\text { Inquiry } \\
\text { Process }\end{array}$ & & & & & \\
\hline $\begin{array}{l}\text { Getting Down } \\
\text { to Writing }\end{array}$ & & & & & \\
\hline $\begin{array}{l}\text { Plan Your } \\
\text { Action }\end{array}$ & & & & & \\
\hline $\begin{array}{l}\text { Monitor Your } \\
\text { Progress }\end{array}$ & & & & & \\
\hline $\begin{array}{l}\text { Principal's } \\
\text { School Culture } \\
\text { Atlas }\end{array}$ & & & & & \\
\hline Comments: & & & & & \\
\hline
\end{tabular}


In May 2012, the researcher sent out 35 letters of introduction which provided an overview of the research study, as well as an invitation to participate in the study. These 35 letter recipients were selected based on one or more of the following criteria: they would need to be either: (a) a principal of a Title I school going through or that had previously gone through the transition, (b) a Title I District Office administrator, or (c) a Title I Director at the state level. Twenty-six of the invited participants responded to the letter within a 2-week period as willing participants. Four of the participants who responded as willing participants generated no follow-up response to initiate their participation in the research study, although repeated attempts were made by the researcher through phone calls and emails to contact them about their participation. Sixteen of the respondents indicated that they were interested in the project and wished to receive an abstract and consent form; two respondents determined that they could not confirm interest without more information; four recipients indicated that they wished to meet with the researcher; nine recipients indicated that they were not interested in participating in the project at this time. At this point it was necessary for the researcher to determine the degree of interest in the project from the pool of educational administrators who responded positively, while considering the population density and nature of the area they represented. To accomplish this, the researcher arranged a meeting to dialogue with those who had in some way indicated a positive, open interest in the study.

Eventually, 22 respondents who requested an abstract received a follow-up letter, which included an agenda with a proposed research timeline, as well as an abstract and a draft of an electronic pdf version of the handbook (with the expectation it would be read, 
with key points highlighted and critiqued before the annual meeting of the Confederation of Oregon School Administrators (COSA) on June, 22, 2012). The four respondents who requested a conference were accommodated, which resulted in all of them indicating they were willing to participate. The researcher identified that the range of educational administrators participating in the study spanned both the rural, suburban and urban districts. A large number of participants represented districts with 300-3,000 students, while some participants worked in districts that range from 3,000-25,000 students.

The researcher received Human Subjects approval on June 20, 2012, then made phone or email contact with all 22 participants to seek approval via the consent form. After gaining consent, the participants were split into 3 groups: a principal's group, FG1; a Title I/Central Office Administrators group, FG2; and an ODE Review Team, FG3.

The following discussion outlines the process and procedures used to evaluate the effectiveness of the handbook during each of the focus group meetings. Each meeting contains descriptions of the agenda; the questions used to guide the discussion; the protocol used to facilitate the meeting; and the tools that were used to evaluate the product. Each section highlights the areas of strength and areas of development that were identified by the three focus groups. In addition to the discussion at each focus group, information was gathered from the participants who have gone through the Title I Transition process. Analysis of the evaluation tools and focus group documents were made available to the researcher, and general observations were made by the researcher while facilitating the focus groups. Evaluators' comments were coded in a notebook, 
which included the evaluation tools of all participants. Notes, comments, and evaluation tools have been coded by the researcher to support confidentiality of participants.

The researcher began each focus group by giving participants an introduction of the Moving to a Schoolwide Title I Program handbook. Information was shared on how it was developed, and the steps taken to bring it to its current stage. The researcher explained that through trial and error as a principal in the field, he recently took his school through a successful transition to a SWP, while developing and field testing a wide array of tools to determine if they should become part of the handbook. The researcher's intent for the focus groups was to have a set of highly skilled educators from the realm of Title I evaluate the effectiveness of the handbook, in hopes it might be further refined so it could be used as a pilot tool for a school planning to go through the transition from TAP to SWP during the upcoming school year. The ultimate goal would be to publish for large scale dissemination as a tool for principals of Title I schools to assist them in making a successful transition that will improve school culture and be sustained over time. The groups are presented in the order in which they were completed.

FG1 principal's group specifics. This group was held on the section floor of the North Portland Branch Library, a public meeting space that was reserved by the researcher at no cost. Food and beverages were provided to the participants, but no other incentives were provided to the group. All participants were required to sign an informed consent document and agreed to complete all provided evaluation tools. The researcher moderated the focus group and had a note taker transcribe the conversation. No major issues occurred during this meeting and all participants were pleasant and engaged in the 
discussion. This focus group consisted of nine participants, all of whom had read the handbook prior to the meeting, and brought notes they had recorded on the Focus Group Data Collection Form, which had been provided by the researcher when the handbook was distributed. The form guided participants to list the key points they identified in each section along with their questions and comments.

The structure of this session was focused around nine essential questions being posed to the group. These nine questions are used to guide use to the overarching questions that prompted the research for this study: What tools and information do school leaders need to assist them to positively shape their school's culture as they move their schools from a TAP to a SWP? Table 7 displays these nine questions.

Table 7

Nine Guiding Questions

Guiding Questions

1. What have been the experiences of principals who have gone through this process?

2. What barriers, roadblocks, and success stories can they share to help others in the future? How well does the handbook present ways to work through and address barriers and roadblocks?

3. What strategies have been successful in building and sustaining a positive school culture during a large change initiative, and are those strategies represented in the handbook?

4. What significant impact, if any, can this product have on student achievement, school leadership, and school culture?

5. What effect did the cohesion of the planning team have on the implementation process? How does the handbook emphasize the importance of selecting a strong team? How effective are the tools in the handbook at assisting principals in selecting a team?

6. How effective are the tools in the handbook in assisting school leaders to create buy-in from their staff for the transition?

7. Does the handbook provide a cultural lens for leaders when making the program transition?

8. How beneficial is the handbook at addressing school culture during the Title I transition?

9. What suggestions do these school leaders have for improving the handbook? 
After the researcher provided background information on the development of the product, participants were encouraged to introduce themselves and share their experiences with Title I. For the first question, participants were asked to write down on a card any problems or frustrations that they experienced while collecting notes/data on the handbook. These two actions helped to break down barriers and reservations held by participants and encourage group interaction. The researcher asked the group if one person would be a "timekeeper" to assist the group in sticking to the allotted time allocated on the agenda. The majority of the time the conversation followed the intended structure, although at times participants did seem to wander a bit off topic. However, the timekeeper for FG1 did a nice job of reminding the group of the time left to discuss a particular topic. The timekeeper's updates prompted the researcher to focus the discussion back to the question that was underway, but if the topic was relevant to other topics being evaluated in the handbook, the participant was allowed to finish their thought before transitioning back to the question being addressed. The group also selected an "assistant," a participant who would take notes and participate in discussion. In turn, the assistant's notes would be cross referenced with the notes taken by the researcher for reliability.

Lessons learned and evaluative breakthroughs for FG1. The general consensus for those who had gone through the process seemed to be agreement that they wished they had more information on how to successfully navigate the transition prior to beginning the transition. They discussed roadblocks they had faced, which could have 
been avoided with some guidance. Many of them complimented the handbook, saying its use could have made their transition experience more positive.

I found the transition difficult for me and my staff; there was lots of resistance to change. I could have used this handbook as a guide. I feel that I may have been able to avoid some pitfalls.

My school's transition was rigorous but smooth; we were already sort of functioning as Schoolwide, and so the majority of staff was on board.

One person had a very negative experience attempting the transition and would not recommend moving to a SWP without making sure that the majority of the staff was on board with the decision.

Our school began the process, but with so much resistance to change...we abandoned the process and chose to refine what we are currently doing in our Targeted-Assistance program.

We spent close to $\$ 10,000$ dollars on an outside consultant to help guide us through the process, but she ended up making the process more stressful.

Since not every participant had gone through the process, the group found it beneficial to hear from those who have experienced the Title I transition, and could compare their experience to the handbook. FG1 also seemed pleased with the fact that the handbook was not pushing schools to use an outside consultant to guide the process.

Barriers and experiences that were shared in FG1 include: opposition from staff (union issues), negativity from parents and the community around change, funding issues that impede program offerings and interventions, and contractual issues like having enough time to meet with staff members without exceeding contract hours. The majority of FG1 felt that the handbook sufficiently addressed these issues, while four group members pointed out that they would like to see more additions in the dealing with fear 
of change and negativity from the school community. FG1 participants were pleased to find the successful strategies pointed out by principals which had worked in their schools (e.g., having a shared mission and vision, surveying all school constituency, as well as having a school leadership team with parents, classified staff, certified staff, and community businesses are addressed in detail in the handbook).

FG1 members all agreed that the handbook had the ability to significantly improve the transition process for principals in the future. By impacting the rate of success for a transition to a SWP, the achievements of students in each building can also be directly impacted. By following the process and using the handbook, schools can identify the strengths and weaknesses of the school and address them. Themes which were discussed that the handbook promotes are: shared leadership, professional development, program effectiveness, and improving school culture through a collaborative process.

FG1 felt the handbook provided extensive detail on the importance of building a highly effective planning team. The tools provided in the handbook that concentrate on the development of the school's planning team are located in Section 1, Determine Your Readiness. According to FG1's rubric results, the outcome yielded four accomplished and six exemplary marks, reassuring the researcher the tools regarding SWP Planning Team either met or exceeded the evaluators' expectations of assisting principals in selecting effective teams.

In terms of looking at the handbook from a cultural lens, FG1 felt that there was an indirect connection that was made between the handbook and the leaders having a 
cultural viewpoint. A few comments from evaluators give some examples of the indirect connection below:

Doing a schoolwide survey helps get an understanding of where your school and community are.

Moving to a Schoolwide program is a cultural lens point of view; this could be directly stated in the handbook.

Expand on the importance of the cultural lens a bit; how can we ensure equity for all students?

This feedback led the researcher to reexamine the connection between the handbook as a cultural lens for leaders. Both the Principal's School Culture Atlas, and the addition of Tool 1.0, Involve All, assists leaders in "assessing through a cultural lens" during the course of the process. On the other hand FG1 members felt the handbook did a first-rate job of addressing school culture. The Assess Your School Culture Tool was identified as a strong point by evaluators of FG1.

In my building, the further I got in the process, I began to realize that I was not just changing a program. I was taking on a negative school culture. At the beginning of the handbook, I found the Assess Your School Culture Tool (1.0) very helpful.

All participants in the group felt that using the assessing tool for school culture was a great way to begin. There was a great deal of discussion about the benefit of school site visits, and being able to use the school tour guide to focus the scope of the visit. This led to an in-depth discussion regarding school visits, and to the positive effects they have on school culture. FG1 discussed the importance of allowing a staff the opportunity to see how other buildings function, and having the time to share and learn from others. The detail that the handbook provides around school site visits was a strength identified by the 
group. FG1 was also satisfied with the content provided by the handbook on creating buy-in.

Creating buy-in starts with activity 1 , having everyone analyze the data and identify strengths and a weakness is a powerful activity that puts everyone on the same page.

FG1 felt this was properly addressed through the tools in the handbook that support the comprehensive needs assessment. The handbook provides survey samples for staff, students, and teachers, as well as data collection methods and activities for sharing, analyzing, and strategizing around the data.

The evaluators of FG1 provided some beneficial suggestions for improvement.

This is a great tool; I would like to see more strategies for dealing with negative attitudes and staff resistance.

The "track your communication" area is a strength in the handbook. Leaders need to make sure things are clear and understood, log meetings and activities should be documented. Great job, I suggest providing some quote from the experts here.

Before conducting FG2, the researcher made some additions to the handbook in response to the suggestions made in FG1. These suggestions prompted the inclusion of more examples of why it is important to deal with negative attitudes and staff resistance, as well as providing more information from practitioners in the field on the importance of documenting the process.

\section{FG2 Title I/Central Office Group Specifics}

This group took place at Radio Room PDX's lower patio which was reserved at no cost to the researcher. Food and beverages were provided with no additional incentives, as was done in FG1. Each participant was required to sign an informed consent document, and each agreed to complete all provided evaluation tools necessary 
for completion of the focus group. The researcher took on the role of moderator; the focus group had an assistant take notes. The note taker was a friend of the researcher, who was not a part of the study, and only attended FG2 for the purpose of taking notes at the researcher's request. All participants were engaged in the discussion and agreeable. The group had 10 participants, all of whom had read the handbook previous to the focus group discussion. Each participant brought their notes compiled on the provided Data Collection Form.

The same structures with nine guiding questions were used to facilitate the discussion in FG2. The researcher began by giving the participants some background and introduction to the development and future plans for the handbook. After introductions the participants introduced themselves and shared their experience with Title I. They recorded their first question by writing it down on a note card, addressing any problems or frustrations they experienced while collecting notes/data on the handbook. These two steps worked well during the focus group and seemed to assist in opening up the dialogue among participants in FG2 as well. The researcher enlisted a timekeeper and group assistant to allow the researcher to cross-reference notes with the note taker. The researcher observed more discussion in this focus group took place around the process of the ODE requirements in relation to the handbook, than did discussion around the staff and students that had occurred at the FG1 meeting. One could conclude that this difference could be based on the distinction between building principals and central office administrators. In terms of the research, it was beneficial to get both of these perspectives, as each group provided beneficial and unique information on various areas 
in the handbook that will enhance its effectiveness. The following section addresses the findings of FG2. These findings are based on the nine essential guiding questions (p. 146).

Lessons learned and evaluative breakthroughs for FG2. There were several overlapping discussions that were topics in FG2 which were also topics in FG1. Most of the factors were positive reflections and highlights of the handbook, and the general feedback was consistently positive. Some of the Central Office Title I staff members were familiar with the process, and had undergone the transition from TAP to SWP. They had experienced roadblocks, such as school leaders not having a clear vision which led to issues and built resistance among staff. Other issues were brought up, such as staff not feeling any ownership in the planning process, and in turn not fully implementing the program because they felt disconnected from it. Some evaluators commented:

I remember that it was difficult to get survey data back from parents as we went through the process. I like the suggestion in the handbook on how to elicit parent feedback. The survey during parent conferences was a great idea...using Survey Monkey made it immediate.

Starting on page 17 the foundational supports start in building the inclusion process to gain support from the larger majority; i.e., creating a yearlong schoolwide plan and mapping.

The handbook explains ways to prevent or minimize the amount of resistance by keeping open communication with the staff and community members, and welcoming and incorporating their feedback. These are all critical in this process.

Negative attitudes and fear of change...the handbook outlines many activities that a principal can do to build collaboration, but I would like to see something more specific on dealing with negative people.

Through these discussions with FG2 the researcher learned that the additions made to the handbook (e.g., such as information on the inclusion process and the collaboration 
process, and on how to gather information from all school constituency) had addressed the concerns in which these areas were lacking when they were analyzed by FG1. The researcher also learned that both FG1 and FG2 had administrators that continued to want more information on dealing with negative people, even after additional narrative and suggestions were added on dealing with a fear of change. The researcher realized that "negative people" is a key roadblock for school leaders in implementing this transition. The researcher spent time going back to the literature and research to make some beneficial additions that would address this problem. FG2 also discussed success stories, identifying that successful school transitions were based on three key factors; collaboration, clear vision, and open communication. One evaluating participant stated: "Collaboration is a big one, I found that this was a reoccurring theme in the handbook, a collaborative approach to change is promoted through the process." The researcher learned that his personal experiences with the process aligned with what he was hearing from evaluating participants. The collaborative approach was much more apt to be sustained and implemented by all staff, whereas the top-down approach usually left some staff in a mode of resistance.

FG2 felt that the Moving From a Targeted-Assistance to a Schoolwide Program Handbook had the potential to impact schools and districts in a positive way by saving districts money, implying that it allows principals to make the transition without hiring or contracting outside sources to lead the process. A few evaluators pointed out that saving money is a huge plus in today's economy as district across the country are experiencing large class sizes and lack of programs due to funding. 
This handbook should be available on the ODE website to be accessed by all Oregon Principals. The Crosswalk located at the beginning of the text aligns the entire handbook to the state standards.

One evaluator suggested making the handbook available to all on the ODE website. This may be a possible option in the future; however, that would be a decision made by the researcher after completing the dissertation, which could be achieved by completing all 10 steps of the $\mathrm{R} \& \mathrm{D}$ process and taking the handbook to scale.

Positive overlaps found by the researcher that was also pointed out in FG1 include these reoccurring themes;

1. Both groups felt that the handbook effectively stressed the importance of building a highly effective planning team and that there was ample guidance to assist administrators in doing so.

2. The cultural lens was brought up as having an indirect connection in FG1; however, in FG2 the group felt that the cultural lens was addressed throughout the handbook. Several evaluators pointed out that the Principal's School Culture Atlas kept the reader engaged in reassessing the work being done throughout the year through a cultural perspective. This validated the researcher's reasoning for adding this tool as a checkpoint analysis throughout the handbook.

3. Participants voiced disagreements on the work and definition of "culture," which prompted the researcher to have the definition of School Culture in reference to the handbook clearly stated at the beginning of the handbook. 


\section{FG3 ODE Review Specifics}

This group functioned much differently than either the FG1 or FG2 groups, largely due to the fact that there were only three members, all of whom had agreed only to evaluate the handbook and provide written feedback. This group did not discuss the nine guiding questions as they did not function as a focus group. They functioned as evaluators, using the evaluation rubric only as a guide to measure the effectiveness of the process in accordance with ODE guidelines and requirements. This meeting took place during the Teacher Effectiveness Workshop, held at the Sheraton Hotel in Portland, OR. During the hour-long session, the participants (who had read and reviewed the handbook prior to the meeting) went through the handbook section by section for accuracy, effectiveness, and process alignment with ODE's guidelines. Then the Crosswalk was cross-referenced with the Oregon Title-IA Handbook. Each participant used the Evaluation Rubric (refer to page 132) plus their additional notes and comments to evaluate the handbook's effectiveness. This rather concise process was utilized due to the busy schedules and availability of the participants from ODE.

Notes for both the FG1 and FG2 groups were transcribed by the note taker in a paraphrasing manner that outlined the general comments of each of the participants as they spoke during the meeting. These notes were then examined by the researcher and reoccurring themes were identified. A comparison of notes was made by the note taker and the assistant. The research analyzed the notes for themes, issues, suggestions, and comments to create a data source to assist in making improvements to the handbook. However, notes complied from FG3 were taken directly from the Evaluation Rubric only. 
Lessons learned and evaluative breakthroughs for FG3. The evaluators of FG3 evaluated the handbook based on its ability to guide a principal through the Title I transition as outlined by ODE during the yearlong transition. Fortunately, the evaluation results were positive, the group felt that the handbook was representative of their process, and was open ended enough to keep the integrity of the transition process.

FG3 affirmed the handbook's process and pointed out the top key strengths of the handbook.

1. The book followed the ODE process-they indicated that the handbook followed all the steps listed in the Comprehensive Needs Assessment.

2. The handbook was open ended-all of the tools are left up to the planning team to complete any way they see fit for their building. They highlighted that the current handbook draft keeps the integrity of the transition process and grant proposal instead of providing teams with canned answers to the ODE grant questions.

3. FG3 felt that the staff activities the handbook provided to principals help the school leader provide the necessary documentation, providing evidence of staff collaboration in creating the grant, which is a requirement for approval. FG3 also pinpointed changes for improvement and revision of the handbook:

1. They suggested removing the actual grant questions from the handbook, and suggested instead describing the requirement. FG3 felt that providing the question was a bit enabling to the staff, and felt the school should be using the 
grant in alignment with the handbook on their own. This was a revision the researcher made based on the FG3 feedback.

2. FG3 felt that Figure 1.8 Hall and Hord's (2006) Creating a Context Supportive of Change, should be adapted into a chart that SWP Planning Team can take notes on and use a progress monitoring tool. This revision was also made by the researcher after debriefing the FG3 handbook evaluation.

Overall the preliminary field test supported the handbook's (product)

effectiveness in all the evaluated areas as indicated by the scores from the evaluation rubric. Reviewer comments and suggestions for improvement were all extremely positive overall. Most of the evaluators' comments further supported the need for such a product and validated its helpfulness to school leaders engaging in the process. Based on the supportive findings of the evaluators and their suggestions for improvement, the initial product revision stage of the R\&D process took place.

\section{GAE Pilot School Research Findings}

General information: The information collected on piloting the handbook Moving to a Schoolwide Title I Program: The Path Principals Should Follow to Maintain a Healthy School Culture was provided by Mr. Johnson (school principal) based on his experience, through field notes, principal reflection, and debriefs between the principal and researcher during the transition process at GAE. The information encompasses notes from the GAE staff, planning team, and administration. This section shares the findings of the handbook based on the nine guiding questions and the overall research question (some questions have been modified to fit the piloting school experience); the questions 
are answered in specific reference to GAE's experience, as they piloted the handbook and the tools to guide them through the process. GAE did not have the funds to hire a consultant; the handbook was the key tool used to guide the transition process, along with the ODE planning grant, and ODE guidelines. The researcher was also used as a resource to the principal in answering questions about the Title I transition and assisting the principal as needed. Most conversations between Mr. Johnson and the researcher took place by phone; however, they met in person on three occasions to discuss the progress on the Title I Transition.

1. Explain your experiences in using the handbook as a guide through the Title I Transition process with your staff?

Through field notes and ongoing discussion with Principal Johnson it is clearly evident that the handbook performed the task of providing guidance to the GAE staff. Principal Johnson revealed three key components that the handbook provided in guiding a staff successful through the transition.

- The Handbook Crosswalk: the activities correlate with the ODE transition process. Principal Johnson found that if you follow the handbook in order and you can also complete components of the SWP Plan Grant (required by ODE) as you hold your planning meetings. This also proved to save the principal time coordinating the activities around the grant; the Handbook Crosswalk provides the staff activities for each section of the grant. The activities are listed with descriptions under the Tool column of the Handbook Crosswalk.

- The Yearlong Planning Roadmap: the yearlong planning roadmap provides a visual guide of where you are headed or where your team should be in the process on a monthly basis. Principal Johnson made a photocopy of the roadmap located on p.19 of the handbook and posted in on his wall as a visual daily reminder. The roadmap assisted him in setting planning meetings and building agenda, keeping pace with the transition, and staying on top of ODE's grant expectations. 
- Staff Activity Sheets: the activities supplied in the handbook went over well with the GAE staff. Principal Johnson found that by using the activities sheet as a lesson plan during staff meeting promoted collaboration, open communication, and buy-in. The activity sheets assisted in building trust between the SWP Planning Team and the staff, and were used as a regular practice giving the staff an update of the plan and soliciting feedback, suggestions, and discussion.

2. What barriers, roadblocks and success stories can GAE share to help others in the future? How well does the handbook present ways to work through and address barriers and roadblocks?

Barriers and Roadblock; Principal Johnson dealt with two key barriers and roadblocks that were a consistent factor in implementing the Title I Transition.

- Funding: As a part of GAE's Comprehensive Needs Assessment the SWP Planning Team analyzed the strengths and weaknesses of their school through parent, student and staff surveys. Then, the SWP Planning Team and staff provided possible solutions to address the areas of need found within the data. Principal Johnson expressed that many good out-of-the-box interventions were discussed by the SWP Planning Team however, with the lack of funding and resources that many of the ideas were not realistic, or could not be sustained over time if they were put in place. The funding issue is a key factor for not only Oregon schools, but all school across the nation as the current economy is predicting a shortfall in public school funding over the next 2 years (Forbes, 2013). With regard to the handbook, Principal Johnson felt strongly that tool 7.0, the Impact Inventory, did address the lack of funding the lack of funding. Mr. Johnson stated, "When coming up with solutions and interventions, our SWP Planning Team used this tool to measure the suggestion in the three categories: impact on students, impact on finances, and impact on political climate. The impact inventory helped our team set realistic goals; many of the ideas were eliminated due to finances. It also helped the team see the sustainability for themselves, instead of ideas being rejected by the administration, so it allows the principal to be a neutral party or active participant in the decisions."

- Staff Resistance: Principal Johnson expressed his frustration with the fact that no matter how collaborative and transparent a school is, there is always going to be someone who is resistant to change. Sometimes staff become too comfortable with the status quo, many times they oppose the change due to personal reasons instead of what is best for students. Mr. Johnson pointed out that the Moving to a Schoolwide Title I Program handbook has a helpful 
section on dealing with resistance to change. I feel that the handbook did an adequate job of broaching the subject, however, change and resistance is a whole subject within itself. Providing some guidance on books and articles that principals could use to deal with staff resistance was an addition that the piloting principal felt would be very beneficial.

Success Stories; the following two areas highlight successes that helped the GAE staff as they piloted the handbook during the Title I transition.

- Communication \& Collaboration: following the handbook ensured that communication and collaboration were happening on a regular basis. Each tool and activity involves staff input, opinion, and insight. The Select Your Team, Identify Your Needs section was an excellent resource for putting together a group of people that are representative of the school community. The Conduct Your Assessment section provides examples of how to involve everyone in the school survey. I felt that tool 5.0 School Compact Builder was an efficient way to get the goal accomplished. At GAE we had our students, staff, school site council, SWP Planning Team and Parent Teacher Organization (PTO) all involved in the process and we created a compact that is well received by everyone.

- Planning \& Organization: Mr. Johnson expressed that we felt strongly about principals taking the time to use the planning tools. "The planning tools will make the process easier for you; it may seem like busy work, but if you actually use the documents and take notes on them they make writing the grant much easier." The planning tools in the handbook that the principal found most helpful were: Figure 1.4, Collection and Analysis Checklist. The checklist helped Mr. Johnson compile a notebook of resources that was reviewed with the SWP Planning Team to analyze key areas of GAE. The Communication logs are something that can benefit any school principal whether they are going through a Title I transition or not, it is just record keeping. Every administrator school should be doing this anyway but most do not. Mr. Johnson stated that he will continue using this log even after the transition.

3. What strategies have been successful in building and sustaining a positive school culture during a large change initiative, and are those strategies represented in the handbook?

GAE found that during this large change initiative that encouraging collaboration through structured PLC's and Data team discussion was instrumental in building and 
sustaining a positive school culture. GAE noted that professional development was also a key factor; in order to have effective PLC and data driven discussions, the staff needed to be trained on how these structures should run. Celebrating success is also another strategy that made a positive impact in positively affecting the school culture during the transition. During staff meetings GAE would give progress updates, and give kudos to staff members publicly for their dedication and achievements. After analyzing the survey data they SWP Planning Team did not only share the areas of improvement with the staff, but first celebrated the things that were working well at GAE, and provide staff with a long list of positives that was also shared in the parent newsletter as well. The handbook addresses building a positive a sustainable school culture throughout the handbook. Tool 1.5 Assessing Your School Culture, was an eye opener for GAE. It highlighted the school's strengths and weakness, and the staff noted that they had a lot of positive things happening that they could build on. The assessment led GAE into deep discussion about ways which they could improve the culture for all school constituency. Principal Johnson felt that this powerful tool should be revisited throughout the handbook at the beginning middle and end, as a progress monitoring tool to assess the school's culture throughout the process. "I feel that as a school it is beneficial to monitor the improvement of the school culture, just as much as we monitor student achievement data." The Cultural Community Involvement Map (Tool 4.0) is a great way to plan for increased parent involvement throughout the year. The Reculturing Compass is a useful reflection tool for the building principal to use throughout the transition; it's quick, easy, and gives a strong indication on ways to boost and sustain positive school culture. GAE found that having 
parents as members of the SPT, and involving Site Council and PTO in the decision making process was very valuable. They brought a new element or perspective to our community involvement events, GAE is looking forward to trying the new approach to community involvement next school year that is now documented in their SWP plan. Principal Johnson indicated that the Principal's School Culture Atlas gave him good ideas on practical ways to enhance his school culture through appreciation of students, staff, and parents as they went through the process. Mr. Johnson shared these examples: during the parent surveys that were conducted during parent conferences in the school's computer lab (as suggested in the handbook) pastries and coffee were provided to parents along with student-made cards that said "thank you for caring." Mr. Johnson began recognizing teachers over the intercom during school announcements for outstanding instruction or leadership, and as a staff, GAE increased the ways in which they recognize students. GAE previously had awards assemblies in place on monthly basis; they also began recognizing student accomplishments by school newsletter, parent notes, and daily school announcements. Principal Johnson attributes these new improvements to the collaborative work they staff has done this year while using the handbook as a guidebook through this transition year.

4. What significant impact, if any, can this product have on student achievement, school leadership and school culture?

Principal Johnson has the belief that the impact that the handbook will have at GAE will be revealed over time. By using the handbook to recreate the Title program from a TAP to a SWP, changes have been made that will impact student achievement. 
GAE has made changes in curriculum, grading, and the overall structure for providing support to students. However, those are just the steps for getting the ball rolling. Johnson feels GAE will face more challenges in the 2013-2014 school year when they begin to function under a SWP. The staff's sustainability and dedication provided Johnson with insight on how strong the collaborative approach the handbook provided was in creating a successful and sustainable program. "I feel that this year we have done a lot of beneficial work, and I am hopeful that it will pay off by improving the academic growth of all students."

The handbook can provide an immediate impact on school leaders that are embarking on the transition from TAP to SWP. Johnson emphasized that fact that you get out of the handbook what you put into it: "The handbook is time consuming, it's a yearlong process. If you don't take the time to follow the steps outlined you could be missing something or making extra work for yourself in the long run.” On a personal note Principal Johnson felt that the handbook enhanced his motivation and ability to impact school culture.

It made me realize that I could be doing much more, and it motivated me to do more. Small changes pay off; the handbook discusses the importance of building staff and student relationships. GAE staff began saying "hello" to at least 10 students a day that are not in their homeroom class, and saw a decrease in behavior referrals.

The impact on school culture was significant at GAE. Johnson revealed that he had been unsure of his ability to improve the culture at GAE. Stating that GAE like every other school across the U.S. has norms, attitudes, and beliefs that have become traditions 
and not all of them are positive. One of the reasons that Mr. Johnson agreed to participate in piloting this study was to work on improving the school culture. Johnson stated,

This year I see a shift for the better; the handbook activities has made our staff reflect, refocus and make efforts to improve our daily practice. We have also shaken things up by breaking negative norms and taking some people out of their comfort zone.

Johnson admitted that not everything has been easy. This year Mr. Johnson has met with teachers and union representatives about passive aggressive behaviors, negativity, and poor instruction more than any year of his 4 years at GAE. "It is not personal; my job is to make sure everyone is giving the best to each and every student."

What effect did the cohesion of the planning team have on the implementation process? How does the handbook emphasize the importance of selecting a strong team? How effective are the tools in the handbook at assisting principals in selecting a team?

According to Principal Johnson the cohesion of the GAE team was a key factor in getting goals, deadlines, and the overall planning grant accomplished. "We all had different strengths, and everyone was willing to give their best to the group." The GAE team strategized the best way to provide, share and gather information from the staff, and in doing so they were able to keep meetings positive, focused, and beneficial. After the GAE planning team identified their mission and vision, there was a sense of unity and they were able to disagree respectfully. Mr. Johnson stated that the SWP Planning Team came up with a census voting scale to deal with disagreements; this method proved effective in keeping meetings productive. "Team cohesion makes the planning process much easier to handle." 
Moving to a Schoolwide Title I Program: The Path Principals Should Follow to Maintain a Healthy School Culture emphasizes the importance of building a team that is able to function on a high level throughout the process. At the beginning of the handbook, the section entitled The Selection Process provides information, tips, and qualities to look for that assisted the principal in getting the right people on board. Principal Johnson used Tool 3.0, Team Construction, and Figure 1.3, Boswell's Triangle, while constructing his SWP Planning Team at GAE.

On a scale from 1 to 10 , I would give us an eight on our effectiveness. There is always room to grow, but I am pleased with our team. We have parents, community members, staff-both classified and certified, and administrators working toward creating a plan to meet the needs of all students.

5. How effective are the tools in the handbook in assisting school leaders to create buy-in from their staff for the transition?

Mr. Johnson said that while $96 \%$ of the GAE staff was fully in support of the Title I transition, 4\% said that they were not fully on board with the transition but were willing to support it and see how it played out. In September, the GAE staff was almost 50/50 with regard to the transition. The tools and activities in the handbook did a nice job of promoting collaboration, which in turn created buy-in and support. Johnson feels that as the staff began to make decisions on the curriculum, interventions were used, and they began to structure the program and take ownership of the proposed SWP plan. Ownership turned into buy-in for the change; now we see that $96 \%$ of the staff is looking forward to beginning the work that they have designed for the 2013-2014 school year.

Tools that contributed to GAE buy-in according to Principal Johnson were the staff survey alignment along with sharing and prioritizing the results. Once the survey 
from staff, students, and parents were collected and results were shared as a staff, not only did the staff feel heard, they also saw the need for certain changes. This was very helpful in creating buy-in among the staff; they realized that there was a need for improvement that was revealed through their own survey responses. The School Compact Builder was another valuable resource that was advantageous in gaining support. It was created by all and outlined the responsibilities of everyone; what does GAE expect from parents, students, and what can parents expect from the staff. The GAE staff created a compact that is a contract which the teacher, the student, and the parents sign, and return to the office.

We have never had a school compact; I think the accountability piece will be huge in ensuring that everyone does their part to make the student successful. Including the child themselves, in elementary school most responsibilities fall on the school and sometimes the parents, but there are things that the student should be doing each day to help themselves as well.

Mr. Johnson gave the example of coming to school ready to learn and work hard and ask for help when they need it. Johnson pointed out that his school is preparing each student for high school graduation; each year students should be meeting the challenge of taking on more responsibility. Principal Johnson's preparation comments are in reference to the 40/40/20 goal that Oregon has set for 2025. By 2025, 40\% of high school graduates will go on to college (community or university), $40 \%$ will enter into trade school, and $20 \%$ will enter the workforce prepared with the skills they need to succeed (Crew, 2013).

6. Does the handbook provide a cultural lens for leaders when making the program transition? 
Mr. Johnson's opinion was favorable in the handbook's ability to provide a cultural lens. "I have never really been quite sure how to change the cultural perspective or mindset of others. The handbook helped us reexamine our curriculum, approach for dealing with behaviors, as well as our need to serve all students, not just the majority." Johnson goes on to say that the handbook may not have changed the values and opinions of his staff, but it did create new approaches and curriculum changes that will indeed benefit the small percentage of minority students. Does the handbook provide a cultural lens for leaders when making the program transition? Many changes have been made that positively affect students and families at GAE; changes that have been overlooked in previous years. Some of these changes include providing a translator for families during conferences, IEP meetings, and other school events, as well as incorporating stories into the curriculum that have leading characters from a variety of ethnic backgrounds that provide information about other cultures. A big change for GAE is that they reached out to some minority parents and helped them get involved in the PTO, SWP Planning Team and Site Council. Johnson pointed out that he and GAE have a long way to go in terms of building equity for all school constituencies. Mr. Johnson plans to continue to examine policies, procedures and norms through a cultural lens and push for improvement.

7. How beneficial is the handbook at addressing school culture during the Title I transition?

Principal Johnson called attention to the fact that it takes time to change a school's culture. He feels that the handbook was an instrumental tool in identifying the strengths and weaknesses of the school culture at GAE. Johnson also feels that 
throughout the transition process, the handbook helped them address and work through issues that would not normally be discussed or addressed during a normal school year. The handbook prompted discussion such as: negativity, mutual respect between staff and students, monitoring student progress, and growth vs. labeling and tracking. Johnson indicated that these have been ongoing issues at GAE, and revealed that there have been breakthroughs and emotionally charged staff discussions. "Changing a culture is not an easy task, it is going to rattle people emotional cages, and make them reflect on their own educational practices and personal beliefs. I used the handbook as the scape goat to help in getting some key changes in place." Johnson found that saying, "Let's 'pilot' this idea, or "I found the activity in the handbook that may be beneficial for us," was a way to enter into school culture discussion. One GAE staff member stated, "We have been hit with a barrage of change this year; although it can be intense, there are a lot of positive and exciting changes happening at our school!”

8. What suggestions does Mr. Johnson have for improving the handbook?

"I am not a writer" stated Johnson, "the handbook gave me what I needed in terms of making a successful transition at GAE, and I am certain that many other schools will also benefit from this tool as well." Johnson pointed out that each school is different and some schools face even more obstacles, resistance and barriers than GAE. Mr. Johnson drew attention to the fact that there is not a handbook out there that is a catch all for every problem, he suggested providing a resource list or quick reference guide of articles, books, and resources that principals can choose to pull from that may further assist them in their navigation of the process. 
The handbook is an excellent tool; however, I believe that the success of the handbook relies on the work ethic of the principal and SPT. It's sort of like a school compact: what must the principal do to ensure success?; what must the SWP Planning Team and staff do; what can we expect the handbook to do? Then, as we begin implementation, how will we hold ourselves accountable for doing what we set out to do?

Humorously, Principal Johnson suggested that the researcher create a handbook for monitoring the accountability of the Title I program once schools have successfully made the transition.

This study began with developing the research question: What can school leaders do to positively shape their school's culture as they move their schools from a TAP to a SWP?

Principal Johnson revealed several key points for leaders as they shape their school cultures during this yearlong process. Johnson emphasizes the importance of making the process collaborative; collaboration is critical in gaining staff buy-in. Spend time building a SWP Planning Team that will be able to function at a high level. The team should be reflective of the entire school (parents, community members and staff) and represent other cultures, backgrounds and experiences. Johnson also pointed out the importance of properly using the information that is gathered during the Comprehensive Needs Assessment as a staff. Reflecting on the data, identifying strengths and weaknesses, and using the data to create a mission and vision from your team to address the issues is a great way to show your staff the need for the change, and begin building on how you will address the change. Lastly, Johnson discussed challenging negative norms and behaviors, having difficult conversations, and continuing with the work despite the fear of change that may be looming amongst staff. 


\section{Summary}

Moving to a Schoolwide Title I Program: The Path Principals Should Follow to Maintain a Healthy School Culture was designed and developed to provide a guide for principals and school leaders as they lead their schools through the transition from a TAP to a SWP. The handbook was developed using the R\&D process, which included an extensive literature review, a needs assessment, three focus groups for preliminary field testing for validation, and revisions; then the handbook was piloted at GAE for the main field test and operational product revision. The first seven steps of the process are outlined in this chapter. The product was reviewed by 22 experts in the field who provided formative evaluation of the handbook's content, format, and practicality. All suggestions, notes, and reviewers comments were considered for improvement of the handbook. The piloting school principal provided a wealth of information on the handbook based in GAE's experience participating in the main field test, as the principal used the handbook to guide his staff through the transition from a TAP to a SWP. The researcher used the nine essential guiding questions as the format for sharing the pilot school's experience testing out the product. The educational R\&D process resulted in the development of an educational leader's guide ready for dissemination and implementation in a school setting. 


\section{CHAPTER V \\ CONCLUSION, SPECULATIONS, AND RECOMMENDATIONS \\ FOR LEADERSHIP}

\section{Introduction}

This chapter summarizes the R\&D of a PBL tool, Moving to a Schoolwide Title I Program: The Path Principals Should Follow to Maintain a Healthy School Culture. Specifically, the chapter discusses the overall assessment of the research experience; reveals the results of the operational product revision (step 7 of $R \& D$ process); speculates about further development and use of the handbook; and presents conclusions and implications, suggestions and strategies for dissemination and use of the handbook, as well as recommendations for future study. Lastly, this chapter provides recommendations for school leadership.

\section{Summary of Activities}

This study's intent was the construction, field testing, revision, and refinement of an educational leader's guide to aide principals of Title I schools in making a successful and sustainable transition from a TAP school to a SWP. An educational leader's guide was developed using the R\&D methodology as recommended by Borg and Gall (1989) and Dick and Carey (1985). The R\&D methodology used to develop the educational leader's guide consisted of a seven-step cycle (see Figure 2.5, p. 89).

The idea for developing the guide was established through an extensive literature review that began in the summer of 2009. The relevance of the problem was also revealed 
through discussions with professional educational administrators ranging from principals of schools from urban, suburban, and rural districts as well as Title I Coordinators, central office administrators, and superintendents. A prototype of the product was developed prior to the 2011-2012 school year, and preliminary field testing began in August 2011 at Stratton Elementary as the SWP tested out the tools and activities in their initial stage of creation. The preliminary field test also included evaluative feedback from three focus groups of expert reviewers, a principal's group, a group of central office administrators and Title I Coordinators, and a compliance group of three ODE personnel. The product was then revised and refined based on the preliminary findings, and the main field testing occurred for further validation. The main field testing began in late August 2012 at GAE. This field test utilized the principal as the key facilitator in making the transition from a TAP to a SWP, while using the handbook to guide his school's change path.

\section{Operational Product Revision}

Based on the data collected at GAE during their time piloting Moving to a Schoolwide Title I Program: The Path Principals Should Follow to Maintain a Healthy School Culture, additional revisions occurred as a result of the main field testing of the product. The additions and revisions are listed below:

1. A reference guide on "resistance to change" was added at the end of the Dealing with Change section of the handbook. The guide provides a list of authors and change-related books; this list can be used to point principals in the right direction, if needed. Principal Johnson felt strongly that it would be 
very beneficial for principals to have this addition when going through the process. It also became apparent that each focus group wanted more information provided in the Dealing with Change section. Instead of trying to encapsulate a variety of issues that may arise, the researcher felt that guiding school leaders to the wealth of reliable resources and literature available in the field was the most logical way to address this subject. In addition to the resource guide, the narrative was expanded in the Dealing with Change section on understanding your district contract.

2. After ongoing discussion with Principal Johnson and school leaders in the field, the researcher decided it would be beneficial to add a figure and a description of the 40/40/20 model. The figure is a pie chart with an explanation of the goal: "By the year 2025: 40\% of Oregonians will have a bachelor's degree or higher, 40\% will have an associate's degree or work related certification, and 20\% will have a high school diploma" (ODE, 2013, p. 1). This addition was made to page 20 of the handbook and is located directly after the Yearlong Schoolwide Planning Roadmap. The handbook has been an evolving tool over time.

3. Major edits and revisions to the handbook include creating subheadings that align with the Handbook Crosswalk, and changing all the narrative text to the Cambria 12-point font, and all tools text Georgia 12-point font. The changes were made to improve the ease and readability of the handbook. 
4. In discussing the benefit of the Principal's School Culture Atlas, the decision was made to place it in the handbook a total of six times, each time with new questions as way to ensure self-reflection on the readers' part. This tool was noted by Principal Johnson as a beneficial tool for contemplation of the process.

5. In reflection on the definition of culture, which continued to spark ongoing discussion from evaluations throughout the research, the definition of culture as it relates to the handbook is now clearly highlighted in red in at the beginning of the handbook in the Definition of Terms.

6. Through the editing process, the Yearlong Roadmap was improved through spacing and readability. Many dashed and spacing issues were corrected, and reviewers felt that it is now more user friendly, by adding clear headings and removing unnecessary spaces and hyphens.

7. The text on tool 2.5, All Involved, was revised to clearly outline and reflect an inclusive process for creating a Family Involvement Plan. The tool now lists four key steps that the school should follow. These steps are: (a) Elementary School will work with parents to develop and revise a school/parent involvement plan that is distributed to parents and made available to the school community; (b) Convene an annual meeting to which all parents shall be invited and encouraged to attend, to inform parents of their school's participation, explaining the requirements and hopes of the parents to be involved; (c) Offer a flexible number of meetings, both AM and PM times, 
and may include, transportation, child care, or home visits, as such services relate to parental involvement; and (d) Involve parents in an organized, ongoing, and timely way in the planning, review, and improvement of the parent-involvement process.

8. The Survey Dissemination and Collection Strategy was revised based on the discussion with Principal Johnson, the researcher's experience and other principals' experiences across the state. The tool now provides two examples of how other school's disseminated their survey, it also lists the benefits and risks of each example.

In general, the piloting principal and researcher felt that the handbook, Moving to a Schoolwide Title I Program: The Path Principals Should Follow to Maintain a Healthy School Culture is a product that can be immediately used at its current stage to guide school leaders through the transition from a TAP to a SWP while creating or improving their school culture. The product promotes collaboration, shared leadership, academic achievement; and school improvement. The results will be different at each and every school that uses this resource, as SWP Planning Teams work through the handbook to create a plan that best suits the needs of their schools.

\section{Overall Conclusion and Assessment of the Experience}

The purpose of the study was to create an educational leader's guide to be used in assisting a principal's successful transition from a TAP to a SWP, while at the same time maintaining, reshaping or creating a positive school culture. The following research objectives were achieved. 
1. The literature review revealed that there is a lack of information with regard to principals making a transition from a TAP to a SWP. SWP proved to be more effective in the program's ability to serve more students in need of support.

2. The literature review supported the contention that school culture affects all aspects of a school experience. It influences, for instance, casual conversations in the staff lounge, the importance of professional development, the value of differentiated instruction, and the promise of assuring that all students learn (Deal \& Peterson, 1999). Chenoweth and Everhart (2002) suggested that schools serious about creating significant changes in teaching and learning that will positively impact student achievement must go through the difficult process of reculturing. Reculturing is defined as challenging current practices, patterns, and norms by examining them, and implementing change when it is appropriate for the success of all students.

3. A guide for principals to use in Oregon's Title I schools was developed using the $R \& D$ process to evaluate and refine the book to assist school leaders in making a successful and sustainable Title I program transition. The transition from a TAP to a SWP has been strongly recommended to Oregon Title I schools that qualify based on their free and reduced number. As the research indicated the SWPs have the ability to serve and support larger numbers of students than TAPs.

4. The guide for educational leaders leading the transition from a TAP to a SWP was further developed by the principal and SWP Planning Team at GAE. 
When the researcher began this dissertation process in 2009, he began studying school culture, and felt it was a significant topic to address after completing his first year as a building principal. However, during the four years since the beginning of this process, the researcher has had the opportunity to not only gain experience as building administrator, but has also served as the District Title I Coordinator and Superintendent's designee. Those experiences shaped the researcher's decision to create a handbook for principals that addresses the Title I transition while using the lens of school culture as a means for creating a sustainable program change. Through a variety of administrative roles, the researcher's belief became stronger in the fact that such a R\&D handbook would be beneficial to school leaders.

Over the past four years, the researcher utilized most of the information provided in the handbook through a variety of presentations to educators, both in and out of his own district. One of the most recent presentations given by the researcher on this work was at the Oregon School Board Associations $66^{\text {th }}$ Annual Conference, which took place on Friday, November 8, 2012. This presentation was entitled "Title I: A Collaborative Approach to Improving Programs While Creating/Maintaining a Positive Culture.” During this presentation the prototype of the handbook was shared with audience members, and information was shared about creating a positive transition to a SWP to serve more students and improve program effectiveness.

Throughout this process the researcher has been continually surprised by the amount of information and positive feedback that has been shared with him around the research on Title I, school culture, and change. He has received information from 
educators through email, phone calls, letters, and meetings. Through this dissertation work, the researcher has been invited to participate in statewide and national conferences as a speaker, panelist, and educational consultant. This dissertation has literally opened up a whole new world, full of opportunity and unlimited experiences.

Two SWP Planning Teams have already benefited from the tools and resources provided in the handbook. Stratton used the methods and handbook framework to guide them to a successful program transition. Currently, GAE is halfway through the transition process and feeling positive about the staff buy-in, collaborative planning, and changes that have taken place due to the tools and activities the handbook. The researcher will continue to provide support to GAE for the remainder of the school year, until June 1, 2013, when the school submits their Title I Planning Grant to ODE.

Through conducting the dissertation process over the past four years, the researcher has gained a reputation as an expert in the area of Title I, and is grateful for a deep understanding of the research, as well as the practical know-how to create a handbook that can assist school leaders in creating a positive and sustainable change to benefit students.

\section{Researcher's Reflection}

In assessing this experience, I would say that I have grown as a researcher as well as an educational administrator. When dealing with change, collaborative leadership, school culture, and resistance to change, I rely on concrete experiences coupled with research. Through this process, I have learned to look at situations as a complete whole, and identify factors within the whole that stand out as being especially relevant. In 
working with schools to reshape or positively impact school culture, many principals find themselves on the outside looking in as detached observers. Throughout this experience I have moved from a detached observer of the school environment to an involved performer. I have learned to tune into the problems of the people that make up the school environment — students, parents, community members, and so forth, taking the time to understand their backgrounds, and lead from a social justice lens to make the system better for all school constituents.

As a building leader, I have made reflective practice a part of our school's normal routine. We spend time assessing what is working, and what needs to be changed to best meet the needs of the students. Over the past four years I realized that I am no longer looking for the quick fix. I now meet with a leadership team once a week and we discuss the problem, analyze it, and brainstorm possible solutions. When we find a solution that may work, we field test it through planned strategies, and then assess the effectiveness of the outcome.

\section{Speculations About Future Research}

\section{Future Research and Goals}

Future research interests include: the monitoring and accountability of Title I programs; implementing successful data teams; and dealing with staff resistance. These topics are all areas that emerged during the dissertation process; topics that not only spark high levels of interest during principal meetings, education discussions, and workshops, but they are also topics that principals must be familiar with as academic rigor and accountability expectations continue to increase each year, and as states move to a growth 
model to monitor the achievement of every student. Topics such as dealing with staff resistance and implementing effective data teams may spark the publishing of educational articles, books, websites, or state and national presentations.

A new research interest is focused on developing successful early childhood centers to provide services and support for economically challenged communities. This year, the researcher worked as part of a school team on a proposal that was funded through the Oregon Community Foundation to begin the initial planning phase around a P-3 Alignment. This grant will bridge the gap between the school and the community partners involved in providing services for children from prenatal to age 3 (e.g., the community health center, Northwest Regional Educational Service District, mental health services, Head Start, and local childcare providers).

Along the lines of future research, there may also be a need for studying the impact and the ability to transition a "brick and mortar" charter school into a hybrid model, offering the brick and mortar model, as well as online course options for students. Currently, Oregon school districts are beginning to create "web academies" to maintain district average daily membership and stop declining enrollment, which is a ramification of the rapid development of online schools and online ESD school offerings. A recent ODE news release points out that after years of declining enrollment, this year, some districts are seeing a slight increase. Districts such as Scio School District, GreshamBarlow, and Estacada have increased their numbers by providing online educational opportunities (Greene, 2013). Districts with existing charter schools are finding it quicker to transition their charter schools into hybrid models, which offer online courses. 
Short-term goals include: (a) Presenting with a panel of educators at Washington State University's Globalization, Diversity and Education Conference in February 2013; (b) Creating a Principal's Forum called PEP, Principal Empowering Principal. This group would communicate through a password-protected blog and monthly meetings, where principals can share success stories, frustrations, ask questions, and provide support to each other at they work in the field; and (c) Continue as an active member of the Portland State University's Educational Administration doctoral cohort, to support colleagues as they work to dissertation completion.

Long-term goals include publishing an educational text on the improvement of

Title I schools, and working as an educational consultant contributing to the improvement of struggling schools, and helping school leaders manage the change process. Career goals include becoming an assistant superintendent of curriculum and instruction, and eventually becoming a district superintendent.

\section{Development}

Following the first seven steps of the R\&D process has led to the development and refinement of the handbook, Moving to a Schoolwide Title I Program: The Path Principals Should Follow to Maintain a Healthy School Culture. If this product was to be taken to scale, the research would complete the $\mathrm{R} \& \mathrm{D}$ process by completing the last three steps.

- Step 8. Operational Field Testing: This step could be completed in a variety of different ways, but the optimal opportunity would be for several schools or districts throughout Oregon with representatives from rural, urban, and suburban districts to pilot the handbook. The piloting principals would then share the roadblocks and success stories pertinent to their use of the 
handbook, which in turn would support the researcher in making a quality final product revision.

- Step 9. Final Product Revision: This step includes the refinements, edits, and improvements that were made evident after analyzing the data from the Operational Field Test. At this time the handbook would be professionally edited, and perhaps even reviewed by a graphic designer for improvement of the visual design, who may present design ideas, color schemes, and a more appealing layout than that created by the researcher in the piloted document.

- Step 10. Dissemination and Implementation: This step consists of finding ways to make the product available to principals. This could be done a number of ways: e.g., the handbook could be published by an Oregon ESD, adopted by ODE, or even published by a publishing firm. The researcher could offer professional development workshops to provide support for implementing the transition from a TAP to a SWP by facilitating of the use handbook.

Full completion of the R\&D process, Steps 1 through 10, as demonstrated by Borg and Gall's (1989) research has proven that the R\&D cycle is an effective means to develop, field test and refine educational products useful to school practitioners.

\section{Use of the Product}

There are a variety of ways in which this product can be used. The most traditional way would be for a building principal to use the handbook sequentially to guide their staff through the transition from a TAP to a SWP. This way proved to be effective for the GAE staff. The handbook could also be used by selecting activities ad hoc that best meet the needs of a particular staff as they move through the yearlong transition, without necessarily following the handbook in sequential order.

The handbook could also be used on a larger scale by a superintendent who is using it as a coaching tool to guide a group of Title I Principals through the yearlong process in their schools. This district model could assist multiple schools in making the transition all within the same school year. The strategizing and planning around the 
transition could be discussed by a leadership team of principals, district level administration, and the superintendent. Principals could then go back to their schools to test out the collaboration activities and come back to their district leadership team meetings, and share their personal experiences. This model would allow the leadership team to be a support system to the principals facilitating the process. This could be an effective way to move a number of TAP schools through to SWP while improving school culture, collaboration, and accountability.

Another avenue that could be beneficial in the use of this product comes from a research perspective. A researcher could identify a school in a state outside of Oregon to pilot the handbook and determine how the handbook measures up and complies within a different state context and culture. Researchers could also utilize the handbook to discover whether or not adjustments need to be made to assist principals in their state. Large scale research could include using the handbook to transition a statewide group of Oregon schools entering the transition process. The study could measure the effectiveness of the transition process and monitor its sustainability over time.

\section{Principal's Role During the Transition Process}

Throughout the yearlong transition, it is important for principals to have the skills needed to take on a variety of roles to ensure a smooth transition process. Researchers point out that no one person in a school is the most knowledgeable or experienced practitioner (Murphy, Smylie, Mayrowetz, \& Louis, 2009). Rather, the principal needs to be aware of the strengths of the people around them and tap into each individual's expertise so they can all work together to create an effective and sustainable program 
change. Through reflection of this study I have identified five interconnected areas for principals to focus on to develop a strong professional culture of collaboration and staff buy-in throughout the yearlong transition.

- Facilitating the decision-making process with staff and community: During this process the principal must work to build a SWP Planning Team that is reflective of staff, parents and community members. The principal must share authority by providing meaningful opportunities for the team members to participate in significant decisions about the new SWP plan. It is important for the principal to communicate that each team member is of vital importance to the group. The principal needs to work as a team member that is not afraid to facilitate the discussions among the team, and allow team members to sometimes take the lead in discussion.

- Providing support for the SWP planning team: It is the principal's responsibility to provide information and professional development to the SWP Planning Team so they can function effectively. The team members need the skills to understand and verbalize the team's vision, set measurable goals, create norms for operation, set and follow agendas, and complete tasks. The principal is responsible for providing guidance and feedback to the team, as well as support and encouragement.

- Be an Instructional Leader who makes data driven decisions: As the instructional leader, the principal should conduct classroom walkthroughs providing constructive feedback to staff. The principal should also attend data team meets and assist in guiding teams in making data-driven decisions. In taking on the instructional leader role, the principal needs to provide educational resources and professional development opportunities that learning, teaching and assessment practices.

- Be a collaborator in managing and monitoring the change process to ensure progress: The principal and SWP Planning Team ensure that the entire school community understands the reason behind the new program change and are on board with the vision. This includes taking survey of all school constituencies, and involving parents in the building of a school compact and family involvement plan.

- Be an involved performer in developing a culture of accountability: The principal and the SWP Planning Team hold all individuals accountable for reaching their goals. To build this culture of accountability the principal must be a visible active member involved in the daily activities. The principal must collect evidence of document progress, through data team assessments. The 
principal and the SWP Planning Team make it clear that each team matters, and that every grade level making growth is helping the school as a whole.

\section{Recommendations for Leaders}

Research proves that certain leadership actions can be taken to ensure transformative results (Muhammad, 2009; Reeves, 2004; Schmoker, 1999). A list of recommendations for leadership has been compiled by the researcher, based on the researcher's experience over the past 3 years studying Title I programs. As a practicing

principal in the field, the researcher feels this is a way to share helpful insights regarding Title I, school culture, and change.

Use the data to guide your plan for serving all students in your building

1. Ensure rigorous goal and data driven instruction: In order to make gains and breakthroughs in achievement, effective principals need to guarantee that the instruction and curriculum being taught is aligned closely to the Common Core State Standards for college and career readiness. Principals should develop a set of effective instructional strategies that all teachers are working to advance. Be sure that students are being held to very similar expectations in each and every classroom. Stress the importance of meaningful student learning data as the foundation for all lesson planning, collaboration meetings, professional development, and academic intervention meetings for students who are struggling.

2. Build and manage a highly functioning staff: Research tells us that the number one factor influencing student achievement is "teacher quality" (Kim \& Sunderman, 2005; McNeil, 2011; ODE, 2010). Principals need to become 
skilled at managing human capital to drive teacher effectiveness and student learning. Principals need to complete at least weekly, if not more frequently, observations in every classroom, create professional development plans for every staff member and support growth through direct feedback and jobembedded professional development. It is also vital for principals to recruit, select, and evaluate teachers based on high standards - publicly acknowledging and rewarding high performing staff members, and counseling out, or, if necessary, dismissing teachers who are not meeting expectations. Increasing and developing teacher leadership is also key. It will take time, but I recommend that principals develop a leadership team, whose main responsibility is guiding the core work in the schools. This team should be made of a variety of staff and district personnel. This skill will not only help principal making the transition from a TAP to a SWP, building highly effective teams is also vital in implementing data teams, PLCs and school committees.

3. Develop a positive school culture that is sustainable over time: As we found in the literature review, principals need to build a school culture where students come first, and professional development and hard work are the norm. Principals should insist on teaching students to have high aspirations for themselves, and on staff holding themselves personally accountable for improving all students' academic growth and helping them reach their goals. In the handbook, principals should use Tool 11, the Accountability Matrix to 
measure and monitor the school's goals, and frequently assess the progress that is being made toward meeting goals. If progress was not being made, I suggested that principals to revisit Activity 1 in the handbook, entitled "What does the data tell us?" This activity allows a staff to collaboratively identify the problem and begin brainstorming solutions. The Impact Inventory tool 7.5 proved to be helpful when narrowing down possible solution and putting in place realistic interventions that can be sustained over time. The principal's cultural atlas, Reculturing Compass tool 8.5, and Assessing Your School Culture, tool 1.5 are all tools the principals and evaluators found to be valuable in developing and shaping school culture.

4. Follow the handbook to build buy-in through a collaborative approach: Successful schools are not made overnight, rather they are made through stages of improvement of all school constituencies. This research study demonstrates that a positive transition can be made from a TAP to a SWP if the process is collaborative and incorporates all school constituents. I recommend that leaders entering the Title I transition process using the handbook, Moving to a Schoolwide Title I Program: The Path Principals Should Follow to Maintain a Healthy School Culture follow the tools and activities in order, and do not skip steps. When the handbook was piloted as a guidebook, evaluators and the GAE principal attested to the fact that it follows the ODE process and complies with the grant. Evaluators and the piloting principal also found that it promoted collaboration, buy-in and shared 
leadership. It is important for principals going through the transition to SWP to remember that they are embarking on a yearlong process. Before reaching the end of that yearlong process, they are required to take a staff vote, and the majority of the staff must be on board with the transition to move forward. Fullan and Ballew (2001) attested to the fact that schools that make changes that were created by all, result in full implementation and sustainability. Following the handbook step by step as a guide will assist school leaders in building buy-in and creating a sustainable transition to a SWP.

5. Do not be a detached observer, be an involved performer: Much of a principal's influence is indirect and takes place by raising the bar on standards and rigor; improving teacher effectiveness and classroom practices; and impacting the school culture. Outstanding principals do not spend the majority of their time behind a desk. They realize their daily actions can directly influence student and staff behavior. In reflecting on each activity in the handbook, Principal Johnson as well as the majority of the handbooks evaluators, indicated that Moving to a Schoolwide Title I Program: The Path Principals Should Follow to Maintain a Healthy School Culture puts the principal in an active role throughout the entire school year. The principal is not on the outside looking in and identifying the problem. The handbook activities and tool make certain that principal is an involved performer: modeling, teaching, collaborating, analyzing data, and sharing ideas. Principal should hold high expectations for everyone, and provide verbal praise for 
student and staff members that are clearly emulating the school's expectations. Many activities in the handbook provide opportunities for principals to provide positive praise to students and staff, to reinforce the positive behaviors that are happening (Deal \& Peterson, 1999).

6. Making Doctoral Work More Problem-Based: As educators entering the doctoral journey toward an EdD, it is important that we choose a study that we are passionate, a study that will impact students achievement and our schools in a positive way. PBL provides us the opportunity to deal with real-life situations and gives us the venue to make radical changes in the field. E. M. Bridges and Hallinger (1995) pointed out that PBL can help doctoral students appropriately apply research, theory, and knowledge to problems that arise for educations policies and practices. This allows educators to base their doctoral work around issues that are relevant to a problem in the field that they deal with on a day-to-day basis.

\section{Conclusions}

Today's schools demand an increased accountability across the nation require a different kind of leadership, one that enables school leaders to better serve their students. In addition to administrative knowledge and skill, Sergiovanni and Starrat (1998) affirmed that leadership development tends to be shaped by a set of "beliefs, opinions, values, and attitudes, which provide a foundation of practice" (p.133). In other words, principals' actions are guided by their educational values and beliefs. It is important for school leaders to believe that all students deserve a quality education. If a TAP school 
begins to see a drop in achievement, or their growth over time has flat-lined, they need to reassess their program. As the number of free-and-reduced lunch participants increases each year, many schools are finding that the TAP model limits the number of students who can receive services. Wong and Meyer (1998) pointed out that the SWP model is more effective in its ability to serve more students.

It can be argued that this study informs principals who feel that their Title I programs are not serving the needs of all of their students, and it assists in providing a reflective means to serve more students while assessing and shaping school culture. This dissertation identified the problem as a lack of information and professional development available to school leaders to assist in guiding them through successful implementation of the transition process. Moving to a Schoolwide Title I Program: The Path Principals Should Follow to Maintain a Healthy School Culture is one answer to this problem. Through the R\&D process, an instrument has been established that can successfully guide principals from a TAP to a SWP while building, reshaping, and addressing school culture. However, there is so much more to learn. What is certain is there is an unequivocal need for improvement in today's school system. The Title I program transition is just one way to begin addressing achievement issues at schools with $35 \%$ or more free-or-reduced lunch population. The transition from a TAP to a SWP will not necessarily make a school more effective, nor will it ensure improved achievement or classroom instruction. Through conversations with educators across the state, it is evident that the transition is not always sustainable or fully implemented by all staff, and many times the efforts for change are overcome by resistance, and the idea toward change is 
abandoned. The handbook promotes the idea that though collaboration, shared leadership, data driven instruction, and staff buy-in, the yearlong transition process is not only doable, but it can also positively impact a variety of factors that contribute to student learning and shape school culture.

Principal Johnson said it best, "You get out what you put in to the process" (personal communication, January 7, 2013), meaning the handbook is a guide that can assist you in a successful program transition, if one takes the time to completely follow it front to back without skipping over or leaving out steps and activities. Nonetheless, the real success of the transition lies in the hands of the school principal and the SWP Planning Team. Do they see a need for the improvement of all students? Are they taking into account all school stakeholders? Can they create a clear vision, and utilize a collaborative approach to gain buy-in from all staff members? Principals, school leaders, and educators who are not afraid to make changes and challenge policies, past practices, and norms for the betterment of all students have the ability to make breakthroughs in the achievement of students each and every year. Moving to a Schoolwide Title I Program: The Path Principals Should Follow to Maintain a Healthy School Culture was created to help principals make a difference for years to come. 


\section{REFERENCES}

Abate, F. R. (2009). The Oxford pocket dictionary and thesaurus. New York, NY: Oxford University Press.

Abedi, J. (2004). The No Child Left Behind Act and English language learners: Assessment and accountability issues. Educational Researcher, 33(1), 4-14.

Anderson, G. L., Herr, K., \& Nihlen, A. S. (2007). Studying your own school: An educator's guide to practitioner action research. Thousand Oaks, CA: Corwin.

Bailey, S., \& Mosher, E. (1968). ESEA: The Office of Education administers a law. Syracuse, NY: Syracuse University Press.

Baker, E. L., O’Neil, H. F., Jr., \& Linn, R. L. (1993). Policy and validity prospects for performance-based assessment. American Psychologist, 48(12), 1210-1218.

Benton, C. C. (1997). A comparison of the effects of two Title I models on reading comprehension (Doctoral dissertation, Fayettville State University). Retrieved from http://digitalcommons.uncfsu.edu/dissertations/AAI3027003/

Bolman, L. G., \& Deal, T. E. (2003). Reframing organizations: Artistry, choice, and leadership. San Francisco, CA: Jossey-Bass.

Borg, W. R., \& Gall, M. D. (1989). Educational research: An introduction (5th ed.). White Plains, NY: Longman Inc.

Borman, G. D., \& Agostino, J. V. (1996, Winter). Title I and student achievement: A meta-analysis of federal evaluation results. Educational Evaluation and Policy Analysis, 18(4), 309-326.

Borman, G. D., \& Hewes, G. (2003). Long-term effects and cost effectiveness of success for all. Educational Evaluation and Policy Analysis, 24(2), 243-266.

Bower, M. (1966). The will to manage: Corporate success through programmed management. New York, NY: McGraw-Hill.

Bridges, E. M., \& Hallinger, P. (1995). Implementing problem based learning in leadership development. Eugene, OR: University of Oregon, ERIC Clearinghouse on Educational Management. 
Bridges, W. (2003). Managing transitions: Making the most of change. (2nd ed.). Cambridge, MA: Da Capo Lifelong Books.

Bridges, W. (2009). Managing transitions: Making the most of change. Cambridge, MA: Da Capo Lifelong Books.

Byrne, P. (2001). Psychiatric stigma. The British Journal of Psychiatry, 178(3), 281.

Caldwell, B., \& Spinks, J. M. (1988). The self-managing school. London, England: Routledge.

Caldwell, B., \& Spinks, J. (1992). Leading the self-managing school. London: Falmer Press.

Caldwell, B., \& Spinks, J. (1998). Beyond the self-managing school. London: Falmer Press.

Carroll, C. M. (2009). At-risk high school seniors: Science remediation for Georgia's High School Graduation Test. Minneapolis, MN: Capella University.

Chall, J. S. (1983). Stages of reading development. New York, NY: McGraw-Hill. Retrieved from http://www.nysrti.org/page/scientific-based-instruction/

Chapman, R. (2008, May 14). Keeping it on the down low: The IDEA, school records and confidentiality [Web log post]. Retrieved from http://randychapman. wordpress.com/

Chenoweth, T. G., \& Everhart, R. (1994). Preparing leaders to understand and facilitate change: A problem-based learning approach. Journal of School Leadership, 4(4), 414-431.

Chenoweth, T. G., \& Everhart, R. B. (2002). Navigating comprehensive school change: A guide for the perplexed. Larchmont, NY: Eye on Education.

Civil Rights Act of 1964, Pub. L. 88-352, 78 Stat. 241 (1964).

Colorado Staff Development Council. (2011). Differences between Title I targetedassistance and schoolwide programs. Aurora, CO: Learning Forward Colorado.

Crew, R. (2013, January 10). [Letter to Board Chair and Superintendent]. Retrieved from http://www.oregon.gov/gov/docs/OEIB/Letter.pdf

Cromwell, S. (2002). Is your school culture toxic of positive? Education World, 6(2), 1. 
Deal, T, E., \& Peterson, K. D. (1999). Shaping school culture: The heart of leadership. San Francisco, CA: John Wiley and Sons.

DeHart, T. (2003). Building positive school culture to increase achievement. Retrieved from http://www.marylandpublicschools.org/MSDE/divisions/leadership/ programs/leadership_learning_series/series2.htm

Dick, W., \& Carey, L. (1985). The systematic design of instruction (2nd ed.). Glenview, IL: Scott Foresman.

DuFour, R. (2004). What is a "professional learning community." Educational Leadership, 61(8), 6-11.

Dynarski, M., Agodini, R., Heaviside, S., Novak, T., \& Carey, N. (2007). Effectiveness of reading and mathematics software products: Findings from the first student cohort. Washington, DC: Institute of Education Sciences.

Ellis, J., \& Magee, S. (2007). Contingencies, macrocontingencies, and metacontingencies in current educational practices: No child left behind. Behavior and social issues, $16(1), 5-26$.

Erpenbach, W. J., Forte-Fast, E., \& Potts, A. (2003). Statewide educational accountability under NCLB: Central issues arising from an examination of state accountability workbooks and U.S. Department of Education reviews under the No Child Left Behind Act of 2001. Washington, DC: Council of Chief State School Officers.

Evers, T. (2010, December). Student records and confidentiality. Madison, WI: Wisconsin Department of Public Instruction.

Friedman, I. A. (1991). High and low-burnout schools: School culture aspects of teacher burnout. The Journal of educational research, 84(6), 325-333.

Fullan, M. (1982). The meaning of educational change. New York, NY: Teachers College Press. Retrieved from http://www.eric.ed.gov/ERICWebPortal/ recordDetail accno $=$ ED 218247

Fullan, M. (1993). Why teachers must become change agents. Educational Leadership, $50,12-12$.

Fullan, M. (1997a). The challenge of school change. Arlington, Heights, IL: Skylight Training and Publishing. 
Fullan, M. (1997b). Emotion and hope: Constructive concepts for complex times. In A. Hargreaves (Ed.), Rethinking educational change with heart and mind, 1997 ASCD yearbook (pp. 216-233). Alexandria, VA: Association for Supervision and Curriculum Development.

Fullan, M. (1999). Change forces: The sequel. New York, NY: Routledge.

Fullan, M. (2004). Leadership and sustainability: System thinkers in action. Thousand Oaks, CA: Corwin Press.

Fullan, M. (2005). Turnaround leadership. The Educational Forum, 69, 174-181.

Fullan, M., \& Ballew, A. C. (2001). Leading in a culture of change. San Francisco, CA: Jossey-Bass.

Gall, M., Borg, W., \& Gall, J. (1996). Educational research: An introduction (6th ed.). New York, NY: Longman.

Gill, B., Zimmer, R., Christman, J., \& Blanc, S. (2007). State takeover, school restructuring, Private management, and student achievement in Philadelphia. Santa Monica, CA: RAND Corporation.

Gilmour, J. B. (2001, May). The Powell amendment voting cycle: An obituary. Legislative Studies Quarterly, 26, 249-262.

Greene, C. (2013). Oregon K-12 enrollment numbers up slightly. Retrieved from http://www.ode.state.or.us/news/announcements/announcement.aspx?ID=8862\& TypeID $=5$

Hall, G. E., \& Hord, S. M. (2006). Implementing change: Patterns, principles, and potholes. Needham Heights, MA: Allyn \& Bacon.

Hargreaves, A. (1994). Changing teachers, changing times: Teachers' work and culture in postmodern age. London, England: Continuum.

Hargreaves, A., \& Goodson, I. (1996). Teachers' professional lives: Aspirations and actualities. In I. Goodson \& A. Hargreaves (Eds.), Teachers' professional lives (pp. 1-27). London, England: Falmer Press.

Hargreaves, D. H. (1995). School culture, school effectiveness and school improvement. School effectiveness and school improvement, 6(1), 23-46.

Hinde, E. R. (2004, Winter). School culture and change: An examination of the effects of school culture on the process of change. Essays in Education, 12, 61-72. 
Hopkins, D. (1989). Evaluation for school development. Bristol, PA: Open University Press.

Howse, R., Lange, G., Farran, D., \& Boyles, C. (2003). Motivation and self-regulation as predictors of achievement in economically disadvantaged young children. The Journal of Experimental Education, 71(2), 151-174.

Hoy, W. K. (1990). Organizational climate and culture: A conceptual analysis of the school workplace. Journal of Educational and Psychological Consultation, 1(2), 149-168.

Hubbard, R. S., \& Power, B. M. (1993). The art of classroom inquiry. Portsmouth, NH: Heinemann.

Johnson, B., \& Christensen, L. B. (2007). Educational research: Quantitative, qualitative, and mixed approaches. Thousand Oaks, CA: Sage.

Jonsson, A., \& Svingby, G. (2007). The use of scoring rubrics: Reliability, validity and educational consequences. Educational Research Review, 2(2), 130-144.

Juel, C. (1988). Learning to read and write: A longitudinal study of 54 children from first through fourth grades. Journal of Educational Psychology, 80(4), 437-447.

Kezeske, M. (2010). History of Title I ESEA. Washington, DC: Office of Education, Department of Health, Education and Welfare.

Kim, J. S., \& Sunderman, G. L. (2005). Measuring academic proficiency under the No Child Left Behind Act: Implications for educational equity. Educational Researcher, 34(8), 3-13.

Klein, A. (2011, January 26). Duncan, key senators sing off same page on ESEA renewal. Education Week. Retrieved from http://blogs.edweek.org/edweek/campaign-k12/2011/01/that_statement_plus_speaker_of.html

Lara, S., \& Whittier, D. (2003). Preparing teachers, student teachers, and schools for the 21st century: Review of recent reports in the U.S. Retrieved from http://emt.bu.edu/ whittier/people/Navarra/htdocs/SoniaDWpaperEdMedia04.pdf

Levin, B. (2001). Reforming education: From origins to outcomes. New York, NY: Routledge 
Levin, B., \& Riffel, J. (1997). School system responses to external change: Implications for school choice. In R. Glatter, P. A. Woods, \& C. Bagley (Eds.), Choice and diversity in schooling: Perspectives and prospects (pp. 44-58). New York, NY: Routledge.

Lieberman, A. (1988). Building a professional culture in schools. New York, NY: Teachers College Press.

Louis, K. S., \& Miles, M. B. (1990). Improving the urban high school: What works and why. New York, NY: Teachers College Press.

Margolin, J., \& Buchler, B. (2003). Critical issue: Using scientifically based research to guide educational decisions. Medford, MA North Central Educational Research Laboratory. Retrieved from http://www.ncrel.org/sdrs/areas/issues/ envrnmnt/go/go900.htm

Marshall, C., \& Gerstl-Pepin, C. I. (2005). Re-framing educational politics for social justice. Needham Heights, MA: Pearson/Allyn and Bacon.

Maryland State Department of Education, Division for Leadership and Development. (2003). Building positive school culture to increase student achievement. Retrieved from www.msde.md.gov

Mathis, W. (2003, May). No Child Left Behind: Costs and benefits. Phi Delta Kappan, 84(9), 679-686.

McClure, P., Wiener, R., Roza, M., \& Hill, M. (2008). Ensuring equal opportunity in public education. Retrieved from http://www.americanprogress.org/issues/ 2008/06/comparability.html

McKeown. (1996). The effects of long-term vocabulary instruction on lexical access and reading comprehension. Journal of Educational Psychology ,15(1), 1-17.

McNeil, M. (2011, August 3). Are 82\% of schools failing under NCLB, as Duncan Warned? [Wed log post]. Retrieved from http://blogs.edweek.org/edweek/ campaign-k-12/2011/08/are_82_of_schools_failing_unde.htmlEducation Week.

Miles, M. B. (1990). New methods for qualitative data collection and analysis: Vignettes and pre-structured cases. International Journal of Qualitative Studies in Education, 3(1), 37-51.

Mills, G. E. (2000). Action research: A guide for the teacher. Upper Saddle River, NJ: Prentice-Hall, Inc. 
Mok, M., \& Flynn, M. (1996). School size and academic achievement in the HSC examination: is there a relationship? Issues in Educational Research, 6(1), 57.

Mok, M., \& Flynn, M. (1998). Effect of Catholic school culture on students' achievement in the higher school certificate examination: A multilevel path analysis. Educational Psychology, 18(4), 409-432.

Morris, C. C. (1997). A study of labeling narratives for self and cultural voices (Unpublished doctoral dissertation). George Mason University, Fairfax, VA.

Muhammad, A. (2009). Transforming school culture: How to overcome staff division. Bloomington, IN: Solution Tree Press.

Murphy, J., Smylie, M., Mayrowetz, D., \& Louis, K. (2009). The role of the principal in fostering the development of distributed leadership. School Leadership and Management, 29(2), 181-214.

Nieto, S. (2004). School reform and student learning: A multicultural perspective. Multicultural education: Issues and perspectives, 5, 401-420.

Nitko, A. J. (2001). Educational assessment of students. Des Moines, IA: Prentice-Hall.

Ogbu, J. U. (1982). Cultural discontinuities and schooling. Anthropology and Education Quarterly, 13(4), 290-307.

Orange County Department of Education. (2002). The No Child Left Behind Act. Costa Mesa, CA: Author. Retrieved from http://www.kings.k12.ca.us/ EdServices/SiteAssets/Categoricals/legalServicesHandbook.pdf

Oregon Data Project. (2013). Direct access to achievement: An integrated approach on how to use data to inform instruction. Retrieved from http://www.oregondataproject.org/

Oregon Department of Education. (2009). Oregon Title I: A program planning guide. Salem, OR: Author. Retrieved from http://www.ode.state.or.us/search/ page $/$ ?id $=1939$

Oregon Department of Education. (2010). Oregon Title I: A handbook. Retrieved from http://www.ode.state.or.us/search/page/?id=1939

Oregon Department of Education. (2012). Education achievement compact. Retrieved from http://www.oregon.gov/gov/oeib/docs/aafinalpreamble.pdf 
Oregon Department of Education. (2013). Priority, focus, and model schools guidance. Salem, OR: Office of Educational Improvement and Innovation.

Pankratz, R., \& Petrosko, J. (2000). All children can learn: Lessons from the Kentucky reform experience. San Francisco, CA: Jossey-Bass.

Peterson, K. D. (2002). At issue culture. Madison, WI: National Staff Development Council.

Peterson, K. D., \& Chenoweth, T. (1992). School teachers' control and involvement in their own evaluation. Journal of Personnel Evaluation in Education, 6(2), 177-190.

Peterson, K. D., \& Deal, T. (1998). How leadership influence the culture of schools. Educational Leadership, 56, 28-31.

Peterson, K. D., \& Deal, T. (2009). Shaping school culture fieldbook (2nd ed.). San Francisco, CA: Jossey-Bass.

Peterson, M. W., \& Dill, D. D. (1999). Understanding the competitive environment of postsecondary knowledge industry. In. M. W. Peterson, D. D. Dill, \& Associates (Eds.). Planning and management for changing environment: A handbook on redesigning postsecondary institutions (pp. 3-29). San Francisco, CA: JosseyBass.

Popham, W. J. (1999). Classroom assessment: What teachers need to know. Needham Heights, MA: Allyn \& Bacon.

Portland State University. (2012). Human Subjects Research Review Committee policy. Retrieved from https://sites.google.com/a/pdx.edu/research/integrity/humansubjects/policy

Purkey, S., \& Smith, M. (1983). Effective schools: A review. The Elementary School Journal, 83(4), 427-452.

Raywid, M. A. (2001). What to do with students who are not succeeding. Phi Delta Kappan, 82(8), 582-584.

Reeves, D. B. (2004). Accountability in action: A blueprint for learning organizations. Englewood, CO: Advanced Learning Press.

Renchler, R. (1992). Student motivation, school culture and academic achievement: What school leaders can do. Eugene, OR University of Oregon ERIC Clearinghouse on Educational Management. 
Sarason, S. B. (1990). The predictable failure of educational reform: Can we change course before it's too late? San Francisco, CA: Jossey-Bass.

Sargent, J. K. W. (2001). Data retreat facilitator's guide. Naperville, IL: North Central Regional Educational Laboratory.

Schmoker, M. (1999). Results: The key to continuous school improvement (2nd ed.). Alexandria, VA: Association for Supervision and Curriculum Development.

Schweiker-Marra, K. E. (1995). Examining the relationship between school culture and teacher change. Paper presented at the annual meeting of the Eastern Educational Research Association, Hilton Head, SC.

Sergiovanni, T. J., \& Starratt, R. J. (1998). Supervision: A redefinition. Boston, MA: McGraw-Hill.

Shank, G. D. (2002). Qualitative research: A personal skills approach. Upper Saddle River, NJ: Prentice Hall.

Sitkin, S. B. (2010). Sense-making in organizational research. In C. Bird Schoonhoven \& F. Dobbin (Eds.), Stanford's organization theory renaissance, 1970-2000 (pp. 409-418). Bingley, West Yorkshire, United Kingdom: Emerald Group.

Sitkin, S.B., Lind, E. A., \& Siang, S. (2006). Six domains of leadership. Leader to Leader, Special Supplement, 27-33.

Slavin, R.E. (2009). Cooperative learning. In G. McCulloch \& D. Crook (Eds.). International encyclopedia of education (pp. 161-178 ). Abington. United Kingdom: Routledge.

Snow, C. E., Burns, S. M., \& Griffin, P. (Eds.). (1998). Preventing reading difficulties in young children. Washington, DC: National Academy Press.

Spillane, J. P., \& Louis, K. S. (2002). School improvement processes and practices: Professional learning for building instructional capacity. Yearbook of the National Society for the Study of Education, 101(1), 83-104.

Spindler, G., \& Spindler, L. (1994). Pathways to cultural awareness: Cultural therapy with teachers and students. Thousand Oaks, CA: Corwin.

Stefkovich, J. A., \& O'Brien, G. M. (2004). Best interests of the student: An ethical model. Journal of Educational Administration, 42(2), 197-214. 
Stolp, S., \& Smith, S. C. (1994). School culture and climate: The role of the leader. Eugene, OR: University of Oregon ERIC Clearinghouse on Educational Management.

Stringer, E. (2004). Action research in education. Upper Saddle River, NJ: Pearson Education.

Sunderman, G. L., \& Mickelsen, H. (2000). Implementing Title I schoolwide programs in a complex policy environment: Integrating standards and school reform in the Chicago Public Schools. The Journal of Negro Education, 69(4), 361-374. doi:10.2307/2696251

U.S. Department of Education. (1996). Mapping out the assessment of Title I: The interim report. Washington, DC: Author.

U.S. Department of Education. (2004, September 15). Title I: Improving the academic achievement of the disadvantaged. Retrieved from www2.ed.gov/legislation/ESEA02/pg1.html

U.S. General Accounting Office. (2000). Title I program: Stronger accountability needed for performance of disadvantaged students. Washington, DC: Author.

Varenne, H., \& Mcdermott, R. (1999). Successful failure: The school America builds. Boulder, CO: Westview Press.

Wagener, C. R., \& Hall-O’Phelan, M. (1998). Improving schools through the administration and analysis of school culture audits. Florida Journal of Educational Administration, 21, 13-25.

Wargo, M. J. (1972). ESEA Title I: A reanalysis and synthesis of evaluation data from fiscal year 1965 through 1970-Final report. Washington, DC: Department of Health, Education and Welfare Office of Program Planning and Evaluation.

Wheatley, M., \& Kellner-Rogers, M. (1996). A simpler way. San Francisco, CA: BerrettKoehler Publishers.

Wiggins, G. (1998). Educative assessment: Designing assessments to inform and improve student performance. San Francisco, CA: Jossey-Bass.

Wolcott, H. F. (1973). The man in the principal's office. Walnut Creek, CA: AltaMira Press. 
Wong, K. (2003). Federal Title I as a reform strategy in urban schools. In. L. F. Miron \& E. P. St. John (Eds.), Reinterpreting urban school reform: Have urban schools failed, or has the reform movement failed urban schools (pp. 55-76). Albany, NY: State University of New York Press.

Wong, K., \& Meyer, S. (1998). Title I schoolwide programs: A synthesis of findings from recent evaluation. Educational Evaluation and Policy Analysis, 20(2), $115-$ 136. 


\section{APPENDIX}

HANDBOOK: MOVING TO A SCHOOLWIDE TITLE I PROGRAM 


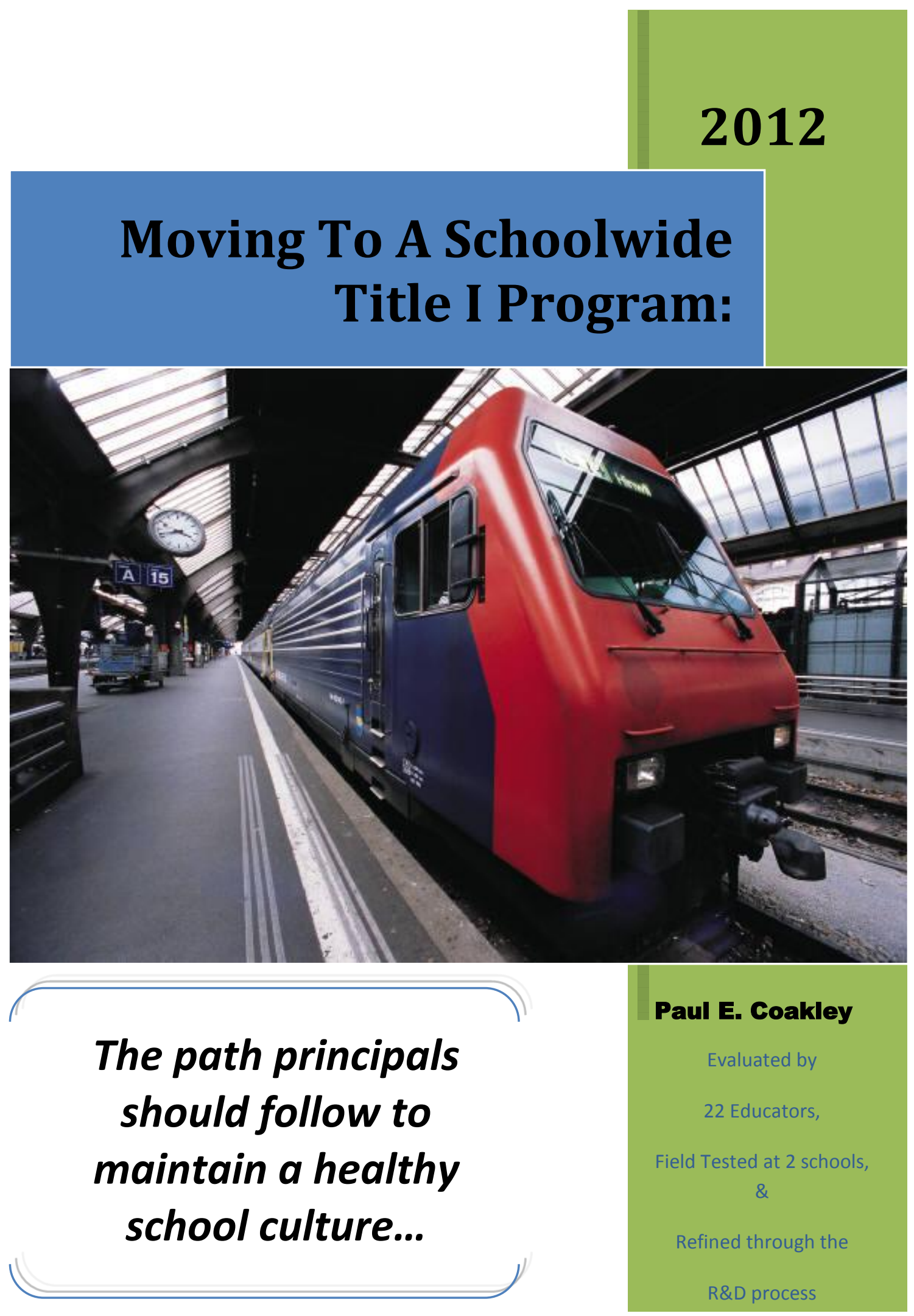




\section{MOVING TO A SCHOOLWIDE TITLE I PROGRAM: What Principals} should know to maintain a healthy school culture

(C) 2012 Paul Coakley, Portland, OR

All rights reserved. No part of this handbook may be reproduced or transmitted in any form or by any means without written permission from the author. 
"Your school will find that sustaining change involves sustaining the energy and commitment of school veterans as well as bringing new people into the culture of change."

(Chenoweth \& Everhart, 2002) 


\section{This handbook is dedicated to the students we serve in Title I schools across the United States. As an educational leader I am devoted to improving the system; in hope of schools providing a quality educational experience for all students regardless of race, gender or socioeconomic status.}

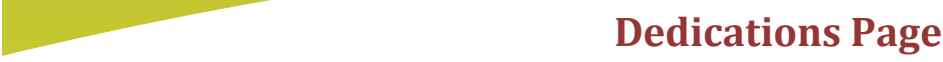

I dedicate this handbook to students of all backgrounds who attend Title I

schools across the US, and the educators who work tirelessly each day to provide a quality education for the students that they serve. Moreover, I dedicate this work to the educators who have enriched my research by sharing their stories, strategies, expertise, and experiences. Your passion, commitment, and leadership are embodied in these words from John F. Kennedy:

"Let us think of education as the means of developing our greatest abilities, because in each of us there is a private hope and dream which, fulfilled, can be translated into benefit for everyone and greater strength of the nation."

-- John F. Kennedy

This dissertation is also dedicated to my daughter, Azaria, and my son, Paul Jr. Azaria, you can do anything that you put your mind to. I am proud of the person that you are growing to be. Keep up your work ethic, positive attitude, and drive to never give up. You are a superstar! Paul, I want you to know that every time I thought about giving up on this process, I looked at you and changed my mind. You can do anything, be anything, and achieve anything that you want. Set your goals high and don't let anyone tell you that you can't! One day you will surpass all that I have ever accomplished. I love you both with all my heart. 


\section{Table of Contents}

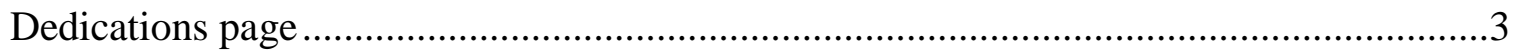

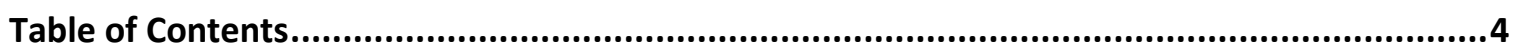

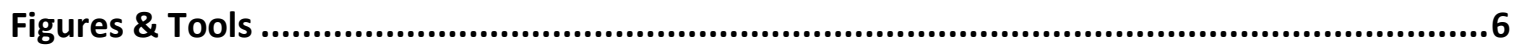

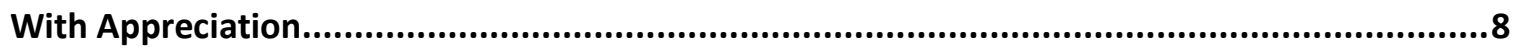

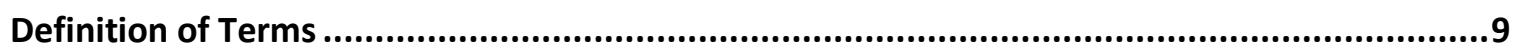

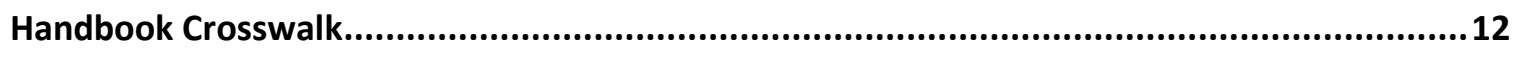

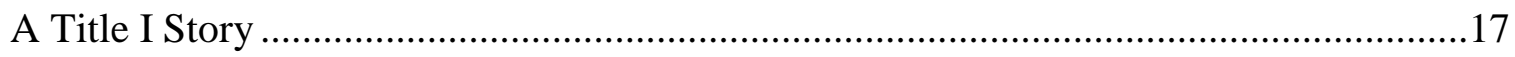

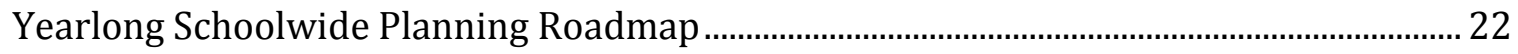

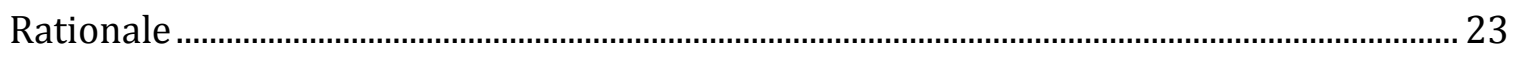

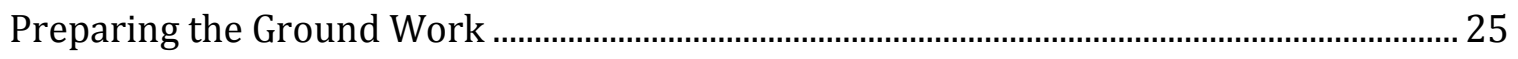

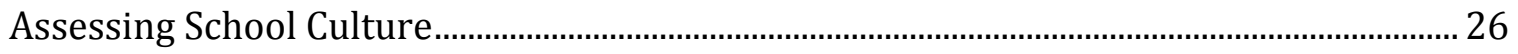

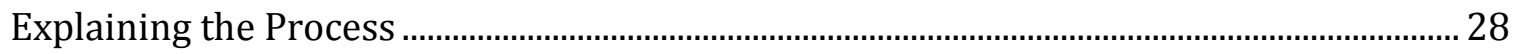

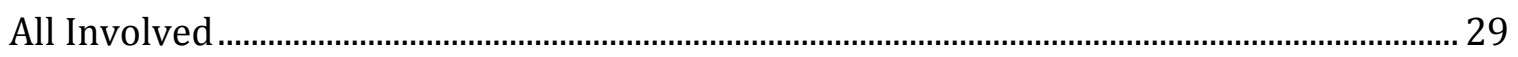

Thinking Outside the Box.......................................................................................................... 30

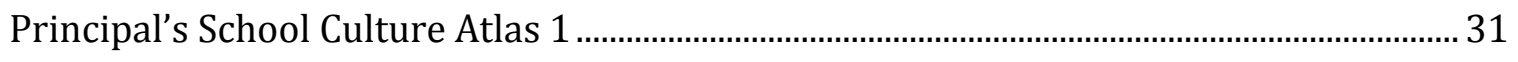

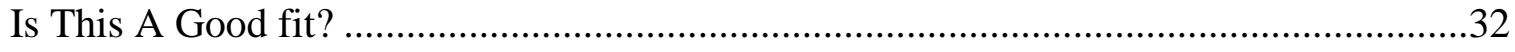

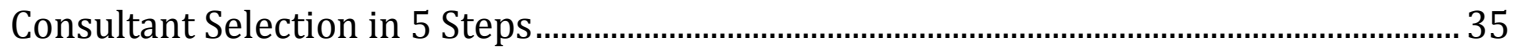

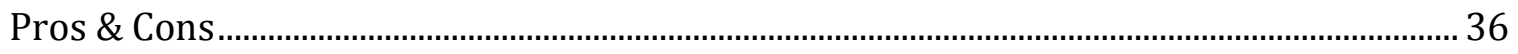

Principal's School Culture Atlas 2 …………………………………………………………. 37

Select Your Team, Identify Your Needs........................................................................38

The Selection Process ……………………………………………………………………………... 38

Components of a High Functioning Team ……………………………………………….... 40

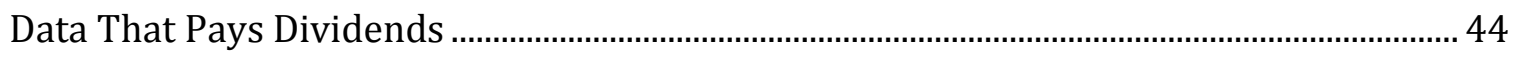




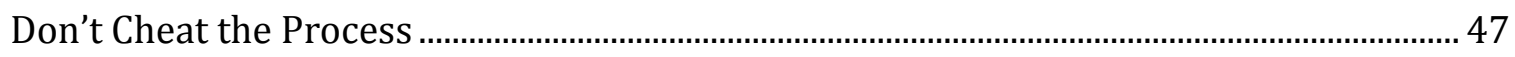

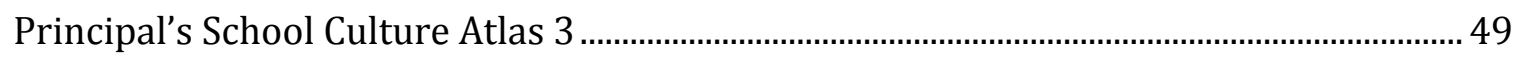

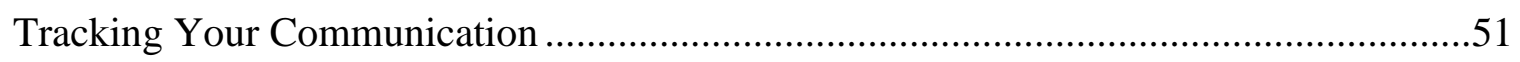

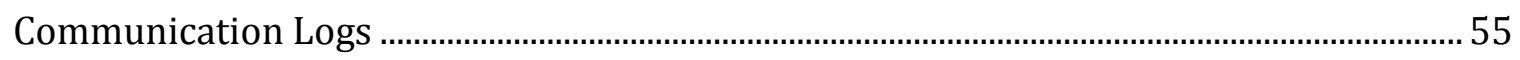

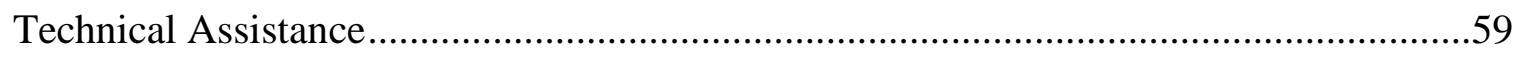

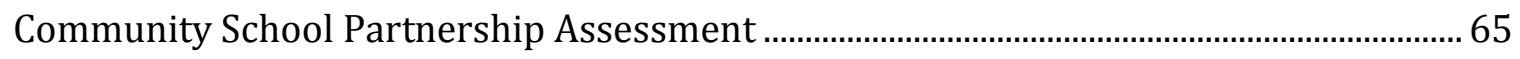

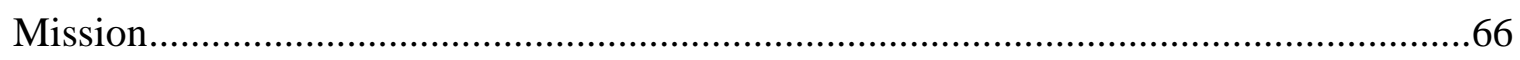

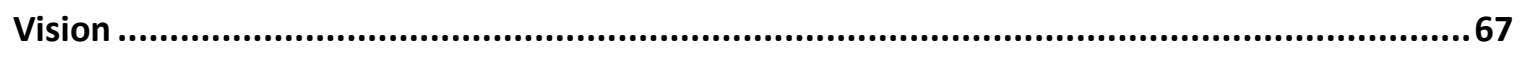

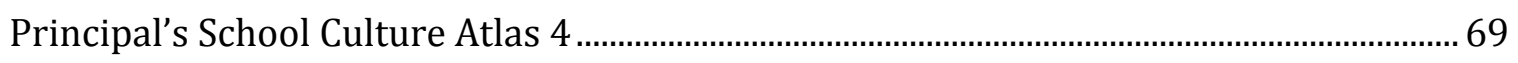

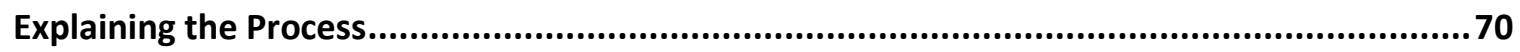

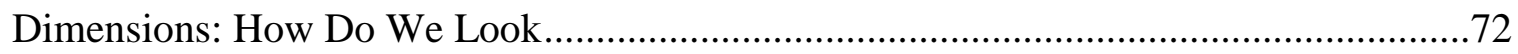

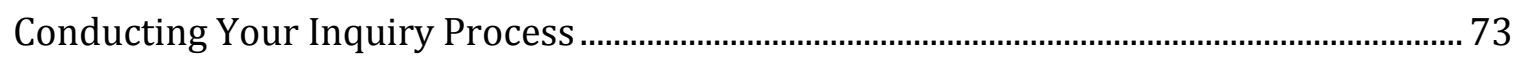

Site Visits to Benefit Your Plan............................................................................................. 75

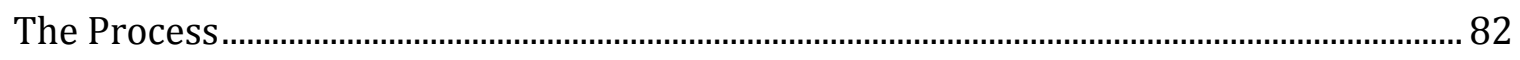

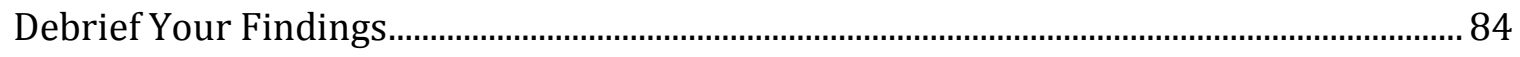

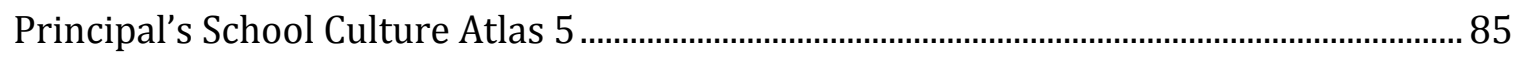

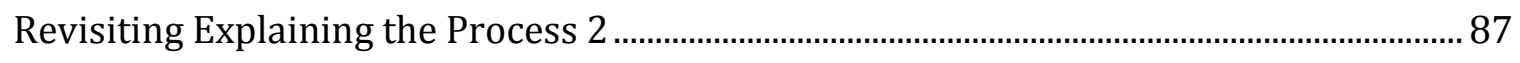

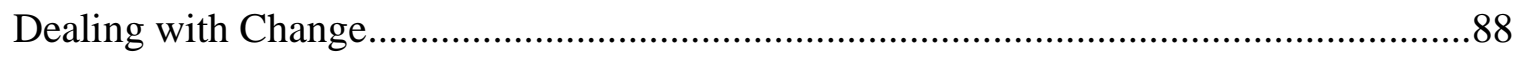

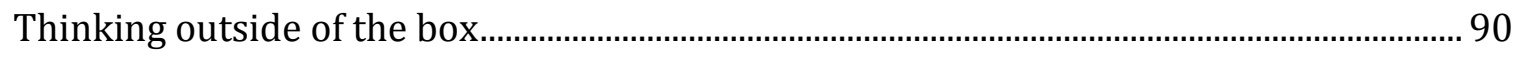

Resistance to Change Quick Reference Guide ......................................................................... 92

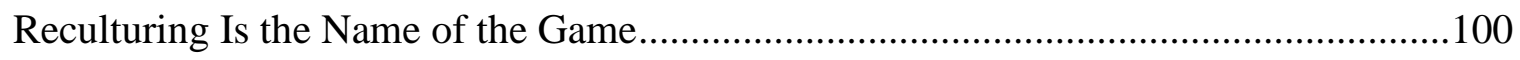

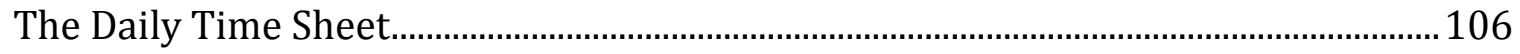

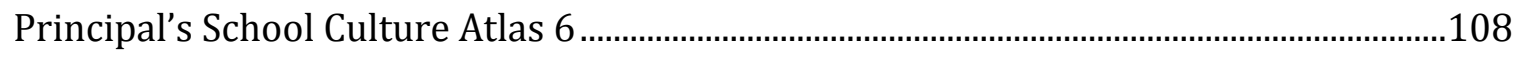

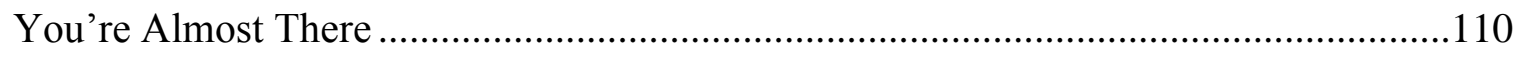

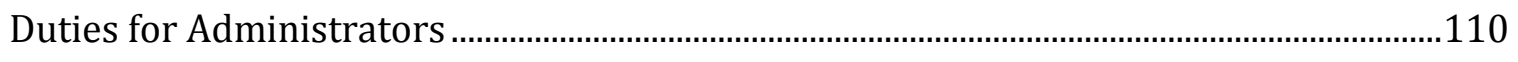

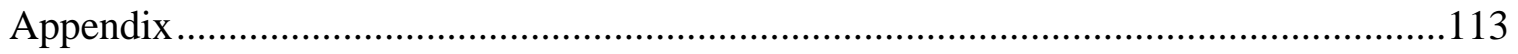

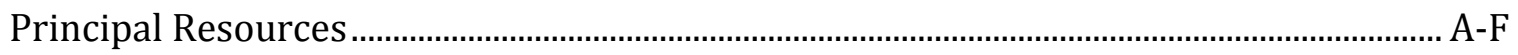




\section{Figures \& Tools}

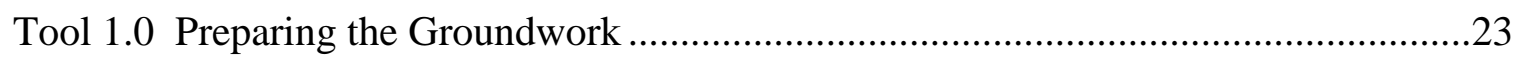

Tool 1.5 Assessing Your School Culture...............................................................27

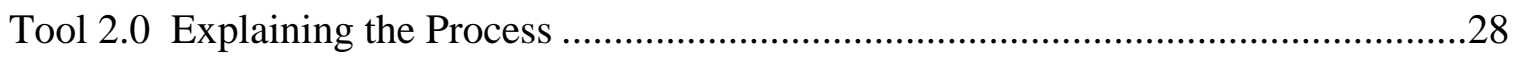

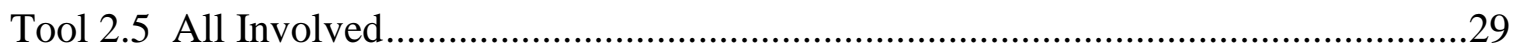

Figure 1.1 Consultant 5 Step Selection........................................................................

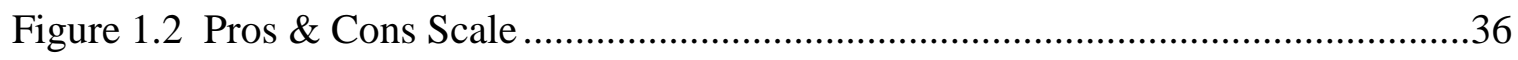

Tool 3.0 Team Construction ....................................................................................40

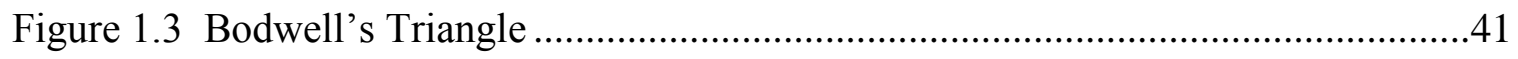

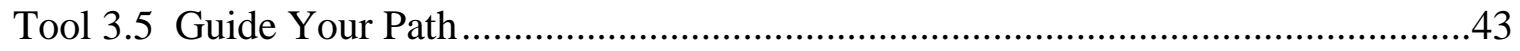

Figure 1.4 Collection \& Analysis Checklist ................................................................46

Tool 4.0 Cultural Community Involvement Map ………................................................53

Tool 4.5 Cultural Assessment of School Community Notepad.........................................64

Figure 1.5 School Constituencies Loop ………………….........................................70

Tool 5.0 School Compact Builder ……………………….......................................

Tool 5.5 Strength \& Weakness Plot..........................................................................

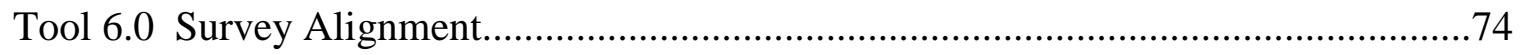

Tool 6.5 (a),(b),(c) Site Visit Tour Guide .............................................................. 77-79

Figure 1.6 Interview \& Focus Group Schedule ………………………………............83

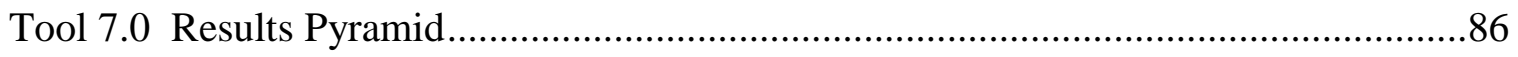

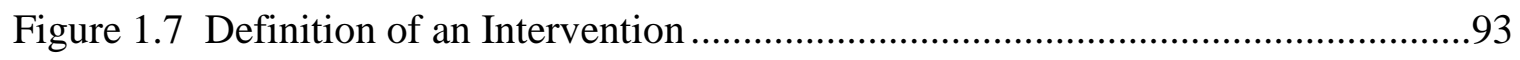


Figure 1.8 Creating a Context Supportive of Change .....................................................94

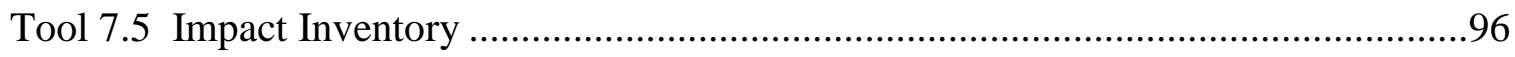

Tool 8.0 Standards Based Curriculum \& Culture ...........................................................98

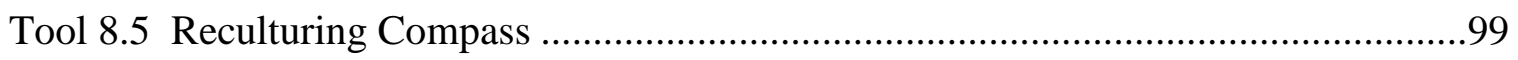

Tool 9.0 Services Scavenger Hunt ....................................................................102

Tool 9.5 Parallel Professional Development \& Priority Needs .........................................103

Tool 10.0 Brainstorming the Transition Process ………................................................104

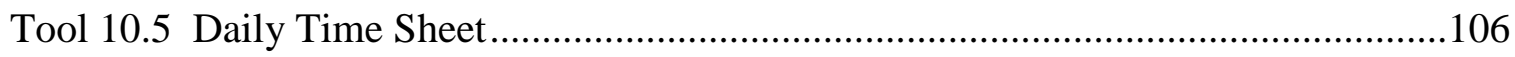

Tool 11.0 Accountability Matrix ………………………..........................................107

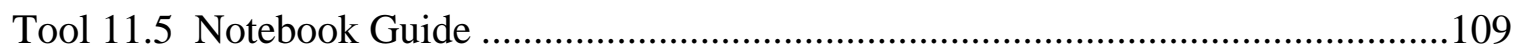




\section{With Appreciation}

Tool 1.5, p. 27: Adapted from Phillips, G \& Wagner C. (2003). School Culture

Assessment. Vancouver, B.C: Mitchell Press, Agent 5 Design.

Figure 1.1, p. 35: Adapted from McCollom Environmental Management Services (2000).

Steps to choosing the right consultant for your services.

Tool 3.0, p. 40: Adapted from Jackson, B. (2005). Common factors of High Performance

Teams. Orem, Utah, Utah Valley State

Figure 1.3, p. 41, Tool 7.0, p.86: Adapted from Howard, R \& Sugai, G. (2007). PBIS

triangles. Cedar

Falls. Area Education Agency.

Figure 1.4, p. 46 Tool 3.5, p. 43, Tool 5.5 p. 72 Tool 9.5 p.103, Tool 11.0 p. 107:

Adapted from Oregon Department of Education. (2009). Oregon Title I-A

Program planning guide.

Tool 6.5, (a), (b), (c), p. 77-79, Tool 8.5 p. 99: Adapted with permission from

Chenoweth, T. \& Everhart, R. Education. (2002). Navigating Comprehensive School

Change: A guide for the perplexed. Eye on Education, Larchmont, NY

Figure 1.5, p. 70 Adapted with permission from LeBlanc, G. (2011). Educational

Consultant

Figure 1.6, p. 83, Tool 7.5, p. 96, Adapted with permission from Kash, L. (2010).

Educational Consultant, Special Education Services. Oregon 


\section{Definition of Terms}

For the purpose of this study, the following terms are defined.

Adequate Yearly Progress (AYP). AYP is an individual state's measure of progress toward the goal of students achieving to state academic standards in at least reading/language arts and math.

Culture. For the purpose of this applied dissertation, the word culture is used to address "school culture." In the context of this paper, school culture is defined as the underlying norms, beliefs, values, and customs that make up the way the staff members, parents, community members, and students feel, act, and behave within an institution.

School Reform/Change. School reform can be defined as the use of a comprehensive, unified school design to transform all aspects of a school in an effort to improve the performance of each of its students (i.e., the act, process, or result of altering or modifying programs, structures and norms in the context of a school setting).

Target-Assistance School Program (TASP). TASP defines a school that receives Title I, Part A funds, yet is ineligible or has chosen not to operate a SWP, and provides supplemental educational services to eligible children identified as having the greatest need for special assistance. 
Schoolwide Program (SWP). SWP is a comprehensive reform model used to upgrade the entire educational program in a Title I school, and it has the primary goal of ensuring that all students, particularly those who are low-achieving, demonstrate at least proficient levels of achievement of the Oregon State Standards.

Pull-out support. A Pull-out program is one in which students are taken out of their regular classroom and provided instruction in a smaller group setting.

Push-in support. A Push-in program is one in which educational support staff go into the regular classroom setting to provide small group intervention support that complements what is being learned in the classroom.

Implementation process. This term refers to the stage in the research process during which recommendations are put into practice. Implementation is the use of strategies to adopt interventions and change practice patterns within specific settings.

Problem-Based Learning (PBL). Problem-Based Learning defines environments where students may act as professionals and confront problems as they occur; problems with fuzzy edges, insufficient information, and a need to determine the best solution possible by a given date. This is the manner in which engineers, doctors, and, yes, even teachers, may approach problem solving, unlike many classrooms where teachers are the "sage on the stage." Using the PBL method students may be guided to interesting solutions to designated problems. 
Research and Development (R\&D). $R \& D$ defines the process of discovering new knowledge about products, processes, and services, and then applying that knowledge to create new and improved products, processes, and services that fill market needs.

School constituents. This term refers to all residents of the school community or district as well as all school affiliates including, parents, students, and staff members.

Free-and-Reduced. This term reflects the percentage of K-12 public school children enrolled in the Free or Reduced Price Meal Program at school. A child's family income must fall below $185 \%$ of the Federal Poverty Level (or $\$ 37,000$ for a family of four in 2006) to qualify for reduced-cost meals, or below $130 \%$ of the Federal Poverty Level $(\$ 26,000$ for a family of four in 2006) to qualify for free meals. Not all eligible children are enrolled in the program, so these numbers do not reflect all low-income school-age children. 


\section{Handbook Crosswalk}

Handbook: Moving To A Schoolwide Title I Program:

What Principals should know to maintain a healthy school culture

Crosswalk in Comparison to: Oregon Title I-A Schoolwide Program Plan Grant

\begin{tabular}{|c|c|c|}
\hline $\begin{array}{l}\text { Oregon Schoolwide } \\
\text { Program Plan Grant } \\
\text { Stages: }\end{array}$ & $\begin{array}{l}\text { Moving To A Schoolwide } \\
\text { Title I Program Handbook } \\
\text { Topics: }\end{array}$ & $\begin{array}{l}\text { Moving To A Schoolwide } \\
\text { Title I Program, School } \\
\text { Culture Components } \\
\text { Tools: }\end{array}$ \\
\hline Planning & August- September & Determine Your Readiness \\
\hline \multirow[t]{5}{*}{ A. Planning Team } & A Title I Story & \\
\hline & $\begin{array}{l}\text { Yearlong Schoolwide Planning } \\
\text { Roadmap, Sept-June }\end{array}$ & \begin{tabular}{|l|} 
Tool 1.5 Assessing Your School \\
Culture \\
- \\
$\begin{array}{l}\text { A one page tool with guiding } \\
\text { questions to assess the culture } \\
\text { of your building }\end{array}$ \\
\end{tabular} \\
\hline & Highly Qualified Staff & $\begin{array}{l}\text { Principal's Attestation Form } \\
\text { (located in Appendix) } \\
\text { - A form that assures all staff are } \\
\text { highly qualified or on a plan to } \\
\text { become Highly Qualified } \\
\text { status. }\end{array}$ \\
\hline & $\begin{array}{l}\text { Is this a good fit?: guidance on } \\
\text { whether or not to elicit a } \\
\text { consultant }\end{array}$ & \begin{tabular}{|l} 
Thinking outside the box \\
- A one page tool with guiding \\
questions geared toward \\
dealing proactively with \\
opposition
\end{tabular} \\
\hline & $\begin{array}{l}\text { The Selection Process: guidance } \\
\text { in planning team selection }\end{array}$ & \begin{tabular}{|c|} 
Tool 3.0 Team Construction \\
- $\quad \begin{array}{l}\text { A one page tool to guide the } \\
\text { principal in building a high } \\
\text { performing SWP team }\end{array}$ \\
\end{tabular} \\
\hline $\begin{array}{l}\text { B. Schoolwide Planning } \\
\text { Summary }\end{array}$ & $\begin{array}{l}\text { Using the Yearlong Roadmap to } \\
\text { Plan Your Path }\end{array}$ & \begin{tabular}{|l|} 
Tool 3.5 Guide Your Path \\
- A two page tool used to set a \\
$\begin{array}{l}\text { yearlong meeting schedule } \\
\text { taking all school constituents } \\
\text { into account }\end{array}$ \\
\end{tabular} \\
\hline C. Communication & Collection \& Analysis Checklist & \\
\hline
\end{tabular}




\begin{tabular}{|c|c|c|}
\hline & What does the data tell us? & 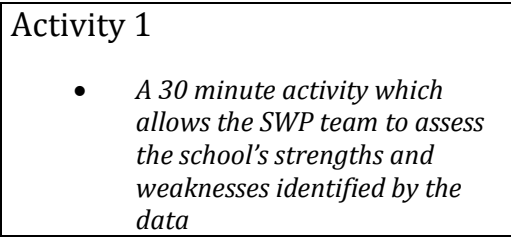 \\
\hline & Tracking your communication & $\begin{array}{l}\text { Tool 4.0 Cultural Community } \\
\text { Involvement Map } \\
\text { • A map to assist leaders in } \\
\text { involving all school } \\
\text { constituency throughout the } \\
\text { year }\end{array}$ \\
\hline & Parent Involvement & \begin{tabular}{|l} 
Communication logs \\
- \\
Recording sheets to assist in \\
proving documentation of \\
meeting dates, agenda topics, \\
participants and meeting \\
outcomes for staff, parents, and \\
school community \\
\end{tabular} \\
\hline D. Technical Assistance & $\begin{array}{l}\text { High Quality Technical } \\
\text { Assistance }\end{array}$ & \\
\hline $\begin{array}{l}\text { Comprehensive Needs } \\
\text { Assessment }\end{array}$ & October-November & Conduct Your Assessments \\
\hline \multirow[t]{4}{*}{ Six grant questions } & Your School Community & \begin{tabular}{|} 
Tool 4.5 Cultural Assessment of \\
the School Community Notepad \\
- A tool that provides critical \\
guiding questions to assist \\
teams in creating a writing \\
description of their school \\
community
\end{tabular} \\
\hline & Mission \& Vision & 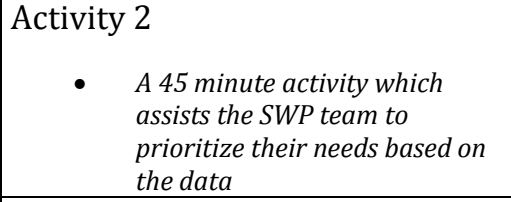 \\
\hline & Explaining the process & \\
\hline & School Compact & \begin{tabular}{|l} 
Tool 5.0 School Compact Builder \\
- $\quad$ This tool is used to assist Site \\
Councils, PTA's and Community \\
members in constructing a \\
school agreement compact that \\
enhances the school culture
\end{tabular} \\
\hline Five key dimensions & Dimensions: how do we look? & $\begin{array}{l}\text { Tool 5.5 Strengths \& Weaknesses } \\
\text { Plot } \\
\text { - A one page tool to assist the } \\
\text { SWP team in analyzing the data } \\
\text { through } 5 \text { key dimensions }\end{array}$ \\
\hline
\end{tabular}




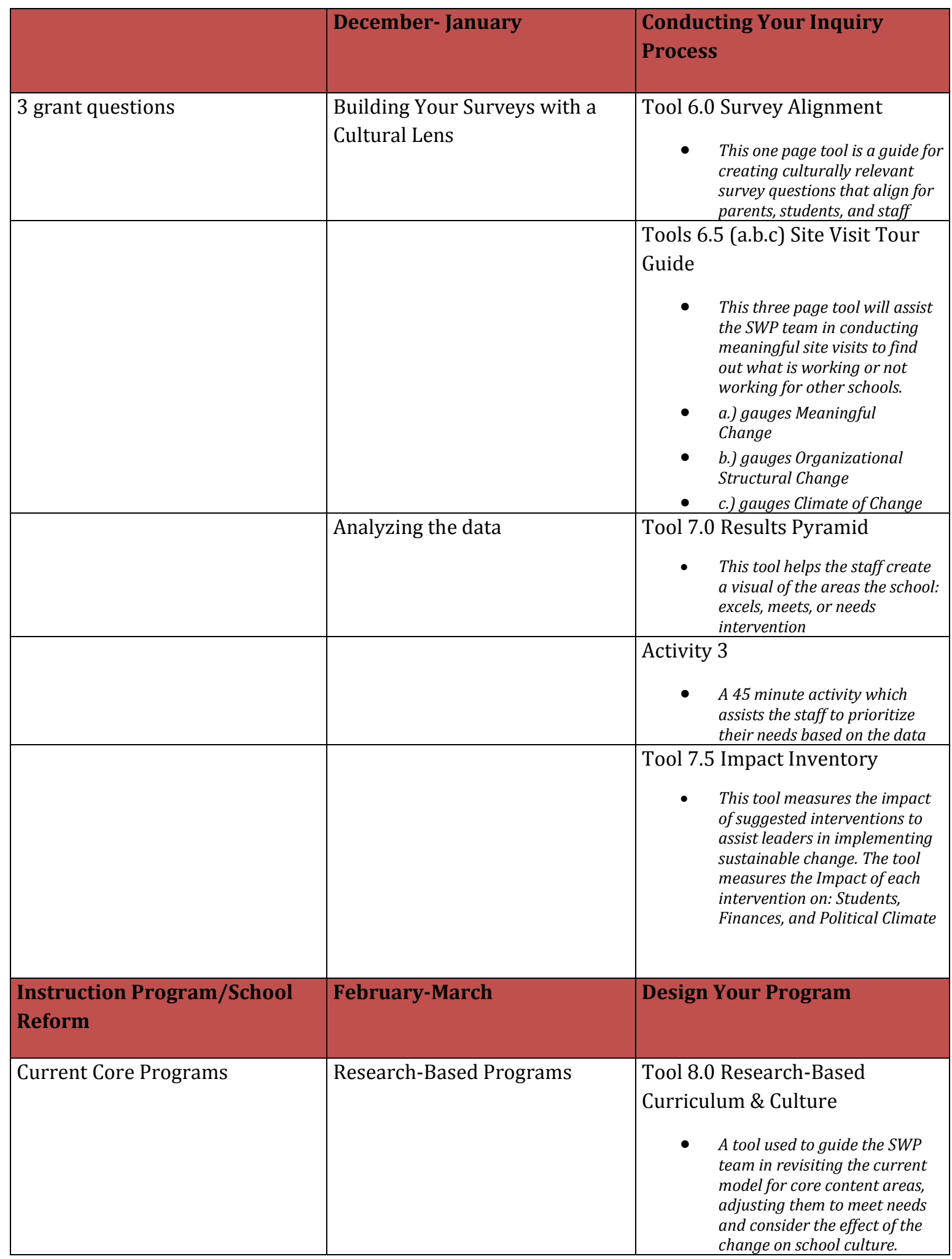




\begin{tabular}{|c|c|c|}
\hline & Transparent approach to change & \begin{tabular}{|l} 
Tool 8.5 Reculturing Compass \\
• \\
$\begin{array}{l}\text { This tool engages school } \\
\text { constituency in a conversation } \\
\text { that openly addresses the fear } \\
\text { of change }\end{array}$ \\
\end{tabular} \\
\hline \multirow[t]{3}{*}{ Student Assessment Chart } & $\begin{array}{l}\text { Assessment \& Universal } \\
\text { Screeners }\end{array}$ & 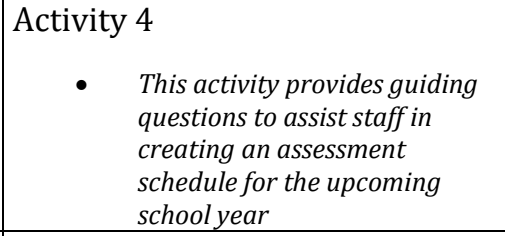 \\
\hline & Data Team \& PLC’s & \\
\hline & Meeting the needs of all & \begin{tabular}{|l} 
Tool 9.0 Services Scavenger Hunt \\
- \\
This tool assists in finding \\
strengths and weaknesses in \\
the school's ability to serve \\
struggling learners, Special \\
education students, ELL, Tag, \\
and Homeless students
\end{tabular} \\
\hline Professional Development & April & Getting down to writing \\
\hline \multirow[t]{2}{*}{3 grant questions } & Professional Development & \begin{tabular}{|l} 
Tool 9.5 Parallel Professional \\
Development \& Priority Needs \\
- $\begin{array}{l}\text { This tool is to assist the school } \\
\text { in aligning their professional } \\
\text { development to their school's } \\
\text { priority areas }\end{array}$ \\
\end{tabular} \\
\hline & Save time with Google Docs & \\
\hline Highly Qualified Staff & April & $\begin{array}{l}\text { Principal Attestation Form } \\
\text { (located in Appendix) }\end{array}$ \\
\hline \multirow[t]{2}{*}{$\begin{array}{l}\text { Family \& Community } \\
\text { Involvement Strategies }\end{array}$} & $\begin{array}{l}\text { Look back at what you have } \\
\text { done }\end{array}$ & \\
\hline & $\begin{array}{l}\text { Getting the right people on the } \\
\text { bus }\end{array}$ & \\
\hline $\begin{array}{l}\text { Transition Strategies for } \\
\text { Students }\end{array}$ & April & Ensure a smooth Transition \\
\hline
\end{tabular}




\begin{tabular}{|c|c|c|}
\hline Three grant questions & & $\begin{array}{l}\text { Tool 10.0 Brainstorm The } \\
\text { Transition Process } \\
\text { - } \begin{array}{l}\text { The tool guides teams in } \\
\text { creating a list of actions that } \\
\text { are currently in place for } \\
\text { students transitioning to } \\
\text { another grade level. }\end{array} \\
\end{array}$ \\
\hline $\begin{array}{l}\text { Coordination \& Integration of } \\
\text { Services \& Programs }\end{array}$ & May & Plan Your Actions \\
\hline \multirow[t]{4}{*}{ Two grant questions } & Question Analysis and examples & \\
\hline & Action Plan & Smart Goal Examples \\
\hline & Sharing The Plan & 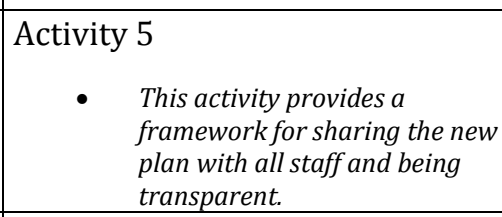 \\
\hline & Staff Vote & \\
\hline $\begin{array}{l}\text { Ongoing Plan to Monitor } \\
\text { Effectiveness of the } \\
\text { Schoolwide Plan }\end{array}$ & May & Monitor Your Progress \\
\hline Ten questions & Progress Monitoring & Tool 11.0 Accountability Matrix \\
\hline \multirow[t]{5}{*}{ Fiscal Coordination } & Revisit Fiscal Planning & Review Tool 6, addressed in Dec. \\
\hline & Create your notebooks & Tool 11.5 Notebook Guide \\
\hline & District Review & (Forms located in appendix) \\
\hline & June & Submit Your Plan \\
\hline & District Review & (Forms located in appendix) \\
\hline
\end{tabular}




\section{A Title I Story}

\section{"If principals dream of a time when they no longer will have to face such disparate expectations as those which seem to pervade their professional lives, they do so because the dream itself affords some comfort rather than because they believe such a day could ever be a reality." (Walcott, 2003)}

Title I is the largest federal education-funding program. It provides funding for high poverty schools in the U.S. to provide support for students who are falling below grade level academically or are at risk of falling behind. Title I schools provide programs that support mathematics and literacy. The following scenario, designed to help illustrate a typical conversation about Title I services, takes place in the office of a small elementary school.

A principal of a Title I elementary School sits down with his Title I literacy and math teachers; the goal of the meeting is for the principal to gather information regarding the details of the program for the current school year. How many students are being served for math and literacy? How much seat time do the students receive per week? How is the Title I instruction supporting the work that is being done in the general classroom setting? "So you are only providing math support for nine, thirdgrade students for thirty minutes each day?" The principal pauses and sits, quiet and frustrated. Then he speaks, "We have over thirty students who qualify for services according to our first-round assessments. You have got to serve more students," he says intently while staring at both teachers. The teachers in turn, acknowledge that they would like to serve more students. Both teachers express that they are trying to provide quality instruction to small groups through pullout support at each grade level, but due to block scheduling and other programs that encompass the school day, it is extremely difficult to serve more students. The principal makes his declaration, "I am requiring you to serve a minimum of twenty students per grade level; this is now your first priority." Then looking at the third grade math assessment results, he quickly identifies eleven more students for the Title I math teacher to add to her caseload. Although the meeting continued for another thirty minutes, and as the principal received the rest of the disappointing information that he set out to gain, the conversation fell flat. The teachers began reporting instead of discussing, saying just enough to not incriminate themselves. In leaving the meeting, one of the teachers says to her colleague, within earshot of the principal, "Our groups are going to be as large as some classrooms. Is that what Title I is supposed to be?"

A few months later, the school celebrates the addition of a computer lab, which was purchased with Title I funds. However, working under the Targeted Assistance model, the lab can only be used by Title I teachers and the students who are being served under the Title I program. Of course, with the lab being new, it creates a buzz among the staff and students around the building. Thirty shiny black monitors, pristine tables and bright colored chairs, plus a Smartboard are waiting for Title I use. Although there is a computer lab for all to use, with the same equipment, the contemporary "Title lab" makes the lab, which was created for all students just two years prior, look like old news. The principal spends an inordinate amount of time with his staff explaining that the funds used to purchase the Title lab restrict the lab use to Title I students and staff only. However, it would allow the struggling Title I students access to support programs that would tailor instruction to meet each student's needs and focus on building their skills on the standards that they were most at risk of failing. Ultimately, this would help them make gains which would also help them in the general classroom, creating a win-win for everyone. 
A few teachers spoke positively about the new lab, expressing excitement for the students in their rooms who were in the Title I program who will benefit from the new technology, using it to become more fluent in literacy and grounded in mathematics. Of course, every school has people who struggle to see what is best for all students due to the fact that they can't see past their own classrooms or sometimes past themselves. "How does this affect me? Why purchase a lab that can't be used by everyone? This doesn't seem fair?" This school was no different. A few staff members rolled their eyes, mumbling to one another after the meeting with flabbergasted looks on their faces, as if the words coming out of the principal's mouth during the meeting were so offensive that they were literally left in dismay by his attempt to improve the school's Title I program.

In the next few days, that small group of negative grumblers began to spread their message of disapproval to any ear that would listen. In the meantime, the Title I program was off to a decent start, the teachers were serving at least 20 students per grade level in their pullout support groups working with the students in groups of ten, while the other students worked on computers, using standards-based instructional programs like Khan Academy or Study Island to develop test preparation skills that support student learning $K-12$. The parents seemed excited about the lab as well; many would grab a visitor's pass and rush to take a look. Because the school is located in an area of high poverty, they were pleasantly surprised by the change, commenting to the principal about the upbeat changes in the school. Of course, the students in the Title I program were ecstatic, which showed not only in their engagement, but also in their behavior, working to please their teachers and coming to Title class prepared and ready to learn.

One parent who volunteers regularly in the library was having a conversation with the school librarian. She happened to mention how nice it was that the school now had two computer labs and went on to talk about the programs, sharing how much they had helped her daughter to become excited about reading. The librarian smiled, and before she could comment, a third-grade teacher who happened to be standing next to the nonfiction bookshelf during her duty-free lunch said loud and sarcastically, "Yeah, it looks great. Too bad no one gets to use it!" This comment sparked several other conversations, one of which was held at the Parent Teacher Organization (PTO) meeting. A few supportive parents sent emails to the principal asking for more information and clarification on the use of the lab, and if it could be accessed by all students. A few parents sent complaint emails that questioned his judgment in terms of fairness and equity. Although the majority of parents did not voice their opinions, everyone had feelings on the matter, and would voice it to others in what they deemed safer surroundings.

What the school community didn't know was that at the end of the previous school year, the principal had met with educational advisors from the State Department of Education, who suggested that his school should think about transitioning from a Targeted-Assistance Title I program to a Schoolwide Title I program due to the increasing enrollment of students in the federal free-and-reduced lunch program, as well as the decrease in achievement on statewide assessments. In discussing today's economy and its effect on the job market, they quickly came to the realization that their school would continue to increase in the number of families and students who would be moving into the low-income housing that surrounded their school community, increasing the number of students on free-and-reduced lunch. The decision to move to a Schoolwide program seemed like a no-brainer to the principal, but he knew we would be 
met with resistance. Some staff members would have a difficult time accepting the change or seeing the benefit of restructuring the way they serve students. He had difficulty gaining buy-in from all staff members on decisions in the past, and knew that to win them over he needed to be more knowledgeable about the Schoolwide model. So, he spent the summer doing his homework, talking with principals of Schoolwide Title I programs, asking questions about the transition, attending workshops, and learning as much as he could about the differences between both programs and the benefit of one over the other. Based on his research, he was certain that a Schoolwide program would best serve his school which had reached the $40^{\text {th }}$ percentile for students receiving free-and-reduce lunch three years ago. He knew that it was time for a change; a large undertaking that would be met, both with opposition, questions, and excitement. When the doors opened on the first day of school, he needed a clear vision and an effective way to articulate that vision. He knew the direction he wanted his school to take in order to begin their journey. Unfortunately, his vision was not completely clear and sometimes foggy at best. How would he gain buy-in? When should he share the information with the staff? Had he waited until it was too late? School had only been in session a little over a month, yet the lack of information to staff and parents seemed to be negatively affecting the school's culture. How could he change the perception, minimize the gripes, whispers and eye rolling, and get everyone back on a positive track? What if others did not see the benefit of the change? How could he prove that it was a necessary change that would be beneficial to all students? He did not want the transition to feel top down. Yet, he did not want it to move too slowly either. What would he do with the Title I money that needed to be spent before the new school year to assist in improving the achievement of his Title I students? The new "Title I" lab, during the transition

year would only be accessed by Title I students, which on many levels

When making a
schoolwide
change, leaders
can assume that
they will
encounter their
share of obstacles,
roadblocks, and
pitfalls as well as
rewards,
triumphs, and
successes.

some guidance and support in getting the ball rolling in the right direction.

Unfortunately, this particular principal muddled through the process by selecting a Schoolwide planning team and holding monthly meetings. They made some decisions based on surveys and school data which led them to a few program and intervention ideas that they put in place to improve academic achievement. Ultimately, their Schoolwide plan was approved by the state, due to the fact that they completed the necessary documents required to make the transition. However, he was met with several barriers, opposition, and roadblocks throughout the yearlong transition. For example, some of the programs and intervention strategies that the 
planning team outlined in their Schoolwide plan were not put to use by all staff, due to the fact that they had little information about the new practice and had not bought-in to the change. The "Walk to Read" idea began with baby steps because many staff members were not on board, and voiced their negative perspectives on ability grouping. Instead of utilizing every staff member as he had hoped, he began with a portion of teachers who were excited about the idea, and hoped it would prove effective enough to spark the interest of the naysayers. Looking back on the process, he found that his key mistake was a misstep that he took with regard to the culture of the school. By waiting to openly share and discuss his vision with the staff, as well the reasons and data that guided his decision to look into a change of program in the first place, he unknowingly allowed hearsay, anxiety about job stability, and dissention to fester. Although he worked through these roadblocks and eventually gained buy-in from the staff's majority by providing more surveys, having open discussion during staff meetings, allowing the staff to assist in identifying the school's priorities and providing opportunities for members of his planning team to update the staff on the monthly meetings. Still, he was not able to get everyone on board. He realized that for a few members of his staff, that first misstep was all it took for them to take issue with the change, and he had somehow influenced their decision to keep a closedminded view of the process. Fortunately, the change led to a stronger Title I program that currently supports and serves more students. Unfortunately, he is still working to combat the naysayers who continually argue that the transition is more work for the same pay for the teachers.

This story shows us how important it is for school leaders to spend time gaining support from the large majority during a change process. The time that is spent building support fosters a positive school culture, which will impact the fidelity of the changes that are being made. Leaders, who briefly address issues and concerns by providing minimal communication, feedback and buy-in, foster a negative culture. These types of change efforts are met with opposition, sabotage, and in many cases, failure.

This case is typical of the Title I transition from Targeted-Assistance to Schoolwide. Principals end up taking their bumps and bruises as they struggle through this large change initiative. In some cases, the school will opt out of the transition and continue with the status quo because they do not want to rock the boat and damage the culture. For example, some principals are met with so much opposition that they begin to blame the transition process for the negative school environment; so, they decide that the best thing for their school is "consistency." Instead of completing the transition to a Schoolwide model, they update their Smart Goals and continue with their current Targeted-Assistance program. Sadly, the students are the ones who suffer in those cases. Schools continue to see gaps in achievement as they receive students who need support, but are not getting that support due to the structure of their Targeted-Assistance program.

This principal, like many others, has a heart for his students and hopes to create an environment that will meet the academic needs of all. As educational leaders, we are responsible for managing policies, regulations, and procedures to ensure that all students are provided a safe learning environment that meets state curriculum standards as well as the district's mission and the school's vision. It is our job to work collaboratively with parents, teachers, community members, administrators, and the local school board to provide a quality education for the students we serve. 
In our current economy, each year our schools are experiencing higher numbers of families falling into the low-income category, and numbers for students qualifying for free-andreduced lunch are rapidly increasing. The U.S. Department of Education strongly recommends that schools that have reached $40 \%$ free and reduced lunch serve their students through Title I's Schoolwide model (2009). In order to achieve these recommendations, school leaders must take their buildings through the yearlong planning process moving their buildings from a Targeted-Assistance program to a Schoolwide program. 


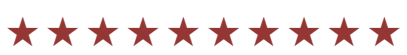

By the year 2025:

$40 \%$ of Oregonians will have a bachelor's degree or higher.

$40 \%$ will have an associate's degree or work related certification.

20\% will have a high school diploma

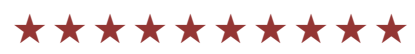

\section{Oregon's 40-40-20 Goal}

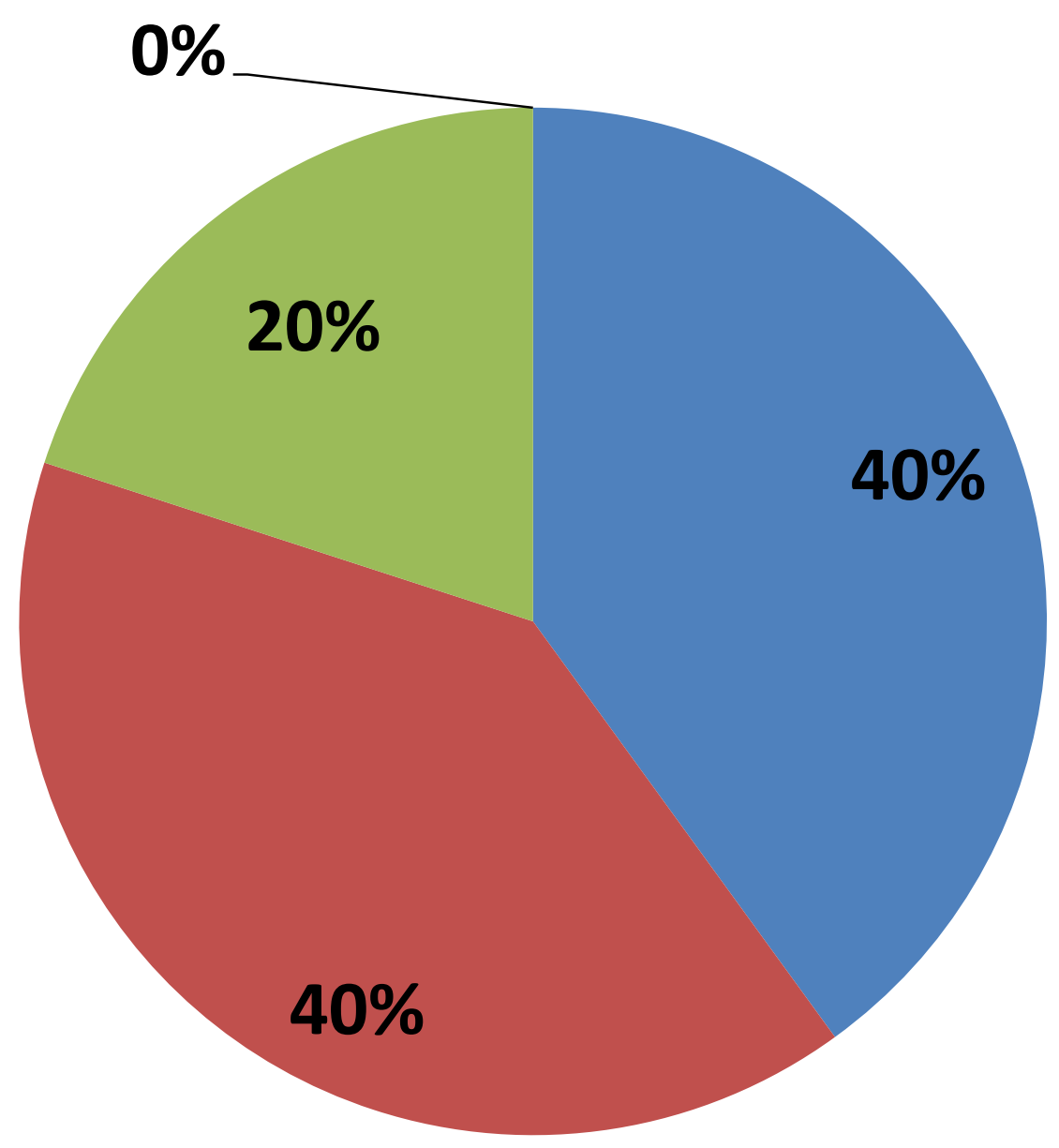




\section{YEARLONG SCHOOLWIDE PLANNING}

ROADMAP

This yearlong roadmap should be used to keep you on track with the key tasks that must be done throughout the school year, to complete the transition successfully.

\begin{tabular}{|c|c|}
\hline \multicolumn{2}{|c|}{ August - September - Determine Your Readiness } \\
\hline $\begin{array}{l}\text { Get feed back from your staff } \\
\text { Review the Schoolwide Plan and Handbook }\end{array}$ & $\begin{array}{r}\text { Share information will all constituents } \\
\text { Complete Tools } 1.0-3.0\end{array}$ \\
\hline \multicolumn{2}{|c|}{ October - November - Conduct Needs Assessment } \\
\hline $\begin{array}{l}\text { Collect Data on Five Key Dimensions } \\
\text { Be Transparent, gain staff support \& buy in }\end{array}$ & $\begin{array}{r}\text { Analyze the data and share results } \\
\text { Complete Tools } 3.5-4.5\end{array}$ \\
\hline \multicolumn{2}{|c|}{ December - January - Conducting Your Inquiry Process } \\
\hline $\begin{array}{l}\text { Build Your Survey with a Cultural Lens } \\
\text { Distribute, then collect \& analyze }\end{array}$ & $\begin{array}{r}\text { Prioritize Your School's need as a staff } \\
\text { Complete Tools } 5.0-6.0\end{array}$ \\
\hline
\end{tabular}

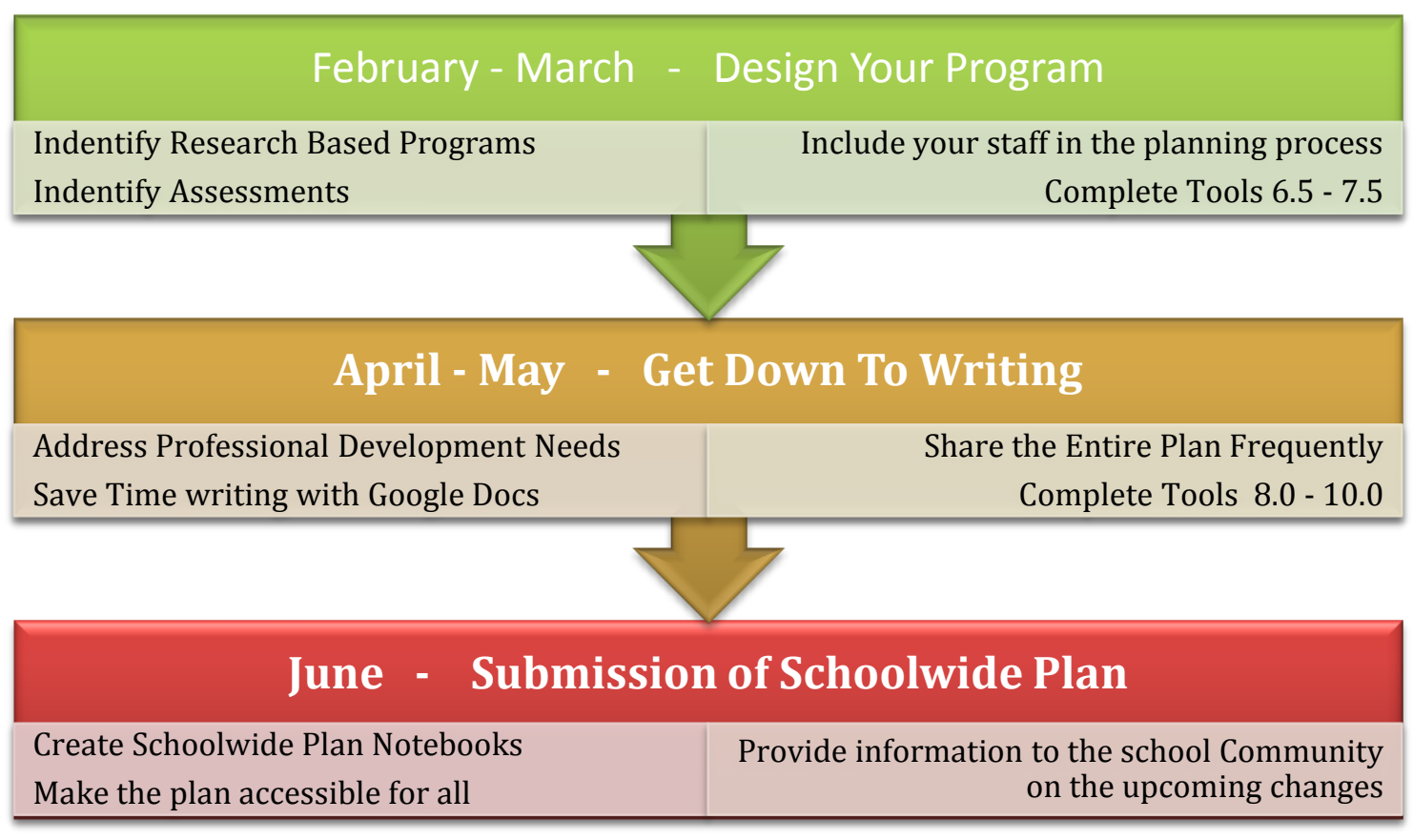




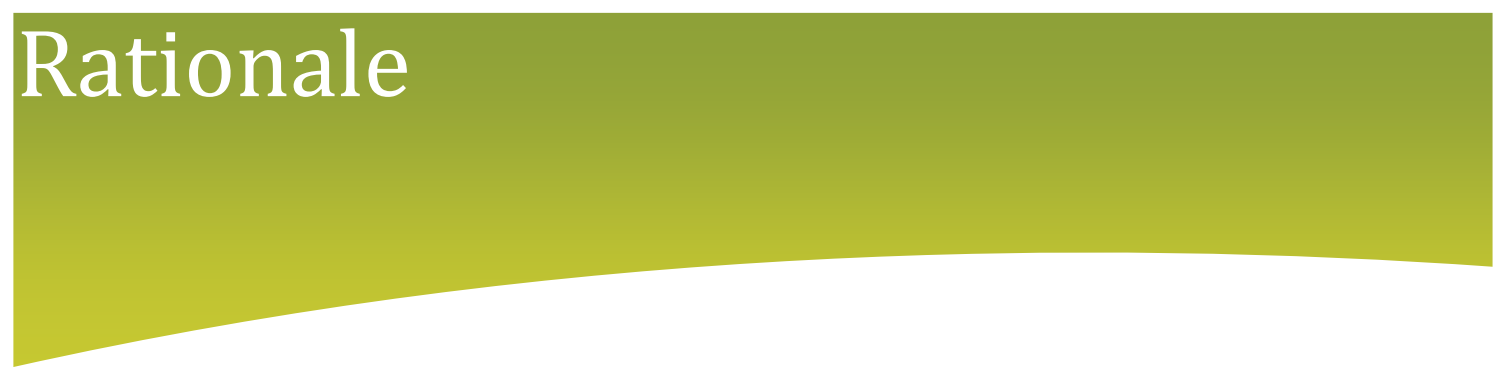

The current research points out a slight advantage of Schoolwide over Targeted-Assistance, because more students are served under a Schoolwide Program model. The Schoolwide program model has also proven more flexible in the way Title funds can be used. (Benton, 1997; Borman \& Agostino 1996; Zimmer, 2007). In my opinion, Title I schools should begin to prepare for the transition to a Schoolwide program model once their schools reach 35\% free-and-reduced lunch based on the simple justification of serving more students. As educators we are faced with the difficult challenge of providing a successful learning environment for all students. The Targeted-Assistance model makes it difficult, if not impossible, to serve schools that have a large percentage of students who qualify for Title I services. I believe that transitioning to a Schoolwide Title I program will not only give you the ability to serve more students and provide flexibility in the use of your Title funds, but you can enhance, sustain, and reshape your school culture at the same time. This handbook will assist you making a successful transition from Targeted-Assistance to Schoolwide. Please let the Tools be a roadmap to making your goal! 


\section{Entering into the process}

Congratulations! If you have decided that moving to a Schoolwide Title I program will be most beneficial for your school, there are many things that you will need to consider before you begin. First and foremost, will you initiate the process yourself or work with an

How will you collect the required data needed and reports?

The process you are entering takes one school year of planning. How will you plan for success?

Does your staff respond best to getting information from you regarding school change, or do they work best with an outside person?

Is funding an issue that could impede the process? How will you overcome these barriers?

Do you have a support person that should definitely be a part of your planning team?

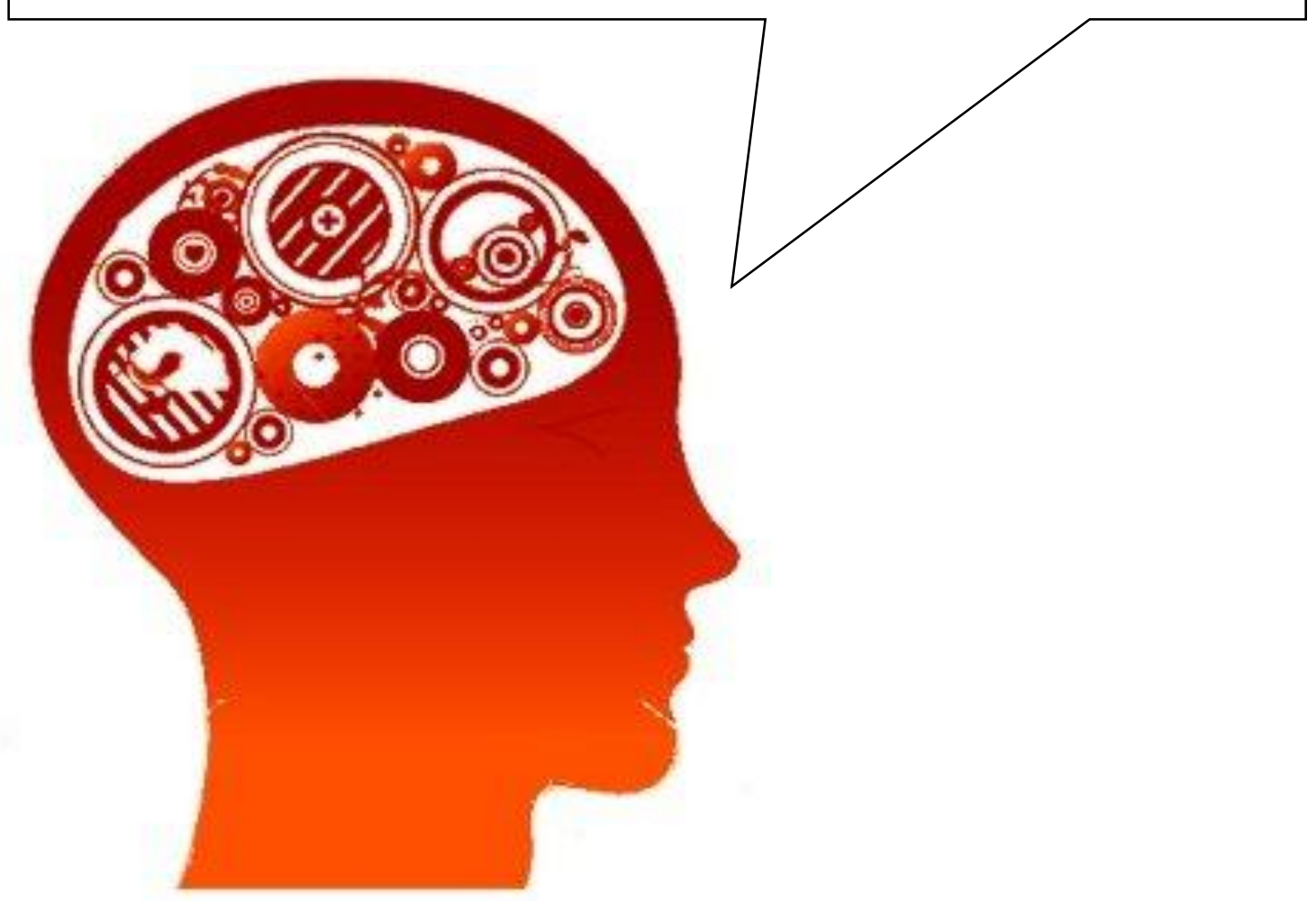




\section{TOOL 1.0 PREPARING THE GROUND WORK}

In the boxes list the documents that your team will need to review in each of the five categories to make a clear assessment of the overall picture of their school. This tool will help you as a building principal in creating packets of information that will be beneficial to your planning team as you begin the process.
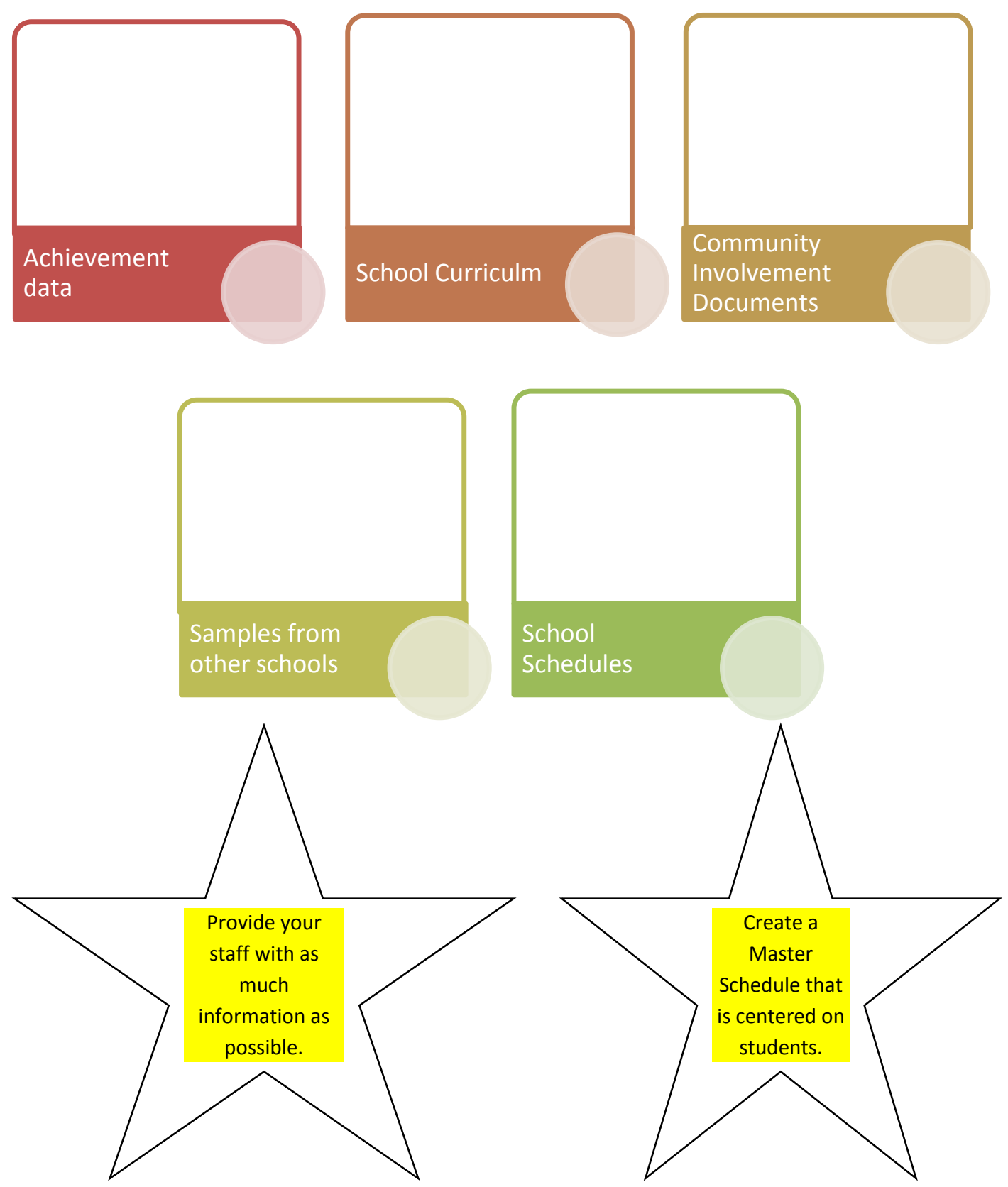


\section{Assessing School Culture}

Research has proven that school culture is a mainstay in cultivating school change. Every school has a culture, and schools have the ability to improve their school culture. Wagner \& Hall-O'Phalen identify school culture as the missing link to school improvement. This key component is often overlooked when schools engage in significant change (Levine \& LeZotte, 1995; Seizer, 1998; Phillips, 1996; Peterson \& Deal, 1998).

School culture is the shared experiences of all school constituencies that build a sense of community, family, and collaboration. Schools with positive cultures are in agreement on how to do things, and why something is worth doing. Open and honest communication is encouraged, and a common goal or vision fills the school.

As principals, how can we determine or assess the culture of our school's current state? Tool 1.0 Assessing Your School Culture has been adapted and refined by Phillips (1996). It has been used across the United States and Canada to quickly and accurately assess the present state of any school's culture.

\section{Important Tips \& Suggestions}

- Distribute the survey to teachers and administrators only.

- Distribute surveys without the scoring page (We are educators: we look ahead, and it skews the results every time!)

- Ensure that everyone understands that this is an anonymous survey-no names.

- Involve teachers in the collection and tabulation of the surveys.

- Share the results with the staff at the next faculty meeting. During this meeting, many faculty schools select one or two items for improvement. These items will be a part of your Schoolwide plan.

- The survey can be administered again later as a progress monitoring tool. 


\section{Tool 1chool Culture}

\section{SCORING 1= NEVER 2= RARELY 3=SOMETIMES 4=OFTEN 5= ALWAYS}

1. Teachers and staff discuss instructional strategies and curriculum issues.

12345

2. Teachers and staff work together to develop school schedules.

3. Teachers and staff are involved in the decision-making process with regard to materials and resources.

4. The student conduct code is a result of collaborative staff work.

5. The planning time allotted to teachers and staff is used in collaborative teams rather than isolation.

12345

\section{Collegiality}

1. Teachers and staff tell stories of celebrations that support the school's values. $\begin{array}{lllll}2 & 34 & 4\end{array}$

2. Our school reflects a true sense of community (administration, teachers, students, parents and school community.

12345

3. Our school schedule is student centered and reflects our achievement goals. 12345

4. Our school appreciates, recognizes, and celebrates the hard work of its staff. 12345

5. There is a rich and robust tradition of rituals and celebrations, including holidays, special events, and recognition of goal attainment that encompasses all school constituencies.

6. The administration and unions work to best serve the students.

12345

\section{Self-Determination/Efficacy}

1. When something is not working in our school, the faculty and staff are proactive rather than reactive.

2. Members of the school community seek to define the problem/issue rather than blame others.

3. The staff is motivated to make sound instructional decisions without the prompting of administration.

12345

4. People work here because they enjoy serving the needs of the students.

5. The school is valued and respected by its community.

Scoring Your School Culture Assessment: the lowest score is 17 and the highest score is 85 . Before engaging in an elaborate and extensive analysis of the school culture, this quick tool can assist in determining the wise allocation of time and resources.

17-40: Critical and immediate attention necessary. 41-59 Modifications and improvements are necessary. 60-75 Monitor and continue making positive adiustments. 76-85 Outstanding School Culture 


\section{TOOL 2.0 EXPLAINING THE PROCESS}

This tool helps you create a timeline for the process using the handbook activities. The stars highlight tips from principals that worked for them in the field during their transition. This tool is revisited later in the handbook.

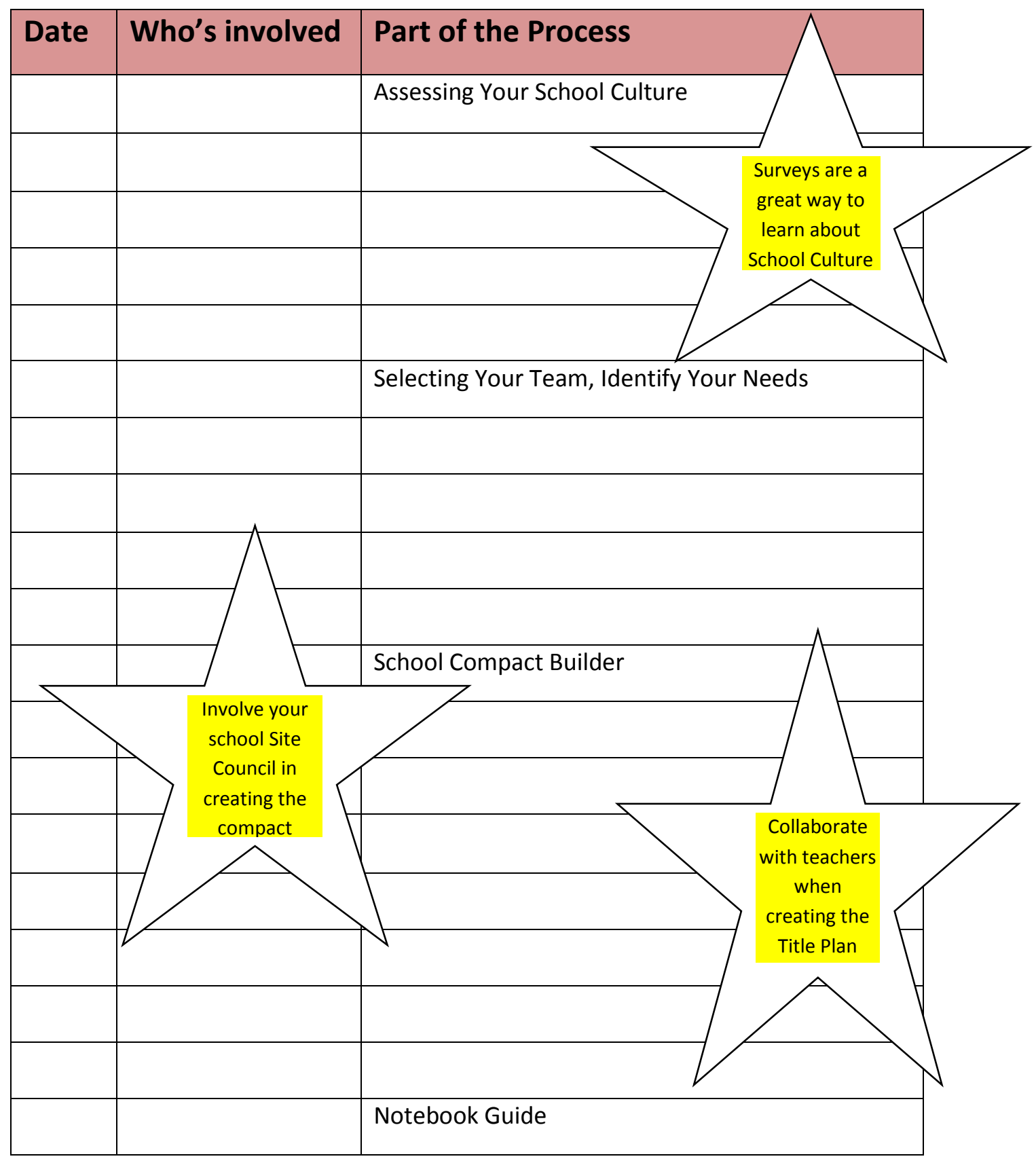




\section{TOOL 2.5

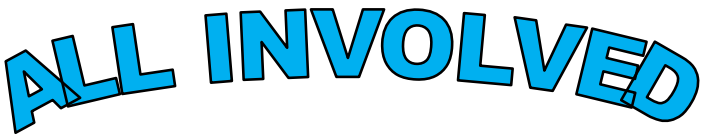

**** Mission Statement, highlight the schools or districts commitment to parent involvement.

Keeping Parents Involved in the Decision-Making Process

A.

Elementary School will work with parents to develop and revise a

school/parent involvement plan that is distributed to parents and made available to the school community.

\begin{tabular}{|l|l|l|}
\hline Date & Activity & $\begin{array}{l}\text { Parents/Community } \\
\text { Involved }\end{array}$ \\
\hline & & \\
\hline & & \\
\hline & & \\
\hline & & \\
\hline
\end{tabular}

B. Convene an annual meeting to which all parents shall be invited and encouraged to attend, to inform parents of their school's participation, explaining the requirements and hopes of the parents to be involved.

\begin{tabular}{|l|l|l|}
\hline Date & Activity & $\begin{array}{l}\text { Parents/Community } \\
\text { Involved }\end{array}$ \\
\hline & & \\
\hline & & \\
\hline & & \\
\hline & & \\
\hline
\end{tabular}

C. Offer a flexible number of meetings, both AM and PM times, and may include, transportation, child care, or home visits, as such services relate to parental involvement.

\begin{tabular}{|l|l|l|}
\hline Date & Activity & $\begin{array}{l}\text { Parents/Community } \\
\text { Involved }\end{array}$ \\
\hline & & \\
\hline & & \\
\hline & & \\
\hline & & \\
\hline
\end{tabular}

D. Involve parents, in an organized, ongoing and timely way, in the planning, review, and improvement of the parent involvement process.

\begin{tabular}{|l|l|l|}
\hline Date & Activity & $\begin{array}{l}\text { Parents/Community } \\
\text { Involved }\end{array}$ \\
\hline & & \\
\hline & & \\
\hline & & \\
\hline & & \\
\hline
\end{tabular}




\section{Thinking Outside of the Box}

Ponder these questions, take notes, and use them as a proactive way of thinking to assist you in reaching your goal as you deal with opposition that may arise throughout the year.

How can the Schoolwide transition benefit your school?
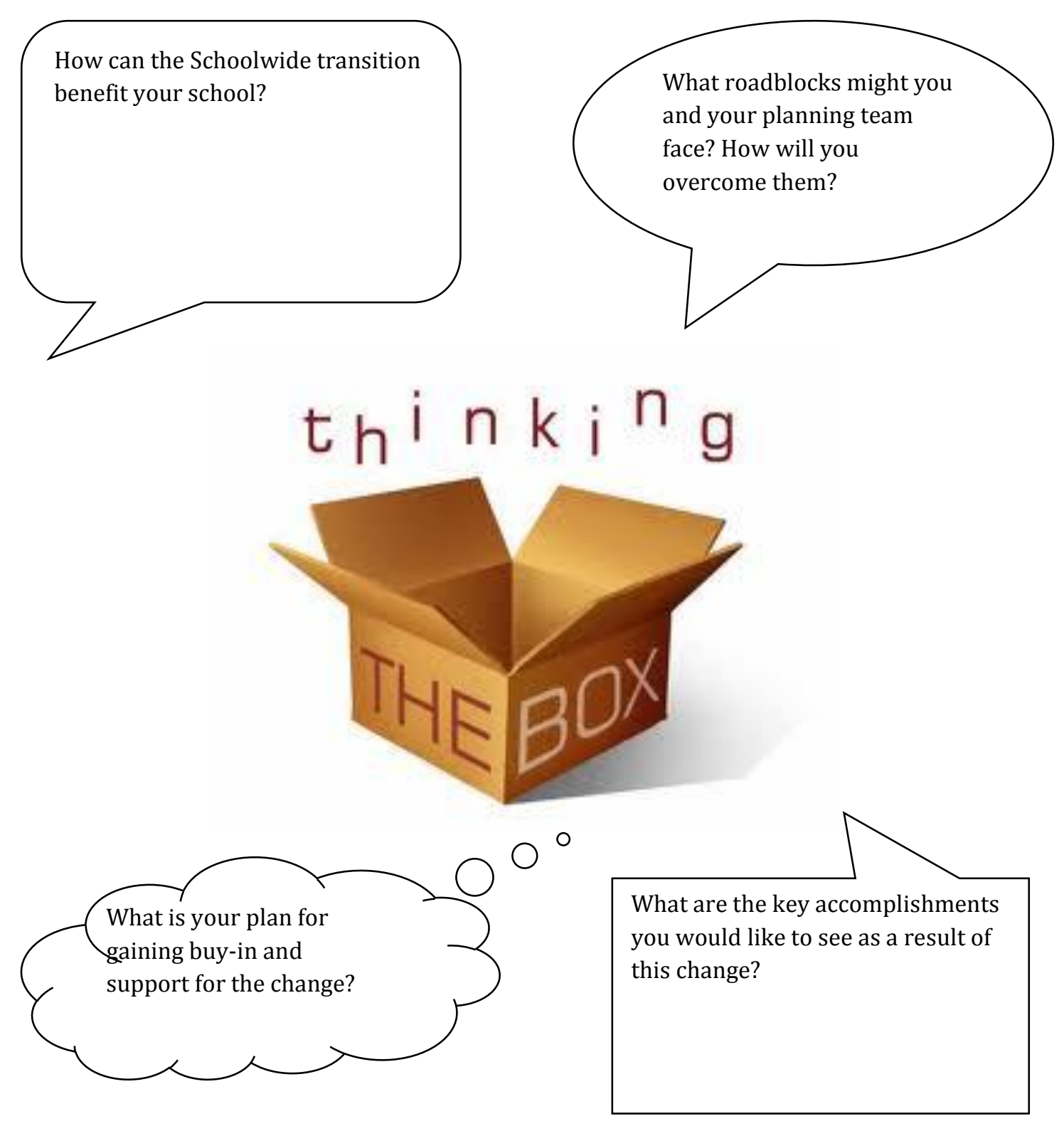
PRINCIPAL'S SCHOOL CULTURE ATLAS 1

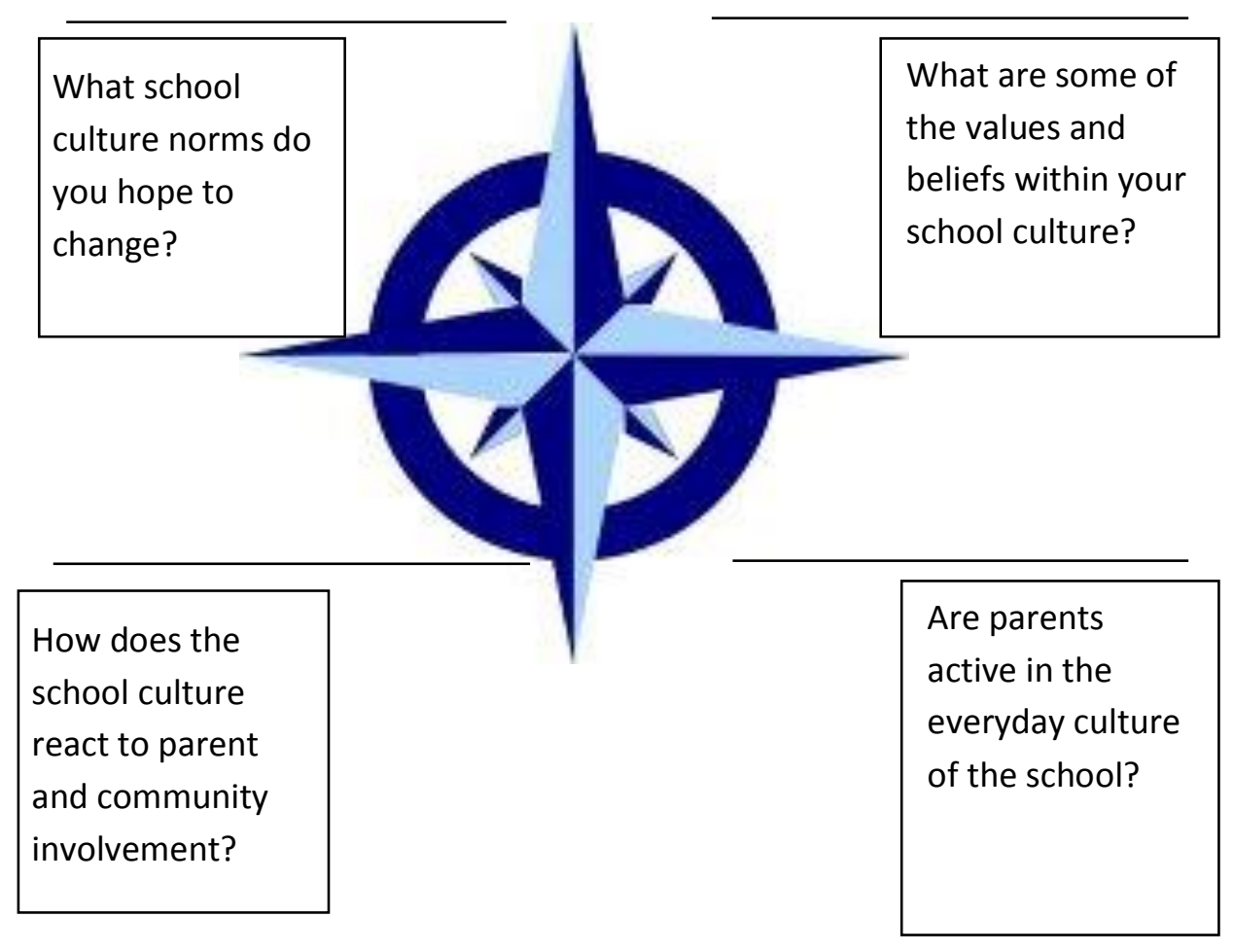

REFLECTION 


\section{Is this a good fit?}

"Whenever you're in conflict with someone, there is one factor that can make the difference between damaging your relationship and deepening it. That factor is attitude." (William James, 1910)

Hiring a Consultant 101

After polling 30 principals, 11 out of 30 recommended the use of an outside consultant when making the transition from a Targeted-Assistance to Schoolwide Title I program. But hang on a second, don't run out and hire a consultant just yet. If you go this route, you need to know what you are looking for - and how to know when you have found it.

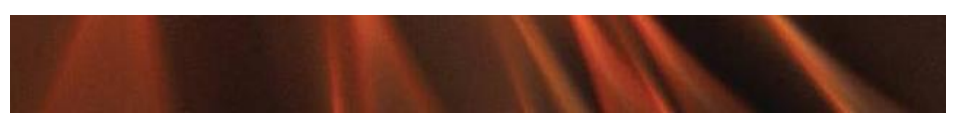

You Need a Good School Fit

Choosing to work with an expert can be beneficial or detrimental to a school's culture. Be sure that the person you choose fits the values, beliefs, and commitment of your staff. To ensure a successful transition you will need to gain buy-in and support from your staff. Characteristics that you will want to look for are someone who is a good listener, one with clarity of the process, who is not afraid to ask the compelling questions and has the ability to make others feel at ease.

Being knowledgeable is great, but if the information does not work for your building the information is useless. If your staff feels that the information they are receiving is not beneficial, it could end up causing resentment and negative attitudes that can affect and slowly eat away at the positive culture that we are working to maintain. 


\section{You Need Someone Who Understands Your Role}

Before hiring a consultant, be sure the person understands the role of the Principal. I suggest that if you are looking to hire a person who has successfully been through the process before that you enlist an educator, preferably an administrator or teacher. He or she should have a good idea of your hours, obligation to parents, students, and community members, the kinds of struggles you face, and the financial concerns you are currently facing as well as what funds may look like in the future. Schools need people who have been in the trenches with others in the field who have success stories that they can share and motivate others. Be sure that this person has done their homework. Any consultant that is worth their weight in salt will gather information on your district, school, and school community before they walk into that first meeting. This will be a good indicator as to whether or not this person will be able to help you. The number one reason that Principals used a consultant was to save them time. Note, your consultant should be freeing you up and saving you time, not over burdening you with additional work.

\section{You Need a Specialist}

If you are going this route, I highly recommend using a consultant with Title I experience who has gone through the process. Each state has a list of recommended consultants who have led schools through the transition process effectively. In using someone who has worked with a school in your state, you can use that school as a reference. Contact previous schools that have worked with them to gather information about the transition process, the consultant's effectiveness, and the consultant's ability to lead the staff. Be sure to select someone who is not afraid to engage with the staff in person and answer questions. Be leery of consultants who are adamant about meeting over Skype or conference phone, or would like to create web based 
trainings for your staff. Although those tools can be highly effective, it may be a red flag that the consultant is not comfortable answering staff questions. Meet with them in person to get a feel for whether they are someone with whom you would want to enter into a yearlong process. Ask questions about their background, qualifications, credentials, and specialized areas of knowledge. What is their track record for successfully transitioning a Targeted-Assistance school into a Schoolwide program?

\section{You Need a Flexible Perspective}

Hiring someone with a "top down" perspective can definitely impede the process. You need someone who not only listens to you and your staff, but also assists them in making the process as painless as possible. Each school is different and consultants need to be flexible enough that their approach will work for any school, no matter how difficult, sensitive or high maintenance the environment is.

\section{You Need to Feel Comfortable With Confidentiality}

Since consultants are going behind the scenes of your school, they will gain access to a lot of sensitive information in regards to staffing and possible decisions that could affect the people in your building. Leaking information at the wrong time or people receiving second hand information prematurely can cause dissention among the ranks.

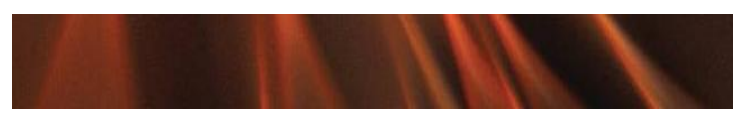




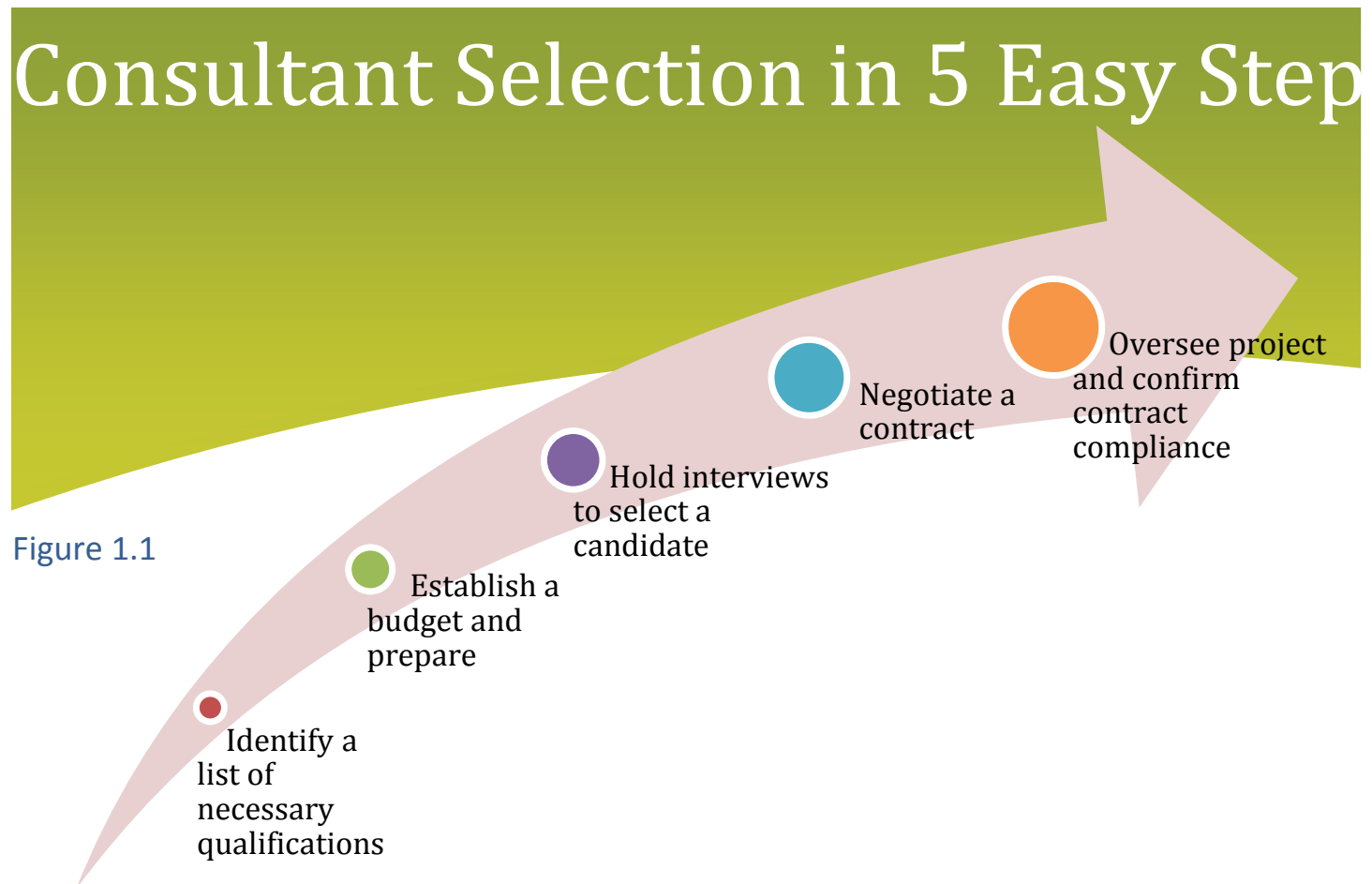

Consultant 5-Step Selection: These 5 steps will guide you through the process, if you decide to use a consultant during your transition.

Your consultant needs to be professional and ensure you that you can provide them with sensitive information and that, in turn, it will be kept confidential.

Now that you have more insight on selecting a consultant, it is also important to remember that they will not work for everyone. Before making a hasty decision, please read this handbook and use the ranking scale at the end of the text to gain insight on which avenue to take as you enter this yearlong journey. Brainstorm and take notes as you consider this question:

\section{Does the positive outweigh the negative?}


Figure 1.2

What are the pros as I see it in using a consultant?

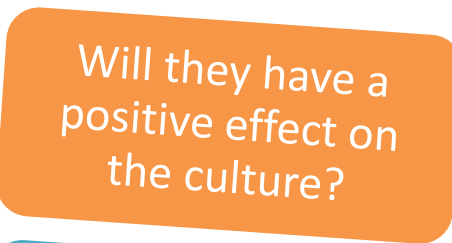

Will they save me time? How so?
What are the cons as I see it in using a consultant?

Will they have a negative effect on the culture?

Will they add more stress? How so?

Is funding a factor? How so? 
PRINCIPAL'S SCHOOL CULTURE ATLAS 2

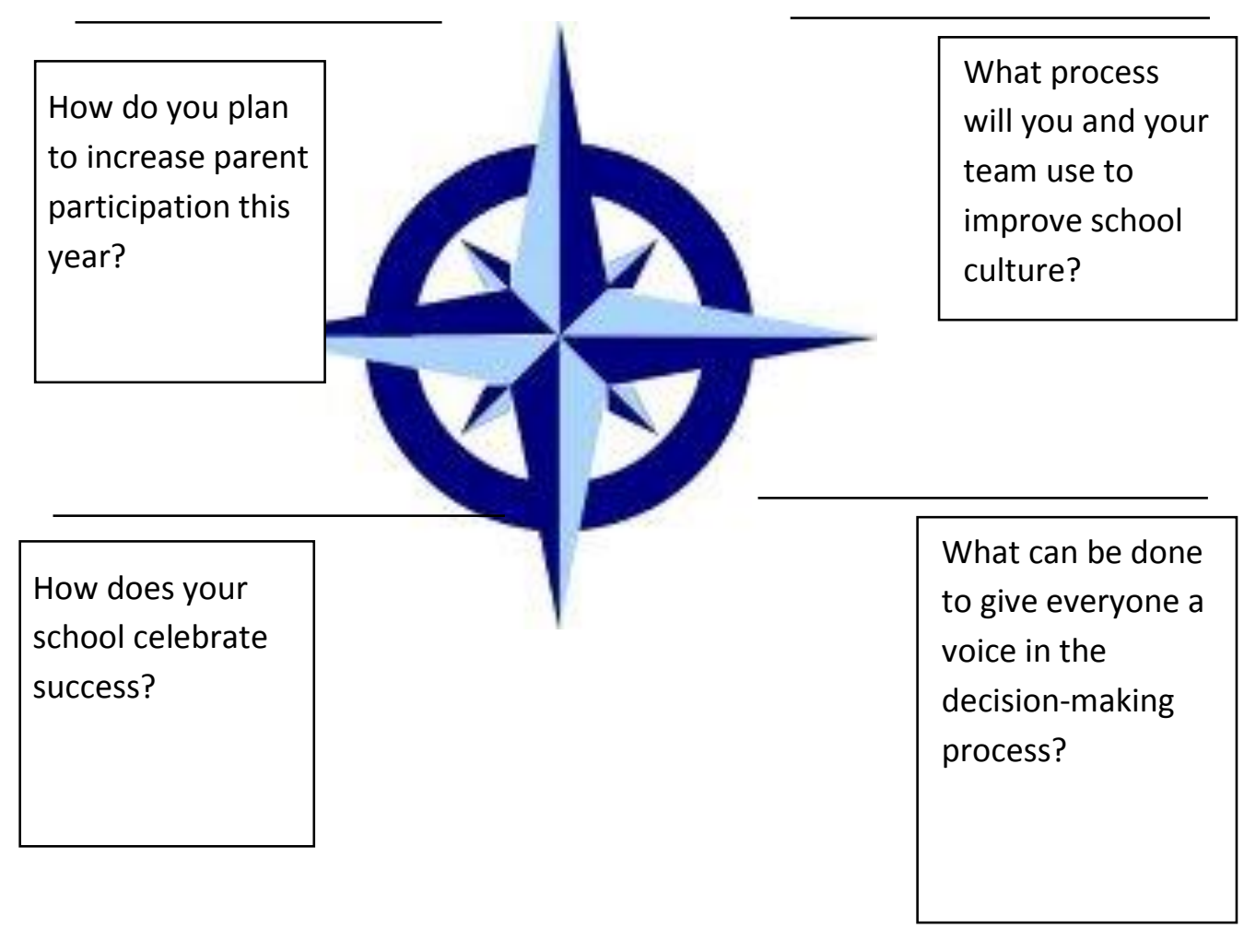

REFLECTION 


\section{Select Your Team, Identify Your Needs}

\section{"Valuable aspects of the school's existing culture can be reinforced, problematic ones revitalized, and toxic ones given strong antidotes." (Dean \& Peterson, 1999)}

\section{The Selection Process}

To begin this process you must select a Schoolwide Planning Team (SPT). Your SPT will work with you through every step of the process for the entire year to create a plan that will benefit the needs of the students in your school. Selecting your SPT team will be one of the most important decisions that you can make in this process. I like to think of them as the positive ambassadors of the message you are trying to convey. Your committee should be comprised of parents, licensed staff, classified staff, administrators - building and district level, and Title I staff members.

The SPT team should comprise of a variety of skills. When selecting staff members in your building to be on the SPT, select members who can consistently produce positive results, can work well collaboratively, and can think outside of the box. Your team will need to have an attitude of "belonging" to a team. There will be times when someone will have to compromise their opinion or viewpoint for the good of the team. Being a team member is a key requirement, so having a positive attitude is important. Of course you don't want to select anyone who will sabotage the process; however, schools always have a few people that are neutral or on the 
fence. This is a good opportunity to win over people that may not be quite on board with the program change. Being a part of the team, decision making process, and the outcome of the program will build trust and gain support from members of your staff who feel the same way. Select parents who are respected by the community, active in the school, and have the time to commit to the process. Be up front with them about the time commitment.

You may be thinking that it is difficult to assess whether someone has the ability to be a good contributing member of your SPT. Remember you are looking for people who care deeply about the school and want to see all students succeed. Your SPT members should be people who believe that two heads are better than one, and everyone has a contribution that they can make to the team.

It is important to remember that although a team may appear to be culturally homogenous, each member comes with their own set of values which go beyond gender, ethnicity, or socioeconomic status. High performing teams must take these values into account as they collaborate.

Tool 2.0 will assist you in constructing your Schoolwide planning team. Researchers have identified a combination of personalities that thrive when put together, forming a High Functioning Team. This tool will guide you in making a team selection that will benefit you throughout the yearlong transition. 


\section{Tool 3.0 Team Construction}

\section{Components of a High Functioning Team}

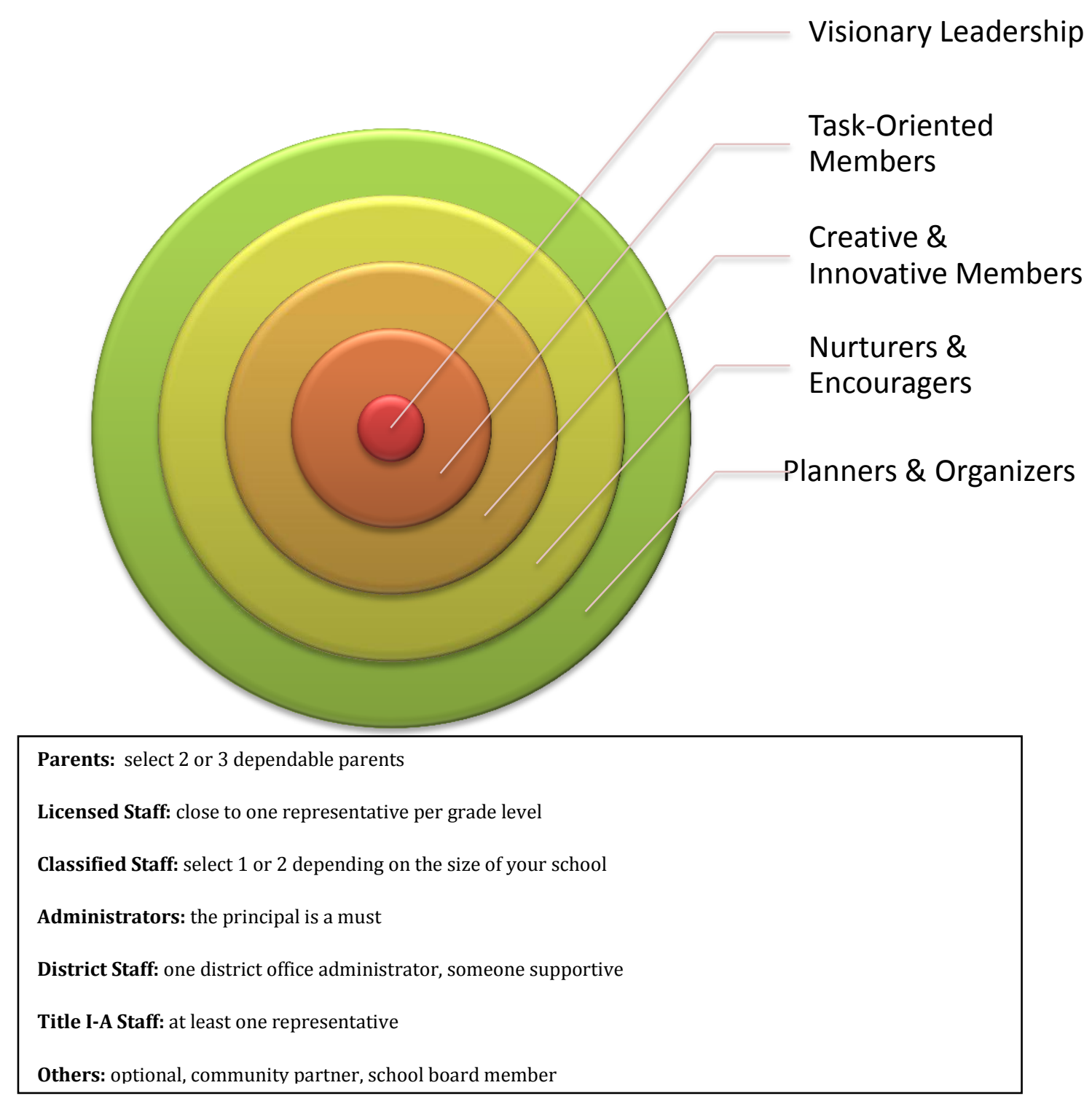


It is important for principals to understand the orientation of Tool 2.0. Taking these roles into account will assist you in creating a team with all the components of success.

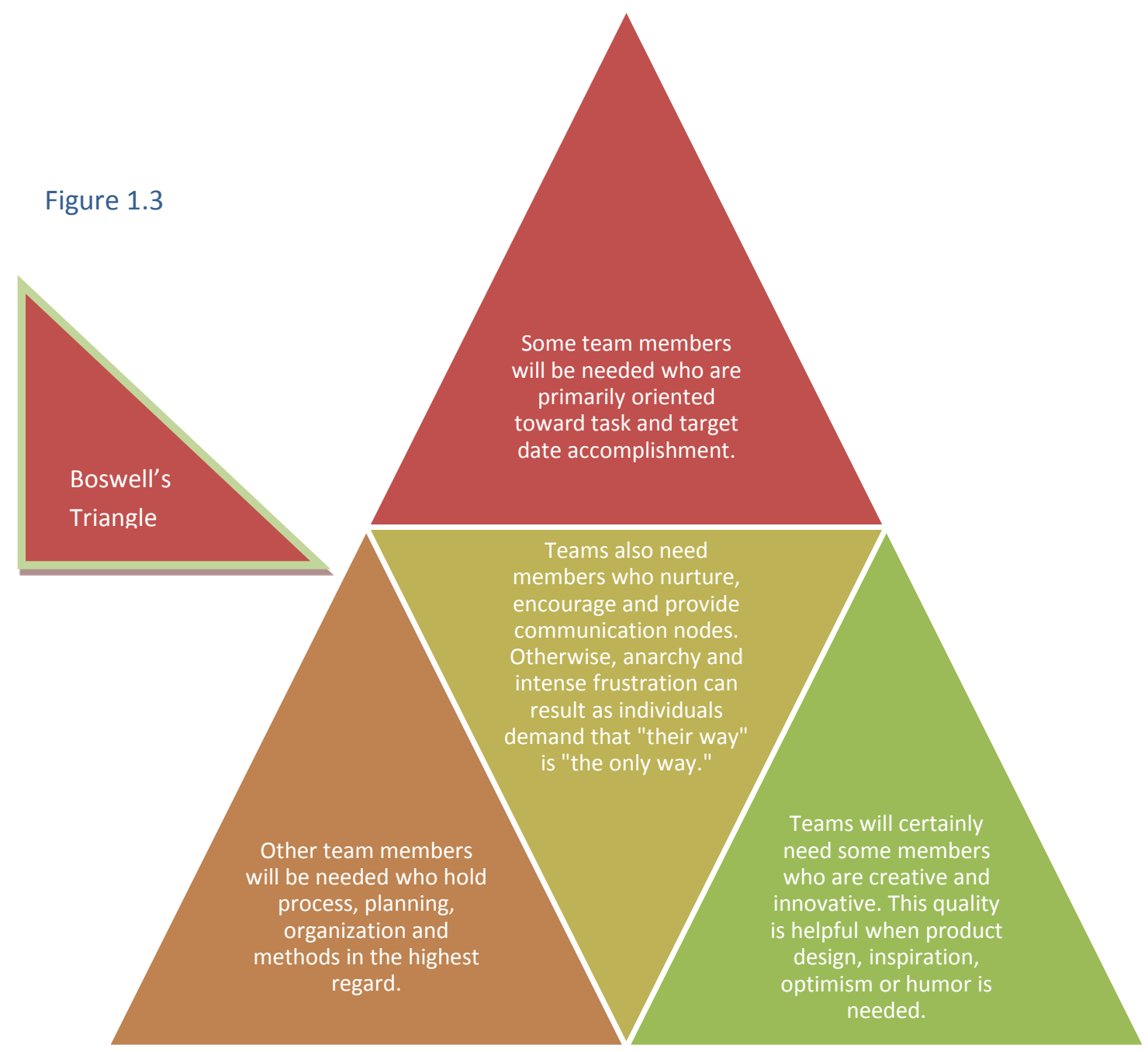

Bodwell's triangle is extremely useful because it sheds light on aspects of the selection process that school leaders may not think about when selecting a team. When this process is used, it also falls into the category of valuing others and respecting all which will, in turn, foster a positive school culture. If the team members are comfortable with the process, they will relay their message of positivity to staff, parents and others who are interested in the process. 
In selecting your SPT you will have a variety of members from all perspectives of the school from teachers to parents. However, in maintaining a healthy culture, it is important to let your staff and parents know that everyone has a voice, and will be taking a survey to get their perspective on the school.

On the next page we provide Tool 2.5 to Guide Your Path, Refer back to the Yearlong Roadmap at the beginning of the handbook on p15. Use Tool 2.5 to list the actual dates that you will use each step throughout the school year. This will be helpful in creating a meeting schedule and getting actual dates scheduled on your calendar. As unexpected events arise, dates of course are subject to change, but at least you have a schedule to work from. 


\section{Tool 3.5 Guide Your Path}

February March: Design Your Program
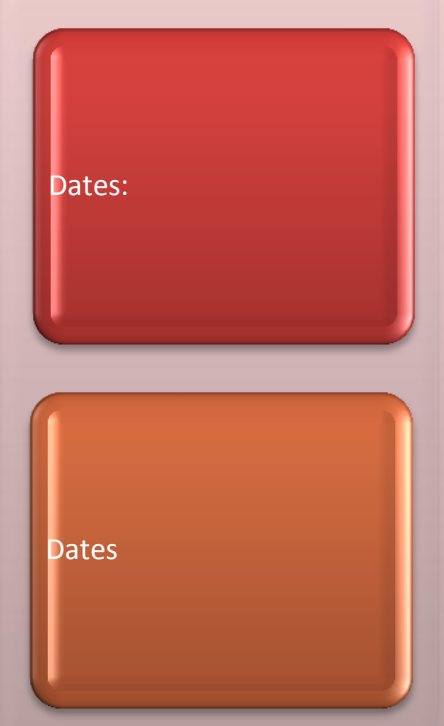

April - May:

Get Down To Writing
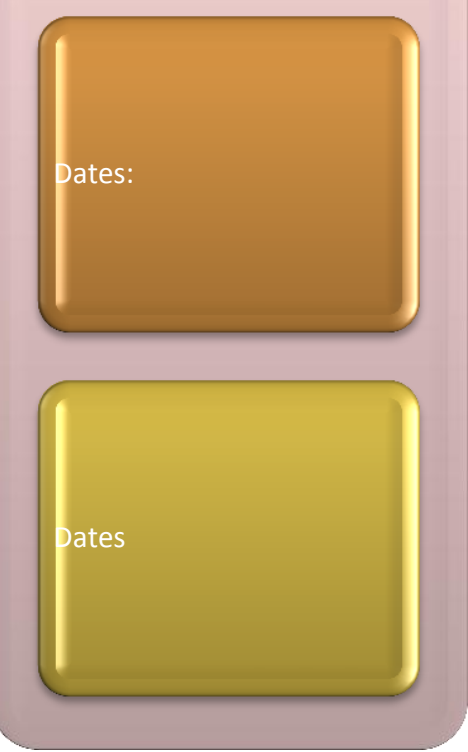

June:

Submission of Schoolwide Plan

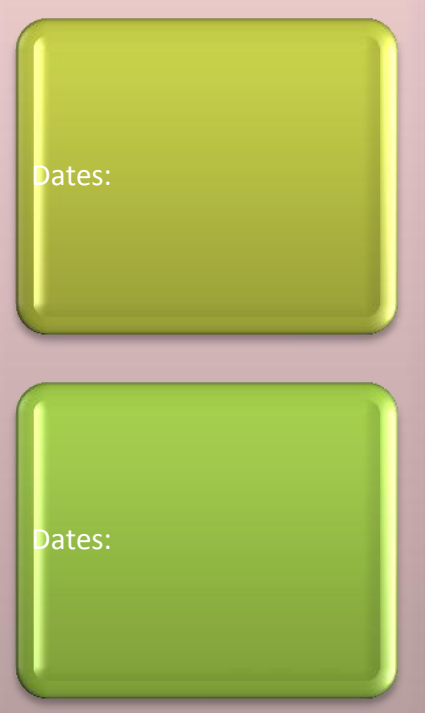




\section{Data That Pays Dividends}

It is the principal's job to provide their SPT with the information that they need to successfully find out what the school's strengths and weaknesses are so they can properly address its weaknesses. Principals going through the process of transitioning their schools from TargetedAssistance to Schoolwide Title I will need to collect data in the following areas: Student Achievement, School Context and Organization, Curriculum and Instruction, Professional Development, and Family and Community Involvement. As school leaders, we are inundated with the importance of data-driven decision making. Stephen White, author of Beyond the Numbers comments, "If efforts to collect and manage data resulted in improved student achievement, there would be little reason to worry about leaving anyone behind. Schools invest considerable resources, time, talent, and technology to collect data, manage it effectively, and complete required reports" (p.15). White goes on to stress the importance of analyzing the data they collect, and addressing the issues that they find within the data to improve the outcome for students.

Not only do school leaders need to provide the information to the SPT, they must also assist them in creating surveys that provide a voice for students, staff (certified and classified) and parents. Then, they are faced with the challenge of gathering meaningful information from the data that will address the needs of the school. Exhibit 1.1 provides information about the kind of data that is important for school leaders to provide to their staff regarding student achievement. In providing the information, principals may choose to scale the information down so that the SPT can easily read the necessary information and begin collaboratively analyzing it. One principal stated, "Personally, when going through the data collection process I choose not 
to bog down my team with reports; instead I provide data summary charts for them to analyze.

This saved time and made the analysis smoother." 
Figure 1.4

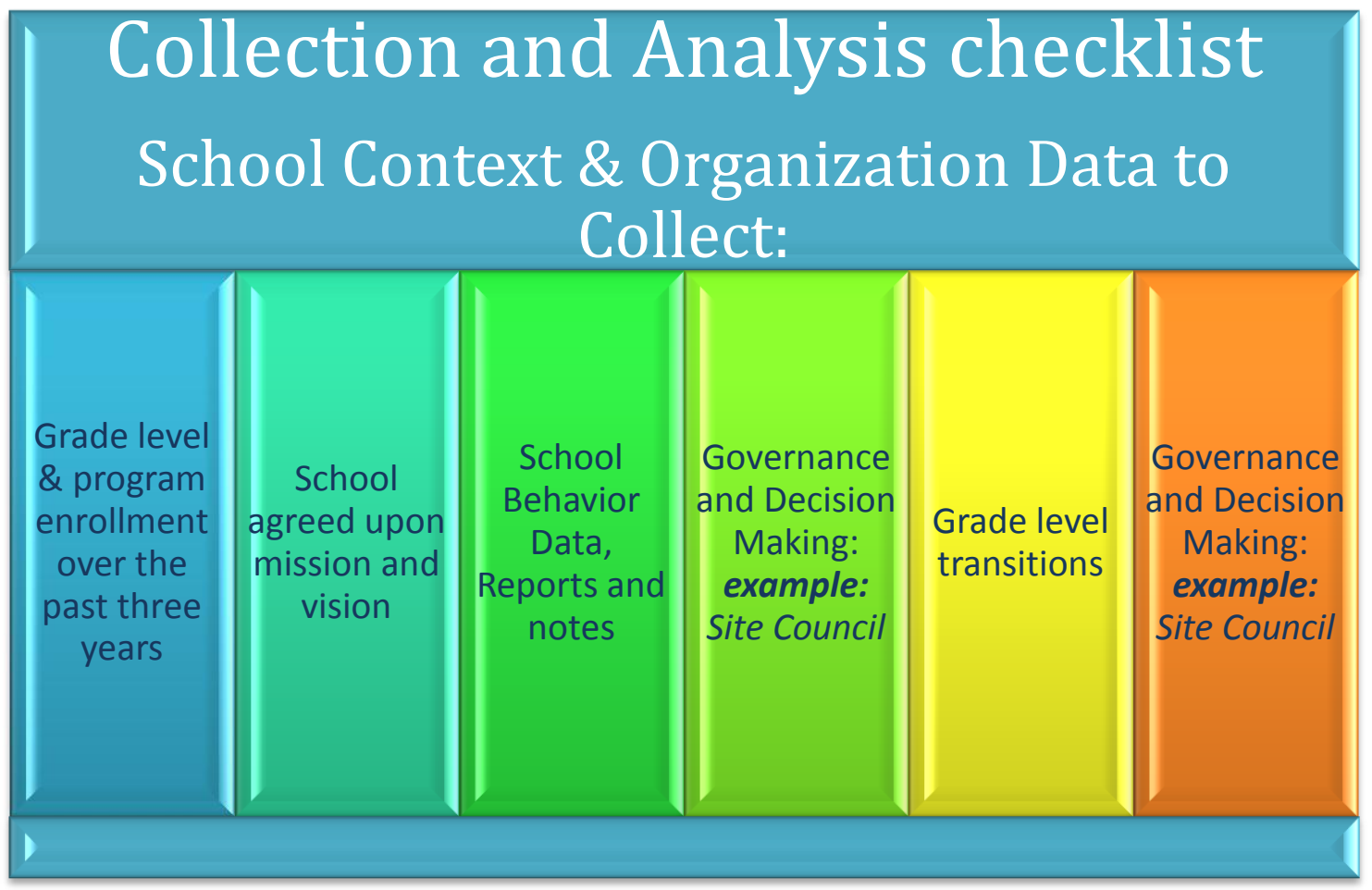

\section{Collection and Analysis checklist Student Achievement Data to Collect:}

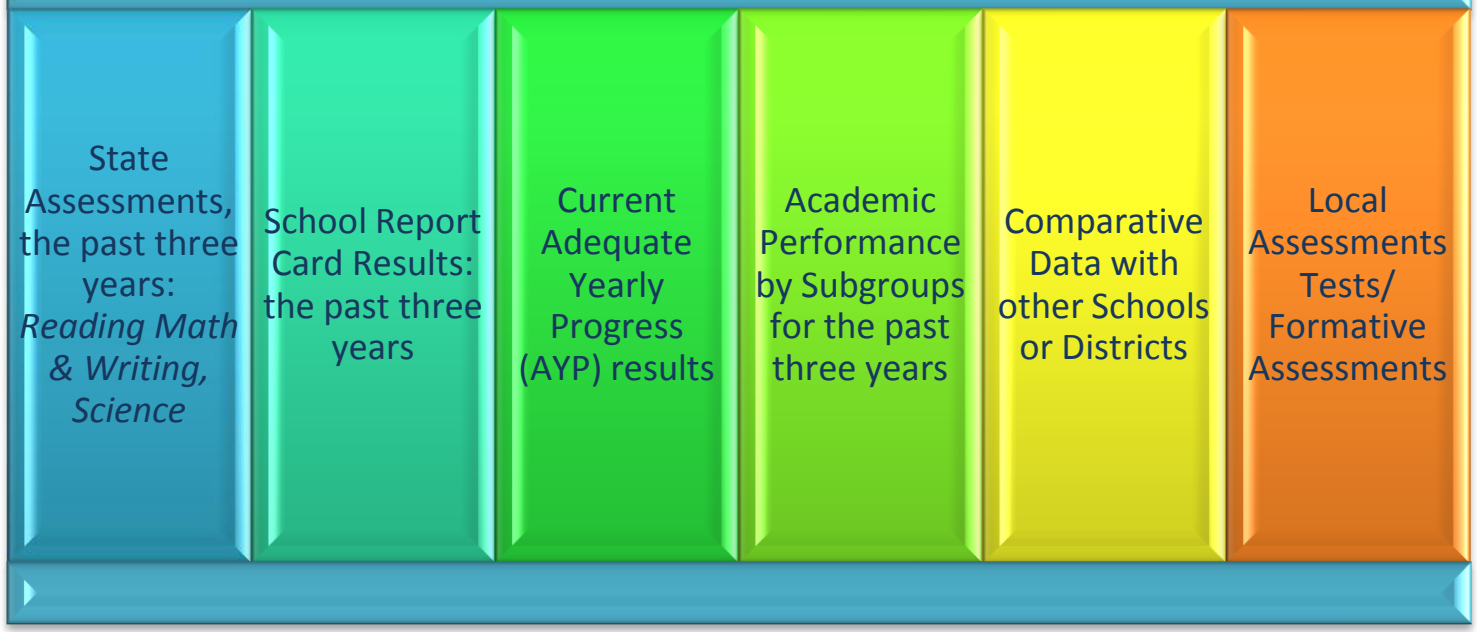


As principals guide their staff through the process of analyzing the data with their teams collaboratively, there is great value in looking at the data like a "treasure hunt." White defines a data treasure hunt as not knowing for certain what, or where it is that we are looking for, but we know it is important to be attentive to all factors if we are going to discover it (2005). The SPT should be not only examining the data but having rich conversations around factors that may affect the data such as teaching strategies and styles, behaviors, conditions, structures, and school culture.

One of the most important (principles of good teaching) is the need for planning. "Far from compromising spontaneity, planning provides a structure and context for teacher and students, as well as a framework for reflection and evaluation" (Spencer, 2003, p. 25). Principals who are planning to enter into the transition process of moving their Title I programs to Schoolwide should begin the data collection process during the summer. For the most part your buildings should be somewhat peaceful and free of interruptions. Take your time collecting the necessary information that you need to provide to your SPT. When your team is selected you should have a vision of the process and be prepared to disseminate the data.

\section{Don't cheat the process}

Principals, no matter how difficult it may be, please don't analyze the data you collect. No matter how tempted you may be to analyze the data as you collect it, you will enhance the culture of your SPT by waiting and analyzing the data together. Collectively working through the data not only builds commitment and trust; it also sparks reflective dialog where the team is having conversations about students learning, teaching, and related issues and concerns. These 
conversations can lead to inquiry questions and educational debates that allow the SPT

members to learn from each other. As a result of these interactions the team begins to recognize weakness and problems, and collectively problem solves to address issues (Hall \& Hord, 2006). 
PRINCIPAL'S SCHOOL CULTURE ATLAS 3

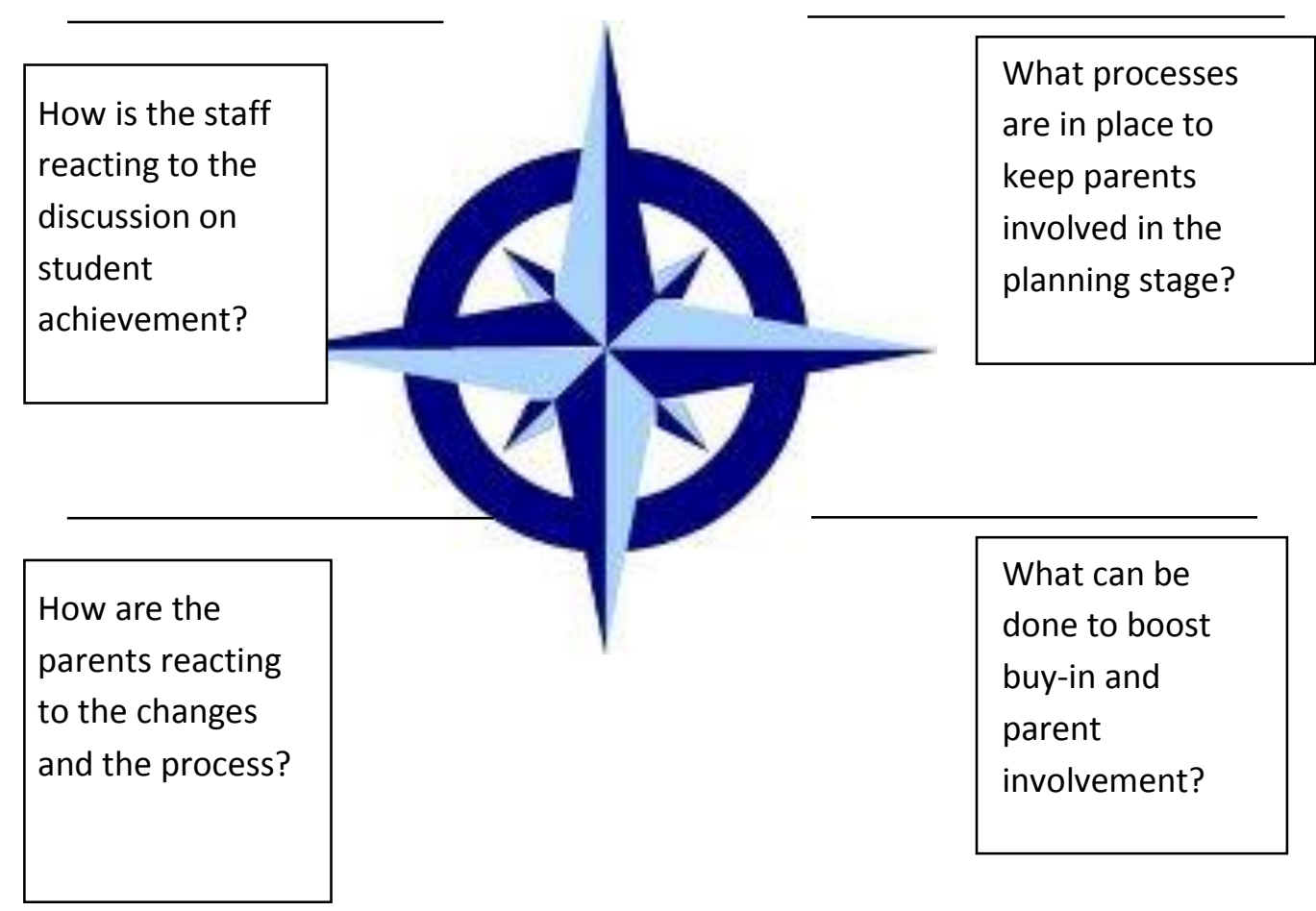

REFLECTION 


\section{What Does The Data Tell Us? Activity I}

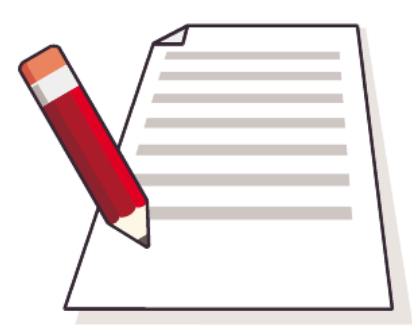

An open discussion, using all the information about student achievement, as well as parent, staff and student surveys that have been collected, allows all participants of the Schoolwide Planning Team to assess the school's strengths and weaknesses in order to determine priorities for improvement areas. The two activities below will help participants with this important exercise.

The principal or school consultant will facilitate a discussion with the planning team by asking questions that focus on information about achievement. This discussion gives everyone an opportunity to understand the information and its value to the Title I Schoolwide planning process; it also gives the team members a voice in the decision-making process.

\section{$\sec$}

\section{The facilitator will ask the following questions:}

$\checkmark$ Is there anything in the student achievement data that you do not understand?

$\checkmark$ If so, what would you like clarified?

$\checkmark$ Is there anything about the information that you find surprising?

$\checkmark$ Is there anything that concerns you?

$\checkmark$ How does the information fit with your feelings about how the students at this school are doing?

$\checkmark$ Does it seem to differ from what you have experienced in the classroom or in the home?

$\checkmark$ Did our students do as well as we expected them to do? 


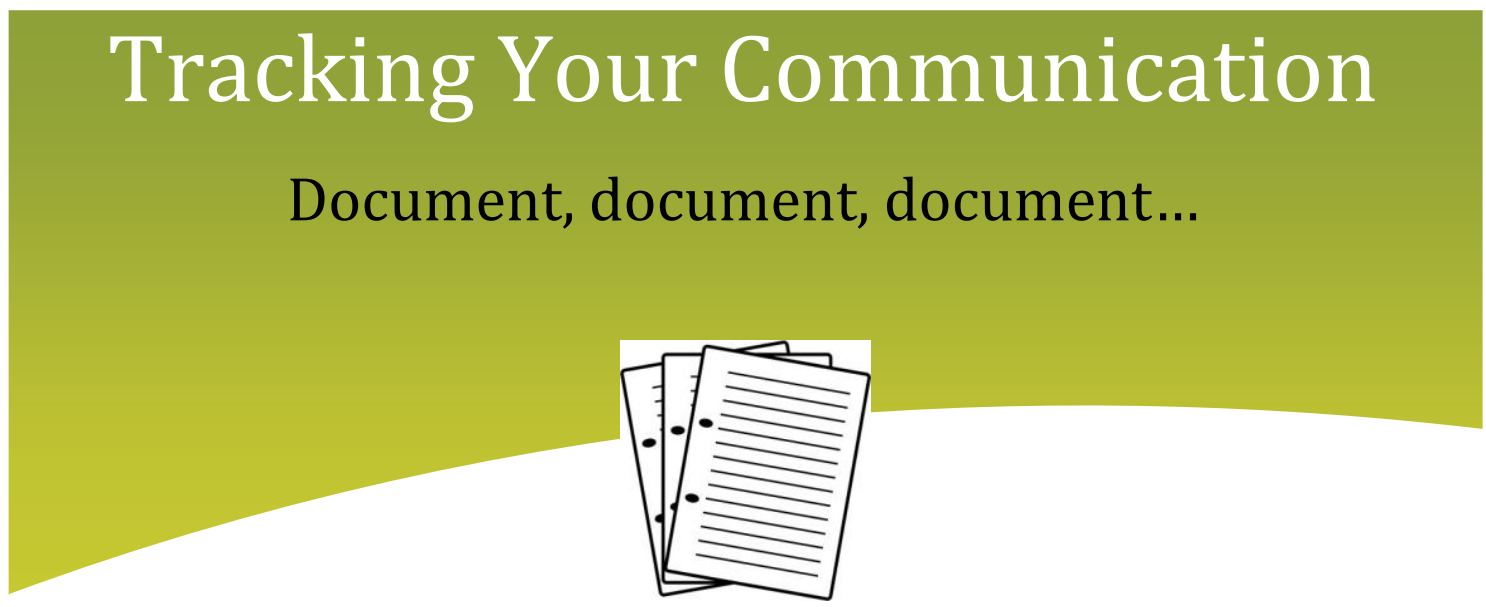

In writing your Schoolwide Plan you are required to provide detailed information to address the statement below.

Describe the processes and opportunities that were used to 1) develop the Schoolwide Plan;

inform the entire staff, parents, community, and district of the Schoolwide planning team actions; 3) solicit and receive feedback from these groups.

As you enter this Schoolwide Process, remember that your goal is to share information with all school constituents all throughout the year. Many principals and Schoolwide teams do spend the time it takes to gain buy-in by consistently meeting with parents, families, community members, and providing ongoing communication to their staff. However, when it comes to documenting the process, many teams struggle to find and collect the information (dates, agenda topics, and meetings) they used in communicating with their school and community.

This handbook provides communication logs that will help you keep track of the meetings and open communication that your SPT used throughout the yearlong transition. This will be beneficial to you as you begin writing the actual grant. 
Schools are located in communities, but are often "islands" with no bridges to the "mainland." In making the transition from Targeted-Assistance to Schoolwide, you will need strong community support, which you can gain by being open, honest, and transparent.

Providing the community with the information they need to understand the value behind the transition will make the change more worthwhile for community members. Schools are more effective at reform when they include the community as an integral and positive part of the change process. 


\section{T00L 4.0 Cultural Community Involvement Map}

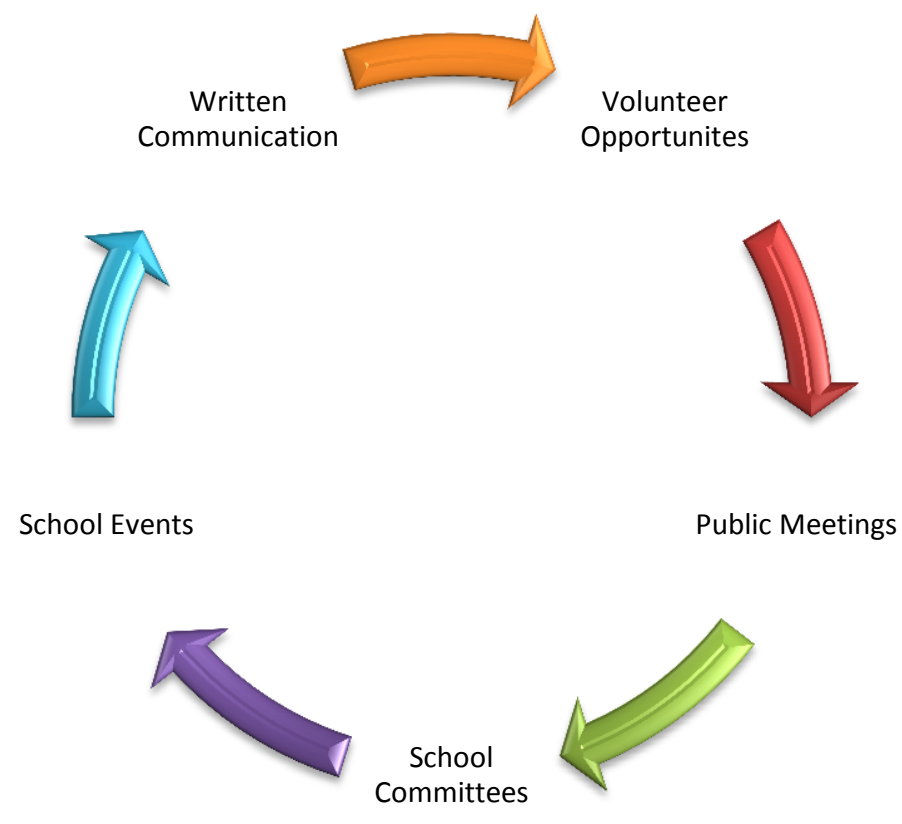

List opportunites and events where your school community can be invloved.

$\bullet$

How will they be informed of these opportunities?

$\bullet$

Principal's Tool 3.0 can be used as a guide to assist you in keeping all school constituents informed and involved in the transition process. In making this Schoolwide transition it is imperative to be transparent, informed, and engaged in the process. Not only is it important to provide these opportunities, it is also key to document them. 
As school leaders, we hear the term "effective communication" constantly. Without effective communication, every interpersonal relationship, every goal, every strategy, every change initiative is at risk. Here is some food for thought as you transition through the Schoolwide planning process.

- Misunderstandings, poor morale, and ineffective relationships rooted in poor communication are commonplace.

- Effective communication is hard. It can be uncomfortable. It can make people angry with you.

- But, it's the only way to solve problems.

- When times are difficult and emotions are running high, how can we be sure we're communicating effectively (and respectfully)?

- It's time to get back to basics.

- Listen to what others are saying. Adjust your style to try and connect with them effectively where they are.

- Don't think it's the other person's job to communicate with you no matter where you are on the organizational chart.

- Remove yourself emotionally from difficult conversations, at first. Listen. Ask questions. Stick to the cold, hard facts when assessing a situation.

- However, when it comes time to implement a decision, it's time to let emotions back into the picture.

- If you find that a conversation or a topic is annoying you in some way, get another person's perspective.

- Effective communication is like exercise. We all know how to do it. We all know that we should do it. Yet it's often neglected.

In these next few pages, you will find four communication logs, two staff logs - Certified and

Classified, a Community Log, and a Parent Log. It may seem strange to log Certified and

Classified staff separately; the only logic for this is to assist you in writing your Title Grant, which gets very specific regarding what communication was held for Certified and what was done for Classified. Logging the communication separately will save you time when you begin completing the grant. The community log is for all school constituencies outside of the staff and the parents of your school. 


\section{Parent Communication Log}

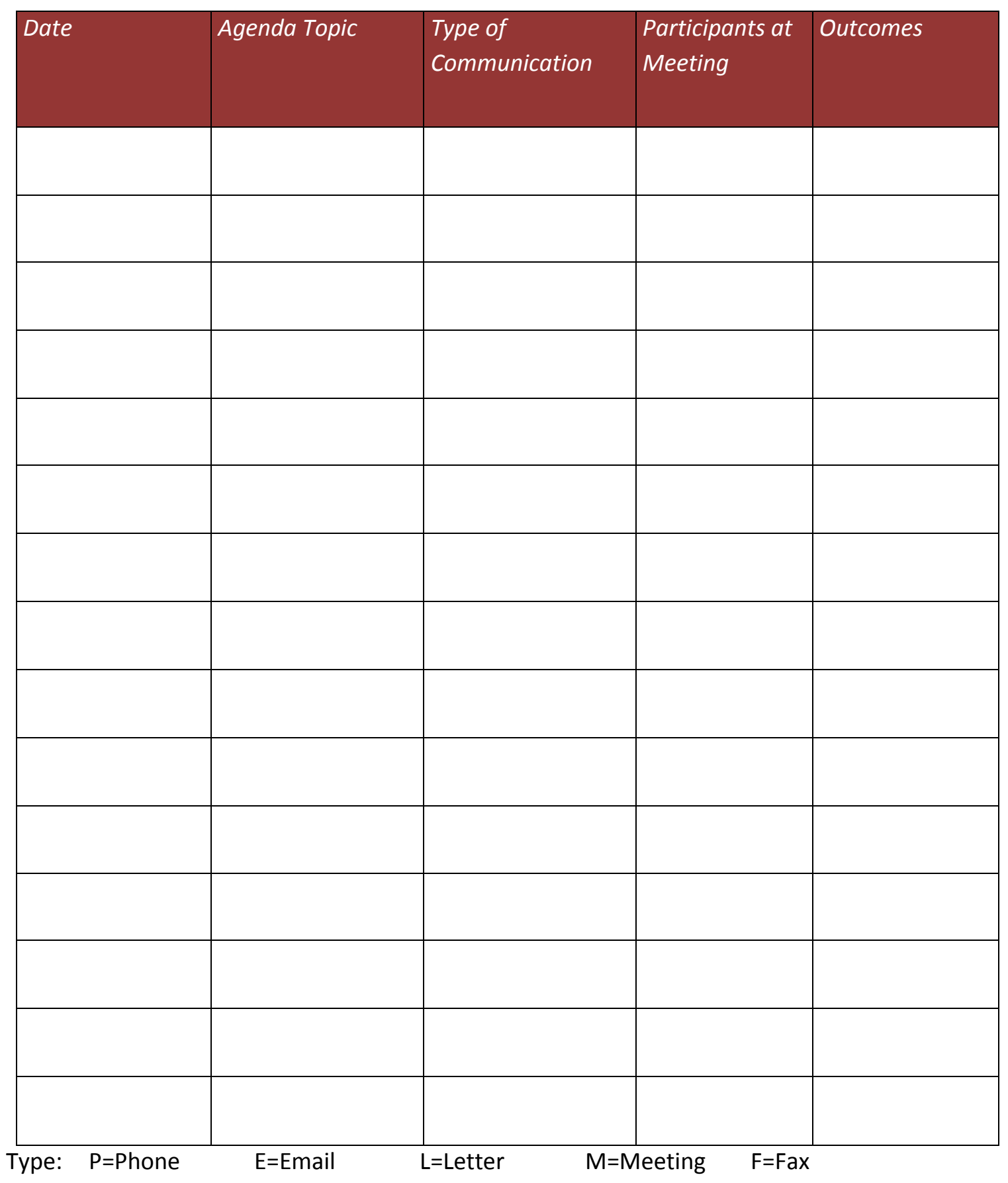




\section{Staff Communication Log (Certified)}

\begin{tabular}{|l|l|l|l|l|}
\hline Date & Agenda Topic & $\begin{array}{c}\text { Type of } \\
\text { Communication }\end{array}$ & $\begin{array}{c}\text { Participants at } \\
\text { Meeting }\end{array}$ & Outcomes \\
\hline & & & & \\
\hline & & & & \\
\hline & & & & \\
\hline & & & & \\
\hline & & & & \\
\hline & & & & \\
\hline & & & & \\
\hline & & & & \\
\hline & & & & \\
\hline & & & & \\
\hline & & & & \\
\hline & & & & \\
\hline & & & & \\
\hline & & & & \\
\hline & & & & \\
\hline & & & & \\
\hline & & & & \\
\hline & & & & \\
\hline & & & & \\
\hline & & & & \\
\hline
\end{tabular}




\section{Staff Communication Log (Classified)}

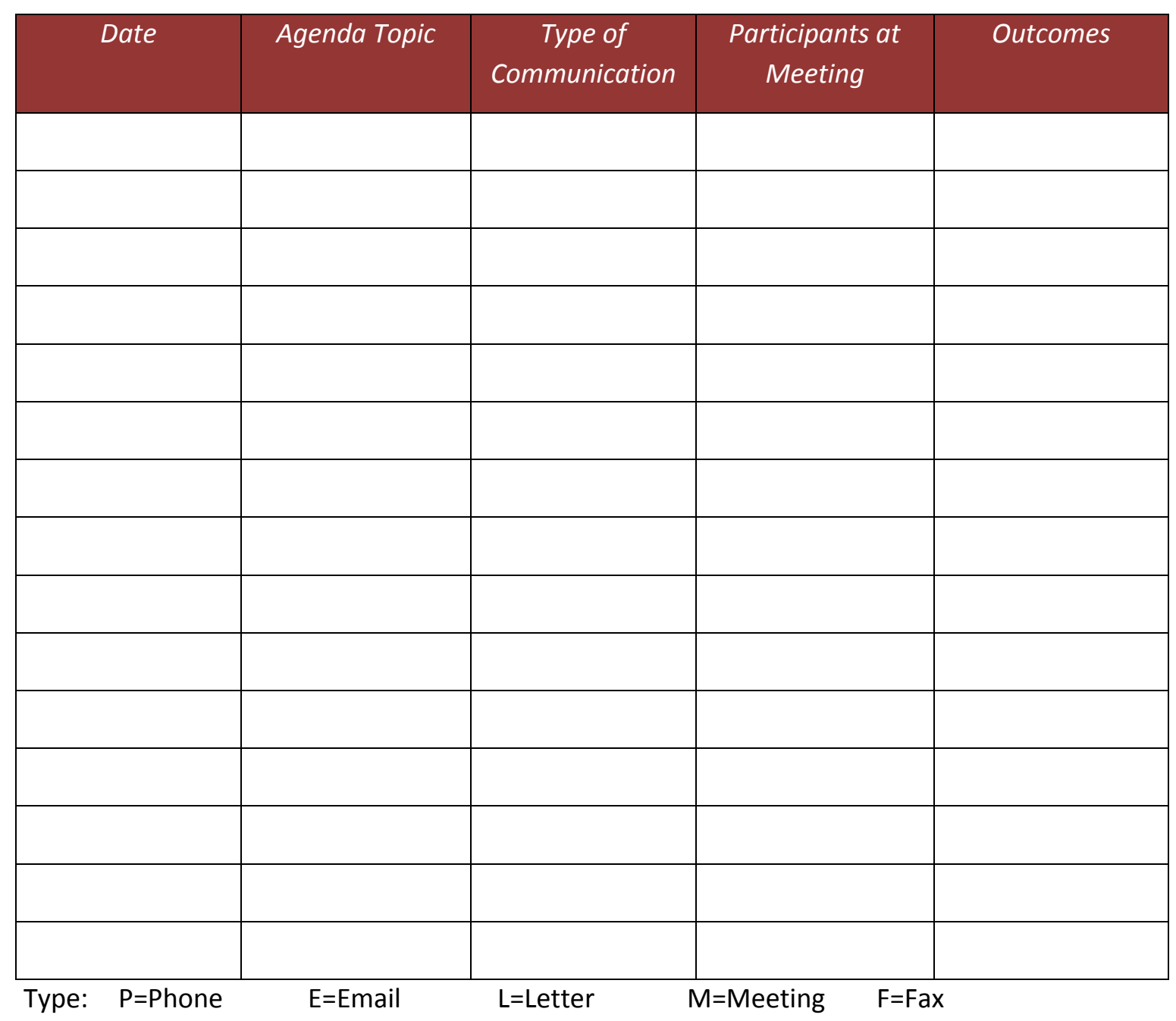




\section{Community Communication Log}

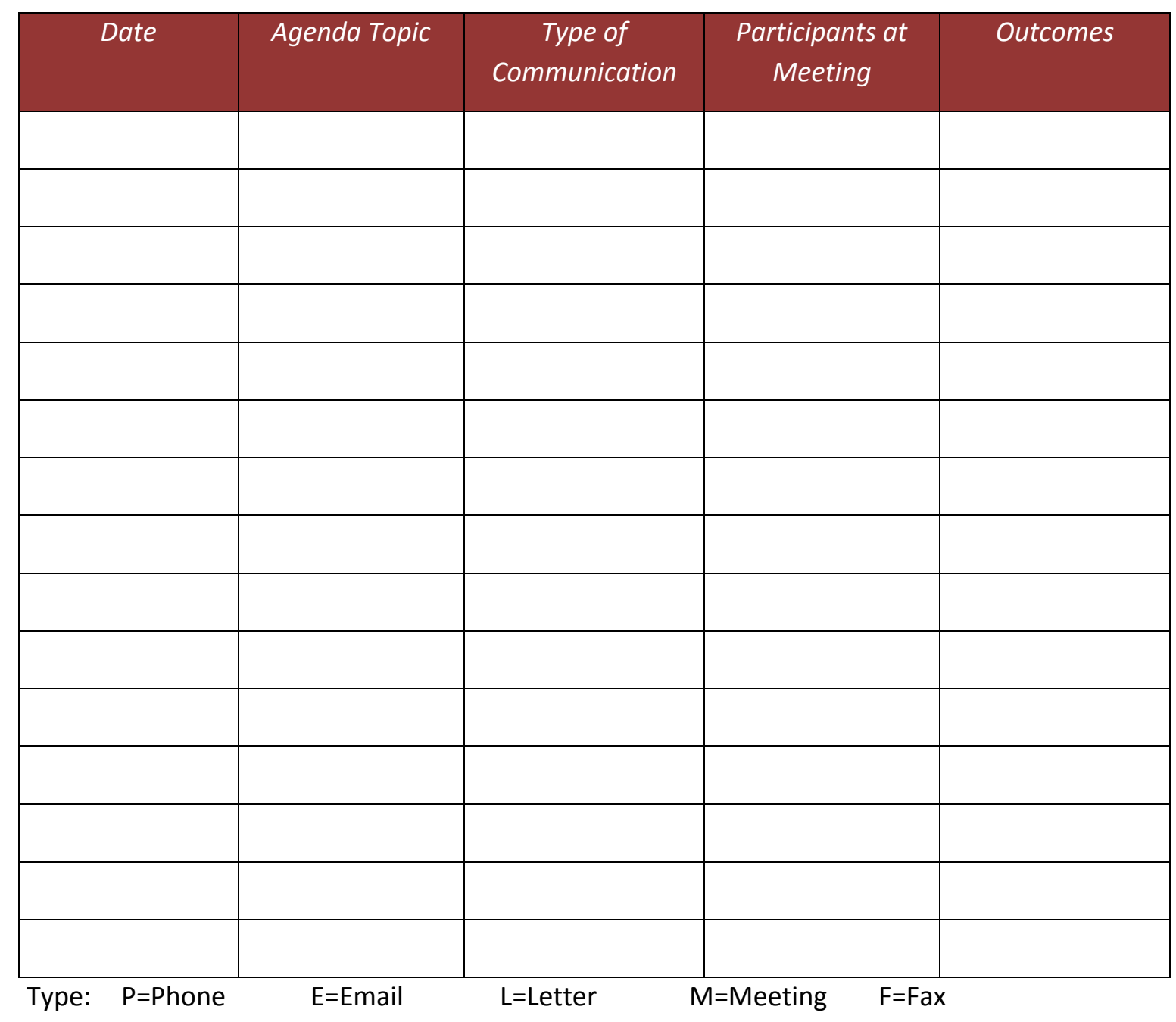




\section{Technical Assistance}

"Educators often use the term technical assistance to define services delivered or received in the pursuit of school and district improvement initiatives. More specifically, technical assistance can be defined as any assistance that identifies, selects, or designs research-based solutions and practices to support school improvement." (Mattson \& McDonald, 2005)

Collaboration is key when school districts and technical assistance providers formulate, implement, and evaluate a technical assistance plan. Collaboration requires an investment of time on the parts of both the district and the provider; however, it increases the likelihood that the resulting technical assistance will be designed appropriately, delivered efficiently, and most importantly, results in an improvement in targeted areas.

The ability to foster real change through new practices requires that the recipient be provided with opportunities and assistance to work with the information, through inquiry and innovation, to put the new ideas and information into practice (Senge, 1990).

1. analyzing data from the state assessments, and other

examples of student work to identify and address areas

$$
\text { of need; }
$$

2. identifying and implementing professional

development, instructional

strategies, and methods of instruction to improve the school's weak areas

that caused the school to be identified for school improvement; and 


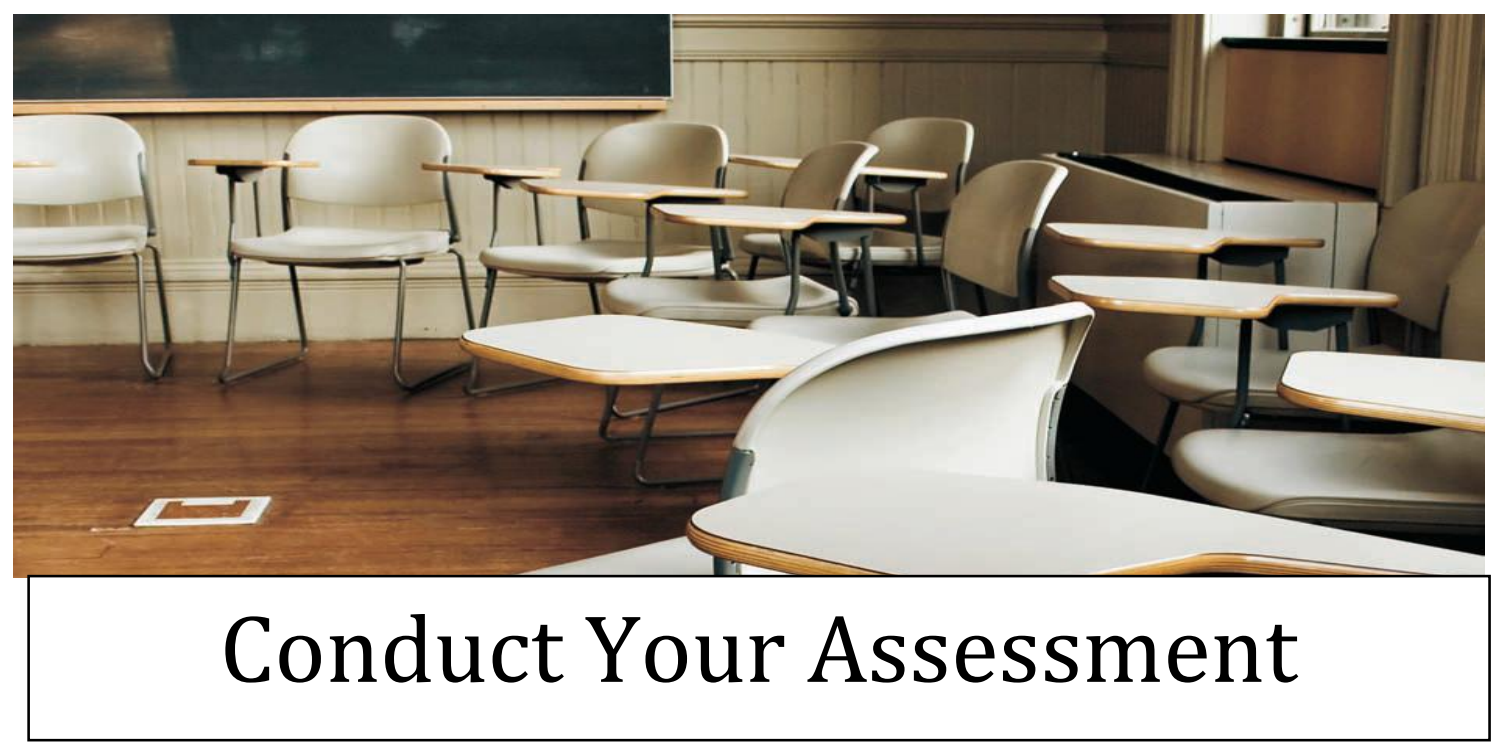

\section{Creating Your Survey}

Building and authoring your survey is easy Question Wizard when you take advantage of the use of technology. Many websites such as Question Wizard and Survey Monkey guide you through the process of creating the questions. Everything is done using an Internet browser. The survey builder allows you to create surveys by copying a survey template from the survey library, or by custom building your own survey from scratch. From the builder, you create, edit, test, and perform administrative functions for your survey...

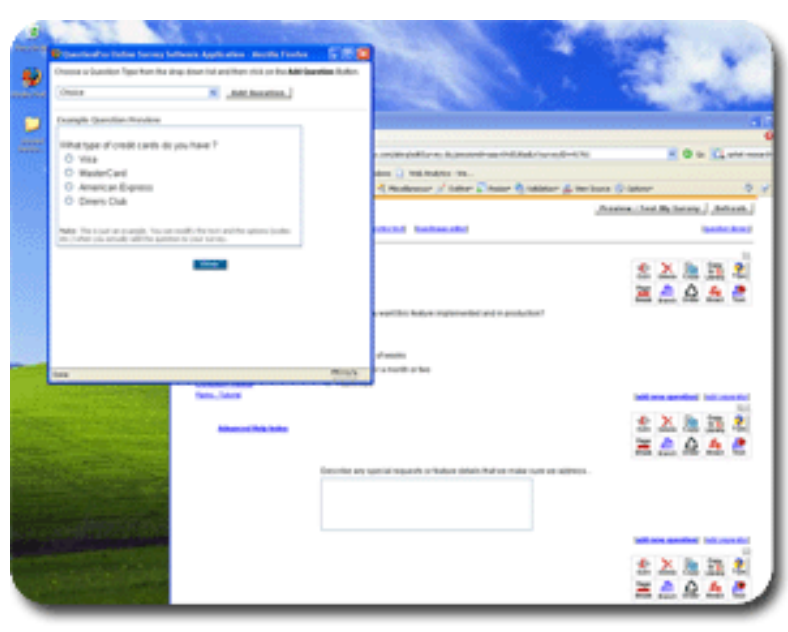

$\underline{\text { View Full Image }}$ 


\section{Question Types:}

- Yes/No

- Open-ended text responses (long answer and short answer)

- Totally customizable Scales (any number of scale points: 3, 5, 7 point scales and any scale type such as agreement, preference, importance, satisfaction, attribute based, etc.)

- Multiple choice, select exactly 1 of $n$ (select a single answer)

- Multiple choice, select exactly $k$ of $n$ (select a fixed number of answers)

- Multiple choice, select as many as $\mathrm{k}$ of $\mathrm{n}$ (select variable number of answers)

- Multiple question batteries (multiple questions using the same scale)

- Rank order (select first choice, second choice...)

- Constant Sum (allocate 100 points among choice options)

- Conjoint full profile descriptor

- Horizontal Scale, Vertical Scale

- Optional Questions, Forced Questions

- Randomization of questions and answers

- Complete Branching

Key suggestion: Conduct Your Parents Survey in a School Computer Lab during Parent Conferences.

These websites also allow the data collection process to be quick and painless. Be sure to have your questions align on the Parent, Staff and Student Surveys. It will also help to build your surveys around ODE's 5 key dimensions areas. Please take a look at the example below.

Survey Alignment Example: Please Refer to Tool 5.0 Survey Alignment on page 61

\begin{tabular}{|l|l|l|l|}
\hline & Staff & Students & Parents \\
\hline Student Achievement & $\begin{array}{l}\text { I use PBIS in my } \\
\text { classroom. }\end{array}$ & $\begin{array}{l}\text { I know the 3 PBIS } \\
\text { rules. }\end{array}$ & $\begin{array}{l}\text { My child understands } \\
\text { and follows the PBIS } \\
\text { rules. }\end{array}$ \\
\hline
\end{tabular}

*Schoolwide Title Survey Examples located in Appendix 


\section{Survey Monkey Question Example}

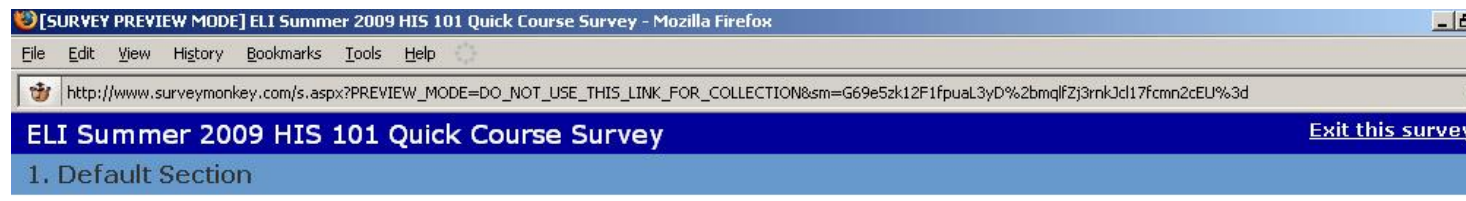

* 1. Who was your instructor for the course?
DelGallo
Esposito
$\Gamma$ Hook
$\Gamma$ Howard
$\Gamma$ Montaner
Porter

* 2. On average, how quickly were your assignments graded and emailed back to you?
Г 24 hrs or less
Г 24 to $48 \mathrm{hrs}$
Г 48 to $72 \mathrm{hrs}$
More than 72 hrs.

* 3. Overall, were you satisfied with the ability to contact your instructor and receive a quick reply to your questions? $\Gamma$ Yes $\Gamma$ No

* 4. Did your instructor send you periodic reminders/announcements about critical course dates and assignments during the course?
Tres
No
$\Gamma$ sometimes

5. Were you satisfied with the feedback that you received on assignments?
Tres
No
Tometimes

6. Was the course gradebook and the explanation of grading in the course clear?

Tres $\Gamma$ No

7. Have you been able to use the $\mathrm{BB}$ discussions either for discussing the assignments or reviewing the materials in the course?
Tres
No
$\Gamma$ sometimes

Done I

\begin{tabular}{|c|c|c|c|c|c|}
\hline \multicolumn{6}{|l|}{ Done } \\
\hline At start & (3) SurveyMonkey - Questio... (3) Downloads & (C) Windows Media Player & $\longdiv { \text { (3) [SURVEY PREYIEW MO... } }$ & Ps Adobe Photoshop CS3 E... & $\ll 5: 42 \mathrm{~F}$ \\
\hline
\end{tabular}




\section{SURVEY DISSEMINATION AND COLLECTION STRATEGY}

"I"Dissemination means more than simply "getting word out," but rather a process by which information is gathered and folded into the dissemination process. What follows is a more detailed explanation of some of the issues around reporting and disseminating.

A critical part of conducting your comprehensive needs assessment is disseminating your survey. Planning the way that you will get authentic feedback from as many parents, students and staff member is a key factor in finding trends of the strengths and weaknesses of the school.

"I) What other schools have done: Many schools find that the best way to disseminate and collect surveys in through the use of technology. Several schools used websites such as Survey Monkey to quickly conduct their surveys. One school used its computer lab during the day to survey students by classroom. The staff meeting was used the same way to conduct the staff surveys, and parent conferences and Open House were the ways they conducted the parent surveys.

" " The benefit: Immediate feedback, the data is clean of bias and influence. There is a good potential for receiving a large number of students and staff participants.

"I) The risk: The parent participation is dependent on event attendance and willingness to participate.

" "What other schools have done: Along the lines of technology, many schools now have access to response clickers, which are used in classrooms to measure student participation and engagement. These clickers can be used in conjunction with a Smart Board via PowerPoint to solicit responses from student, parents, and staff members.

"IIThe benefit: Immediate feedback, the data is clean of bias and influence. There is a good potential for receiving a large number of students and staff participants.

" "I The risk: The parent participation is dependent on event attendance and willingness to participate. 
" " Develop A Dissemination Plan: how will you solicit your survey to students, parents and staff. How will you share the key findings with your SPT and staff?

" Determine how the survey will be disseminated, and then assign timelines and responsibilities.

"What do you hope to accomplish?

"What are the existing issues and concerns?

„What likely motivate your team to take action?

» What can we gain from gathering information from each group?

"What is the perception of the school culture?

"What is the most beneficial way to share these results? 


\section{Tool 4.5 Cultural Assessment/School Community Notepad}

Review these guiding questions as you involve your school community, save your notes to use in assisting you to complete the writing portion of the grant.

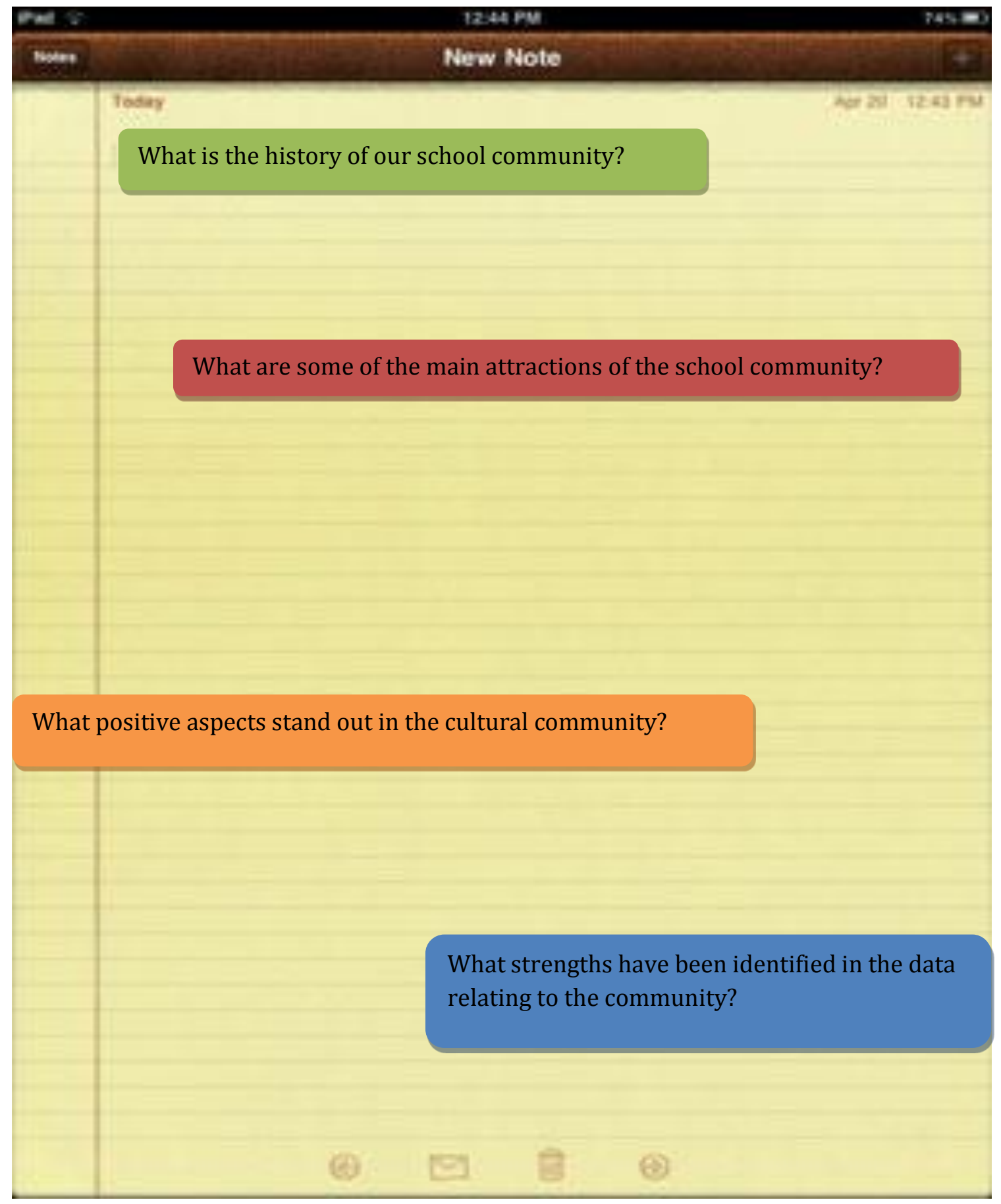




\section{Community-School Partnership}

Building and maintaining effective community school partnerships requires dedicated time and ongoing attention to the collaborative process. This checklist focuses on the process of bringing partners together and working to achieve desired results. This checklist can help partnerships to focus on, assess, and improve the quality of their collaborative efforts.

Our partnership has developed a clear vision.

\section{$\begin{array}{lllllll}\text { Disagree } & 1 & 2 & 3 & 4 & 5 & \text { Agree }\end{array}$}

Our partnership has collaboratively identified the results we want to achieve for children, youth, families, and our community.

\section{$\begin{array}{lllllll}\text { Disagree } & 1 & 2 & 3 & 4 & 5 & \text { Agree }\end{array}$}

Our partnership has successfully engaged a broad base of partners from a range of individuals and organizations representing the school and the community.

\section{$\begin{array}{lllllll}\text { Disagree } & 1 & 2 & 3 & 4 & 5 & \text { Agree }\end{array}$}

Our partnership has developed strategies for coordinating and linking the array of supports and opportunities for children, youth, families, and community members that are available at, or connected to, the school.

\section{$\begin{array}{lllllll}\text { Disagree } & 1 & 2 & 3 & 4 & 5 & \text { Agree }\end{array}$}

Our partnership has established a clear organizational structure. Our partnership has agreed upon the roles that individual partners will play, and ensured that all partners understand and accept the responsibilities of those roles.

\section{$\begin{array}{lllllll}\text { Disagree } & 1 & 2 & 3 & 4 & 5 & \text { Agree }\end{array}$}

All partners involved in our school community have an understanding of who the other partners are, what organizations they come from, and what those organizations do.

\section{$\begin{array}{lllllll}\text { Disagree } & 1 & 2 & 3 & 4 & 5 & \text { Agree }\end{array}$}

Our partnership regularly communicates with all partners to keep them informed about its work.

\section{$\begin{array}{lllllll}\text { Disagree } & 1 & 2 & 3 & 4 & 5 & \text { Agree }\end{array}$}

Our partnership engages in activities to create awareness about and increase support for the work of the partnership. 


\section{$\begin{array}{lllllll}\text { Disagree } & 1 & 2 & 3 & 4 & 5 & \text { Agree }\end{array}$}

Our partnership has identified and mobilized resources (financial and other) from partner organizations and other entities throughout the community.

$\begin{array}{llllllll}\text { Disagree } & 1 & 2 & 3 & 4 & 5 & \text { Agree }\end{array}$




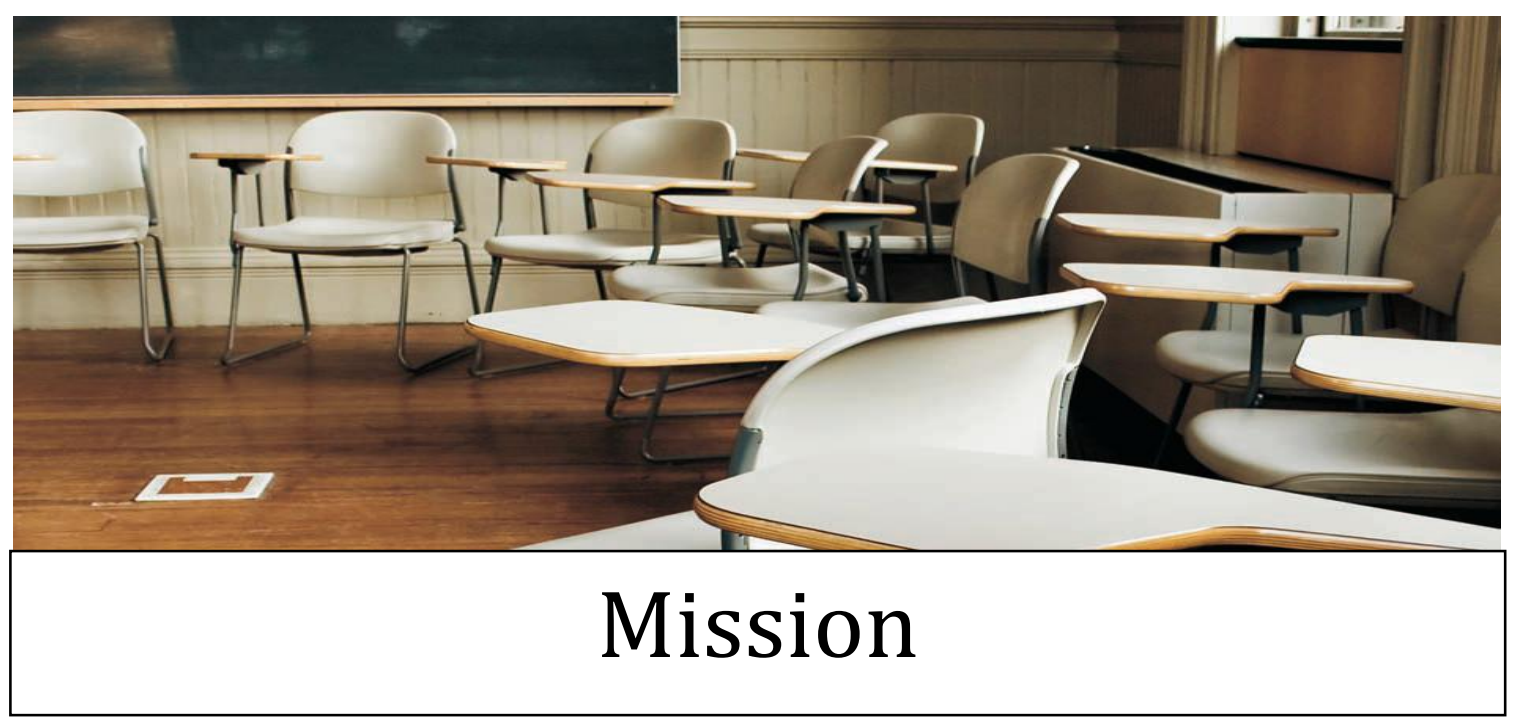

What is your school's mission? If you have to search through your handbook, or you can't recall the entire lengthy statement, you probably aren't making the most of your school's mantra. How can you make your mission statement more meaningful? Bring it into the classroom and give it vision! As you travel through the yearlong transition process, this is a great time to nail down a clear mission for your school

Mountain Gap Middle School Mission Statement

The mission of Mountain Gap

Middle School is to provide each student a diverse education in a safe, supportive environment that promotes self-discipline, motivation, and excellence in learning. The Mountain Gap team joins the parents and community to assist the students in developing skills to become independent and self-sufficient adults who will succeed and contribute responsibly in a global community. that is accepted by all.

A mission statement is the wind that brings you to your desired harbor. It guides your travel and powers your momentum. Mission statements "give educators stronger motivation and provide parents with a clearer picture of what the school values. ... A clear vision and a common mission that identify the kind of learning to be achieved can help keep the school and the efforts of its staff and students on target" (Peterson, 1995). 


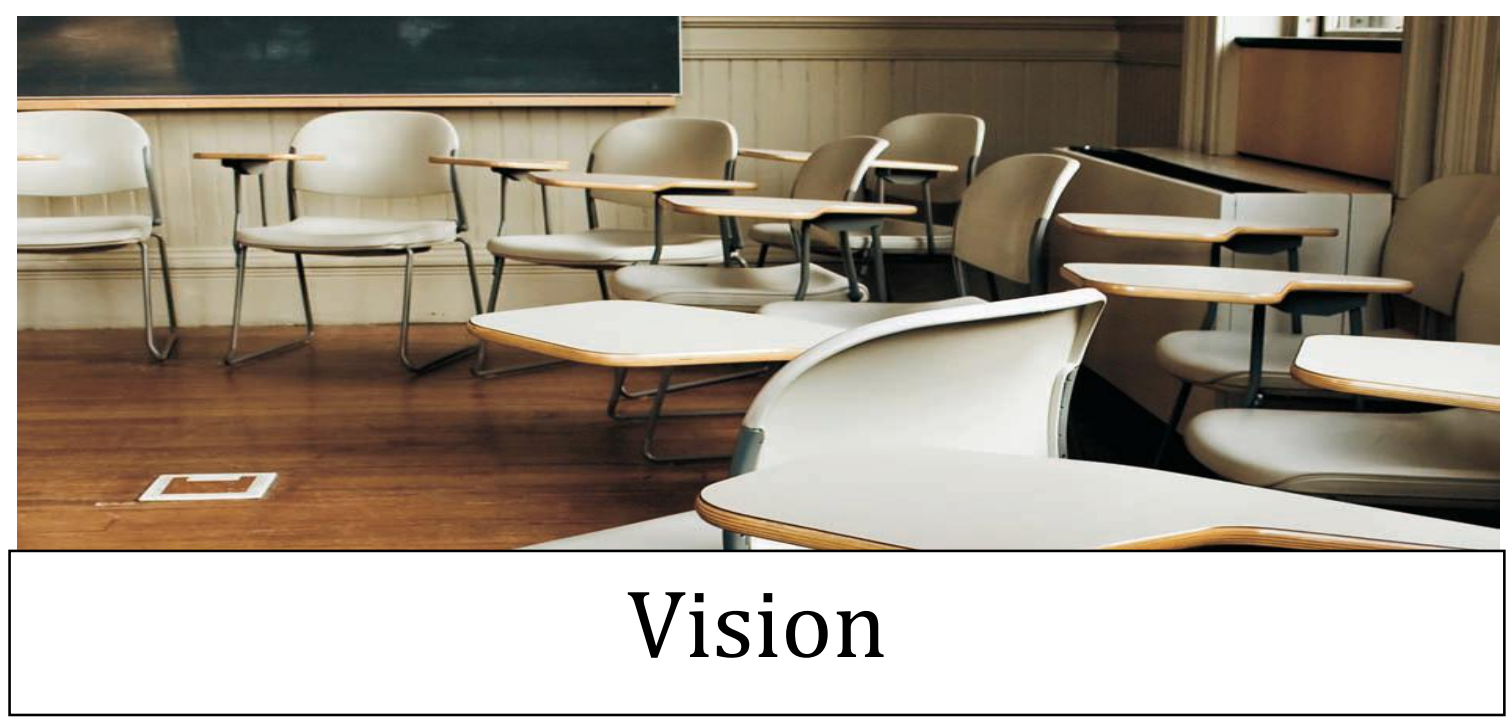

According to the Task Force on Developing Research in Educational Leadership (2003), "Effective educational leaders help their schools to develop or endorse visions that embody the best thinking about teaching and learning. Your vision should be recognized as a common direction of growth for your staff that inspires them to do better. Your vision should also inform parent and students on where the school is heading and why they should join the journey."

\section{Are we achieving our vision?}

- What evidence can you think of that we are meeting our current vision?

- What kind of school do we hope to be?

- What do you think should be reflected in our vision statement?

- What do we need to do differently to achieve this vision?

- How are we different from other schools?

\section{Brentsville's Vision}

Statement

At Brentsville District we believe that all students can learn to their fullest potential. Student learning will be enhanced by national, global, and multicultural perspectives. Graduates will possess the basic knowledge and skills that will assure their proficiency in problem solving and technology. They will be responsible citizens, lifelong learners, and will be prepared for a variety of post graduation options. 


\section{Prioritize Your Needs - Activity 2}

The purpose of this activity is to establish the area of priority in curriculum delivery. The team will break into small groups seated at separate tables in the room, each equipped with flip charts and marker.

\section{$\operatorname{soc}$}

\section{The facilitator will ask the small groups to articulate the schools strengths and weaknesses in curriculum delivery based on the presented data:}

$\checkmark$ In which areas of the curriculum are our students performing well? (a possible answer could be " 6 th grade Geometry") List answers under the heading "Strengths" on a flip chart.

$\checkmark$ In which area of the curriculum data are students performing poorly? (a possible answer could be "writing.") List the answers under the heading "Weaknesses" on another page of your flip chart. $\checkmark$ Why do you think our students are performing poorly in those areas?

\section{3}

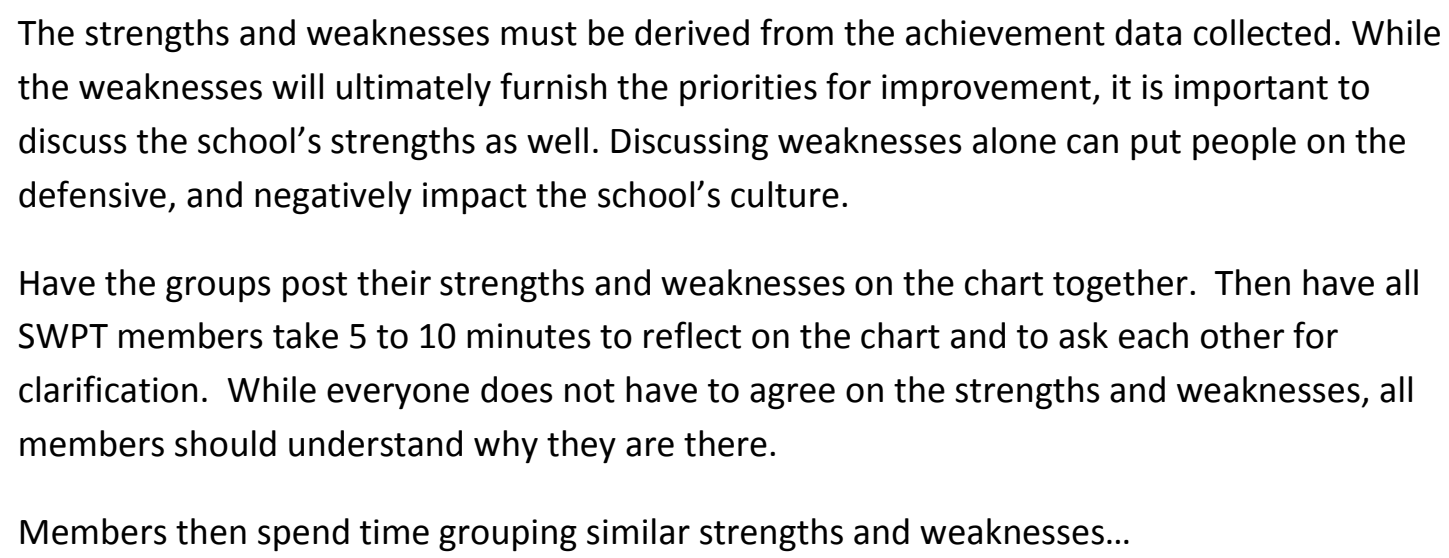


PRINCIPAL'S SCHOOL CULTURE ATLAS 4

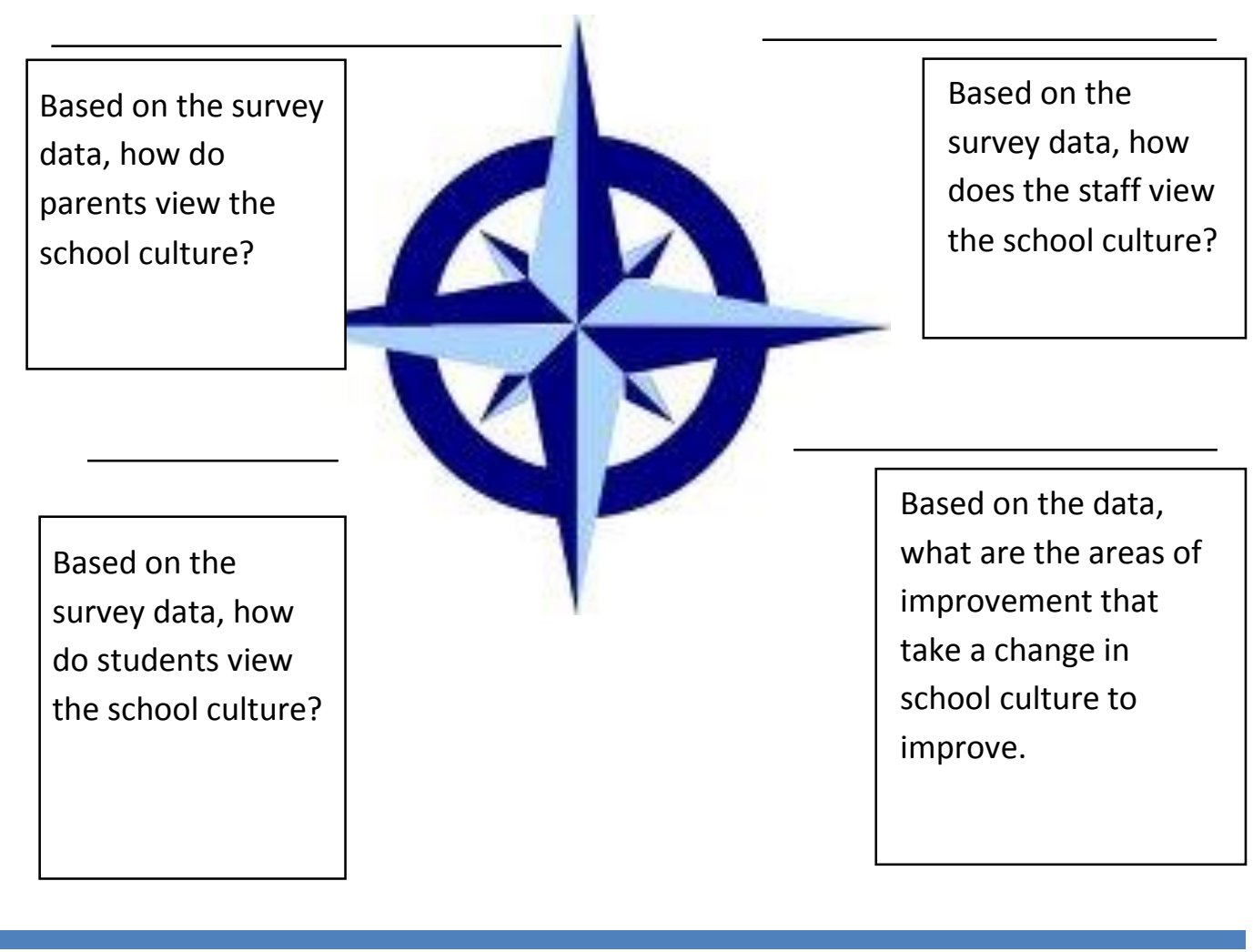

REFLECTION 

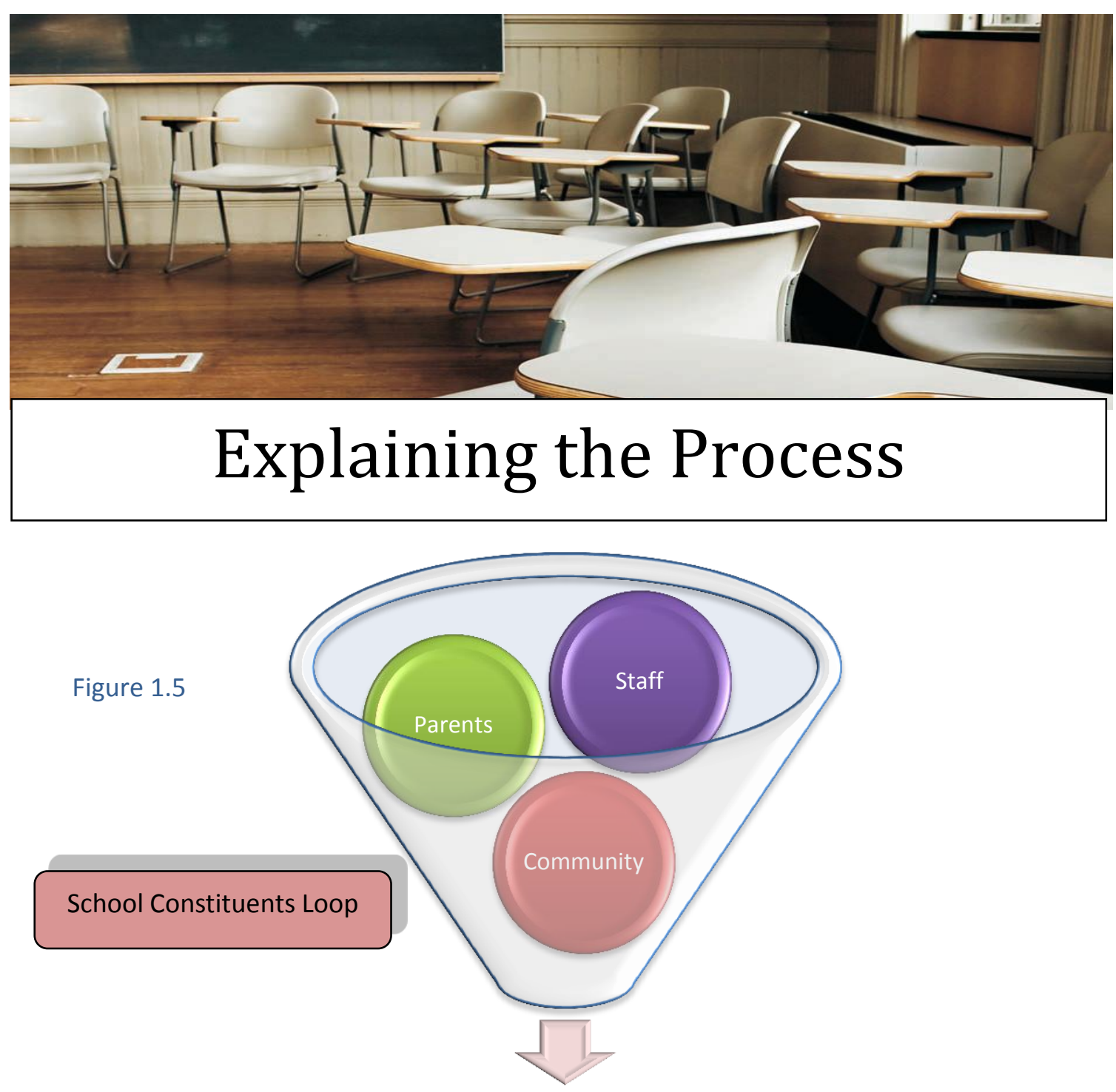

Schoolwide Plan

It is important to keep all school constituents in the loop regarding the work that the SPT is doing. Take the time at staff meetings, parent meetings, community events and student assemblies to explain the process the team is going through and how they hope to positively impact the school through this change. Cultivating these positive conversations will foster a school culture of support and shared vision. 


\section{Tool 5.0 School Compact Builder}

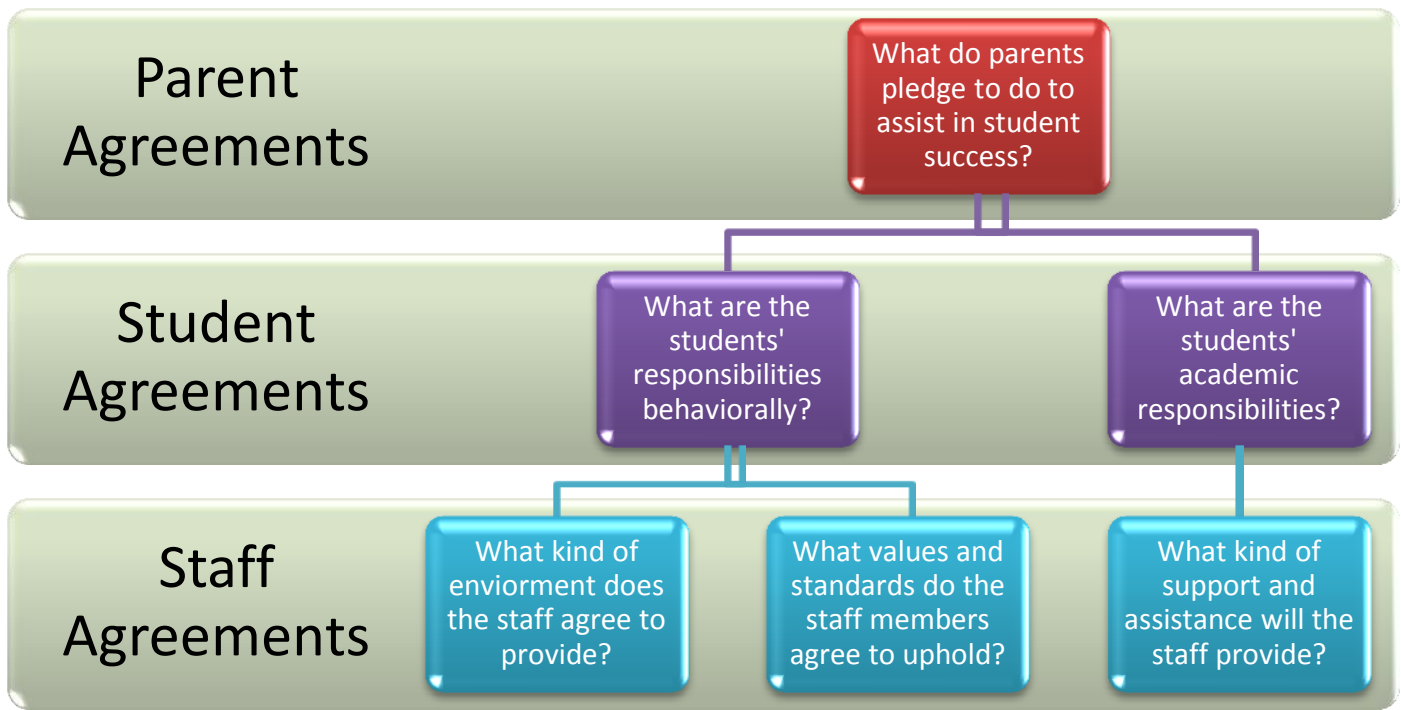

This tool can be used to give direction to the principal as they facilitate the process of building a School Compact with school constituents. Staff should be involved in creating staff agreements, and I also suggest involving parents and students in creating the agreements. Most staff agreements are also contractual agreements that are part of their job requirements. Notice, that the majority of the responsibility is held on behalf of the staff, then students, and lastly, parents.

A sample School Compact is located in the Appendix section 


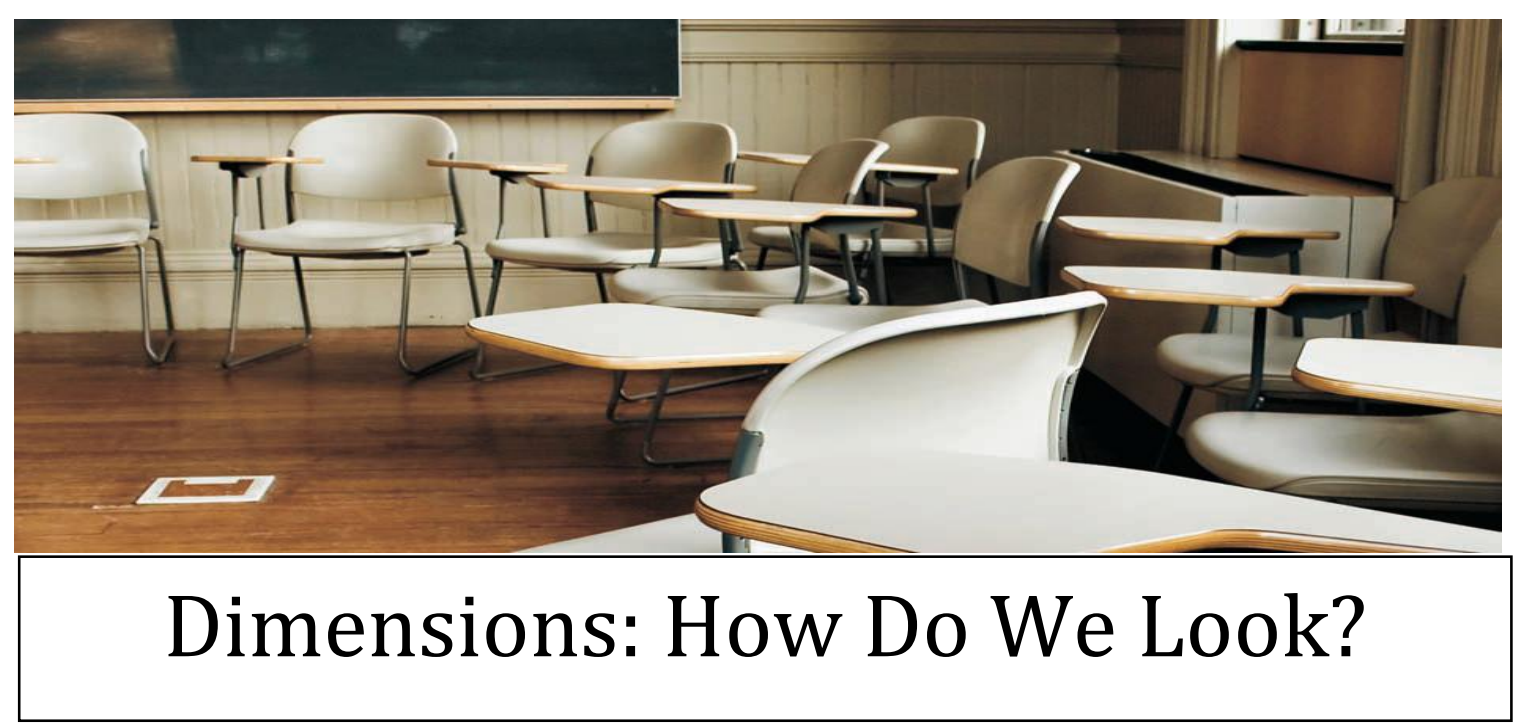

This collection tool 5.5 identifies strengths and weaknesses found in the data based on the five key dimensions. The weaknesses that are identifed will assist the planning team in creating a survey that will dig deeper into the process.

\section{Tool 5.5 Strengths \& Weaknesses Plot}

\begin{tabular}{|l|l|l|}
\hline Dimensions & $\begin{array}{l}\text { Identified Strengths: Data } \\
\text { Analysis Summary }\end{array}$ & $\begin{array}{l}\text { Identified Weaknesses: } \\
\text { Data Analysis Summary }\end{array}$ \\
\hline Student Achievement & $\square$ & $\square$ \\
\hline School Context & $\square$ & $\square$ \\
\hline Curriculum \& Instruction & $\square$ & $\square$ \\
\hline Professional Development & $\square$ & $\square$ \\
\hline Family \& Community Involvement & $\square$ & $\square$ \\
\hline
\end{tabular}




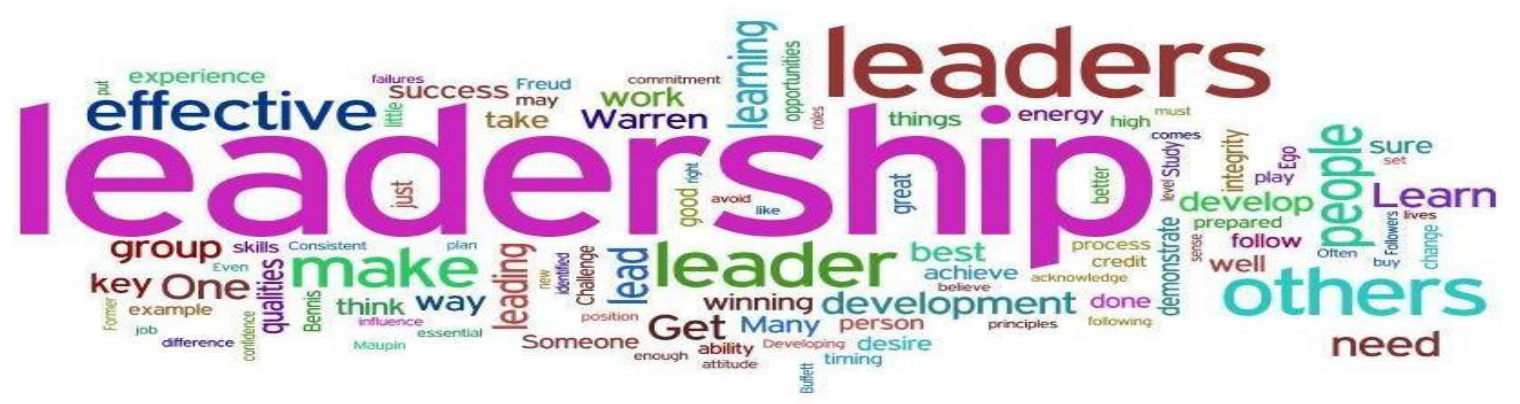

\section{Conducting Your Inquiry Process}

Nice work, you have made it half way through the yearlong transition process! Now that you have identified strengths and weaknesses your data, it is time to create a list of possible solutions to address the issues found in the data. Be sure to include not only your planning team, but also your staff and parents in narrowing down the priorities and creating solutions, and having input in the overall process. When you begin writing the grant, it is important to be able to explain the process that was used by all school constituencies to identify the needs, possible solutions, and strategies to be used to create your action plan.

\section{Possible Solution Draft Chart}

\begin{tabular}{|l|l|l|}
\hline \multicolumn{1}{|c|}{$\begin{array}{c}\text { Instructional } \\
\text { Focus }\end{array}$} & \multicolumn{1}{|c|}{ Priority } & \multicolumn{1}{c|}{ Possible Solutions } \\
\hline Example: Writing & $\begin{array}{l}\text { Schoolwide intervention in writing is } \\
\text { necessary }\end{array}$ & $\begin{array}{l}\text { Decide on a Schoolwide } \\
\text { writing program }\end{array}$ \\
\hline & & \\
\hline
\end{tabular}




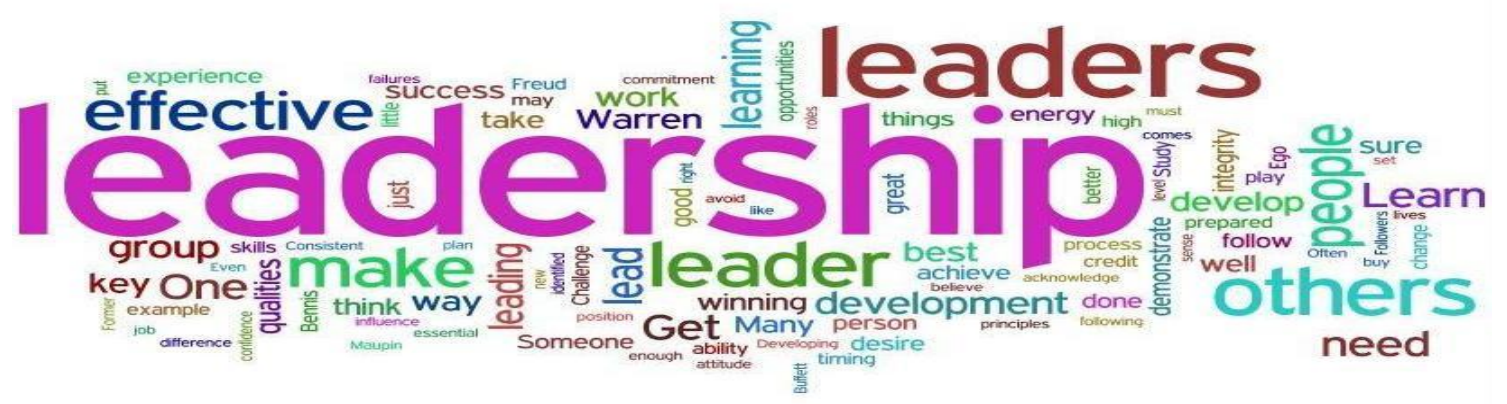

\section{Tool 6.0 Survey Alignment}

\begin{tabular}{|c|c|c|c|}
\hline Survey Quest. \# & Staff & Students & Parents \\
\hline 1.Example column & $\begin{array}{l}\text { I believe students } \\
\text { show respect for all } \\
\text { adults in the school. }\end{array}$ & $\begin{array}{l}\text { I show respect to all } \\
\text { adults in school. }\end{array}$ & $\begin{array}{l}\text { Students show } \\
\text { respect for all } \\
\text { adults in the school. }\end{array}$ \\
\hline 2. & & & \\
\hline 3. & & & \\
\hline 4. & & & \\
\hline 5.Example column & $\begin{array}{l}\text { I communicate } \\
\text { regularly with } \\
\text { parents on } \\
\text { behavioral issues. }\end{array}$ & $\begin{array}{l}\text { I take home } \\
\text { important } \\
\text { information and talk } \\
\text { to my parents about } \\
\text { what is going on in } \\
\text { school. }\end{array}$ & $\begin{array}{l}\text { I regularly read the } \\
\text { information that is } \\
\text { sent home. }\end{array}$ \\
\hline 6. & & & \\
\hline 7 & & & \\
\hline 8. & & & \\
\hline 9. & & & \\
\hline 10.Example column & $\begin{array}{l}\text { I utilize volunteers in } \\
\text { my classroom. }\end{array}$ & $\begin{array}{l}\text { Parents come to my } \\
\text { classroom to help } \\
\text { students with their } \\
\text { work. }\end{array}$ & $\begin{array}{l}\text { I know what } \\
\text { volunteer } \\
\text { opportunities are } \\
\text { available at my } \\
\text { school. }\end{array}$ \\
\hline
\end{tabular}




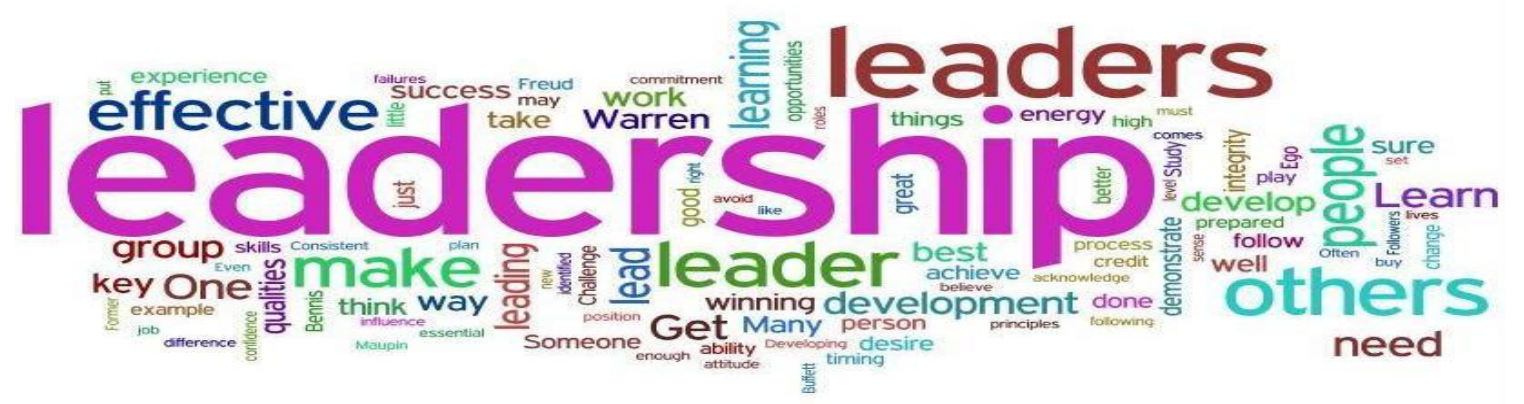

\section{Site Visits to Benefit Your Plan}

\section{"Nothing is more persuasive to staff than hearing and seeing school-change stories from the perspective of other practitioners." (Chenoweth \& Everhart, 2002).}

There are a few reasons that some schools may opt out of conducting site visits (also known as site inspections) of schools that are functioning under a Schoolwide Title I model. However, while good reasons may exist from their perspective for not conducting site visits or inspections, I believe the benefits outweigh the drawbacks by a huge margin. Time and cost are usually the main objections to conducting site visits. The time excuse - and in my mind, that's all it is - falls apart when you lose precious time later in the planning process dealing with issues that could have been addressed and resolved during the site visit. Managing costs is a bit trickier, but the impact of cost can be reduced with smart planning. Now, I did mention some benefits... so what are they?

First and foremost, bringing team members with you to see things that are working or not working in other schools motivates your team and gives them ideas and fresh perspectives. A site inspection should include every aspect of the school and its school culture - it is important to document what is observed to benefit the success of the plan that you are creating - when 
observing take detailed notes. Just because something is successful in one school does not mean that it will always work in another school, but it is good to have a variety of options and ideas available to you. If possible, set up a few site visits to successfully functioning Schoolwide Title I programs and get as many team members to participate as you possibly can. Tool 5.5 Site Visit Tour Guide will provide you and your planning team with a template for what to look for while conducting your visit. At the end of each day be sure to debrief. Spend time discussing what you have learned on your site visits at your next Schoolwide Planning team meeting, staff meeting, and Site Council meeting.

I highly recommend that SPT conduct at least three site visits of Title I schools working under the Schoolwide program model. Principals who provided these opportunities for their teams saw positive changes in motivation, as well as readiness in adapting to change. Looking at schools that have made successful transitions and are actively supporting all students through a Schoolwide model sparks ideas and possibilities of what may be beneficial in their own schools. 


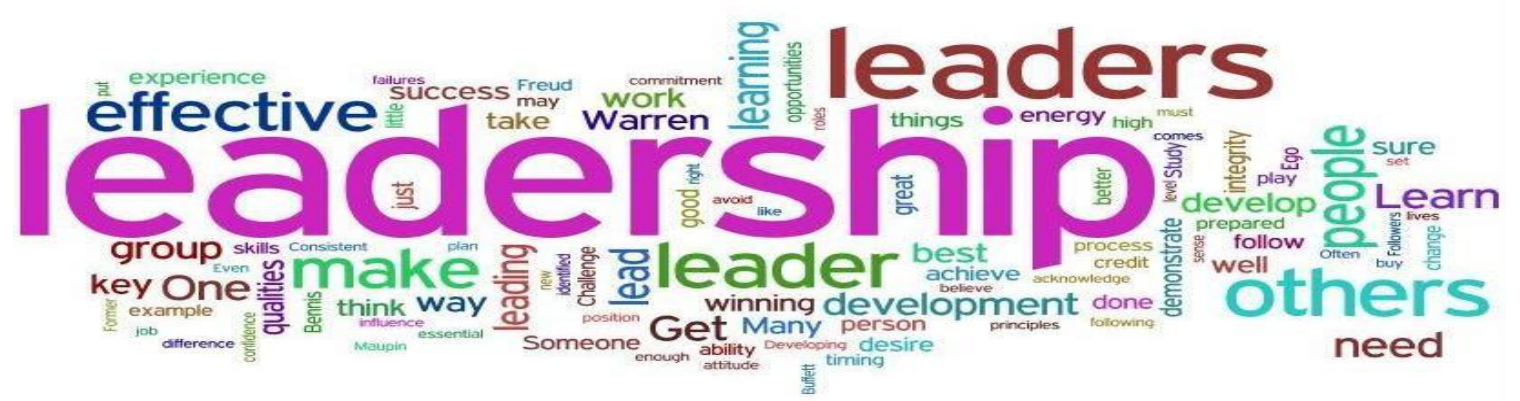

\section{Tool 6.5 Site Visit Tour Guide (a)}

Readiness: Is the majority of the staff supportive of the Schoolwide Program?

Vision: Is there a shared sense of purpose? Can the staff articulate the school's vision and priorities?

\section{Meaningful Change}




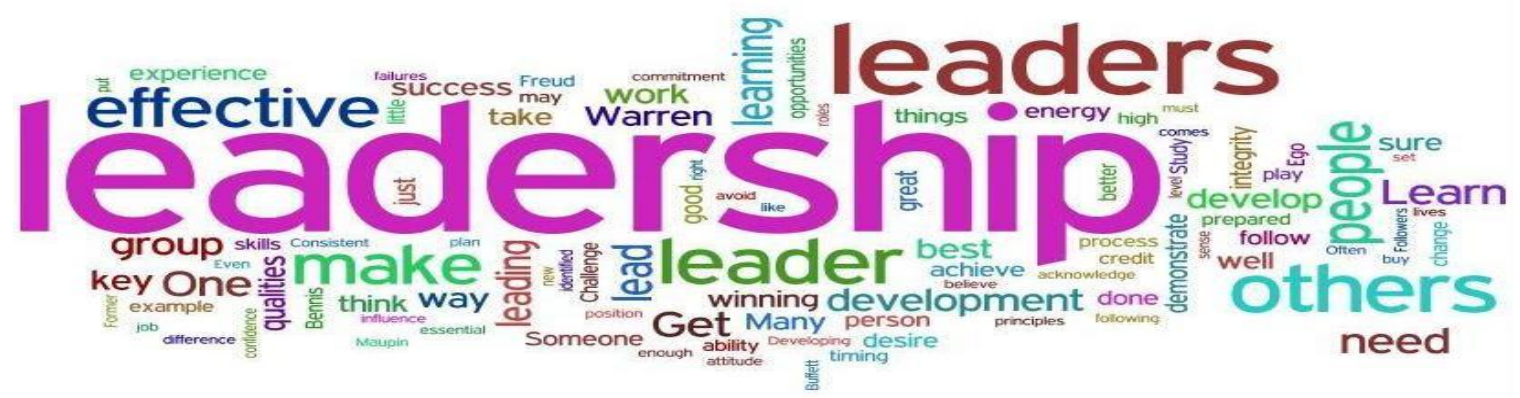

\section{Tool 6.5 Site Visit Tour Guide (b)}

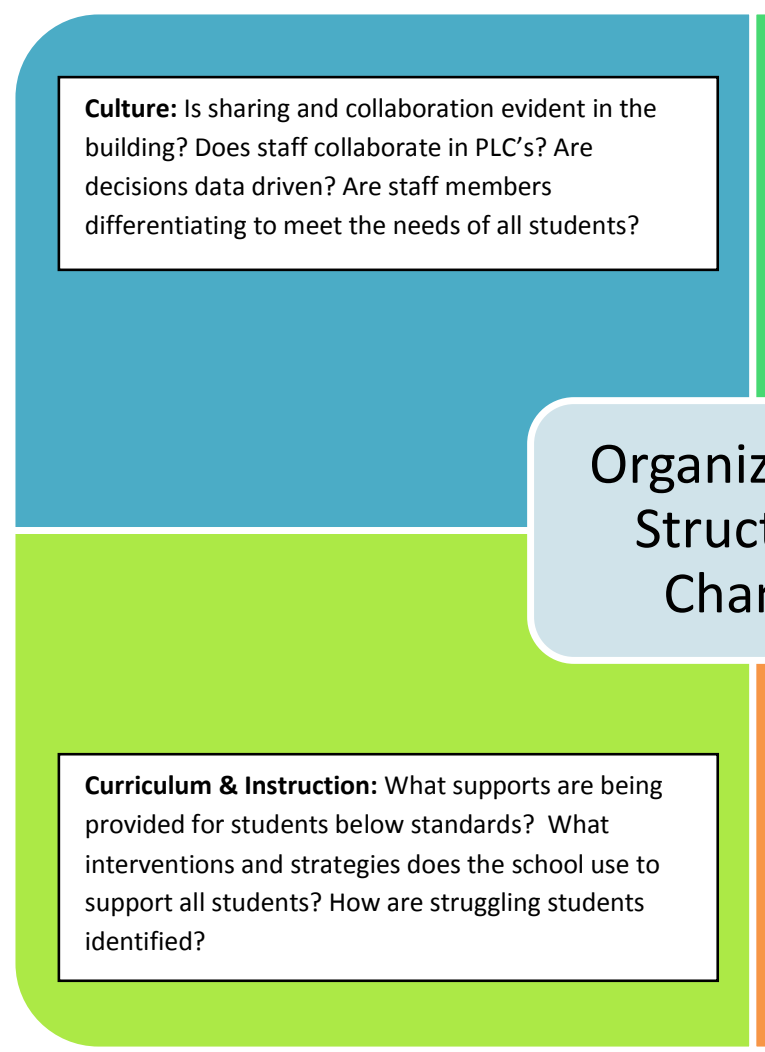

School Governance: How are decisions made and who makes them? Are there procedures for problem solving and inquiry?

Assessment and Feedback: Does the school openly solicit diagnostic information from multiple sources? How does the school reflect upon its practice? 


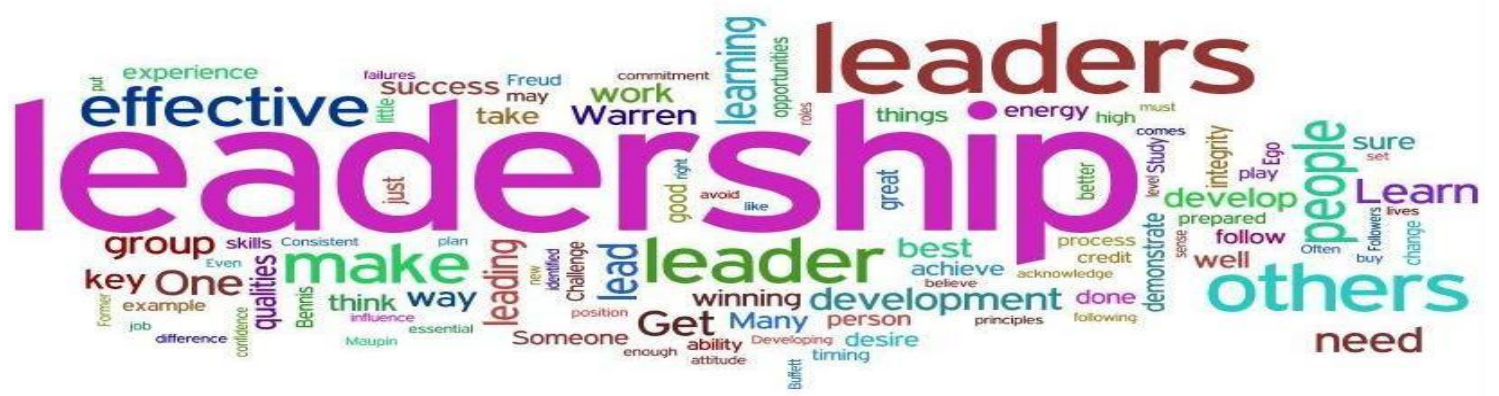

\section{Tool 6.5 Site Visit Tour Guide (c)}

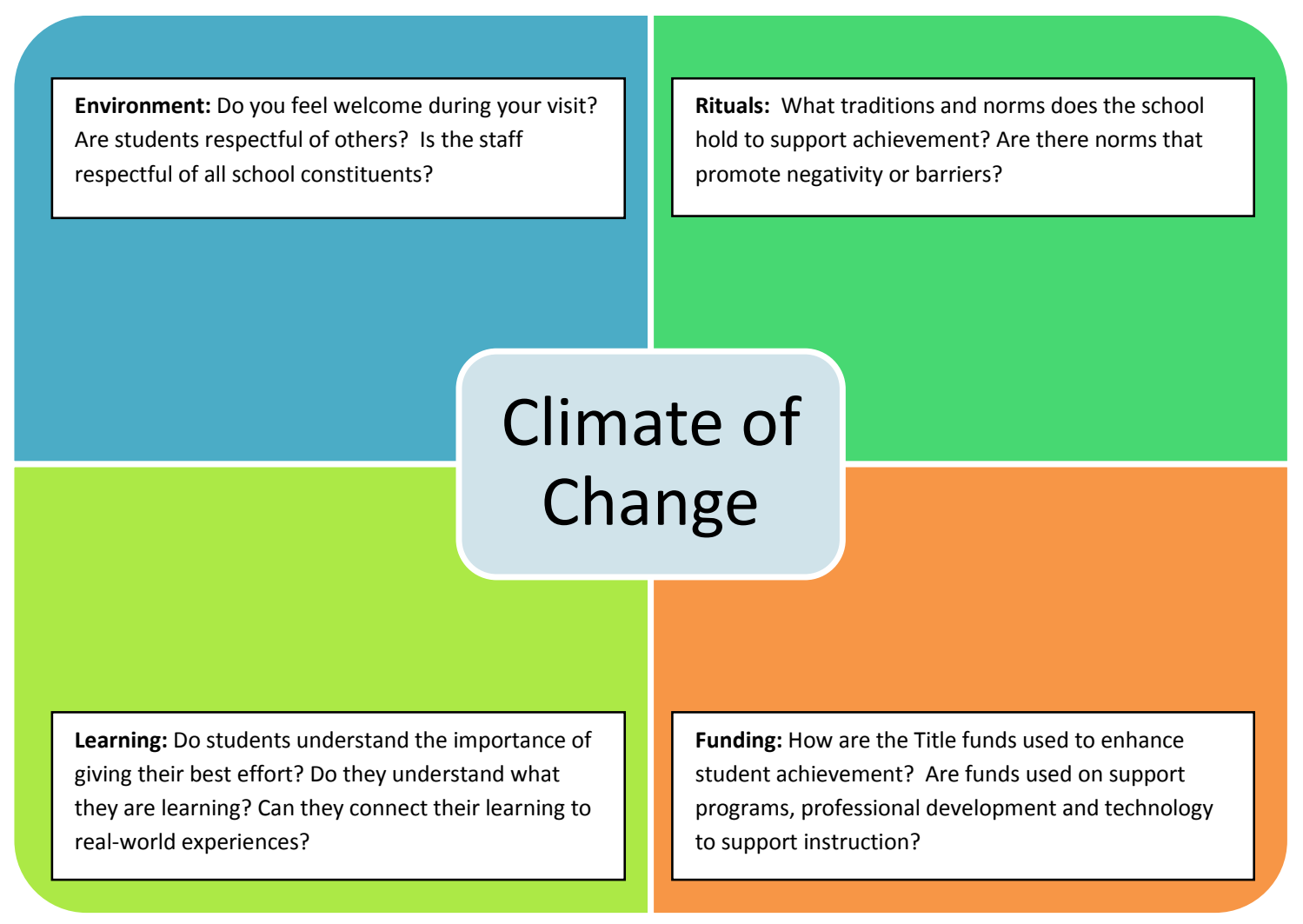




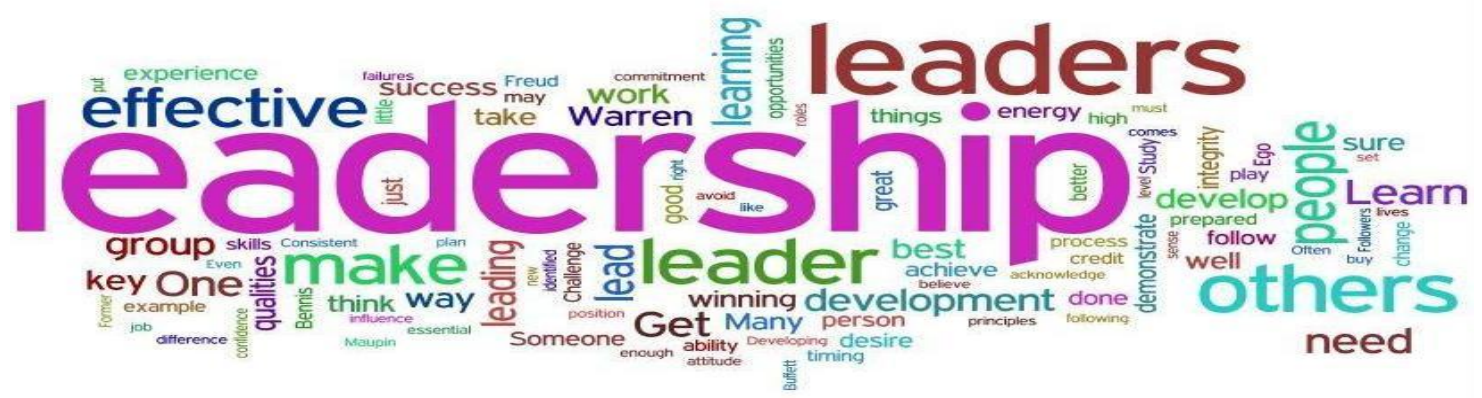

Although school site visits can be very insightful, without the proper guidance it can be much like trying to understand Nike's company culture by touring their Corporate Headquarters. You will only be able to glean a small viewpoint or perspective of what is happening behind the scenes. Most brief visits to organizations provide inadequate information with regard to culture as well insight as to why a program is effective or ineffective. Exhibit 1.3 is based on the Chenoweth and Everhart's tour guide model (2002). The figure has been modified to assist Schoolwide Planning Teams in gaining as much helpful information as they possibly can during their site visit. The data that is collected from the Site Visit Tour Guide will assist you in the Inquiry Process section of your Schoolwide grant, so be sure to store the information for later use. 
The Site Tour Guide focuses on the meaning of change, organization or structure of change, and the climate of change. The questions will help your SPT get a strong sense of the culture of the school as well as spark discussion around the Schoolwide implementation in terms of staff buy-in, fluidity of program, and student support systems. The meaning of change focuses on the staffs' feelings, perceptions, and understanding of the Schoolwide program and the reason behind the change. Structure of change focuses on school governance, instruction, and assessment. Climate of change focuses on the feeling of the school regarding respect for all and a culture of achievement.

Although school visitors and researchers try to be as discreet as possible, gathering staff for focus groups, interviews, and classroom observations is innately disruptive. To ensure that your SPT is collecting enough data to get an accurate picture of the school's culture, strengths and challenges, the team of researchers must talk with as many school constituencies throughout the day as possible. Although this will create work for the school administration at the building which you are visiting, it should be doable if they are given clear directions and ample lead time. 


\section{The Process}

1) Contact the schools you plan to visit well in advance to set up a visitation day.

Choose a day that school administrators and counselors will be there so they can be interviewed.

2) Create a letter of notification for the school concerning your site visit (see Appendix A). The letter should explain the reason for the visit, who will be involved, and how the data will be used. School administrators are responsible for setting up the interviews and focus groups for the day. Include the sample interview/focus group schedule to assist them in planning the day. Exhibit 1.4 shows a sample schedule that you might include with your letter. If possible, ask the school to email you the visitation schedule prior to your visit, so the SPT team can prepare. 


\begin{tabular}{|c|c|}
\hline Figure 1.6 & Interviews and Focus Group Schedule \\
\hline $\begin{array}{c}\text { Time } \\
\text { (please complete } \\
\text { this section) }\end{array}$ & Participants \\
\hline \multirow[t]{4}{*}{ Before School } & Schoolwide Planning Team (45 min.) \\
\hline & Principal and Assistant Principals \\
\hline & Parents (45 Min.) \\
\hline & Counselors (45 Min) \\
\hline \multirow[t]{3}{*}{ During Lunch } & $\begin{array}{c}\text { Students Volunteers, representing grades } 4 \text { or above (approximately } 6 \text { to } 8 \\
\text { students ( } 45 \mathrm{~min} \text {.) }\end{array}$ \\
\hline & Classified Staff (45 min.) \\
\hline & Instructional Staff (45 min.) \\
\hline After lunch & Instructional Staff (45 min.) \\
\hline
\end{tabular}

* The day can be arranged in different ways to work best for your staff. The length of time noted for each interview/focus group is preferred but can be adjusted. We would like our reviewer to talk with at least two groups of instructional staff. 
1) Arrive early and be flexible. Be sure that your team is prepared to collect as much data as possible.

3) Break into small teams. Some of your reviewers will be conducting classroom observations and participating in interviews when permitted. Others will be conducting interviews and focus groups when possible. If helps to have a clear idea of who will be doing what before they arrive.

4) Site Visit Tour Guide. As you conduct your site visit use the tour guide to gather information that will be meaningful to your school's transition

5) Interview/ Focus Group Protocols. To ensure that the research is specific to the data, you will need to assist your school in the Schoolwide program transition, and create written protocols for your SPT to use to guide their inquiry.

Reviewers conducting focus groups should remember the following tips:

- Encourage participants to talk to each other.

- Let the participants know that the discussion will provide you with multiple perspectives, disagreement is ok.

- Allow all members an opportunity to give their input or perspective.

6) Thank you notes. After visiting follow up with a thank you to the school administration and staff for their time and effort. Thank you notes or emails help build cordial relationships with other schools. 


\section{Debrief your findings}

Debriefing will provide your team the opportunity to reflect on the experience, and make it meaningful by identifying what was learned that will be beneficial to their schools. 
PRINCIPAL'S SCHOOL CULTURE ATLAS 5

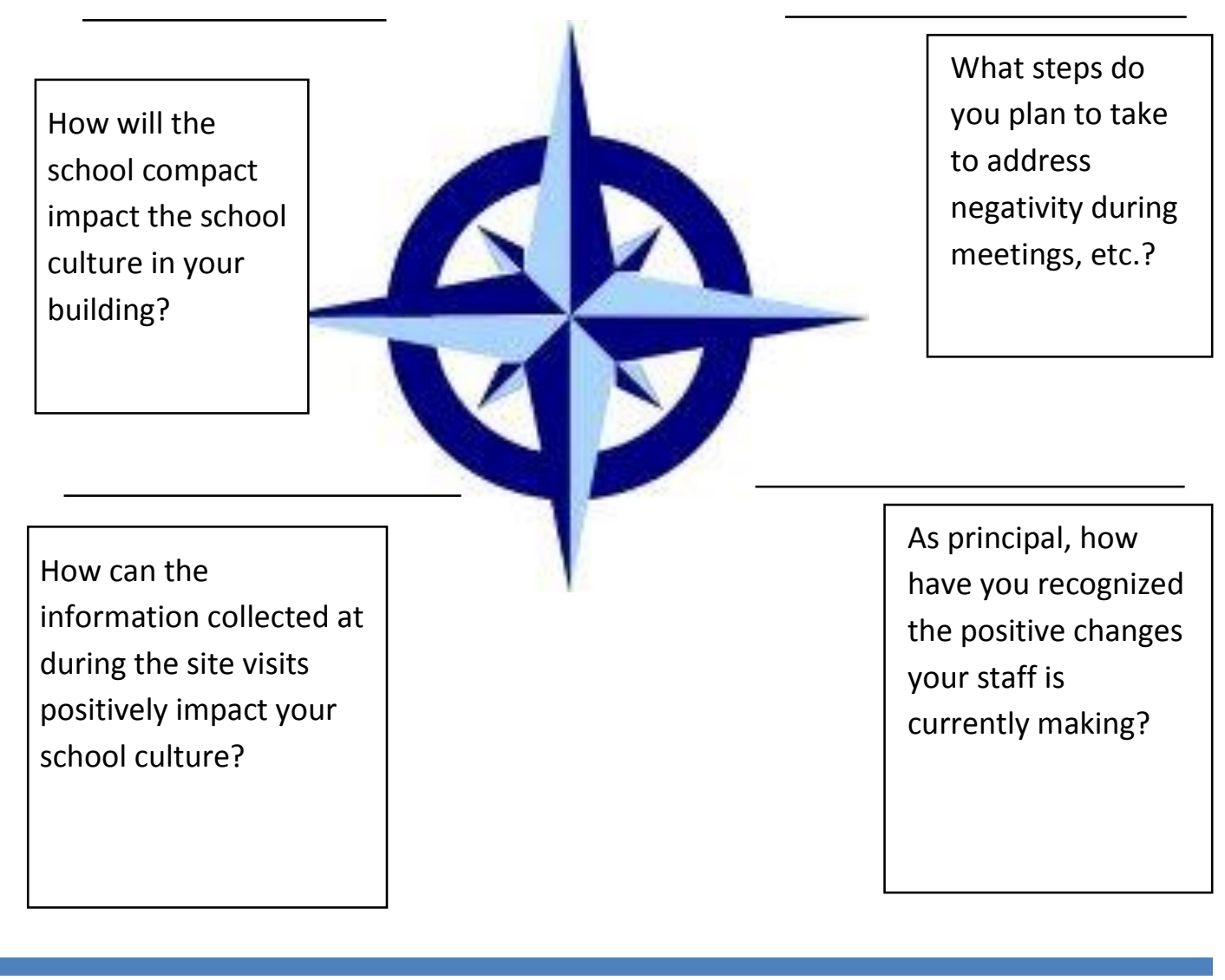

REFLECTION 


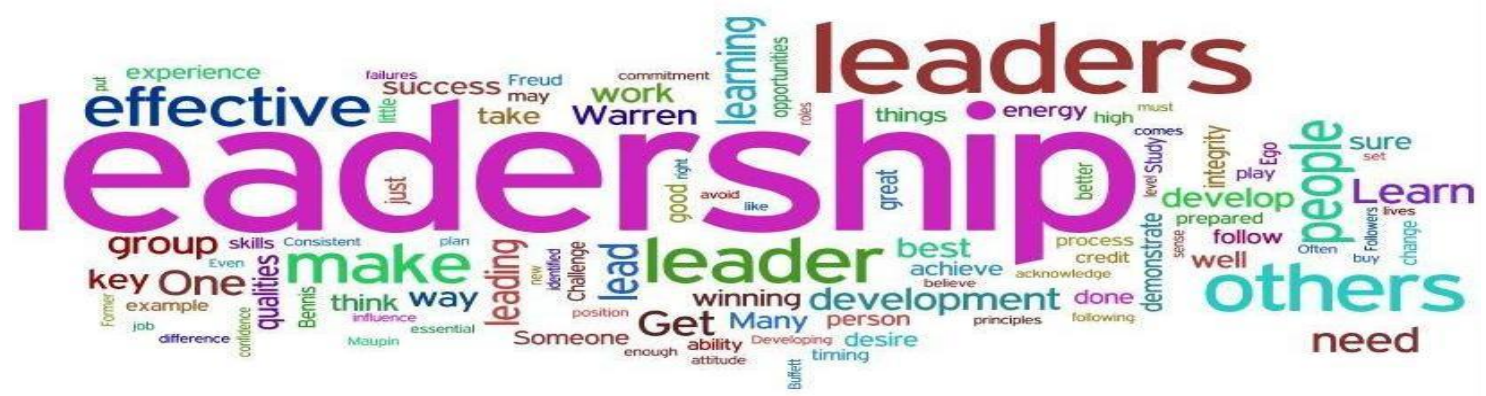

\section{Tool 7.0 Results Pyramid}

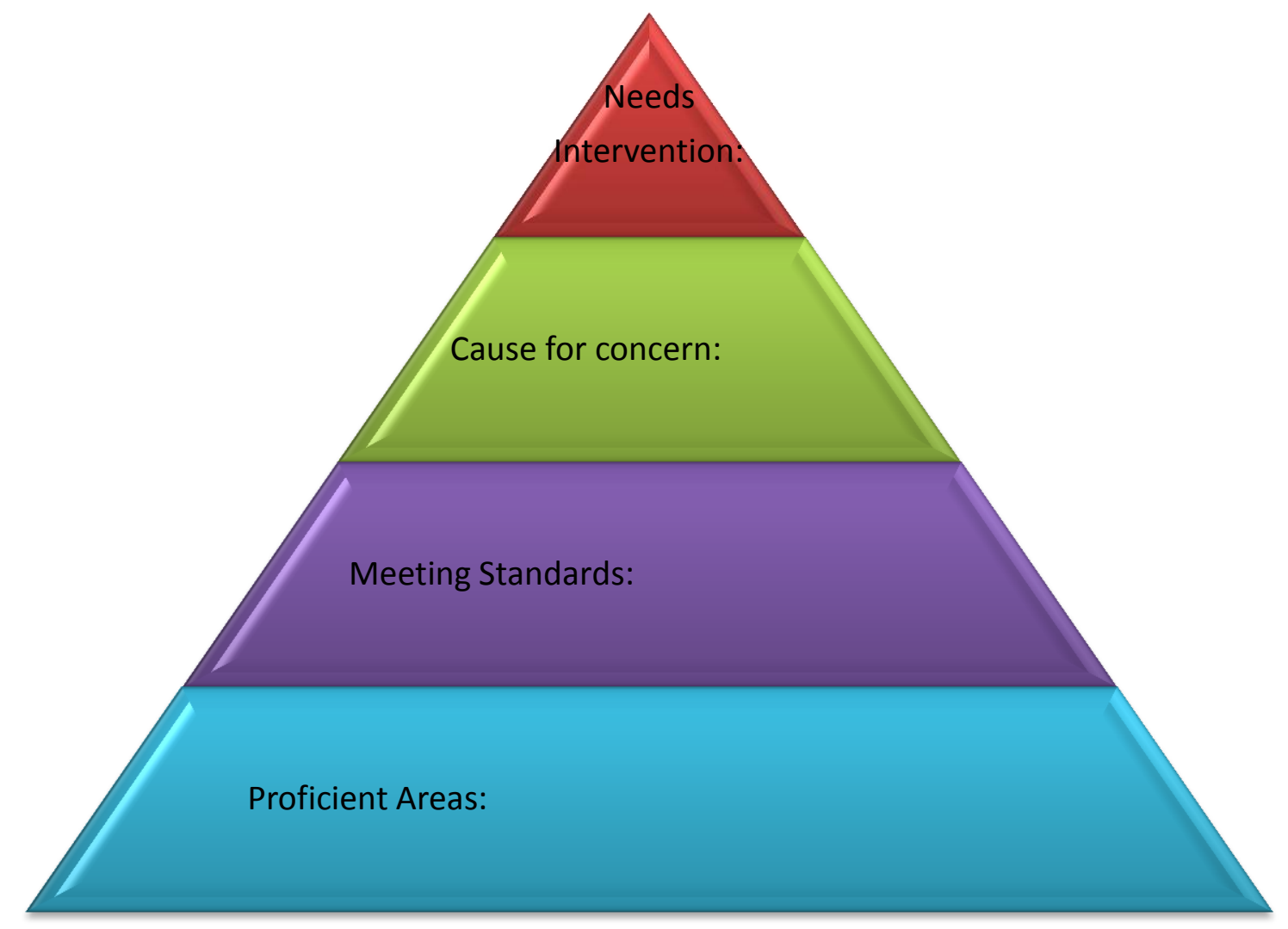

When analyzing your survey results list topics, programs, and interventions that are needed. Things working very well would be placed in the blue category. Your highest needs for improvement would be in red. Red and Green category items need to be addressed in your Schoolwide plan. 


\section{REVISITING EXPLAINING THE PROCESS}

Please revisit this document and monitor your progress. This tool helps you create a timeline for the process using the handbook activities. The stars highlight tips from principals that worked for them in the field during their transition.

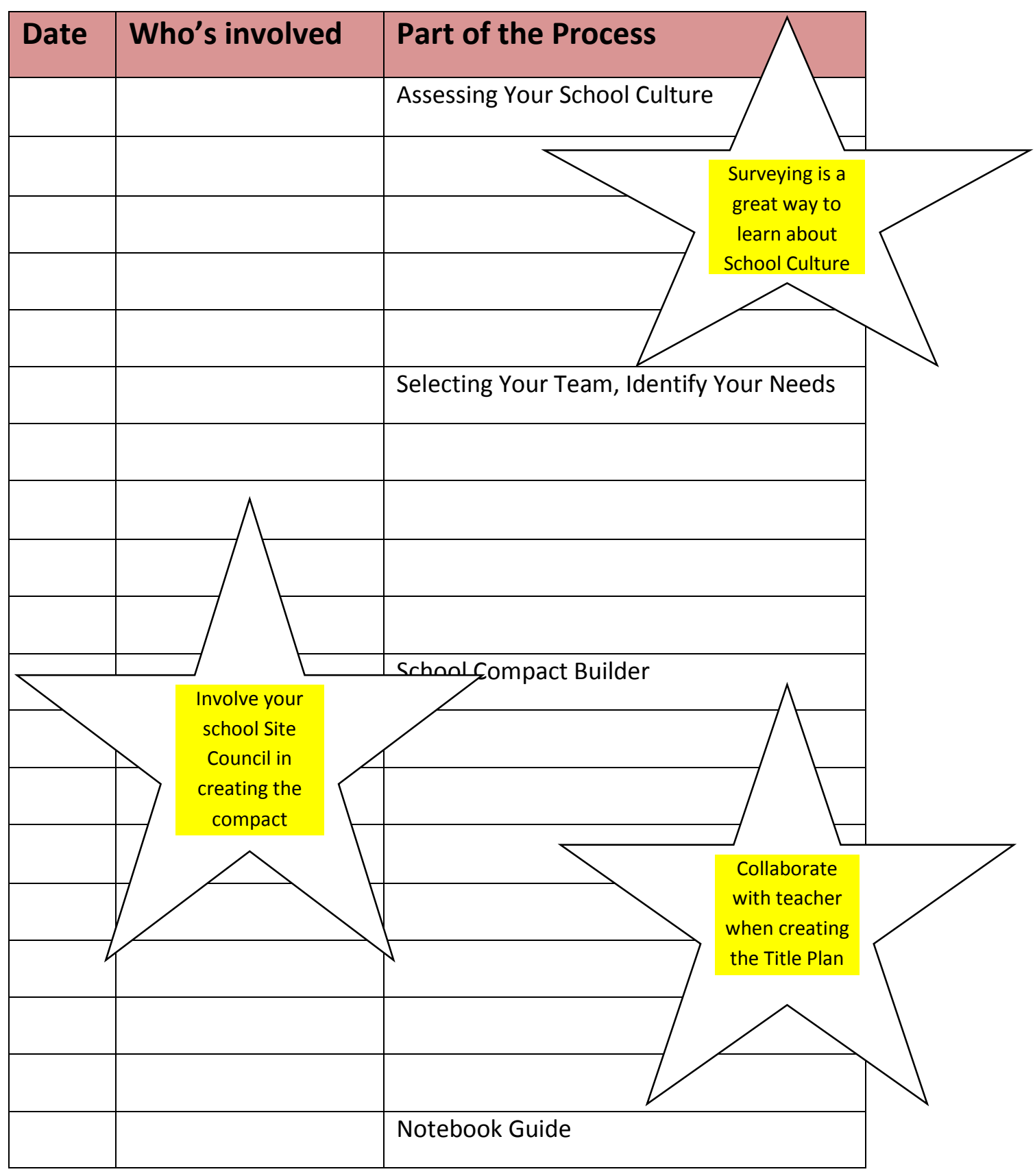




\section{Dealing with Change: "Nothing is more important in the twenty-first century than learning to manage change." (Fullan, 2008).}

One of the key parts of the leadership process is dealing with change. Individuals face change in many different ways. This may vary with the nature of the change and whether it is voluntary, that is, chosen, or involuntary, that is, happening without control or choice. Sometimes it is possible to predict a change, while others occur in an unpredictable fashion.

Schools also experience transitions and changes. The culture of an organization or community is a composite of the individuals who live, work or belong to it. Organizational change is any planned or unplanned alteration of the status quo which affects the structure, technology, and human resources of the total organization.

Brainstorm the opposition that you are facing in your school regarding the Schoolwide Transition and use the Tools to find Strategies that will help you deal with the opposition. The Tools provide some guidance using a Collaborative Strategy and Adversary Strategy.

Once your Schoolwide planning team has identified through the Comprehensive Needs Assessment, the priorities that need to be addressed, share the information with your staff. Give the staff voice in determining the priorities that your school will address in their first year of being a Title I School.

$\checkmark$ Remember that all curriculum that is used must be Research Based and Sustainable. Sometimes a teacher may be turned off by a specific curriculum or program due to a 
bad experience in the past. Tool 7.0 Standards Based Curriculum \& Culture will help your team move forward with creating an action plan to best suit the needs of your school culture.

$\checkmark$ New initiatives can have an impact, whether positive or negative, that will affect students, finances, and political climate. These factors will also impact the culture of the school. Tool 6.5 Impact Inventory will take into account all factors to help your team recognize meaningful, sustainable changes as they create a plan to serve all students. Change is constant in today's school system. Think about the turnover rate for teachers and administrators, the diminishing budget, the change in curriculum expectations, program changes and reductions, grading policies and procedures, as well as new and innovative interventions for achievement. Fullan (2001) asked people to state a word that they associate with change, the responses were both positive and negative, and words that came to mind were: fear, anxiety, loss, danger, panic, as well as, exhilaration, risk-taking, excitement, improvements, energizing. Fullan goes on to explain that change stirs up emotion, and when emotion intensifies, leadership is necessary to maintain composure.

Leading change that sustains a positive culture requires leaders taking on complex issues such as emotions, stress, and criticism. Good school leaders understand that this comes with the territory; they persist in the face of opposition and work to create the best possible outcome for the students they serve. Listed below are three tips for leaders who are working to bring resistant people on board. 


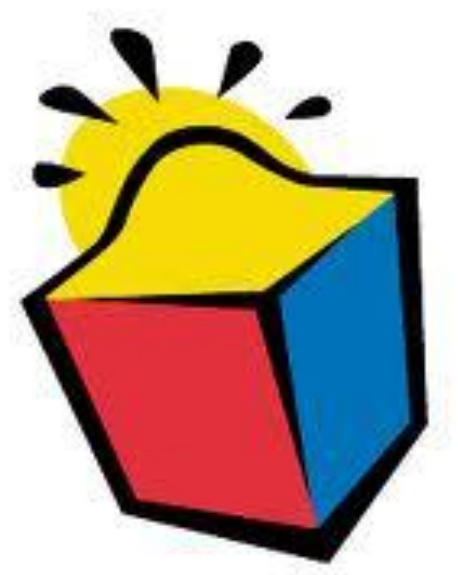

\section{Thinking outside the box.}

1. Proactively address objections. All school change efforts have disadvantages and oppositional issues - be sure to find ways to deal with them. Pre-empt them by anticipating and acknowledging doubts, respond to concerns, and offer solutions that will mitigate fears and worries.

2. Find ways to build momentum. Just as there is always a fraction who oppose change, there is also a small group of people who are the front-line change adopters. You can recognize these folks right away - these are the ones who jump up and say "Let me at 'em!" Use these people to build momentum. You don't have to carry the entire load of the change effort on your shoulders; let these people help you spread the good word.

3. Be a broken record. Stay on message, repeat your compelling arguments, and persist with those who are against the change. Don't let your naysayers off the hook, particularly if they are your staff members; hold them accountable to achieving the department's or organization's goals. 


\section{RESISTANCE TO CHANGE \\ QUICK REFERENCE GUIDE}

The guide listed below will assist you in finding texts that can help you manage staff resistance and opposition to change.

Author

John P. Kotter

Rick Maurer

Todd Whitaker

Seymour B. Sarason

Seymour B. Sarason

Gene Hall \& Shirley Hord

Michael Fullan

Anthony Muhammad

Anthony Muhammad

Robert Evans
Title

The Heart of Change: Real-

Life Stories of How People

Change Their Organizations

Beyond the Wall of

Resistance: Why $70 \%$ of All

Changes Still Fail-and What

You Can Do About it

The Ball

The Predictable Failure of

Education Reform

Revisiting the School and the

Problem of Change

Implementing Change

Patterns, Principles, and

Potholes

Leading in a Culture of

Change

Transforming School Culture:

How to Overcome Staff

Division

The Collaborative

Administrator

The Human Side of School

Change: Reform, Resistance,

and the Real-Life Problems of

Innovation 
According to Hall and Hord's work with regard to the context of the change process, "any action or event that influences the individuals involved or expected to be involved in the process is an intervention" (197, p.143).

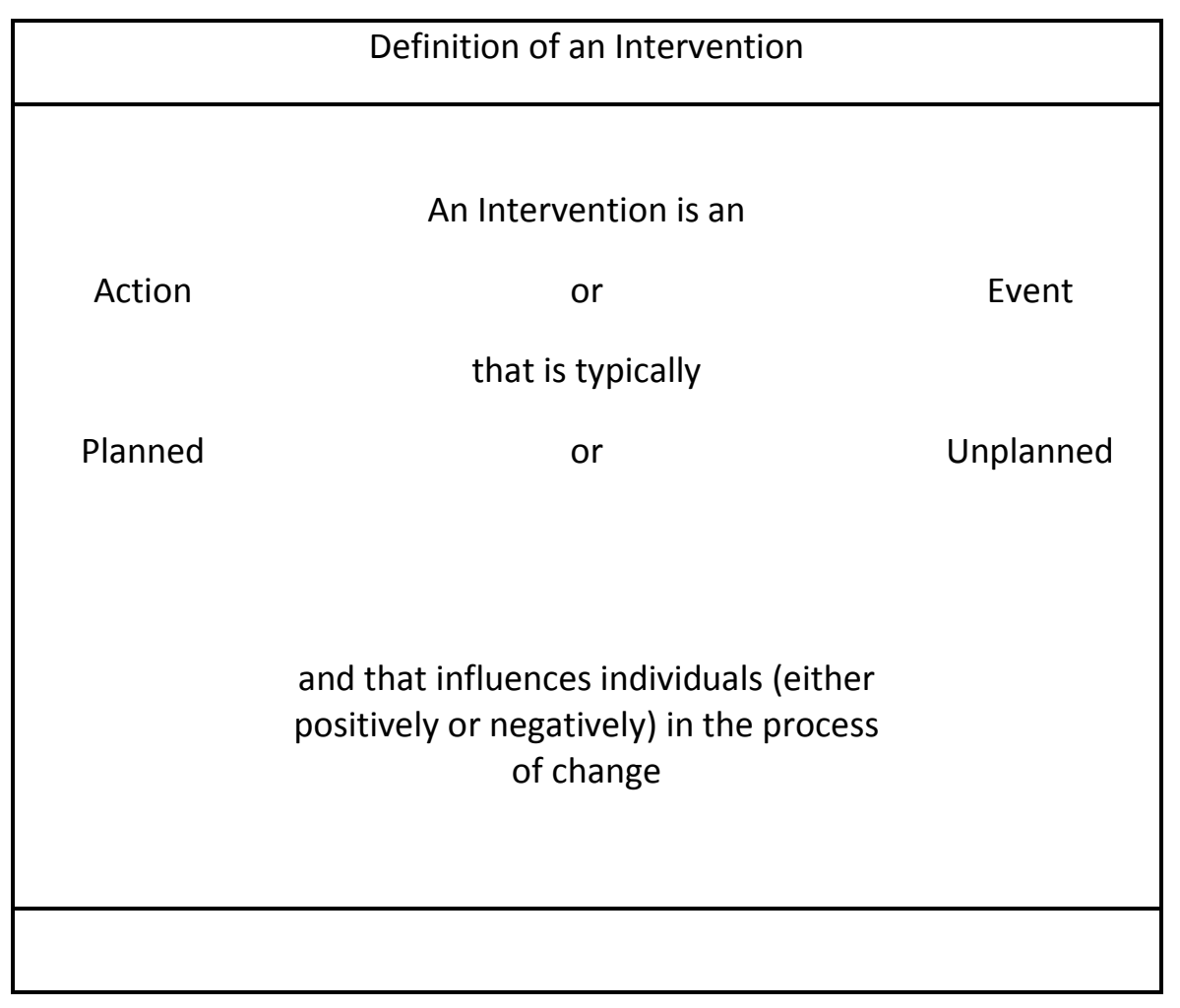

Figure 1.7 
As school leaders navigating through the Title I transition year, we are staging an intervention that will influence our staff, students, and school community. Listed below are two tools that should be considered as you explore this transition. First take a look at Hall \& Hord's Creating a Context Supportive of Change, 2008.

Figure 1.8

\begin{tabular}{|l|l|l|l|l|}
\hline $\begin{array}{l}\text { Developing, } \\
\text { Articulating, and } \\
\text { Communicating a } \\
\text { shared vision of } \\
\text { change }\end{array}$ & $\begin{array}{l}\text { Planning and } \\
\text { providing } \\
\text { resources }\end{array}$ & $\begin{array}{l}\text { Investigating in } \\
\text { professional } \\
\text { learning }\end{array}$ & $\begin{array}{l}\text { Checking on } \\
\text { Progress }\end{array}$ & $\begin{array}{l}\text { Providing } \\
\text { continuous } \\
\text { assistance }\end{array}$ \\
\hline & & & & \\
\hline & & & & \\
\hline & & & & \\
\hline & & & & \\
\hline & & & & \\
\hline
\end{tabular}

\section{Sharing Our New Plan - Activity 3}




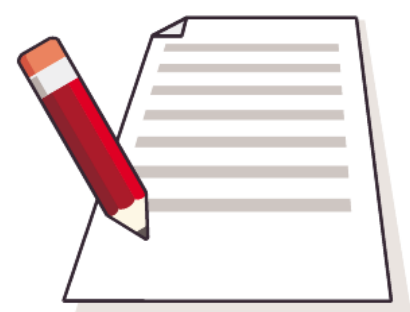

Based on your aligned survey results collected by the SPT and input to the Results Pyramid, your team must now list the school's top 10 strengths and top 5 priorities based on the 5 key dimensions.

The SPT will present the school's top 10 strengths at the beginning of the presentation. Then, each member of the SPT will present the priority list to the staff on one area of the five key dimensions. The team will provide each staff member with a list of the priorities (see example). The staff will rank each list from 5 (high priority) to 1 (low priority).

\section{$\operatorname{soc}$}

\section{Ranking list example}

\begin{tabular}{|l|l|}
\hline Ranking & Student Achievement \\
\hline 4.054 & Schoolwide intervention in writing is necessary \\
\hline & \\
\hline Ranking & School Context and Organization \\
\hline 4.371 & Eliminate verbal harassment for older students \\
\hline & \\
\hline & \\
\hline
\end{tabular}




\section{Tool 7.5 Impact Inventory}

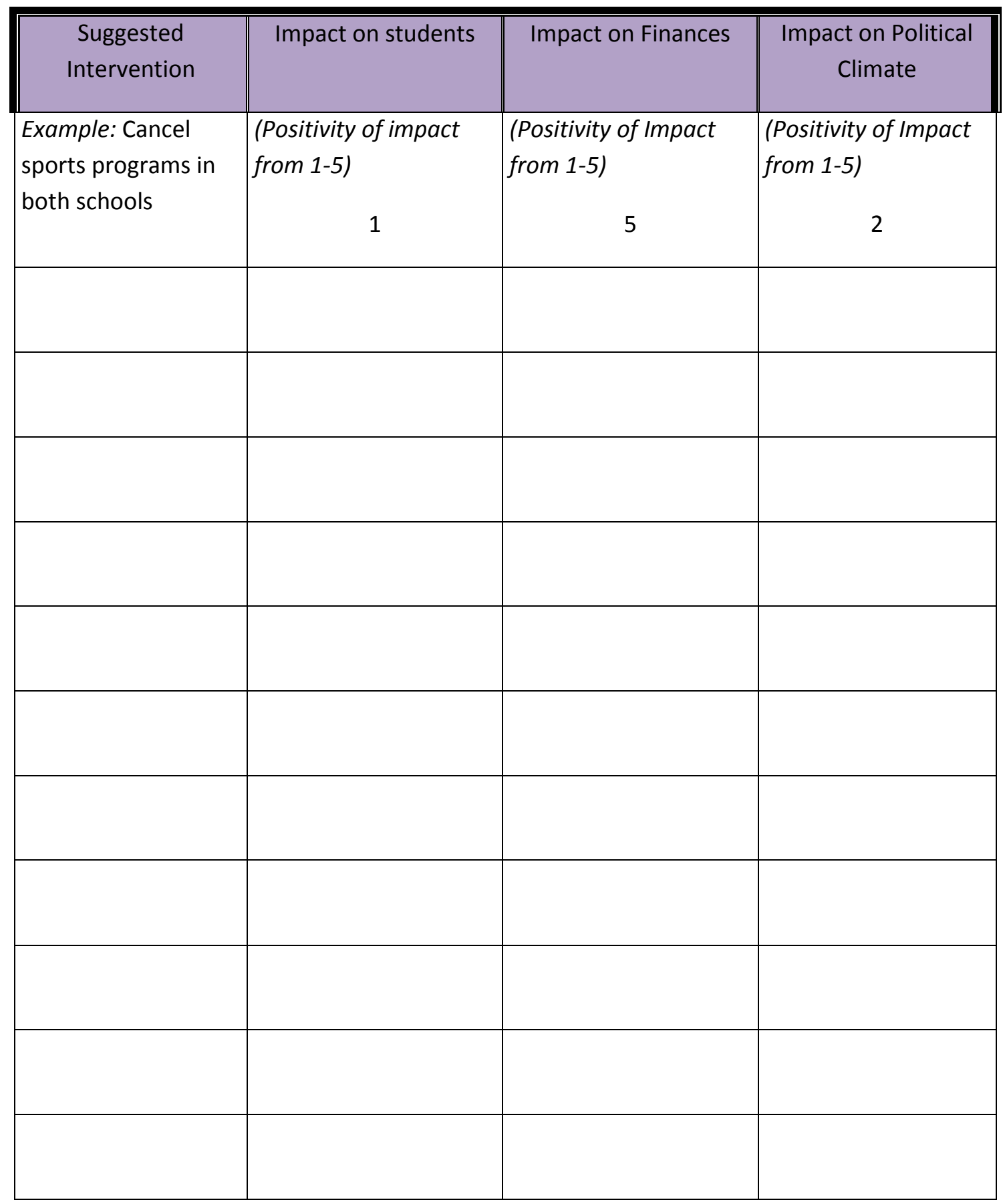

For the purposes of this inventory, Impact on Students includes but is not limited to academic achievement, extracurricular opportunities, social/emotional wellbeing, future preparedness, ability to meet state requirements... 
For the purpose of this inventory, Impact on Finances includes but is not limited to costs associated, including capital outlay, mileage, salary, benefits, grants...

For the purpose of this inventory, Impact on Political Climate includes but is not limited to concerns that might arise from staff, parents, community members, school boards, or impact on the general perception of the school system by others.

Impact Scale: 1 = Substantially negative; 2 = Negative; 3= Neutral; 4= Positive; 5 = Substantially positive 


\section{Tool 8.0 Standards Based Curriculum \& Culture:}

Content Area:

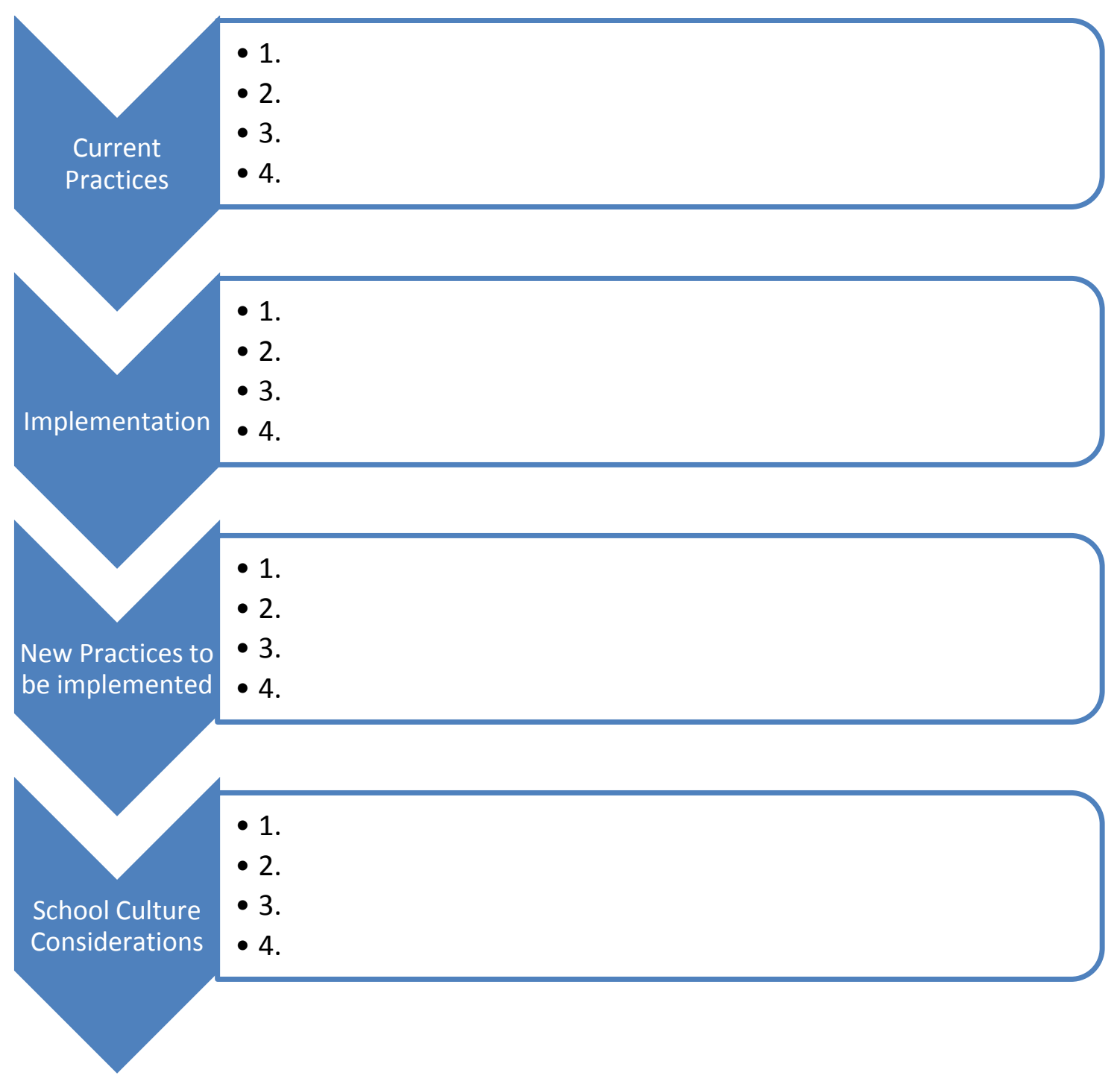




\section{Tool 8.5 Reculturing Compass}

\section{Boost: Reduce:}

Collaboration

Working in isolation

Shared Leadership

Dependent on Principal

\begin{tabular}{|l|} 
\\
\hline Problem Solving \\
\end{tabular}

$\square$

Temporary Fixes

Effective Meetings

Drifting

(Sta

Staff Buy-In

Top down

\begin{tabular}{|l|}
\hline Consensus \\
\hline Recognition of history and \\
\hline
\end{tabular}

$\square$

Majority Rule

current culture

Focus on Teaching \& Learning

Peripheral Issue

Blind Implementation
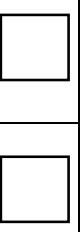

(1)

\begin{tabular}{|lr|l|}
\hline Involvement & & Selective Participation \\
\hline Discussion/ Dialogue & $\square$ & Presentations \\
\hline Reflection & $\square$ & Jump to Conclusions \\
\hline Meaning \& Purpose & $\square$ & \\
\hline
\end{tabular}




\section{Reculturing is the name of the game-}

Tool 7.5 was adapted from Chenoweth and Everhart; this easy to follow checklist helps us assess and monitor the positive changes in our building that influence our school cultures. In essence, we understand school culture to be the underlying shared beliefs, history, assumptions, norms, and values that manifest themselves in patterns of behavior that happen daily in a school setting or, in other words, as Bower (1966) stated "the way we do things around here" (p. 22). Reculturing then is fundamentally altering an organization's culture, its way of doing things. Leaders of high-performing school systems train much of their strategic attention on reculturing, because that's where the bulk of influence for lasting change is located.

Tool 7.5 points out areas in the Boost category that reinforce the positive aspects of school culture. Leaders can accomplish these targets through openly celebrating success, incorporating professional development that fosters commitment to staff and student learning, and being open honest and collaborative in the decision making process.

Tool 7.5 also guides leaders in the Reduce category to diminish norms that can foster negativity and be harmful to school culture. By reducing these areas and replacing them with Boost targets, you will build trust amongst your staff that will positively impact your school culture over time. 


\section{When, What, and How will we assess?}

\section{Activity 4}

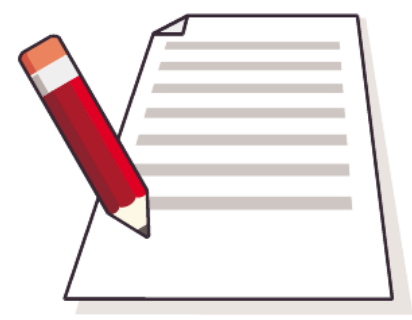

Based on your action plan and the goals that your SPT and staff have set for next year, comes the question of accountability. How will we know if our plan is working, how will we monitor growth, when will we assess? As administrators we know that what gets measured gets done. By building an assessment schedule, you are building accountability around the goals that your school has set. This activity will help you create an assessment schedule for accountability for all with your staff.

Have a staff teacher leader facilitate a discussion with the planning team about the importance of creating an assessment schedule that coincides with Grade Days, Planning Days, and the school calendar. Be sure that your entire planning team is involved in the process of creating the assessment schedule. This activity gives all team members an opportunity to discuss the calendar and provide input.

\section{$\sin 2$}

\section{Steps for Activity:}

\section{$\checkmark$ Use your upcoming school calendar to coordinate your assessment dates.}

\section{$\checkmark$ What content area are you assessing?}

$\checkmark$ How many times a year will you provide a universal screener at each grade level?

$\checkmark$ How many times will you give a diagnostic?

$\checkmark$ Who is responsible for analyzing and sharing the data?

$$
\text { Assessing growth? }
$$

$\checkmark$ As a team, put your plan on paper and share the plan with staff.

$\checkmark$ Did our students do as well as we expected them to do?

\section{3}




\section{Tool 9.0 Services Scavenger Hunt}

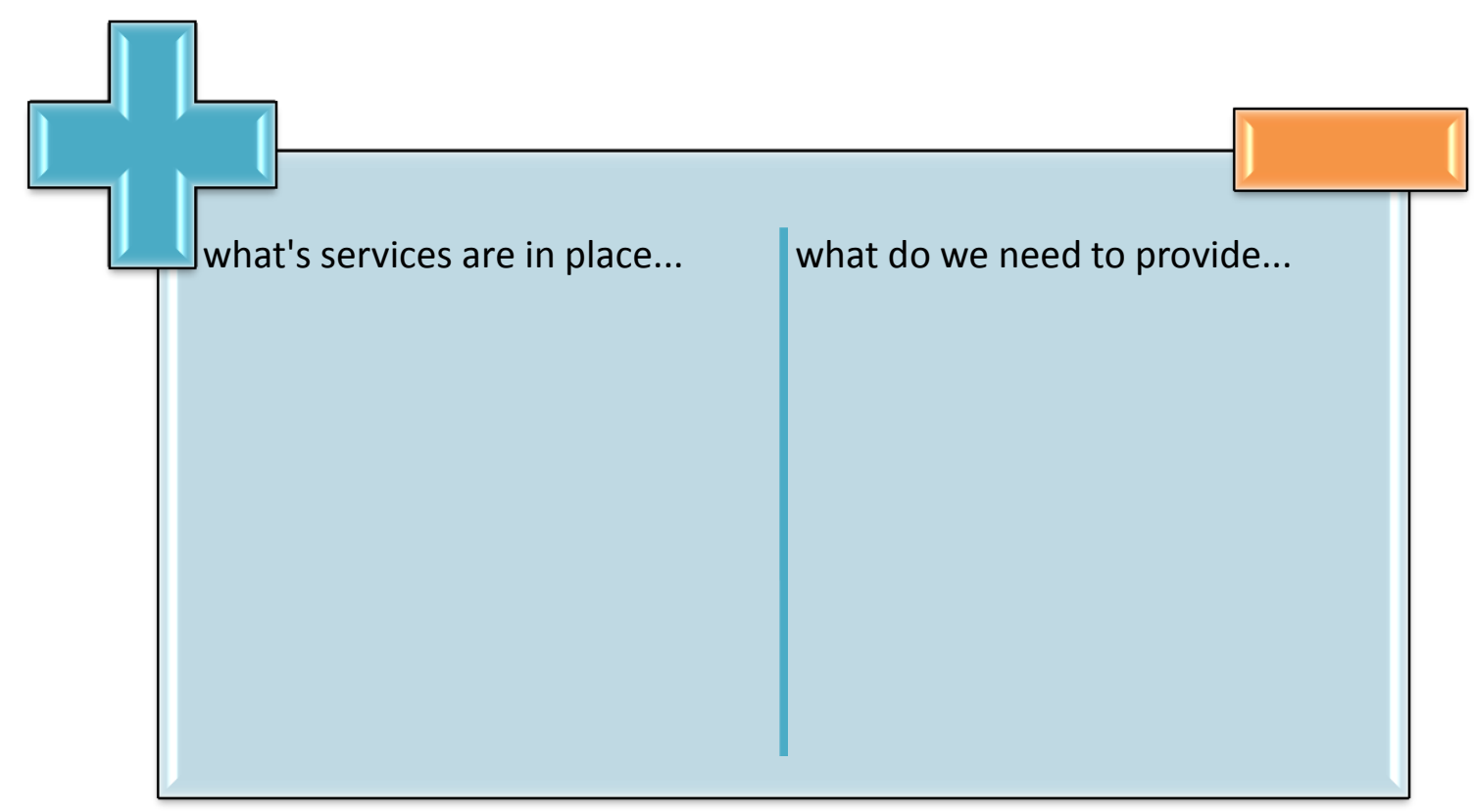

Reflect on Tools 7.0 and 7.5 as the work that you have done will support your SPT in creating a list of positives and identify what needs to be provided that is not yet in place. Tool 9.0 Service Scavenger Hunt is takes a detailed look at what is being provided, and what the school needs to provide or improve on providing. 


\section{Tool 9.5 Parallel Professional Development \& Priority Needs}

This tool records three goals, then your SPT will record ways to support the goal, what professional development is necessary to support the staff, and who is responsible for implementation and monitoring progress.

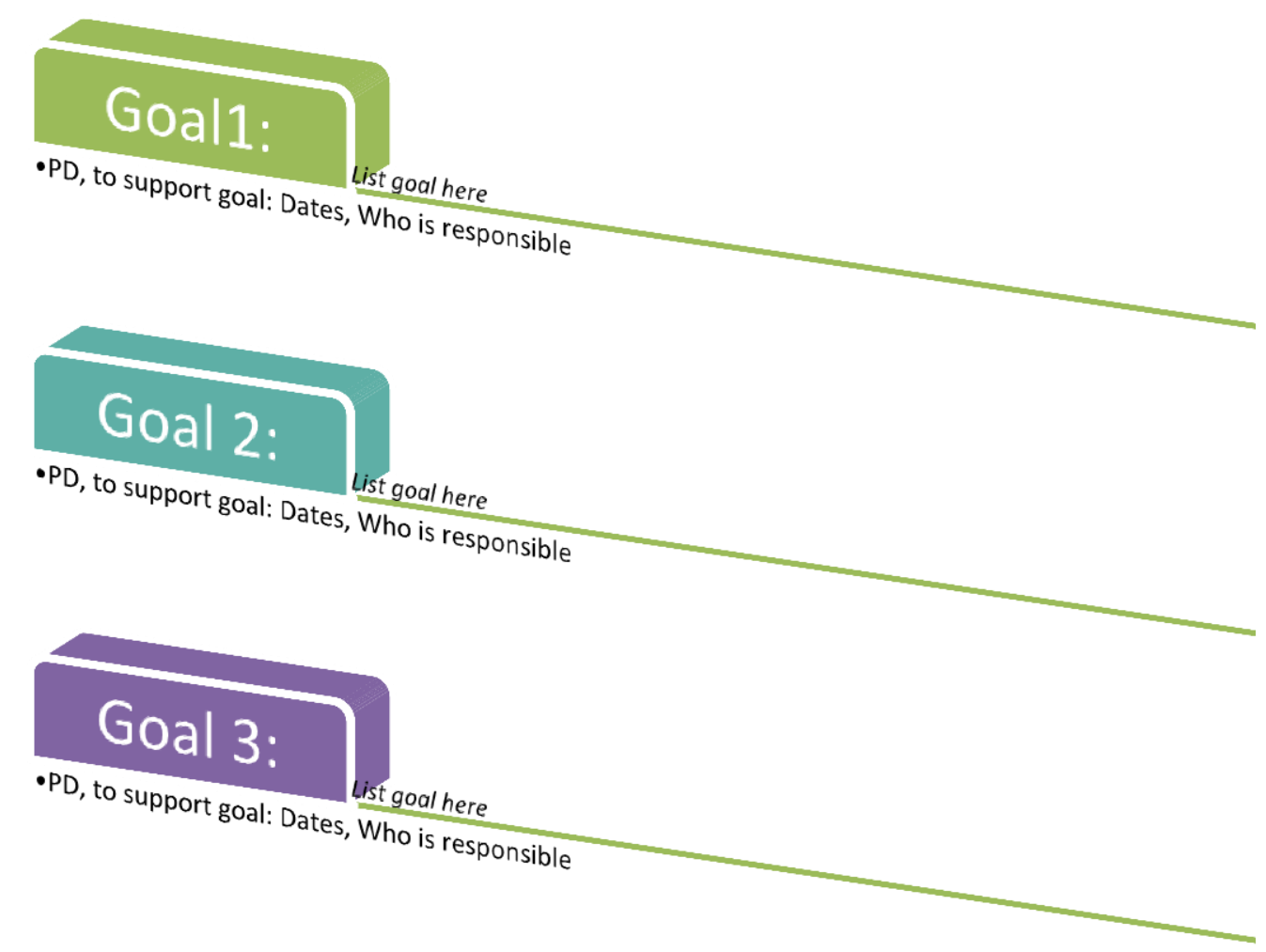

In order to ensure that the professional development that your SPT is planning to provide is directly connected with the school's goals based on the priority needs of the school, we have created Tool 9.5 Parallel Professional Development \& Priority Needs. First, list your goal, then below the goal your team will list professional development ideas that address each goal, as well as the estimated date, and who is responsible for organizing this PD opportunity. 


\section{Tool 10.0 Brainstorming the Transition Process}

This tool can be used to get your teams thoughts on paper with regard to the process they need to take to put an intervention in place. For example, below you see an intervention listed as "Kindergarten Round up" the light blue circle lists a detail of the event. Your team will then record ideas that will assist them in making this transition, as well as record steps in the process.
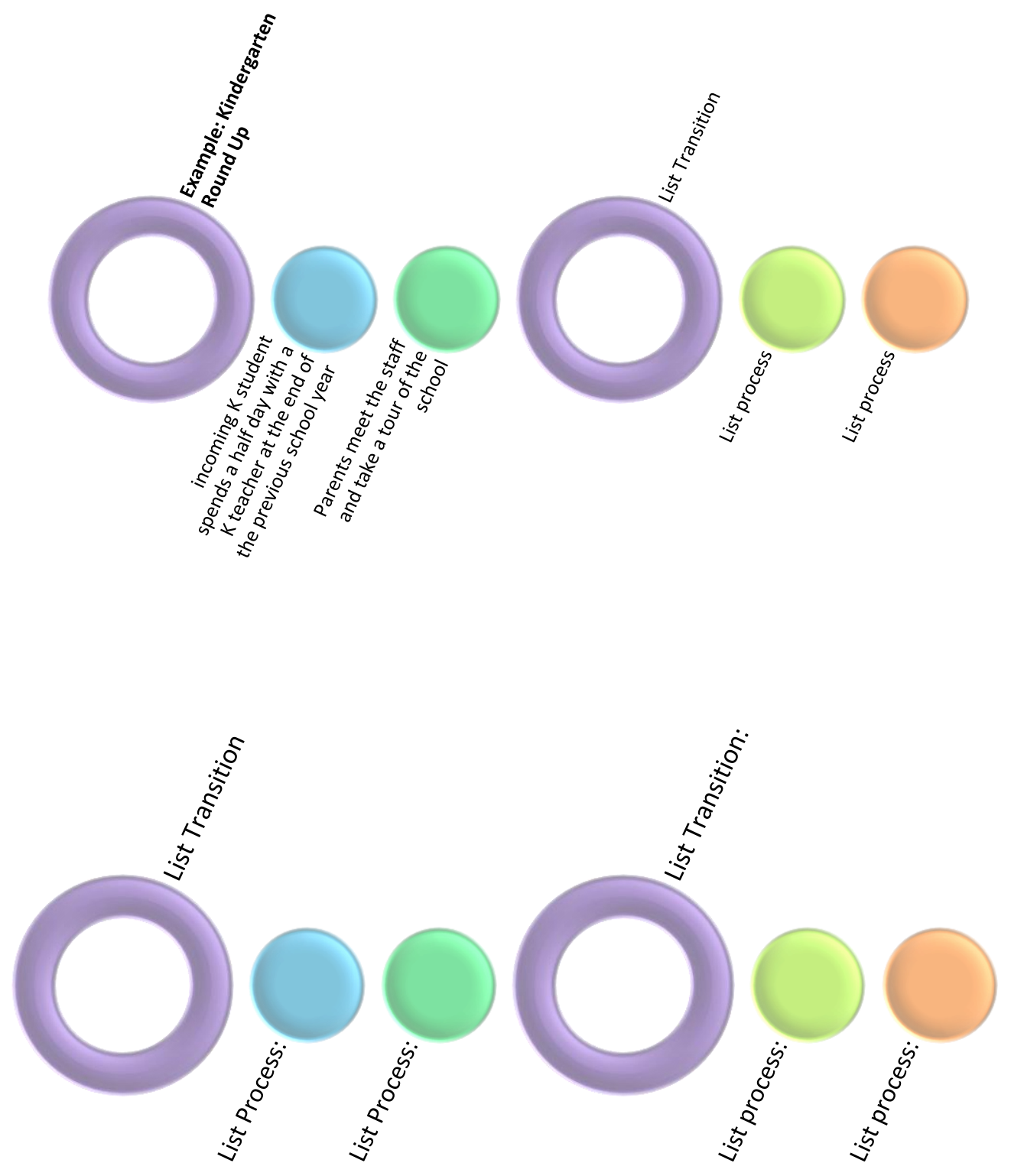


\title{
Sharing the new plan -
}

\section{Activity 5}

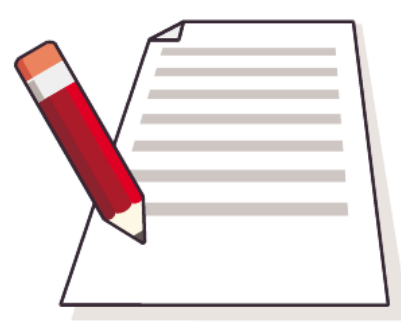

Now that your school has created a draft plan to implement in the fall, it is important that the plan be shared. Address questions openly with all staff members, and be sure to show your staff the ways that they assisted in the creation of the plan. Let your staff know that the Title I plan is a "living, breathing document." If the school notices that something is not working, they can change, revise, or amend it. Remind them that the plan in revisited every year, and that it will be tweaked to best suit your school's needs.

As a team, jot down the transitions strategies and process in place in your building ensure that student transition positively to the next grade level. What needs to be improved?

Have your planning team members lead the charge of sharing the school's new and exciting Schoolwide plan. Have the team member most excited about the assessment schedule share with staff the new schedule, how it works, how it will benefit students, and the teaching and learning process. Be sure that your entire staff is present and can ask questions. Remember you must get the majority of your staff on board by a secret ballot vote.

\section{$\operatorname{soc}$}

\section{Staff vote:}

$\checkmark$ Before completing the adoption of the new plan your staff must take a secret ballot vote.

$\checkmark$ Are there specific concerns to address before voting?

$\checkmark$ Are there certain people on staff that need one-on-one conversations with the principal to become more

\author{
comfortable?
}

$\checkmark$ Be sure to acknowledge your staff's hard work throughout the yearlong transition.

Do something nice for your SWPT!

\section{5}




\section{TOOL 10.5: THE DAILY TIME SHEET}

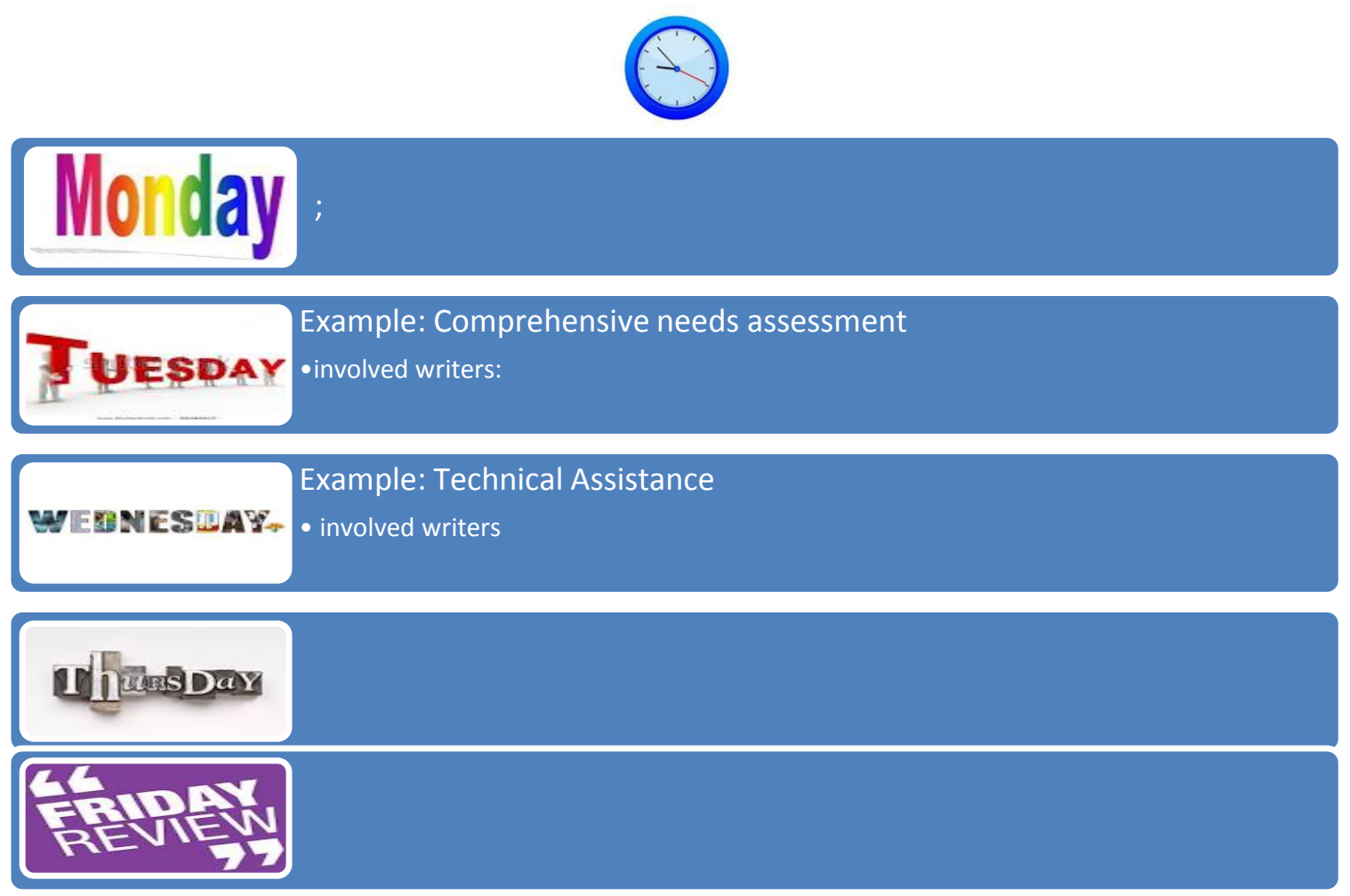

This Daily Time Sheet is a quick way to list out the sections of the grant, and assign writers to each section. Your team should base their writing on the team's and staff decisions for implementing your Schoolwide plan next year. It is important to review the entire document as a team and revise as necessary. A Google doc is a tool that principals used which provides access to all team members, and allows for sections of the grant to be written simultaneously. Remember it is important to make time for writing each day. Good luck! :) 


\section{Tool 11.0 Accountability Matrix}

\begin{tabular}{|l|l|l|l|}
\hline Goals: & Support & Assessment & Accountability \\
\hline Reading & & & \\
\hline & & & \\
\hline & & & \\
\hline & & & \\
\hline Math & & & \\
\hline & & & \\
\hline Writing & & & \\
\hline & & & \\
\hline & & & \\
\hline & & & \\
\hline & & & \\
\hline & & & \\
\hline & & & \\
\hline & & & \\
\hline & & & \\
\hline & & & \\
\hline & & & \\
\hline & & & \\
\hline & & & \\
\hline & & & \\
\hline & & & \\
\hline & & & \\
\hline & & & \\
\hline & & & \\
\hline & & & \\
\hline & & & \\
\hline & & & \\
\hline & & & \\
\hline & & & \\
\hline
\end{tabular}




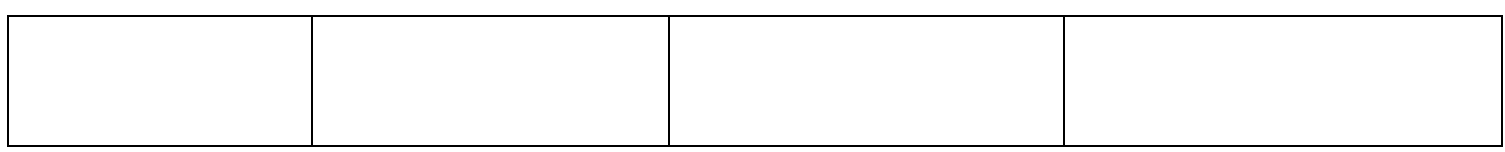

This matrix creates an outline for staff regarding how the school's goals will be supported, assessed, and accountable for the overall progress toward the goal. 
PRINCIPAL'S SCHOOL CULTURE ATLAS 6

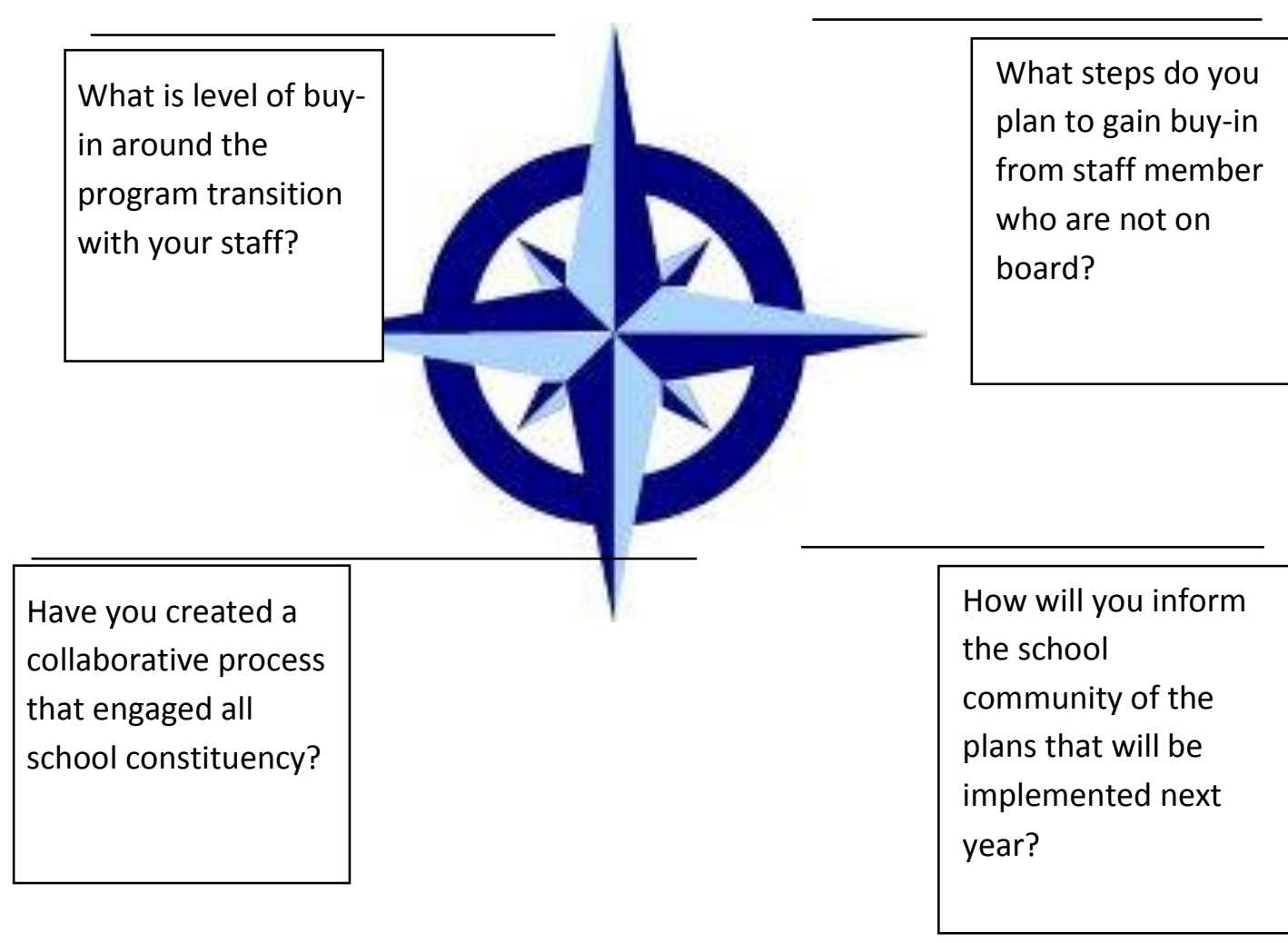

REFLECTION 


\section{Tool 11.5 Notebook Guide}

This tool will assist you in creating a Schoolwide notebook that compiles the school's written grant, and the evidence of the transition process that you will soon be submitting to the state. Located below are the Spine and tabs needed to create your Schoolwide Planning Notebook.

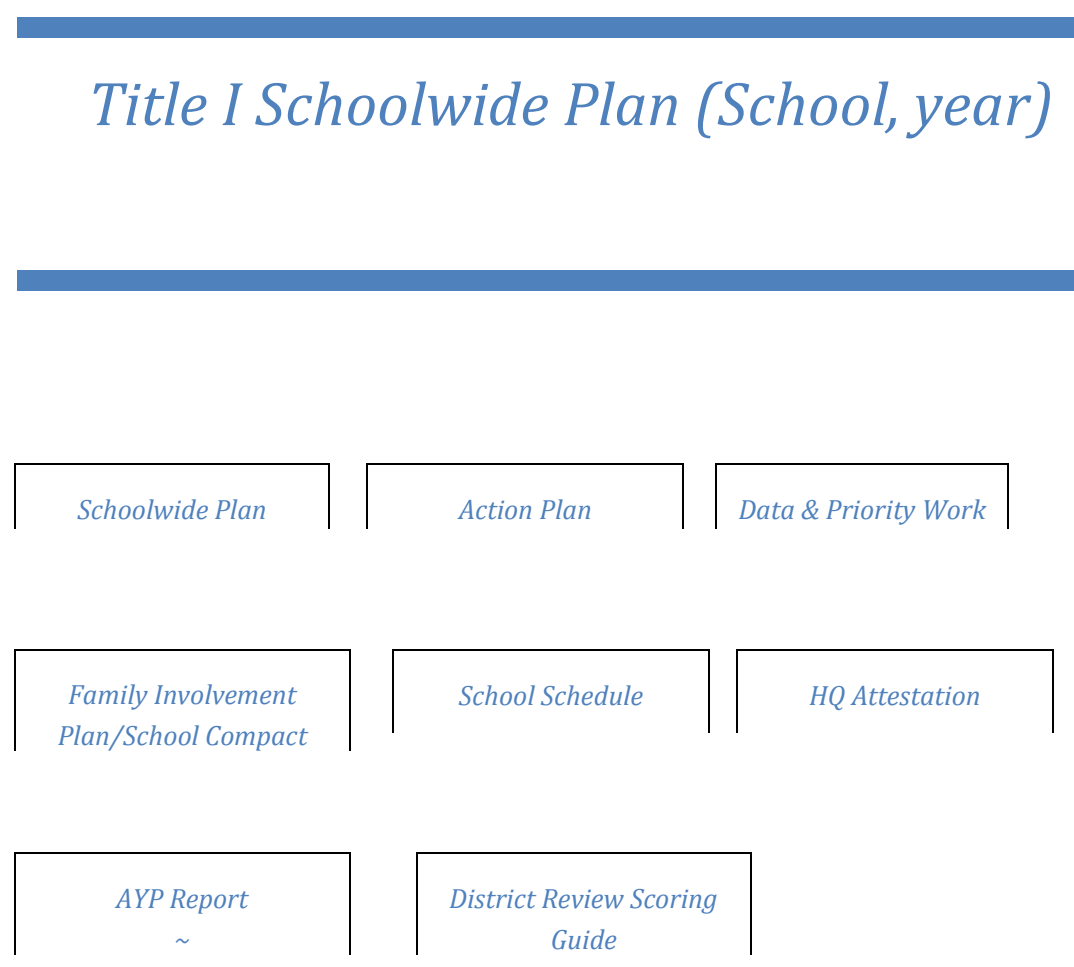




\section{You're Almost There-}

\section{Duties for the Administration}

You have come a long way since the beginning of you journey. Let's reflect. Your school has developed and disseminated a survey to all school constituencies, analyzed the data, and created a plan to address the data. As a school you have put in place a document to help guide you in the successful implementation of your goal, such as: communication logs, school compact, an assessment schedule, and most importantly, a new and improved Title I plan to address the needs of all students through a Schoolwide model. You have also received a majority vote from your staff, and thanks to Tool 10.0, you are probably holding a binder that has the blood, sweat, and tears that you and your planning team poured out in this process throughout the year. Quite an accomplishment! However, don't celebrate too fast. There are still a few steps left in the process before sending your plan off to the state officials to be reviewed. Here is a checklist for your final steps before getting your binder in the mail.

1. District Review Team - This team is make up of four people; in larger districts this team may be comprised of a few principals and central office administrators, while in smaller districts it may be comprised of the superintendent and several school board members. However you decide to select your team, just keep in mind as you begin sharing the plan with this important group of outsiders, to provide them with information about how your school plans to address students' needs in a Schoolwide model. Each team member will fill out forms that you need to collect and add to the back of your 
Schoolwide plan. (District Review forms can be located on your state department's website.)

2. After the District Review team has signed off, the chair of the committee must provide you with a congratulations letter that will also go into the notebook you are submitting. (Congratulations sample letter located in appendix.)

3. Make copies of everything. Create two more notebooks; one for the main office that can be accessed by everyone; one for your own records; and lastly, one to mail to the state for review. (If you are in Oregon, reference the mailing address at the beginning of your Schoolwide Planning Grant.) Remember the deadline for submission is June $1^{\text {st }}$, so give yourself mailing time. Be sure to get it in the mail in plenty of time.

Now you can kick back awhile. Summer vacation is just around the corner and you have earned it! Remember hard work without celebration can lead to burn out! Be sure to celebrate with your staff if you have not done so already, but also celebrate the success of this personal accomplishment as a principal in the field. How you choose to celebrate is entirely up to you, for some it means vacationing, while for another it may be treating yourself to something that you really enjoy. Be creative, do whatever makes you happy, assuming it is legal of course :)!

Now that you have made the successful transition to Schoolwide, your work is cut out for you in the fall! Remember what gets measured gets done! Implement. Monitor. And hold all Accountable.

If you found this to be a helpful guidebook in assisting your Schoolwide Transition, be sure to share it with other principals planning to go through the process. 
About the author: Paul Coakley is currently the principal of Hudson Park Elementary in Rainier, Oregon. He has worked as an educator K-12 for the past 11 years. Paul will be receiving his Doctorate in Educational Administration from Portland State University in 2013. To receive a hardcopy of this handbook please contact Paul at paul_coakley@rsd.k12.or.us

\section{APPENDIX}

Resources for your Schoolwide Planning Project 
Appendix: A

\author{
(Name) District \\ Principal Verification Form Sample \\ 2012-2013 School Year
}

This school is served through Title I-A under the federal No Child Left Behind Act (NCLB) of 2001. Under this Act, certain teachers and instructional assistants (paraprofessionals) were required to meet specific criteria that identify them as "highly qualified" by the end of the 2011-2012 school year. This notification is verification by the school principal that the school is in compliance, or making annual progress, toward this requirement.

All core academic teachers currently teaching in the school are highly qualified.

All teachers hired after September 3, 2002 are highly qualified.

The following teachers are participating in professional development in order to become highly qualified:

Name Subject

Name Subject

All paraprofessionals hired after January 8, 2002 are highly qualified.

All paraprofessionals hired before January 8, 2002 are enrolled in professional development that will result in them becoming highly qualified.

All paraprofessionals are assigned appropriate duties as required by federal rules and regulations.

Copies of this verification are on file at both the school and district office and are made available upon request to any member of the community.

[Principal Signature]

\footnotetext{
1 Core academic subjects are defined by federal regulation and the State of Oregon as: English, reading, language arts, mathematics, science, languages (French, Spanish, Russian, Latin and Japanese), social studies (civics and government), the arts (art, music, drama) history, and geography.
} 
Appendix: B

$$
\begin{aligned}
& \text { (Name) Elementary School } \\
& \text { School Compact Sample }
\end{aligned}
$$

It is important that families and schools work together to help students achieve high academic standards. Through a process that includes teachers, students, and community representatives, the following are agreed upon roles and responsibilities that we as partners will carry out to support student success in school and in life. This compact pledges our school community to increase academic achievement to promote the proficiency of all students.

\section{Staff Pledge:}

I agree to carry out the following responsibilities to the best of my ability:

- Provide high-quality curriculum and instruction.

- Endeavor to motivate my students to learn.

- Have high expectations and help every child develop a love for learning.

- Communicate regularly with families about student progress through conferences, parent-teacher meetings, progress reports, and other available means.

- Provide reasonable opportunities for parents to volunteer and participate in their child's class.

- Provide meaningful homework assignments to reinforce and extend learning.

- Participate in professional development opportunities that support teaching and learning.

- Work collaboratively with colleagues to promote student achievement.

- Assess student progress in reading and math and adjust my instruction when needed.

- Continually work with families and my colleagues to make school a welcoming place in order to help each student achieve academic standards.

- Respect the school, students, staff and families.

\section{Student Pledge:}

I agree to carry out the following responsibilities to the best of my ability.

- Come to school ready to learn and work hard.

- Bring necessary materials to school and complete assignments/homework.

- Know and follow school and class rules.

- Ask for help when I need it.

- Read on my own and with my family every day. 
- Write down assignments, do my homework, and turn it in when it is due.

- Communicate regularly with parents and teachers about school experiences so they can help me be successful in school.

- Respect the school, my classmates, staff and families.

\section{Family/Parent Pledge:}

- Let the teacher know if my child has any problems with learning.

- Use reading and math materials the school sends home each week to help my child make appropriate progress.

- Read to, or with my child 20 minutes per day.

- Keep a list of new vocabulary, high-frequency, or word wall words introduced in class for reference at home.

- Play number games with my child every week.

- Help my child see how to use reading in everyday life.

Student

Teacher

Parent/Guardian

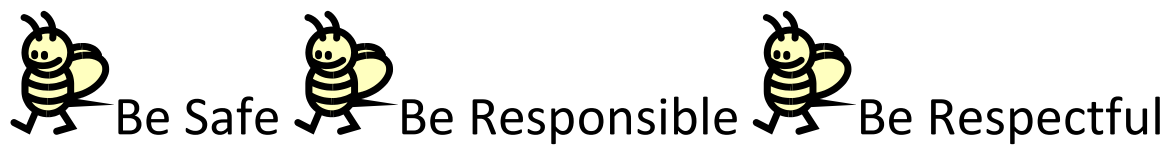


Appendix: C

\section{(NAME) ELEMENTARY SCHOOL'S FAMILY INVOLVEMENT PLAN}

\section{Family Involvement Plan}

This plan establishes the expectations for parent and community involvement with (NAME)Elementary School, a Schoolwide Title I school.

Annually, (NAME) Elementary School will convene a meeting to which parents are invited. At this meeting, the principal and staff inform the parents of the school's participation in Schoolwide Title I, explain the requirements of Title I, and the right of parents to be involved in the school.

(NAME) Elementary School holds a number of meetings for parents at flexible times for the parents' convenience. These include Site Council meetings, PTO meetings, Principal/Parent coffees, and parent conferences. Meetings have been conducted where parents are involved in an organized, ongoing, and timely way in the planning, review, and improvement of the programs for parent and community involvement.

(NAME) Elementary School will provide parents with timely information about programs and services through the handbook, the monthly newsletter, classroom newsletters, PTO meetings, website, phone communication, Alert Now messages, e-mail and events.

(NAME) Elementary School provides parents a description and explanation of the

curriculum in use at the school, forms of academic assessment used to measure progress, and proficiency levels that students are expected to meet. This is done through parent conferences, homework folders, newsletters and other informational flyers.

(NAME) Elementary school will provide frequent student progress reports to parents. This will be done through mid-quarter progress reports, quarterly report cards, parent-teacher conferences, and other personal or written communications. 
(NAME) Elementary School provides a regular time for parents to meet with teachers to formulate suggestions, to participate in decisions relating to the education of their children, and to respond to any suggestions as soon as possible. This is done through parent conferences, Site Council meetings, and other communication tools,

if needed.

(NAME) Elementary School has jointly developed with parents a Home and School

Agreement. This is a written compact that outlines how parents, school staff, and students are partners who share the responsibility for improving student academic achievement. The compact delineates the school's responsibility to provide high-quality curriculum and instruction in a supportive and effective learning environment that enables students to meet the state's academic achievement standards. The Home and School Agreement describes the ways in which each parent will be responsible for supporting student learning and participating in decisions relating to the education of their student(s). The Home and School Agreement also addresses the importance of open communication between teachers and parents on an ongoing basis through parent-teacher conferences and quarterly progress reports to parents.

(NAME) Elementary School gives parents reasonable access to staff, opportunities to volunteer, participate, and observe in their child's class. Parents are encouraged to become active volunteers through PTO, Site council, newsletters, and parent-teacher connections.

This written Family Involvement Plan shall be distributed to all parents of students at

(NAME) Elementary School in an understandable format and in a language parents can understand, when feasible. It has been placed on the school website making it available to the local community. This plan will be periodically updated to meet the changing needs of parents and the school. If the plan is not satisfactory to parents, comments may be submitted in writing to the school that will be responded to, and staff at (NAME) Elementary School will actively work to resolve these concerns.

The staff and administration of (NAME) Elementary School value parent input and contributions. The staff has received training on how to reach out to, communicate with, and work with parents as equal partners. They have also been trained on how to implement and coordinate parent programs and build ties between parents and schools. Parents are provided with surveys to give input as to programs and opportunities they 
would like to have available at the school.

(NAME) Elementary School coordinates and integrates, when feasible and appropriate, parent involvement programs and activities with our Head Start/preschool program. This is done through home visits, parent-teacher conferences, newsletters, flyers, and other personal or written communications.

(NAME) Elementary School sends parents information relating to school and parent programs, meetings, and activities to the extent practicable, in the language parents can understand. The school provides full opportunities, when feasible, for the participation of parents of English language learners, students with disabilities, and migrant students.

This Family Involvement Plan is an effort to cover the range of responsibilities and services (NAME) Elementary School provides to the parents of its students and to the com 
Appendix: D

\section{Survey Alignment Sample}

\begin{tabular}{|c|c|c|c|}
\hline Survey Quest. \# & Staff & Students & Parents \\
\hline 1.Example column & $\begin{array}{l}\text { I believe students } \\
\text { show respect for all } \\
\text { adults in the school. }\end{array}$ & $\begin{array}{l}\text { I show respect to all } \\
\text { adults in school. }\end{array}$ & $\begin{array}{l}\text { Students show } \\
\text { respect for all adults } \\
\text { in the school. }\end{array}$ \\
\hline 2. & & & \\
\hline 3. & & & \\
\hline 4. & & & \\
\hline 5.Example column & $\begin{array}{l}\text { I communicate } \\
\text { regularly with } \\
\text { parents on } \\
\text { behavioral issues. }\end{array}$ & $\begin{array}{l}\text { I take home } \\
\text { important } \\
\text { information and talk } \\
\text { to my parents about } \\
\text { what is going on in } \\
\text { school. }\end{array}$ & $\begin{array}{l}\text { I regularly read the } \\
\text { information that is } \\
\text { sent home. }\end{array}$ \\
\hline 6. & & & \\
\hline 7 & & & \\
\hline 8. & & & \\
\hline 9. & & & \\
\hline 10.Example column & $\begin{array}{l}\text { I utilize volunteers in } \\
\text { my classroom. }\end{array}$ & $\begin{array}{l}\text { Parents come to my } \\
\text { classroom to help } \\
\text { students with their } \\
\text { work. }\end{array}$ & $\begin{array}{l}\text { I know what } \\
\text { volunteer } \\
\text { opportunities are } \\
\text { available at my } \\
\text { school. }\end{array}$ \\
\hline
\end{tabular}


Appendix: E

\section{Implementation Rubric}

\section{Data-Driven Instruction and Assessment}

The rubric is intended to be used to assess the present state of data-driven instruction and assessment in a school. The rubric specifically targets interim assessments and the key drivers leading to increased student achievement.

Rating codes: 4 = Exemplary Implementation 3 = Proficient Implementation $2=$ Beginning Implementation 1 = No Implementation

\section{DATA-DRIVEN CULTURE}

1. Highly active leadership team: Facilitate teacher-leader data analysis meetings after each interim assessment and maintain focus on the process throughout the year.

2. Introductory professional development: Teachers and leaders are introduced to data-driven instruction effectively--they understand how interim assessments define rigor and experience the process of analyzing results and adapting instruction.

3. Implementation calendar: Begin school year with a detailed calendar that includes time for assessment creation and adaptation, implementation, analysis, planning meetings, and reteaching (flexible enough to accommodate district changes and mandates). 
4. Ongoing professional development: Professional development calendar is aligned with datadriven instructional plan: includes modeling assessment analysis and action planning and is flexible enough to adapt to student learning needs.

$-14$

5. Build by borrowing: Identify and implement best practices from high-achieving teachers and schools: visit schools and classrooms; share and disseminate resources and strategies.

$-14$

\section{ASSESSMENTS : LITERACY, MATH}

1. Common interim assessments: Assessments conducted four to six times per year.

Literacy_/4

Math _ _

2. Transparent starting point: Teachers see the assessments at the beginning of each cycle and use them to define the road map for teaching.

Literacy_/4

Math _ _ $\quad$ /4

3. Aligned to state tests and college readiness.

Literacy_/4

Math _ _ 
4. Aligned to instructional sequence of clearly defined grade-level and content expectations.

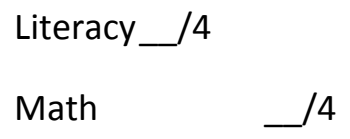

5. Re-assessed previously taught standards.

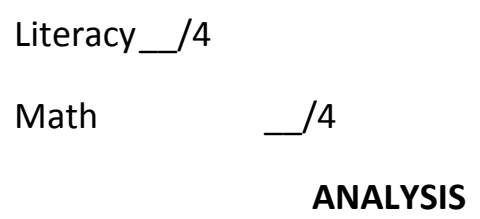

1. Immediate turnaround of assessment results (ideally within forty-eight hours).

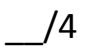

2. Data reports provide user-friendly, succinct item-level analysis, standards-level analysis, and bottom-line results.

3. Teacher-owned analysis facilitated by effective leadership preparation.

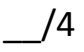

4. Test-in-hand analysis between teacher and instructional leader. 
5. Deep analysis moves beyond what students got wrong to answer why they got it wrong.

\section{ACTION}

1. Planning: Teachers plan new lessons collaboratively to develop new strategies based on data analysis.

2. Implementation: Explicit teacher action plans are implemented in whole-class instruction, small groups, tutorials, and before- or after-school support sessions.

3. Ongoing assessment: Teachers use in-the-moment checks for understanding and in-class assessment to ensure student progress between interim assessments.

$-14$

4. Accountability: Instructional leaders review lesson and unit plans and give observation feedback driven by the action plan and student learning needs.

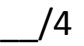

5. Engaged students: Students know the end goal, how they did, and what actions they are taking to improve.

TOTAL: $/ 100$ 
Appendix: $F$

\author{
Congratulations Sample Letter \\ (Printed on Official District Letterhead)
}

May 21, 2012

Dear Principal

Congratulations to you and your planning team at (Name) Elementary School. Your Schoolwide Plan was reviewed by the district and approved to implement this fall. The plan will be submitted to the (__ State Department of Education prior to June $1^{\text {st }}$.

As you begin the implementation of your plan, we encourage you to collaborate with (Name) our District Business Manager to assist in program development.

Please feel free to contact the District Office is you have any questions around Title I services.

Sincerely,

Dr. (Name)

Superintendent, SD 


\section{Moving To A Schoolwide Title I}

\section{The path principals \\ should follow to \\ maintain a healthy \\ school culture...}

As budget belts tighten in the public schools today, more and more schools are moving toward participation in federal Schoolwide Title I Programs. The goal of this handbook is to help school leaders better understand how to transition from a Targeted Assistance school to a Schoolwide Title I school successfully, while fostering a positive school culture through the grueling, yet rewarding year of planning and transition.

This handbook provides tools and tips for working with all school constituencies to transform your Title I program and build a school culture that is accepting of the changes, and fully embraces the implementation of the change.

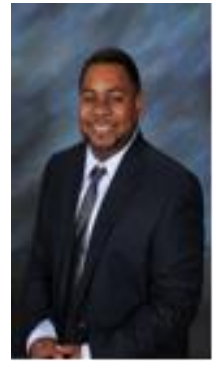

Paul Coakley has served as an elementary principal for the past five years. He has taught at the elementary level, and middle school level working in K-8 schools. Mr. Coakley received his Master's in Educational Administration from Portland State University in 2001. He completed his Doctorate in Educational Administration: Leadership \& Policy in 2013. 